\title{
Underperforming schools and deprivation: A statistical proffle of schools below the floor standards in 2010
}

\section{Education Standards Analysis and Research Division (ESARD)}


The views expressed in this report are the authors' and do not necessarily reflect those of the Department for Education. 


\section{Executive Summary}

Each year, maintained mainstream schools are assessed against a set of floor standards at Key Stages 2 and 4. The standards are based on overall attainment at the end of the Key Stage, and pupil progress in maths and English over the course of KS1-2 for primary schools, and KS2-4 for secondary schools.

\section{Population of Schools Below the Floor Standards}

- A total of 573,000 pupils attended schools that performed below the floor standards in 2010.

- There were 962 schools below the floor at KS2, attended by 269,000 pupils; of these, 76,000 were eligible for free school meals.

- Within the 432 additional KS2 schools with test results below the floor standards in 2009 and who boycotted the tests in 2010, there were 125,000 pupils, 41,000 of which were eligible for free school meals.

- There were 216 schools below the floor at KS4, attended by 179,000 pupils; of these, 48,000 were eligible for free school meals.

\section{Comparing the Below Floor Schools Pupil Population with Other Schools}

- Deprived pupils (those eligible for free school meals and those living in areas of higher deprivation) were the most overrepresented groups in both primary and secondary below floor schools. Pupils in below floor schools live in more deprived areas than those in above floor schools both within the eligible for free school meals group and within those not eligible for FSM.

- Pupils eligible for free school meals made up $16 \%$ of those in above KS2 floor schools, but $28 \%$ of those in below floor schools and $33 \%$ of those in schools that were below floor standards in 2009 then boycotted the 2010 tests; in above KS4 floor schools, $14 \%$ of pupils were eligible for free school meals, compared with $27 \%$ of pupils in below floor schools.

- Separating the FSM and non-FSM populations in below and above floor schools, at both Key Stages, pupils with a special educational need are overrepresented amongst pupils with and without free school meals eligibility in below floor schools; this overrepresentation of SEN is stronger amongst non-FSM pupils.

- White British pupils are overrepresented in below floor schools among the FSM eligible population, but not among non-FSM pupils; this is the case at both Key Stages.

- Overall, pupils of Black or minority ethnicity were distributed proportionately between KS2 below floor schools, KS4 below floor schools, and their above floor counterparts (KS2: $27 \%$ compared with 25\%, KS4: $21 \%$ compared with $22 \%$ ); however, there were a higher proportion of BME pupils in schools below the KS2 floor standards in 2009 which then boycotted the 2010 tests (34\% compared with 25\%).

- Higher proportions of pupils in below floor schools at both Key Stages were identified with special educational needs, compared with those in above floor schools (KS2: $26-28 \%$ compared with $21 \%$; KS4: 33\% compared with $21 \%$ ). The stronger overrepresentation at KS4 was driven by higher proportions of pupils with SEN at school action level, or at school action plus level. 
- Looked After Children are overrepresented in below floor schools at both Key Stages, although their total numbers are small. In the KS2 cohort, $0.5 \%$ of children in below floor schools were Looked After Children, compared with $0.3 \%$ in above floor schools; in the KS4 cohort, $0.8 \%$ of children in below floor schools were Looked After Children, compared with $0.5 \%$ in above floor schools.

- Schools in the East of England and the South East were overrepresented among KS2 below floor schools; those in Yorkshire and the Humber, the North East and the West Midlands were overrepresented among schools that were below the KS2 floor standards in 2009 then boycotted the 2010 tests.

- Schools in the Yorkshire and the Humber, East Midlands and the South East were overrepresented among KS4 below floor schools.

- Schools in Inner and Outer London and the North West were underrepresented among KS2 below floor schools; those in the East of England and the South West were underrepresented among schools that were below the KS2 floor standards in 2009 then boycotted the 2010 tests.

- Schools in Inner and Outer London and the South West were underrepresented among KS4 below floor schools.

\section{Mobility, Attendance and Behaviour in Below Floor Schools}

- There is greater pupil mobility in below floor schools, with a markedly higher incidence of joining the school during the last two years of Key Stage 2 (primary schools) or Key Stage 4 (secondary schools), compared with above floor schools.

- Pupils in below floor schools (both primary and secondary) have consistently higher rates of absence than those in above floor schools, whether or not they are eligible for free school meals; this is reflected in overall absence, persistent absence and unauthorised absence measures.

- Fixed Period Exclusions (FPEs) are received by greater proportions of pupils in below floor schools at KS2 and KS4, than by their counterparts in above floor schools. The incidence of pupils with multiple exclusions within one academic year is also consistently higher in below floor schools, for pupils with and without free school meal eligibility.

\section{School Spending in Below Floor Schools}

- For primary schools with high rates of free school meals eligibility $(\geq 35 \%)$, below floor schools have slightly lower per pupil spending than above floor schools; the reverse is true for schools with lower proportions of pupils eligible for FSM.

- Considering the allocation of school spending between categories such as teaching staff, back office and learning resources, primary schools have similar spending patterns whether they are above or below the floor standards.

- Per pupil school spending is slightly higher for below floor secondary schools compared with above floor schools, at all levels of FSM eligibility. However, above floor schools spend more on teaching staff and less on education support staff and back office expenses, compared with below floor schools; this is true both proportionally and in absolute per pupil spending. 


\section{Attainment and Progress in Below Floor Schools}

- On average, Key Stage 2 attainment in schools above the floor standards in 2010 has increased over the last five years; this is in contrast to below floor schools, which have seen decreasing rates of achievement of the expected levels in English and maths, on average since 2008. Below floor schools that boycotted the tests in 2010 had large decreases in attainment from 2008 to 2009 on average.

- A similar pattern of trends for above and below floor schools is seen for the KS1-2 expected progress measure in English, although with decreases in English progress being less marked than the decreases in achievement of the expected level of attainment in below floor schools, but still important for below floor schools that boycotted the tests in 2010.

- A more positive picture is seen for KS 1-2 expected progress in maths, with all groups of schools broadly improving since 2006, although the increase has not been as steady in below floor schools (including those that boycotted the tests in 2010) as in above floor schools.

- At Key Stage 4, attainment of five good GCSEs (or equivalents) including GCSE English and maths, in both above and below floor schools, has seen steady increases. However, there remains a large gap in attainment between pupils who were eligible for free school meals in above floor schools and those who were not eligible for FSM, plus all pupils in below floor schools.

- Progress in English between Key Stages 2 and 4 has increased for both FSM eligible and non-FSM pupils in both above and below floor schools. Pupils eligible for FSM in above floor schools have similar progress rates on average to those not eligible for FSM in below floor schools, with a large gap in progress between these groups and pupils who are both eligible for FSM and attended a below floor school.

- A similar pattern of gaps is seen for KS2-4 progress in maths, but with much smaller improvements in below floor schools regardless of FSM eligibility.

\section{School-Level Attainment Trajectories}

- School level attainment is volatile from year to year due to the characteristics and prior attainment of the successive cohorts reaching the end of the Key Stage, as well as any changes in school effectiveness.

- The majority of KS2 schools, both below and above floor standards, had no statistically significant year-on-year changes in attainment (expected level in English and maths) between 2006 and 2010 ( $p<0.05$ ). However, a larger minority of below floor schools had statistically significant year-on-year decreases in attainment than of above floor schools, and a smaller minority of below floor schools had statistically significant year-on-year improvements in attainment.

- The majority of KS4 schools which have been open for at least 4 years, both below and above floor standards, were split evenly between having had no statistically significant year-on-year changes in attainment between 2006 and 2010 ( $p<0.05$ ), and having had statistically significant year-on-year improvements. However, among below floor schools, a larger minority had volatile results (both improvements and declines in attainment that were statistically significant) than was the case for above floor schools. 


\section{Contents}

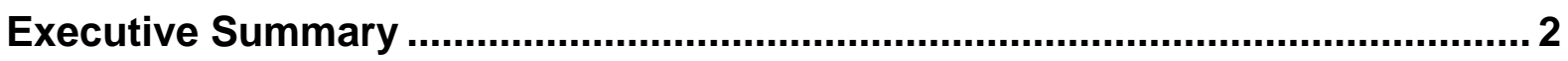

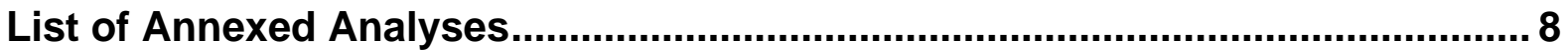

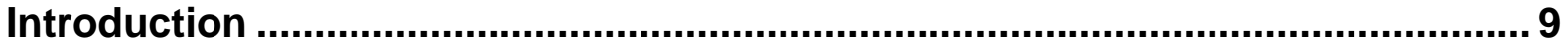

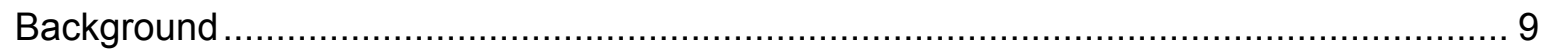

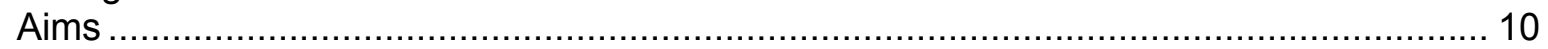

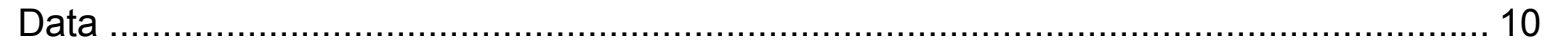

1. Population Profile

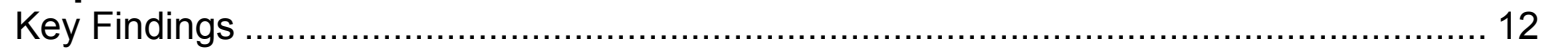

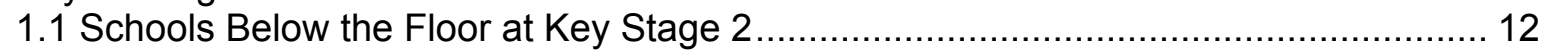

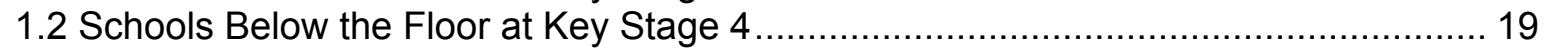

2. Intake in Below Floor Schools Compared With Other Schools......................26

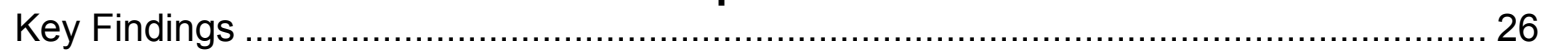

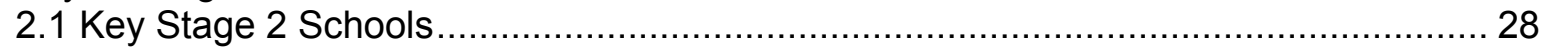

2.2 Key Stage 4 Schools.................................................................................... 34

2.3 Looked After Children in Below Floor Schools at KS2 and 4 ………...................... 40

2.4 FSM Eligible Pupils in Key Stage 2 Schools ...................................................... 41

2.5 FSM Eligible Pupils in Key Stage 4 Schools .......................................................... 46

3. Mobility, Attendance and Behaviour in Below Floor Schools....................... 50

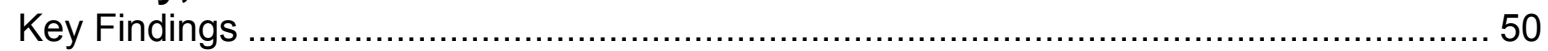

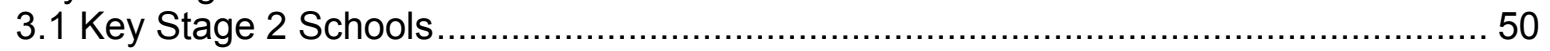

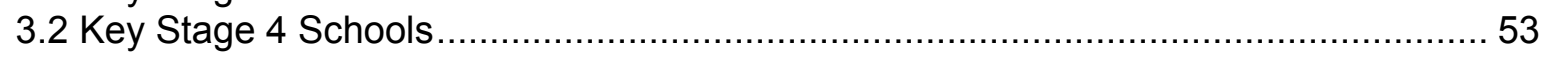

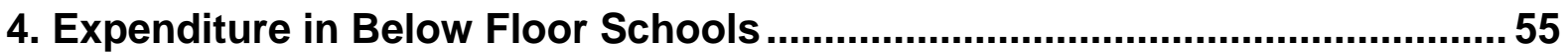

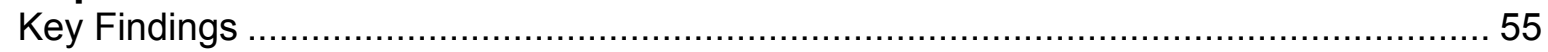

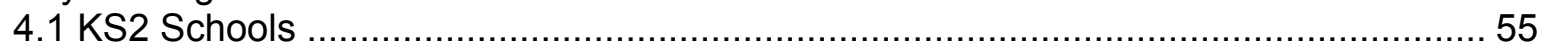

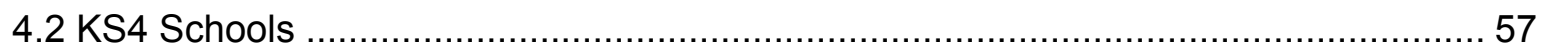

5. Ofsted Judgements for Below Floor Schools...........................................59

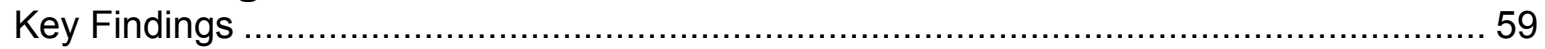

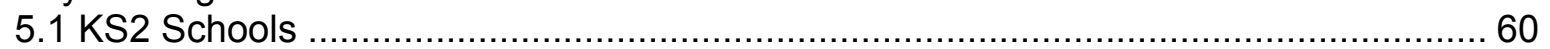

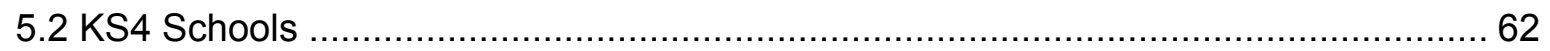

6. Attainment and Progress in Below Floor Schools ......................................63

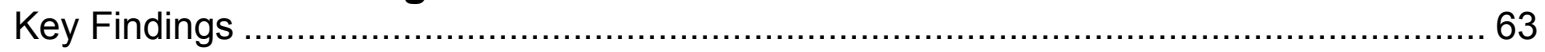

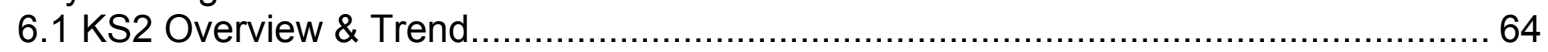

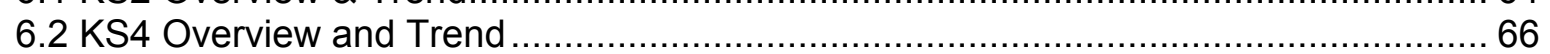

6.3 KS2 Below Floor School Level Attainment Trajectories............................................. 68

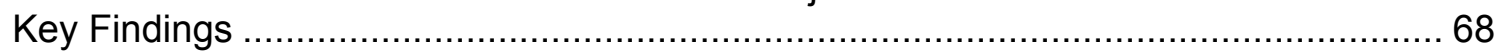

6.4 KS4 Below Floor School Level Attainment Trajectories.......................................... 72

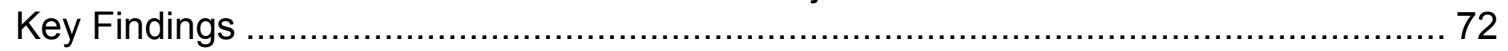

Annex A: Additional Population Profile Information .......................................75

Regional Pupil Characteristics Profile in Below KS2 Floor Schools.............................. 75

Regional Pupil Characteristics Profile in Below KS4 Floor Schools............................... 78

Detailed Population Profile: Key Stage 2 Schools Below the Floor Standards ................. 82

Detailed Population Profile: Key Stage 4 Schools Below the Floor Standards ................ 92 
Annex B: Additional Attainment and Progress Analyses................................ 97

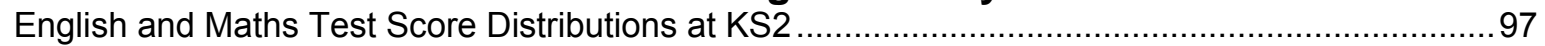

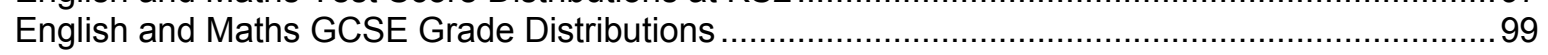

Attainment by Pupil Characteristics in KS2 Below Floor Schools ........................................... 101

Attainment by Pupil Characteristics in KS4 Below Floor Schools ........................................... 107

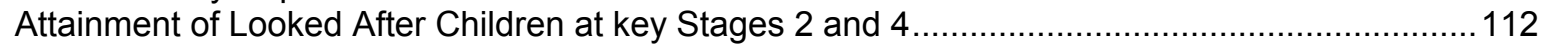

English Progress by Pupil Characteristics from KS1-2 .....................................................113

English Progress by Pupil Characteristics from KS2-4 ..................................................... 118

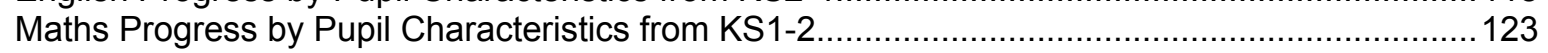

Maths Progress by Pupil Characteristics from KS2-4 ....................................................... 128 


\section{List of Annexed Analyses}

\section{Annex A: Additional Population Profile Information}

- All Pupils in Below KS2 Floor Schools by Region

- FSM Pupils in Below KS2 Floor Schools by Region

- Boys and Girls in Below KS2 Floor Schools by Region

- Underperforming Minority Ethnic Groups in Below KS2 Floor Schools by Region

- Pupils with English as an Additional Language in Below KS2 Floor Schools by Region

- Pupils with Special Educational Needs in Below KS2 Floor Schools by Region

- Below Floor KS2 Schools by IDACI Area Deprivation Band by Region

- All Pupils in Below KS4 Schools by Region

- FSM Pupils in Below KS4 Floor Schools by Region

- Boys and Girls in Below KS4 Floor Schools by Region

- Underperforming Minority Ethnic Groups in Below KS4 Floor Schools by Region

- Pupils with English as an Additional Language in Below KS4 Floor Schools by Region

- Pupils with Special Educational Needs in Below KS4 Floor Schools by Region

- Below Floor KS4 Schools by IDACI Area Deprivation Band by Region

- Detailed Cross-tabulation of Below KS2 Floor Schools Population Characteristics

- Detailed Cross-tabulation of Below KS4 Floor Schools Population Characteristics

\section{Annex B: Additional Attainment and Progress Analyses}

- KS2 English Test Score Distribution for Above Floor Schools

- KS2 English Test Score Distribution for Below Floor Schools

- KS2 English Test Score Distribution for Below Floor 2009 (Boycott) Schools

- KS2 Maths Test Score Distribution for Above Floor Schools

- KS2 Maths Test Score Distribution for Below Floor Schools

- KS2 Maths Test Score Distribution for Below Floor 2009 (Boycott) Schools

- GCSE English Grade Distribution for Above Floor Schools

- GCSE English Grade Distribution for Below Floor Schools

- GCSE Maths Grade Distribution for Above Floor Schools

- GCSE Maths Grade Distribution for Below Floor Schools

- KS2 Attainment by Area Deprivation, School Group and FSM

- KS2 Attainment by Gender, School Group and FSM

- KS2 Attainment by Ethnicity, School Group and FSM

- KS2 Attainment by First Language, School Group and FSM

- KS2 Attainment by Special Educational Needs, School Group and FSM

- KS2 Attainment by Region, School Group and FSM

- KS4 Attainment by Area Deprivation, School Group and FSM

- KS4 Attainment by Gender, School Group and FSM

- KS4 Attainment by Ethnicity, School Group and FSM

- KS4 Attainment by First Language, School Group and FSM

- KS4 Attainment by Special Educational Needs, School Group and FSM

- KS4 Attainment by Region, School Group and FSM

- Attainment of Looked After Children at Key Stages 2 and 4

- KS2 English Progress by Area Deprivation, School Group and FSM 
- KS2 English Progress by Gender, School Group and FSM

- KS2 English Progress by Ethnicity, School Group and FSM

- KS2 English Progress by First Language, School Group and FSM

- KS2 English Progress by Special Educational Needs, School Group and FSM

- KS2 English Progress by Region, School Group and FSM

- KS4 English Progress by Area Deprivation, School Group and FSM

- KS4 English Progress by Gender, School Group and FSM

- KS4 English Progress by Ethnicity, School Group and FSM

- KS4 English Progress by First Language, School Group and FSM

- KS4 English Progress by Special Educational Needs, School Group and FSM

- KS4 English Progress by Region, School Group and FSM

- KS2 Maths Progress by Area Deprivation, School Group and FSM

- KS2 Maths Progress by Gender, School Group and FSM

- KS2 Maths Progress by Ethnicity, School Group and FSM

- KS2 Maths Progress by First Language, School Group and FSM

- KS2 Maths Progress by Special Educational Needs, School Group and FSM

- KS2 Maths Progress by Region, School Group and FSM

- KS4 Maths Progress by Area Deprivation, School Group and FSM

- KS4 Maths Progress by Gender, School Group and FSM

- KS4 Maths Progress by Ethnicity, School Group and FSM

- KS4 Maths Progress by First Language, School Group and FSM

- KS4 Maths Progress by Special Educational Needs, School Group and FSM

- KS4 Maths Progress by Region, School Group and FSM 


\section{Introduction}

This report profiles the intake, characteristics and pupil outcomes of schools below the floor standards in 2010.

\section{Changes from Version 1}

This is a revised version of the Underperforming Schools and Deprivation topic note which was published on 8th July 2011.

The changes are as follows:

- A correction has been made to charts 5.5a and 5.2b on page 62 to the proportions of schools with each Ofsted inspection judgement for Overall Achievement.

- Consequently, the commentary about the chart on page 59 has been amended to reflect the correction.

\section{Background}

Each year, maintained mainstream schools are assessed against a set of floor standards at Key Stages 2 and 4. The standards are based on overall attainment at the end of the Key Stage, and pupil progress in maths and English over the course of KS1-2 for primary schools, and KS2-4 for secondary schools. The 2010 floor standards were as follows:

\section{Key Stage 2}

- At least $60 \%$ of pupils at the end of Key Stage 2 (KS2) achieving level 4 or above in English and maths; and

- National average or above for \% of pupils at the end of KS2 making expected progress in English (national median $=87 \%$ ); and

- National average or above for \% of pupils at the end of KS2 making expected progress in maths (national median $=86 \%$ )

Primary schools failing to reach all three thresholds were designated as below the floor standards for 2010, with the exception of special schools, schools with fewer than 11 pupils in the cohort, schools which subsequently closed, and schools with missing data on one or more measures. Expected progress for KS1-2 is 2 national curriculum levels.

\section{Schools that boycotted KS2 Tests in 2010}

Schools with missing data due to having boycotted the $2010 \mathrm{KS} 2$ tests were assessed against the same criteria using their 2009 test results. Those who fell below all three thresholds are examined separately in this report under the label "Below Floor 2009 (Boycott)". 


\section{Key Stage 4}

- At least $35 \%$ of pupils at the end of Key Stage 4 achieving 5 or more GCSEs $A^{*}-C$ (or equivalents) including English and maths GCSE; and

- National average or above for \% of pupils making expected progress in English (national median $=72 \%$ ); and

- National average or above for \% of pupils at the end of KS4 making expected progress in maths (national median $=65 \%$ )

Secondary schools failing to reach all three thresholds were designated as below the floor standards for 2010, with the exception of special schools, independent schools, schools with fewer than 11 pupils in the cohort, schools which subsequently closed, and schools with missing data on one or more measures. Expected progress for KS2-4 is 3 national curriculum levels.

Under these criteria, 962 primary schools were deemed to be below the KS2 floor standards in 2010; an additional 432 primary schools were below the floor standards in 2009 and had boycotted the 2010 tests. There were 216 secondary schools below the KS4 floor standards.

\section{Aims}

This report aims to provide a statistical resource for individuals and organisations working with underperforming schools in the maintained mainstream sector, making available detailed data analysis to promote an understanding of the pupils intakes, circumstances and pupil outcomes for below floor schools.

Chapter 1 outlines the size, characteristics and geographical spread of the pupil population attending schools below the floor standards. Additional population crosstabulations can be found in annex A. Chapter 2 then compares the characteristics of pupils in below floor schools with those in above floor schools, and focuses on the characteristics of pupils eligible for free school meals in particular. Chapter 3 examines pupil mobility between schools within the course of the Key Stages, levels of school attendance, and the incidence of fixed period exclusions, again comparing schools below the floor standards with other schools. Chapter 4 compares the spending patterns of schools below and above the floor standards, assessing whether underperforming schools tend to use their resources in a different way from other schools. Chapter 5 reports the distributions of Ofsted overall effectiveness grades for below and above floor schools. Chapter 6 provides a comprehensive set of analyses of attainment and progress for below floor schools, at school distribution level, and at group level. As with chapter 2, pupils eligible for free school meals and pupil deprivation form a key focus for the analyses. Pupil characteristics variants on the attainment and progress analyses can be found in annex $B$.

\section{Data}

The data analysed in this report are sourced from the National Pupil Database and other administrative datasets held by the Department for Education. Regular headline statistics for these data are published in Statistical First Releases on the Department's website (with the exception of Ofsted Inspection Judgements, available on Ofsted's website). This report exploits the underlying data to produce 
detailed analyses on the topics described above, specific to below floor schools and above floor schools.

Wherever available, 2010 data are used in this report. However, where indicated, 2009 data have been used to provide information that is not available for 2010 . For example, all Key Stage 2 attainment analyses use 2009 data in order to provide a complete picture for schools which boycotted the 2010 tests. Some data collection cycles mean that 2010 data were not available in time to be included in this publication; for example, data on fixed period exclusions are collected retrospectively and are not yet available for academic year 2009/10. 


\section{Population Profile}

This chapter outlines the size, characteristics and geographical location of the pupil population attending schools below the floor standards. Analyses for Key Stage 2 schools are found in section 1.1, followed by those for Key Stage 4 schools in section 1.2.

\section{Key Findings}

- A total of 573,000 pupils attended schools that performed below the floor standards in 2010.

- There were 962 schools below the floor at KS2, attended by 269,000 pupils; of these, 76,000 were eligible for free school meals, 80,000 were of Black or minority ethnic background, 46,000 had a first language other than English, and 74,000 were identified with some level of special educational need.

- Within the 432 additional KS2 schools with test results below the floor standards in 2009 and who boycotted the tests in 2010, there were 125,000 pupils, 41, 000 of which were eligible for free school meals; 47,000 were of Black or minority ethnic background, 30,000 had a first language other than English, and 33,000 were identified with a special educational need.

- There were 216 schools below the floor at KS4, attended by 179,000 pupils; of these, 48,000 were eligible for free school meals, 41,000 were of Black or minority ethnic background, 23,000 had a first language other than English, and 61,000 had a special educational need.

\subsection{Schools Below the Floor at Key Stage 2}

Detailed cross-tabulations of KS2 pupil numbers by pupil characteristics in each region appear at annex $A$. Charts $1.1 \mathrm{a}$ and $1.1 \mathrm{~b}$ give the geographic spread of below floor schools, and of pupils within those schools, respectively. Charts $1.1 \mathrm{c}$ $1.1 \mathrm{i}$ depict the numbers of pupils with various characteristics in below floor schools. Chapter 2 gives proportionate comparisons of the incidence of key pupil characteristics in below floor schools compared with above floor schools, and of their geographical incidence.

The largest populations of pupils attending below floor KS2 schools were in the South East, West Midlands and Yorkshire \& the Humber. Medium sized populations were located in the North West, East Midlands and East of England. The smallest populations were found in London, the South West and the North East. 


\section{Chart 1.1a}

KS2 Below Floor Schools: Region

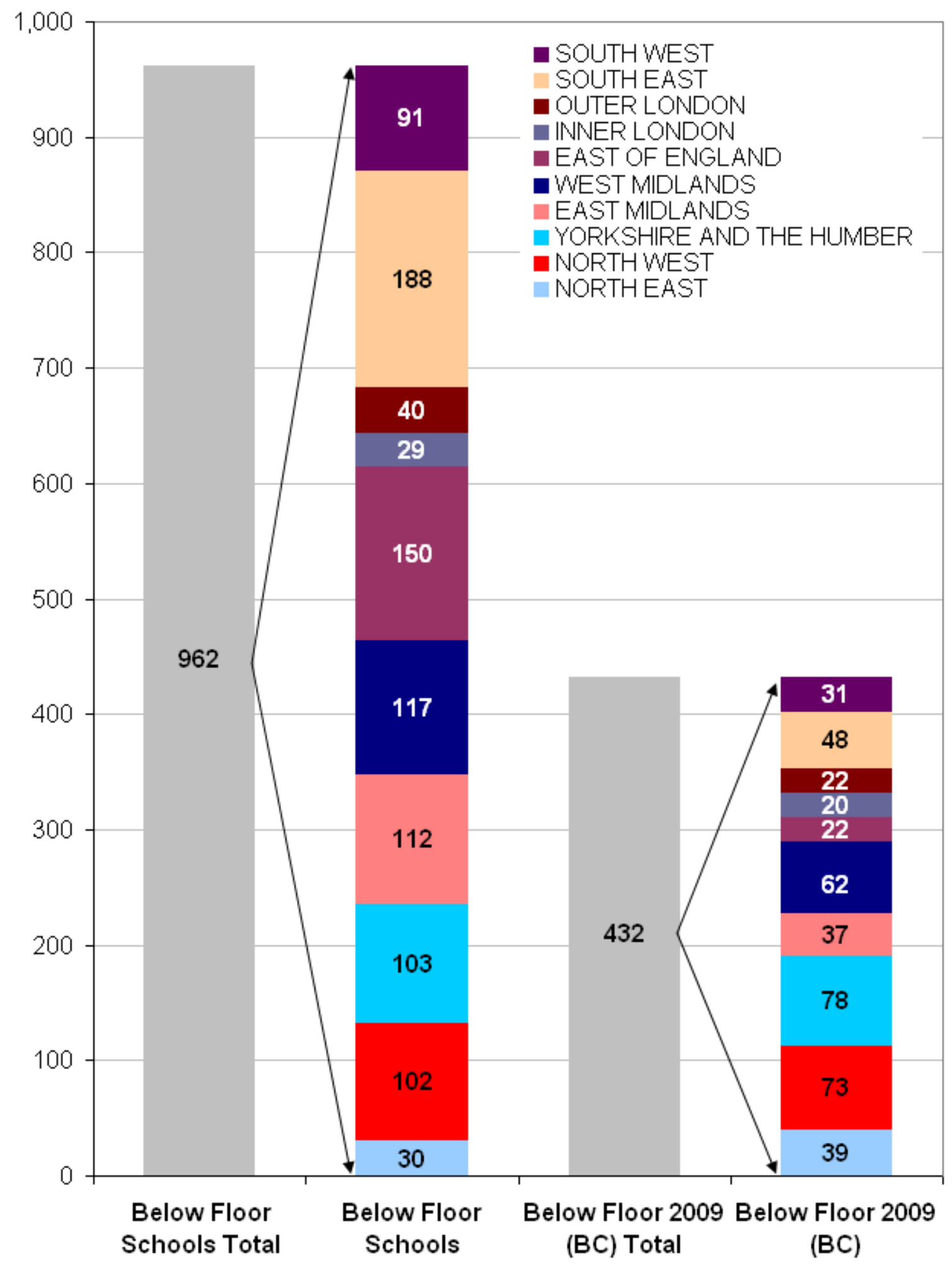




\section{Chart 1.1b}

KS2 Below Floor Schools Population: Region

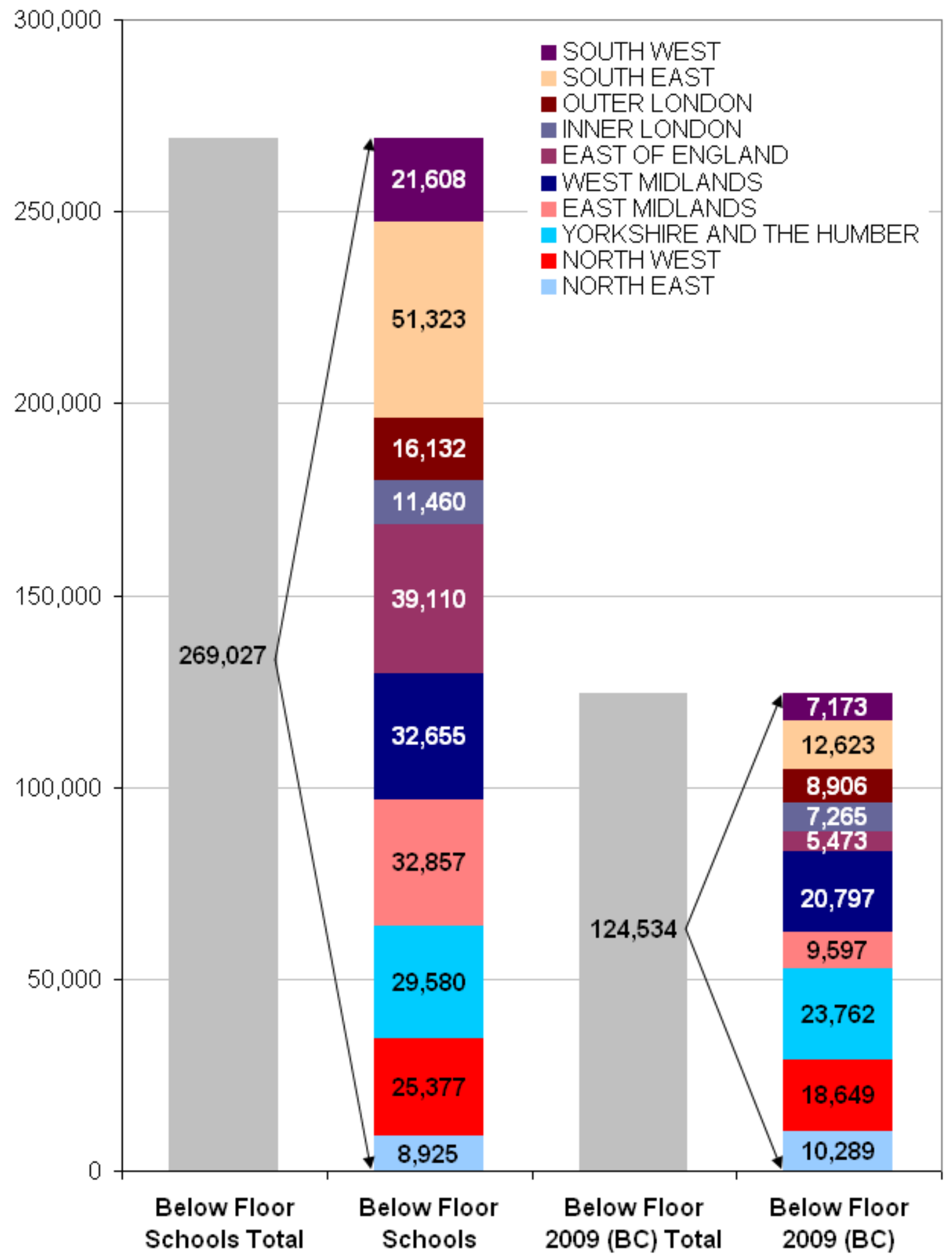




\section{Chart 1.1c}

KS2 Below Floor Schools Population: Boys and Girls

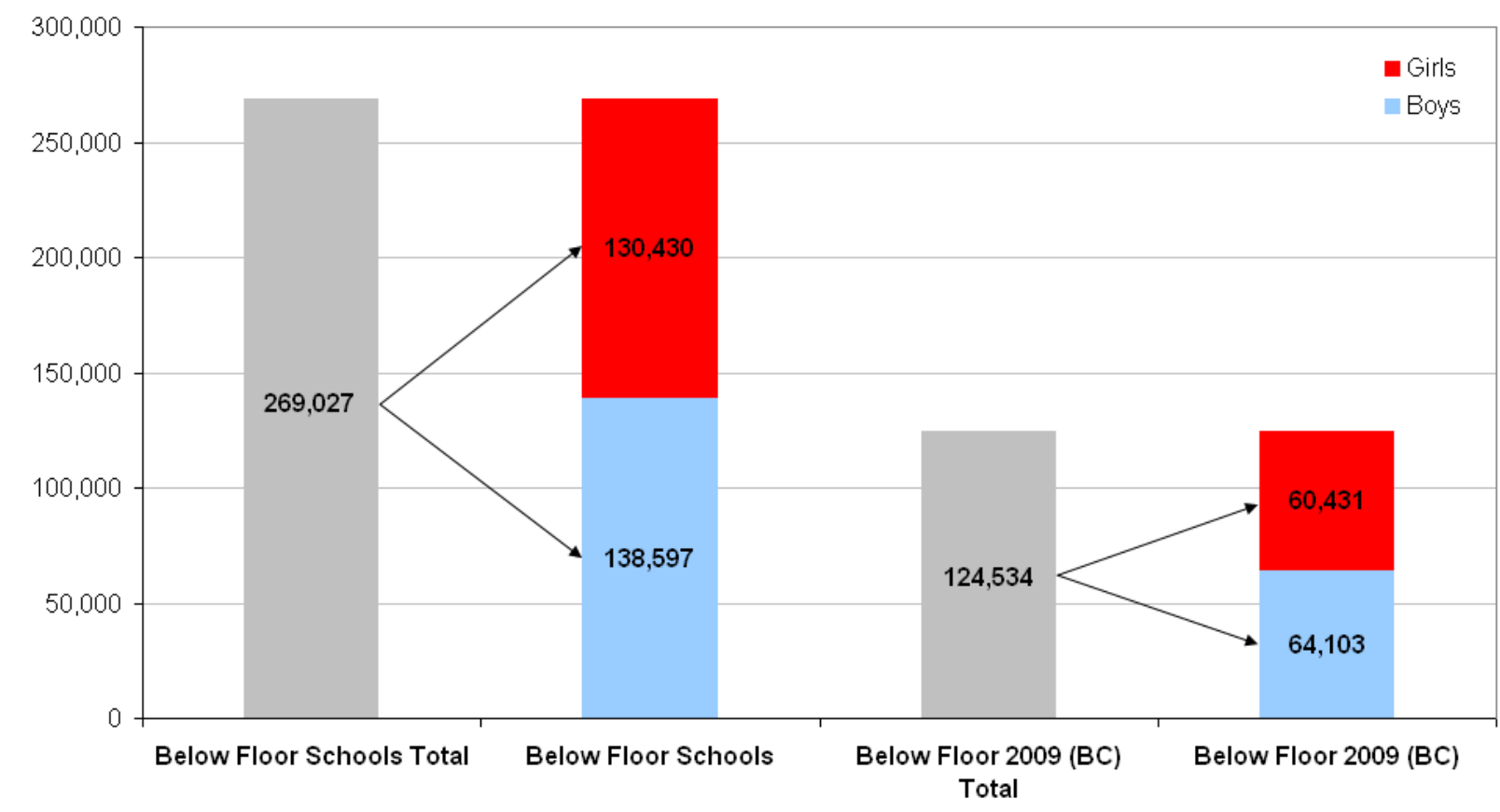

\section{Chart 1.1d}

KS2 Below Floor Schools Population: Free School Meals Eligibility

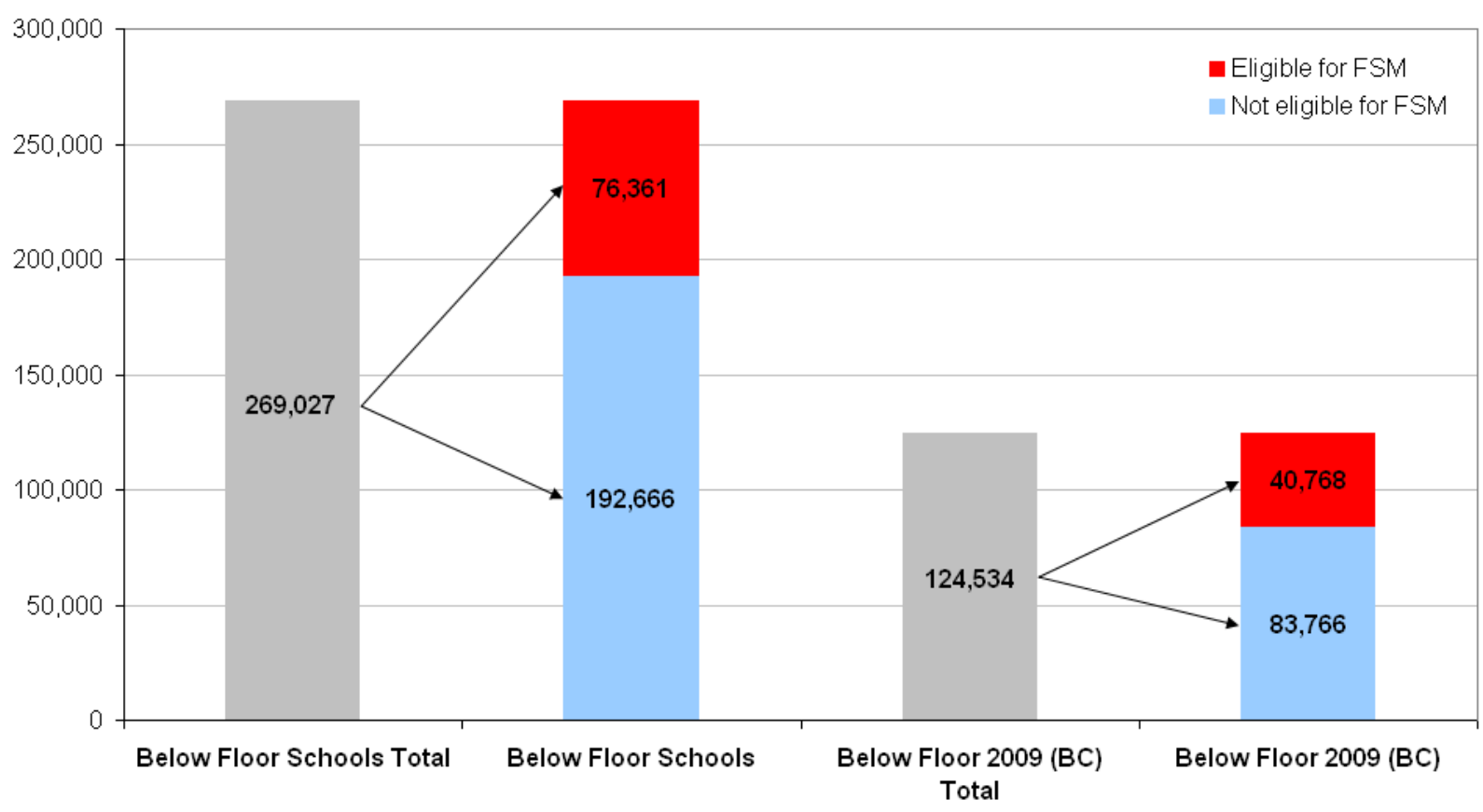




\section{Chart 1.1e}

KS2 Below Floor Schools: School Level Average Area Deprivation (IDACI)

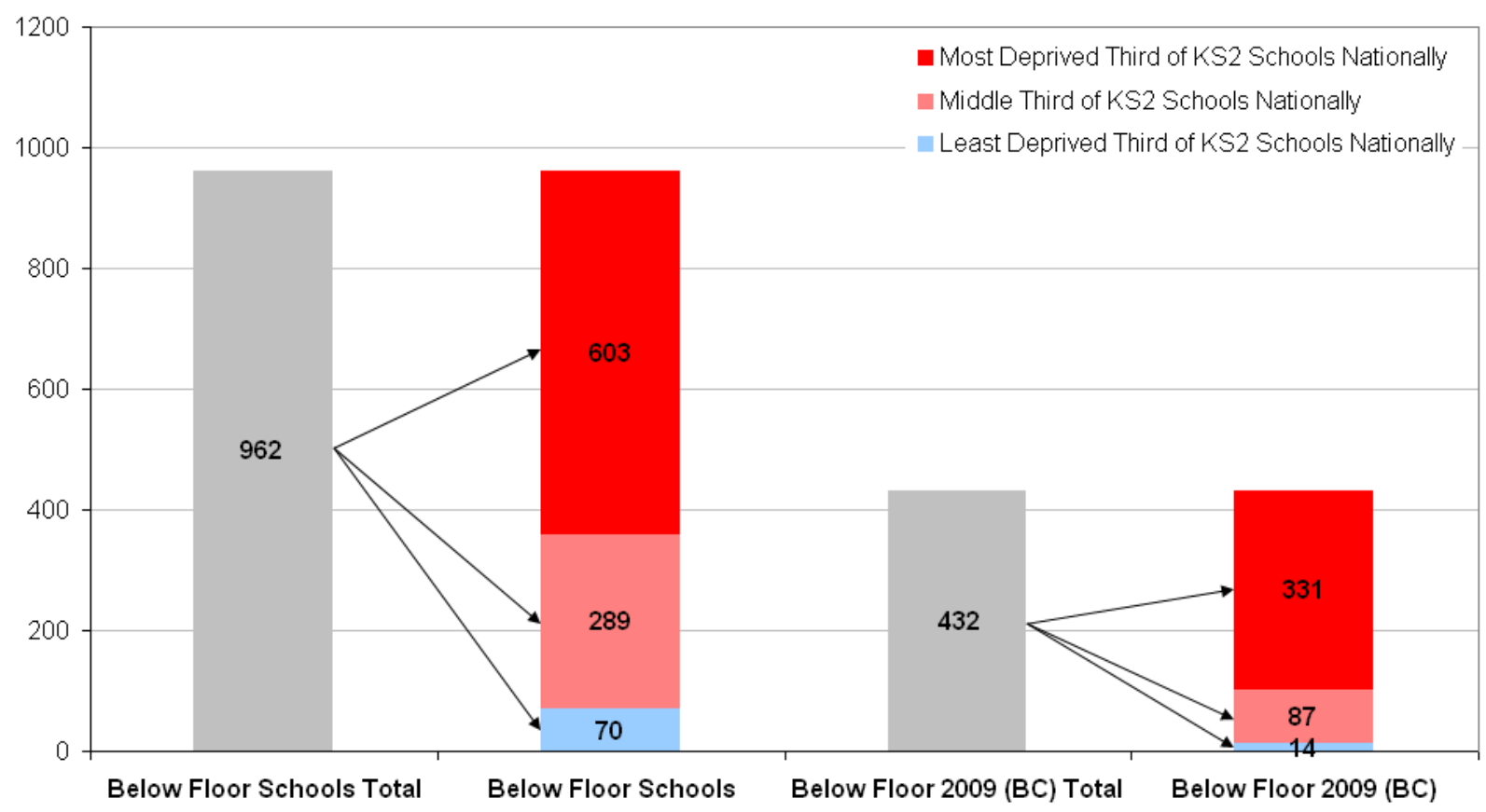

\section{Chart 1.1f}

KS2 Below Floor Schools Population: Ethnicity

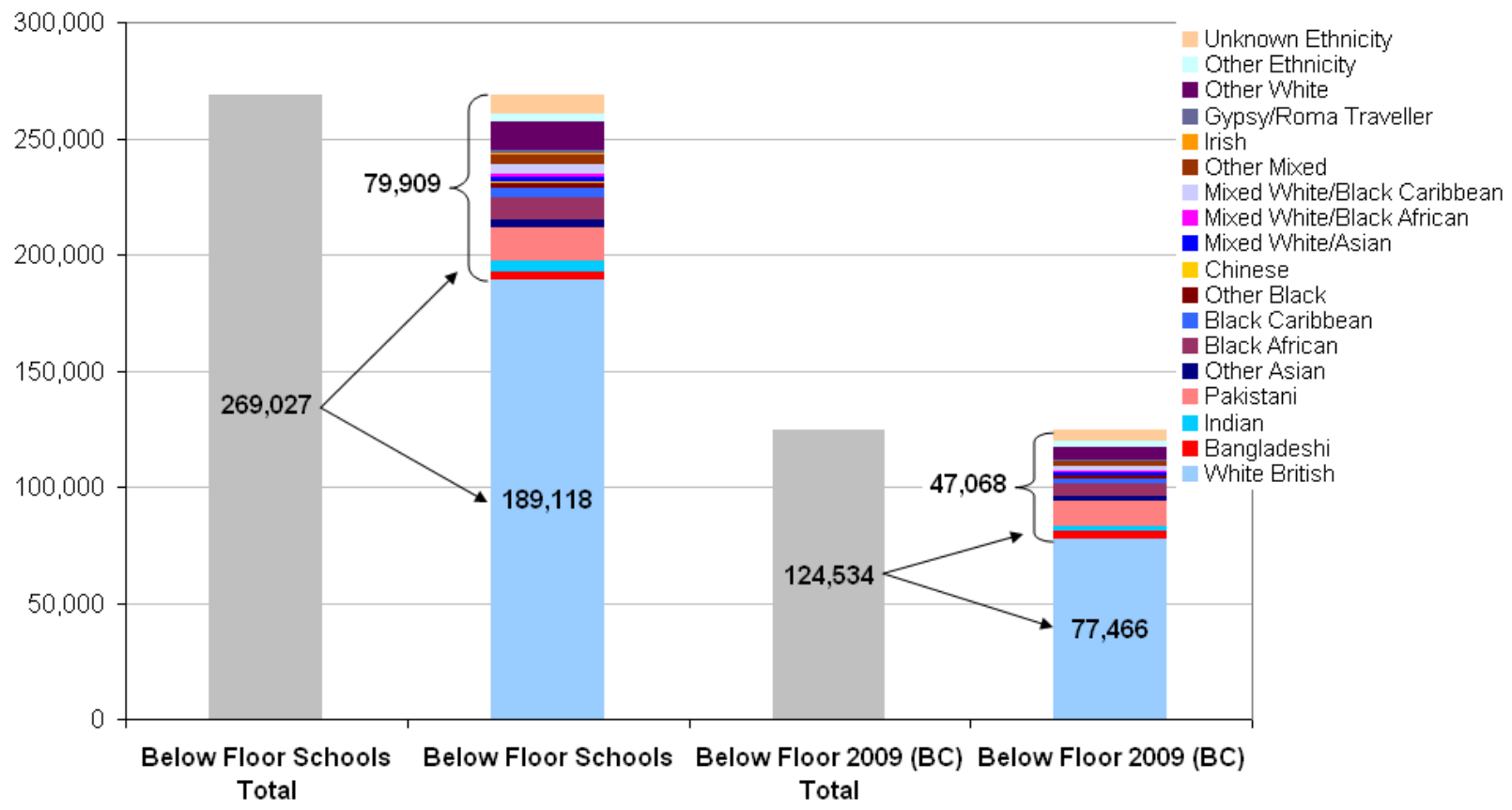




\section{Chart 1.1g}

KS2 Below Floor Schools Population: First language

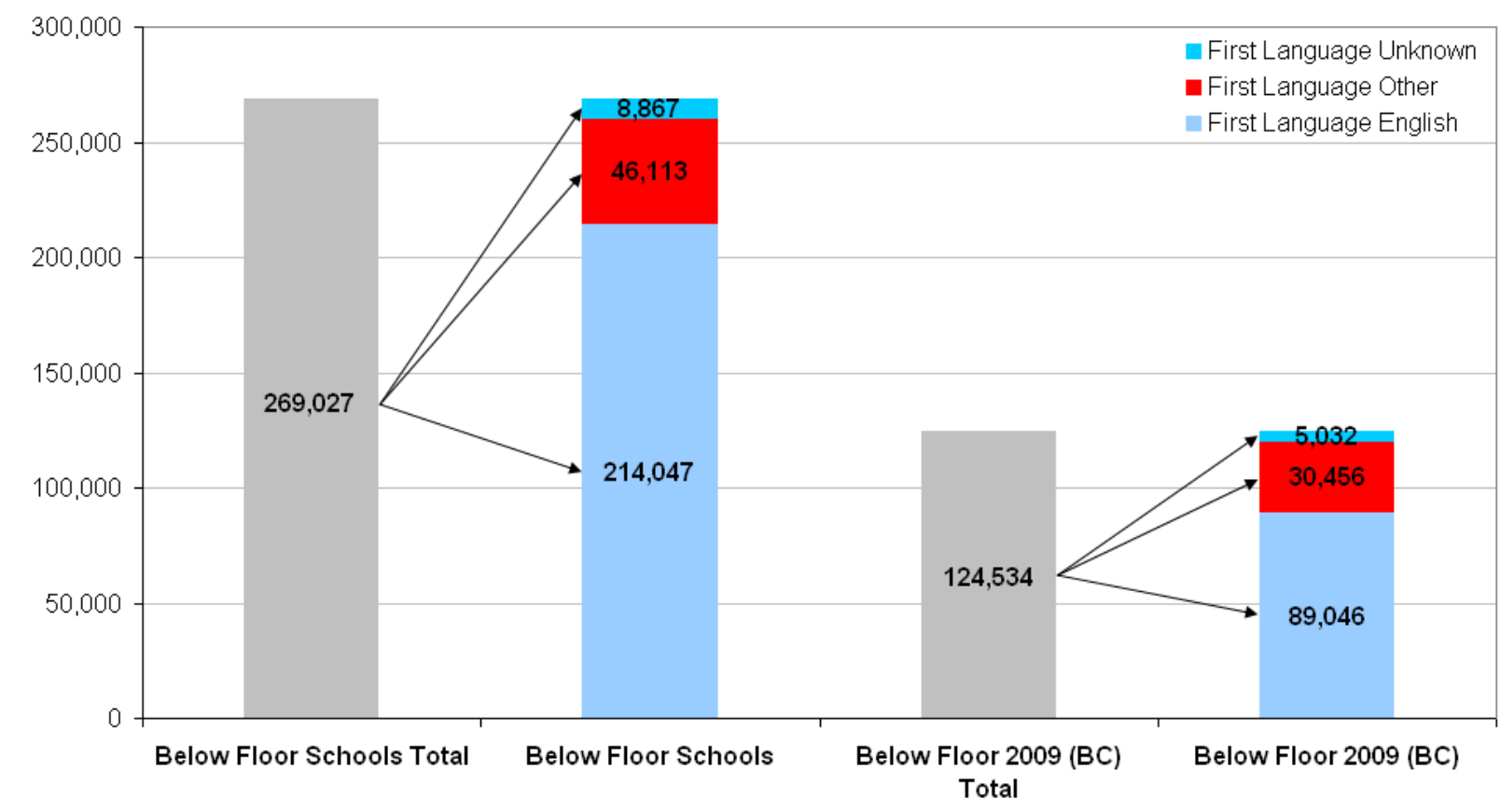

\section{Chart 1.1h}

KS2 Below Floor Schools Population: Special Educational Needs

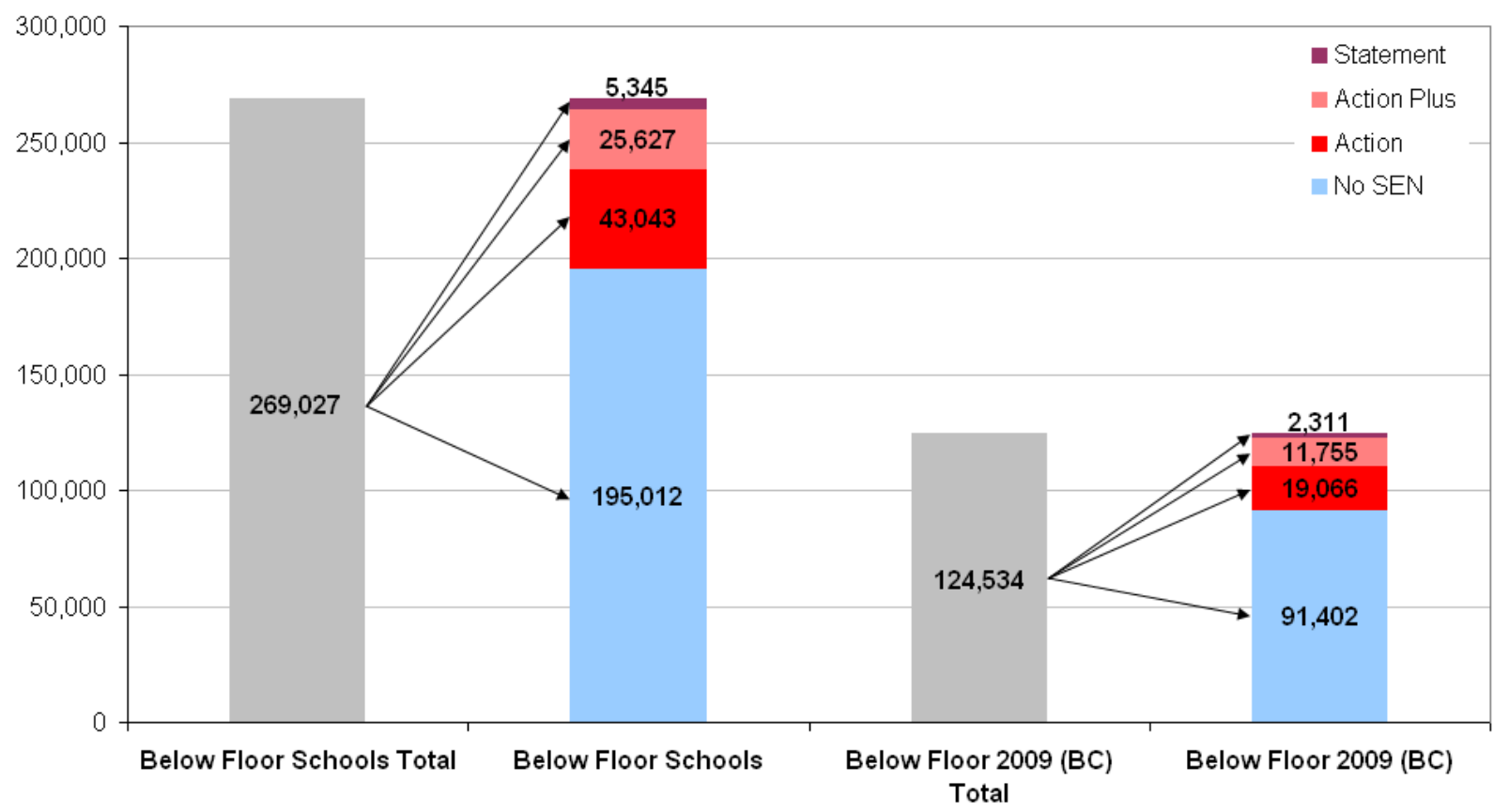




\section{Chart 1.1i}

KS2 Below Floor Schools: National Curriculum Year Group

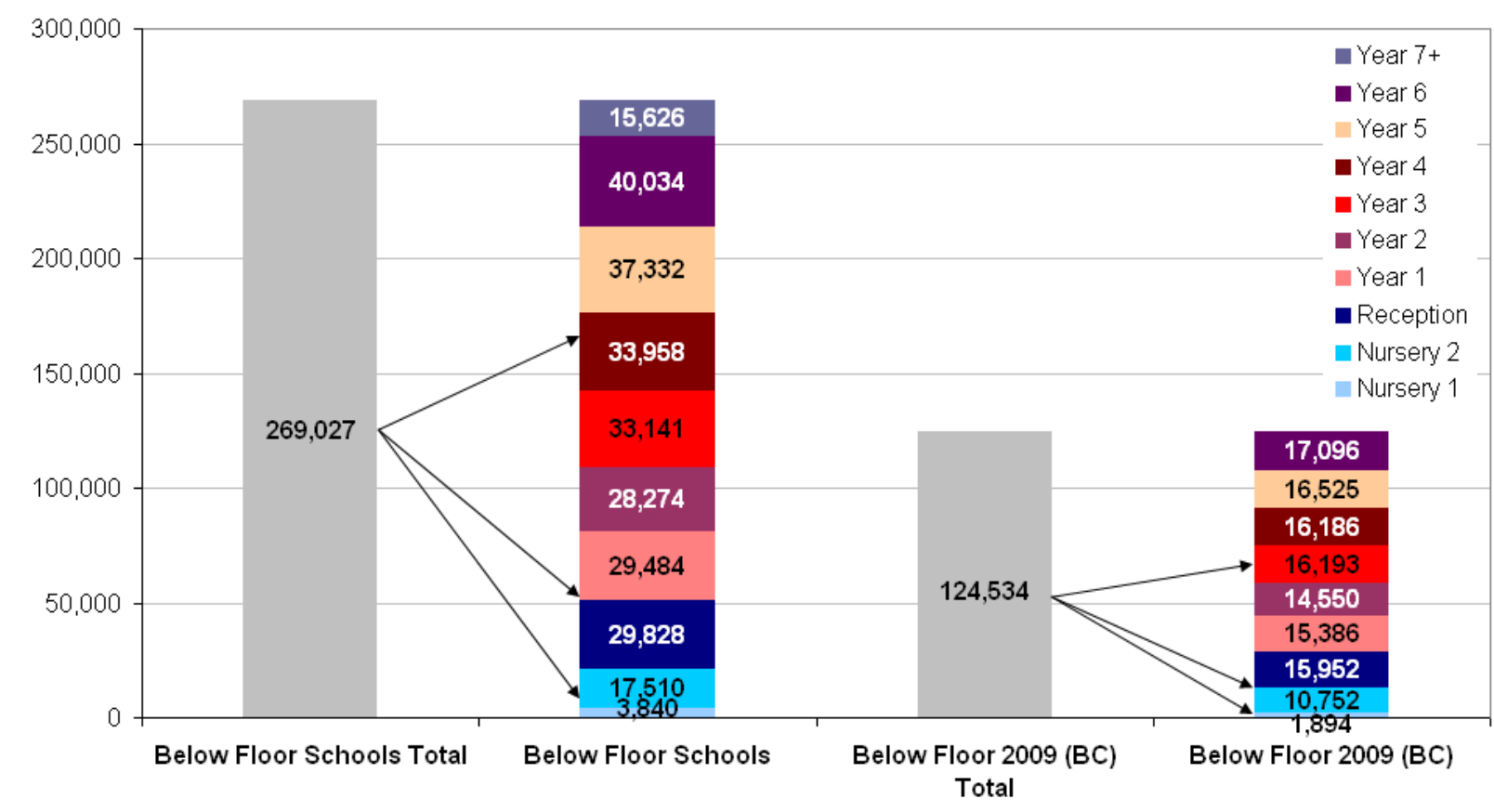




\subsection{Schools Below the Floor at Key Stage 4}

A detailed cross-tabulation of KS4 pupil numbers by pupil characteristics appears at annex A. Charts 1.2a and 1.2b give the geographic spread of below floor schools, and of pupils within those schools, respectively. Charts $1.2 \mathrm{c}-1.2 \mathrm{i}$ depict the numbers of pupils with various characteristics in below floor schools. Chapter 2 gives proportionate comparisons of the incidence of key pupil characteristics in below floor schools compared with above floor schools, and of their geographical incidence.

The largest populations of pupils attending below floor KS4 schools were in the South East and Yorkshire \& the Humber. Medium sized populations were located in the North West, East Midlands, West Midlands and East of England. The smallest populations were found in London, the South West and the North East. 


\section{Chart 1.2a}

KS4 Below Floor Schools: Region

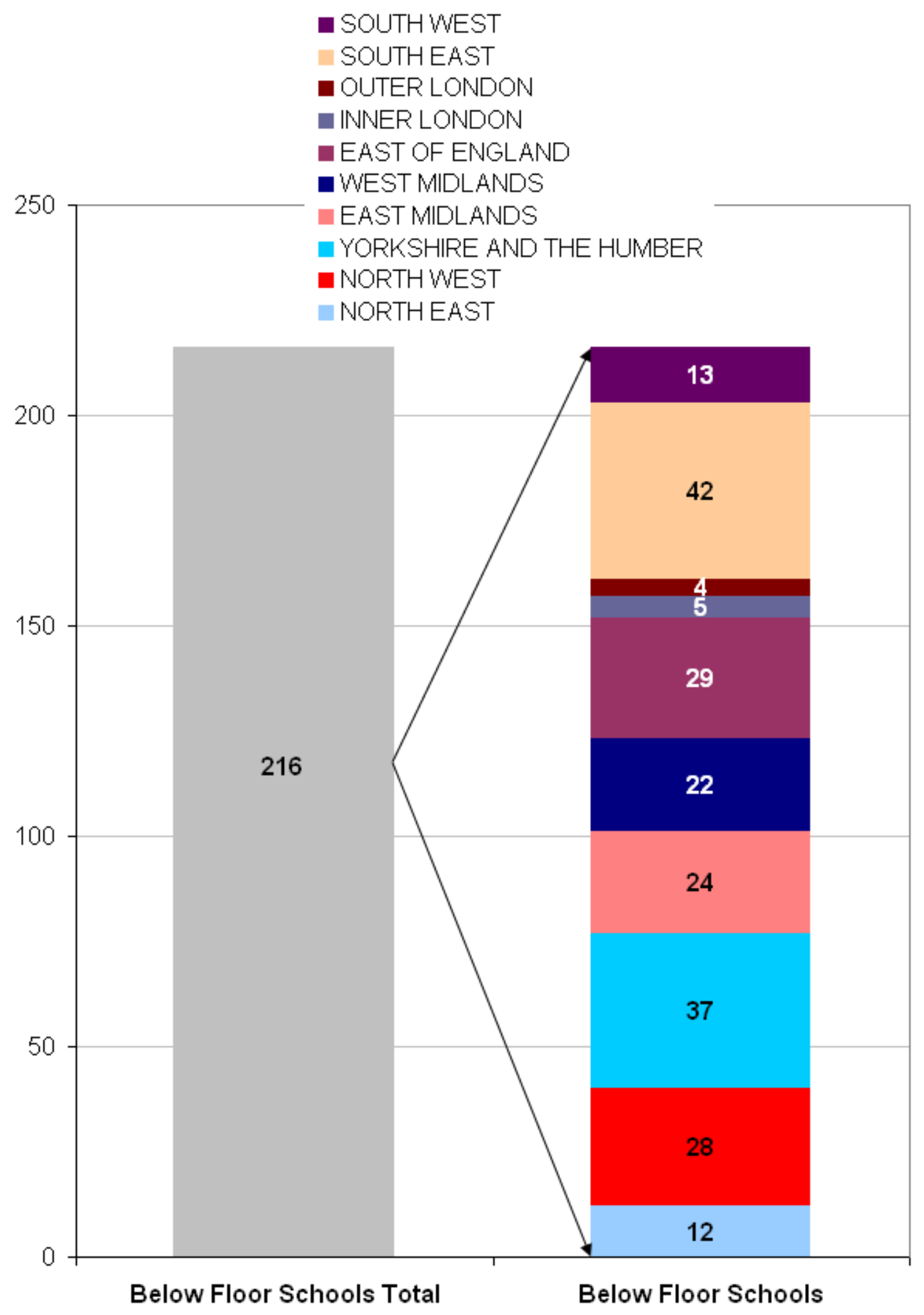




\section{Chart 1.2b}

KS4 Below Floor Schools Population: Region

- SOUTH WEST

SOUTHEAST

- OUTER LONDON

- INNER LONDON

-EAST OF ENGLAND

- WESTMIDLANDS

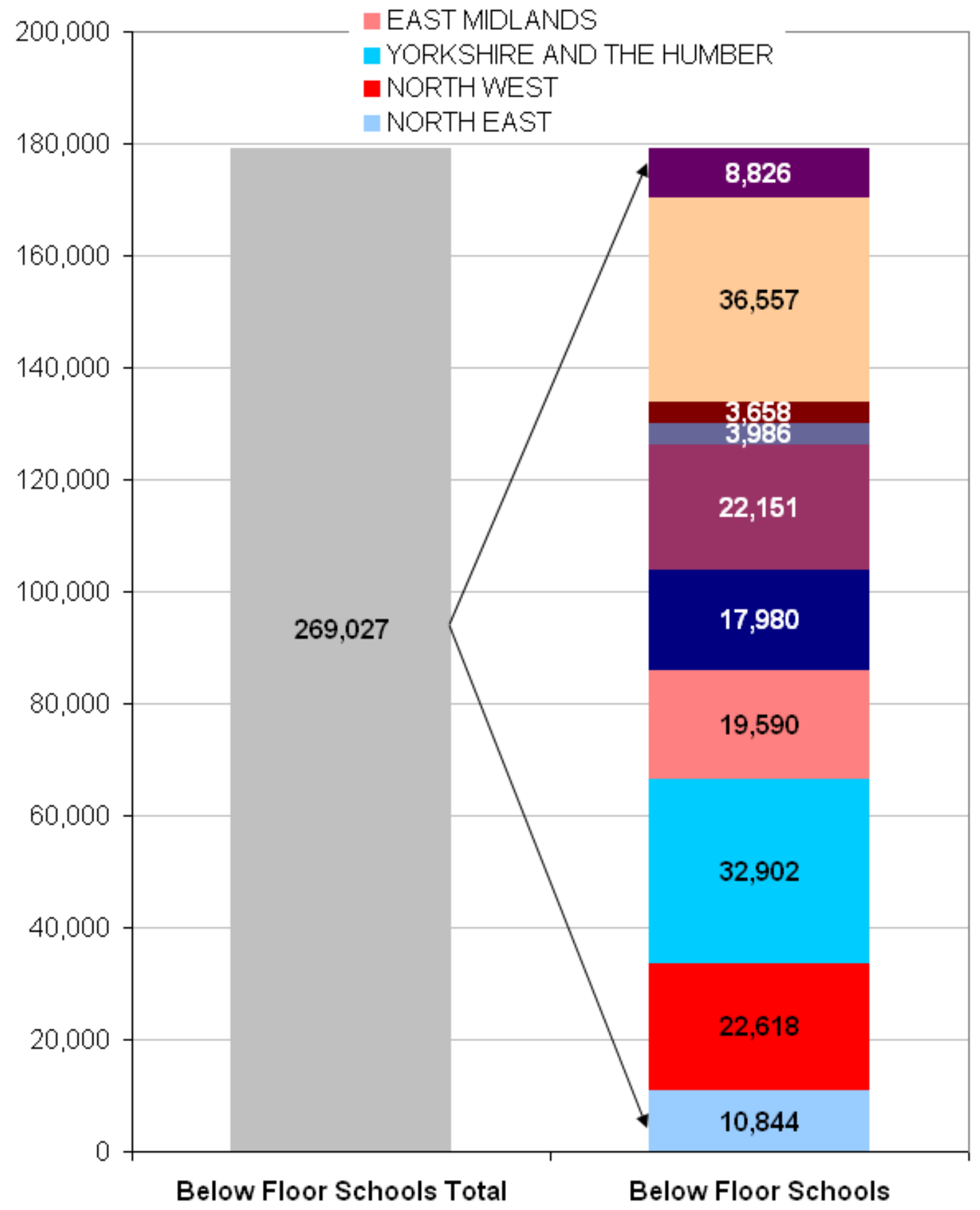




\section{Chart 1.2c}

KS4 Below Floor Schools Population: Boys and Girls

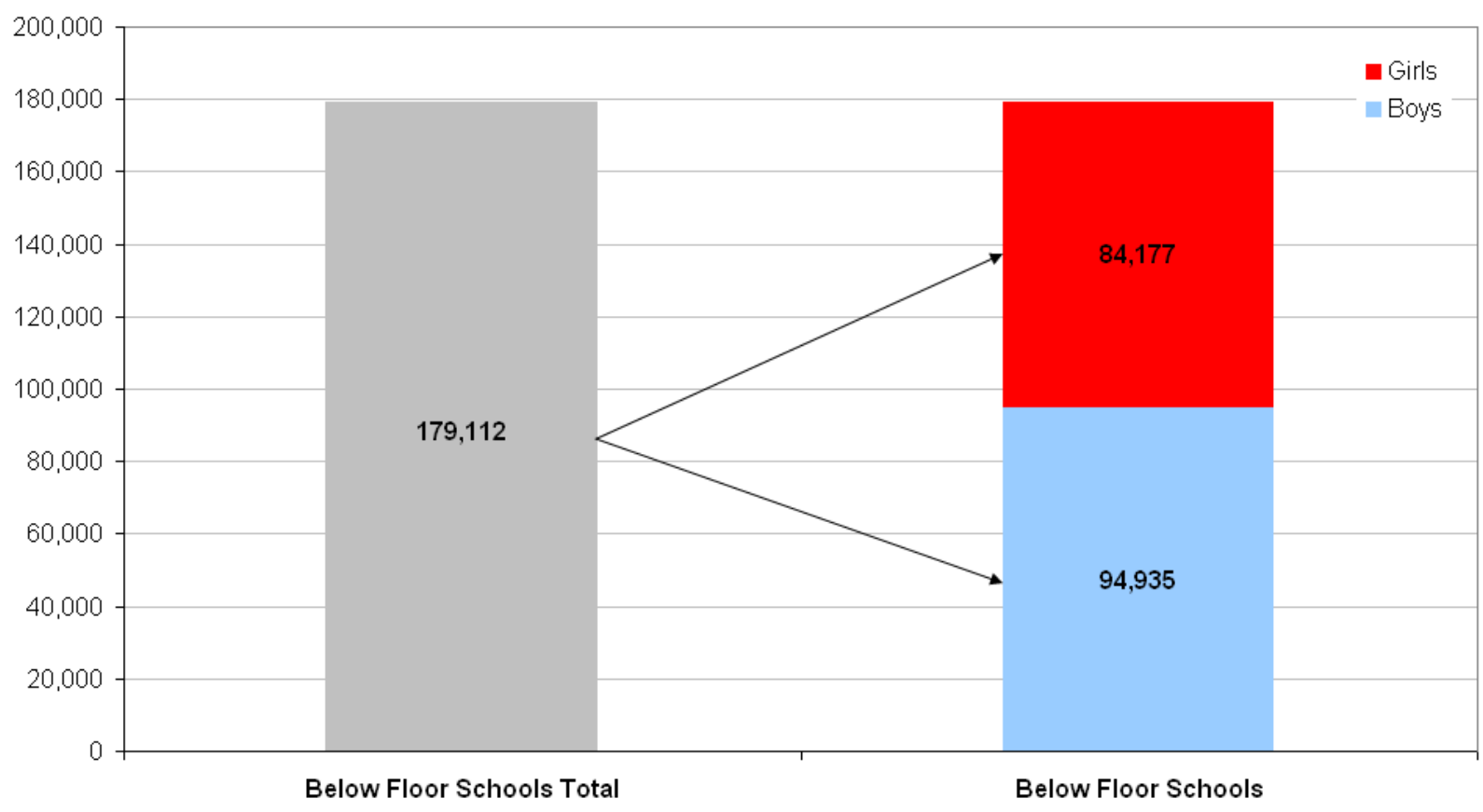

\section{Chart 1.2d}

KS4 Below Floor Schools Population: Free School Meals Eligibility

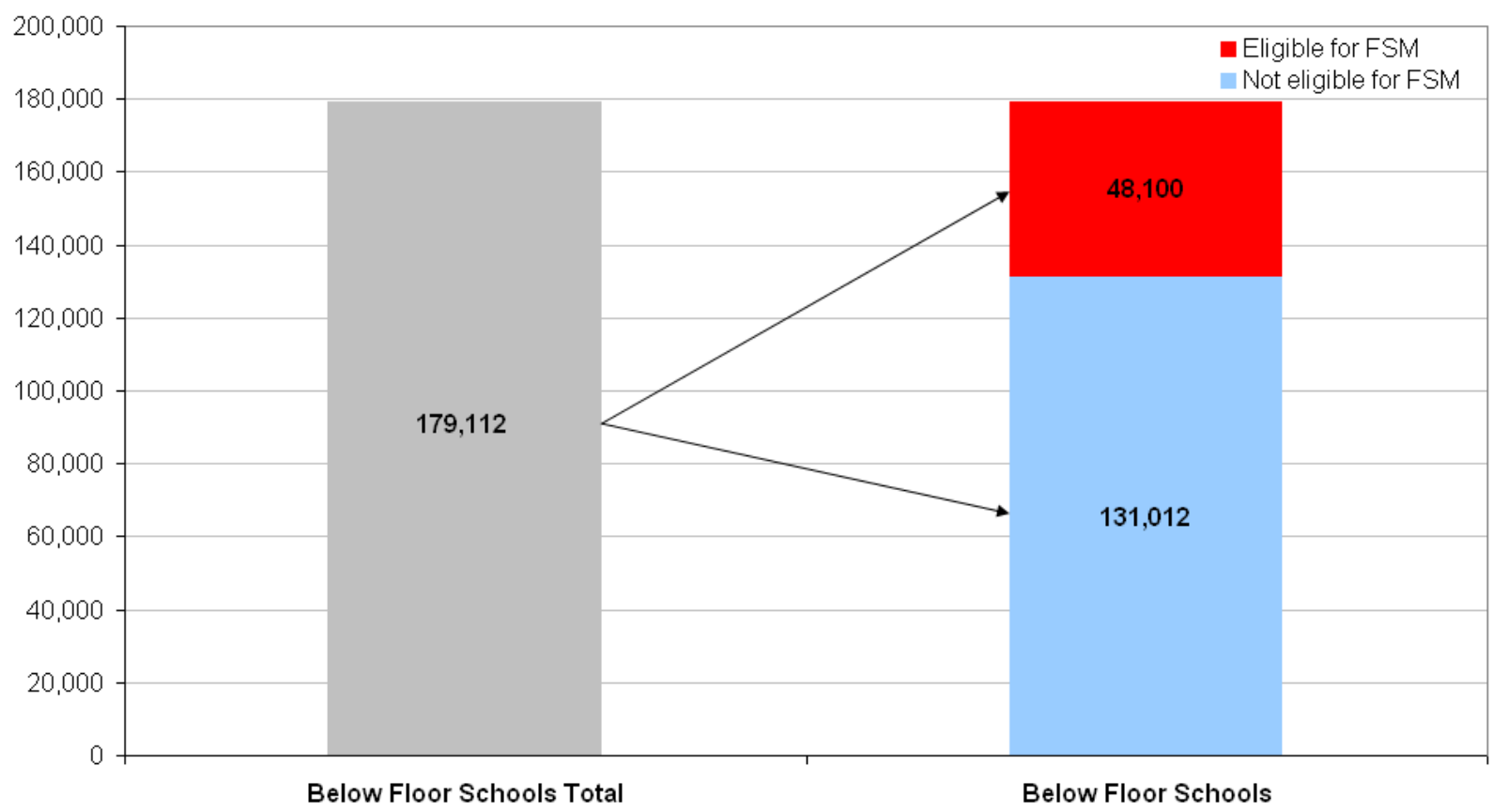




\section{Chart 1.2e}

KS4 Below Floor Schools: School Level Average Area Deprivation (IDACI)

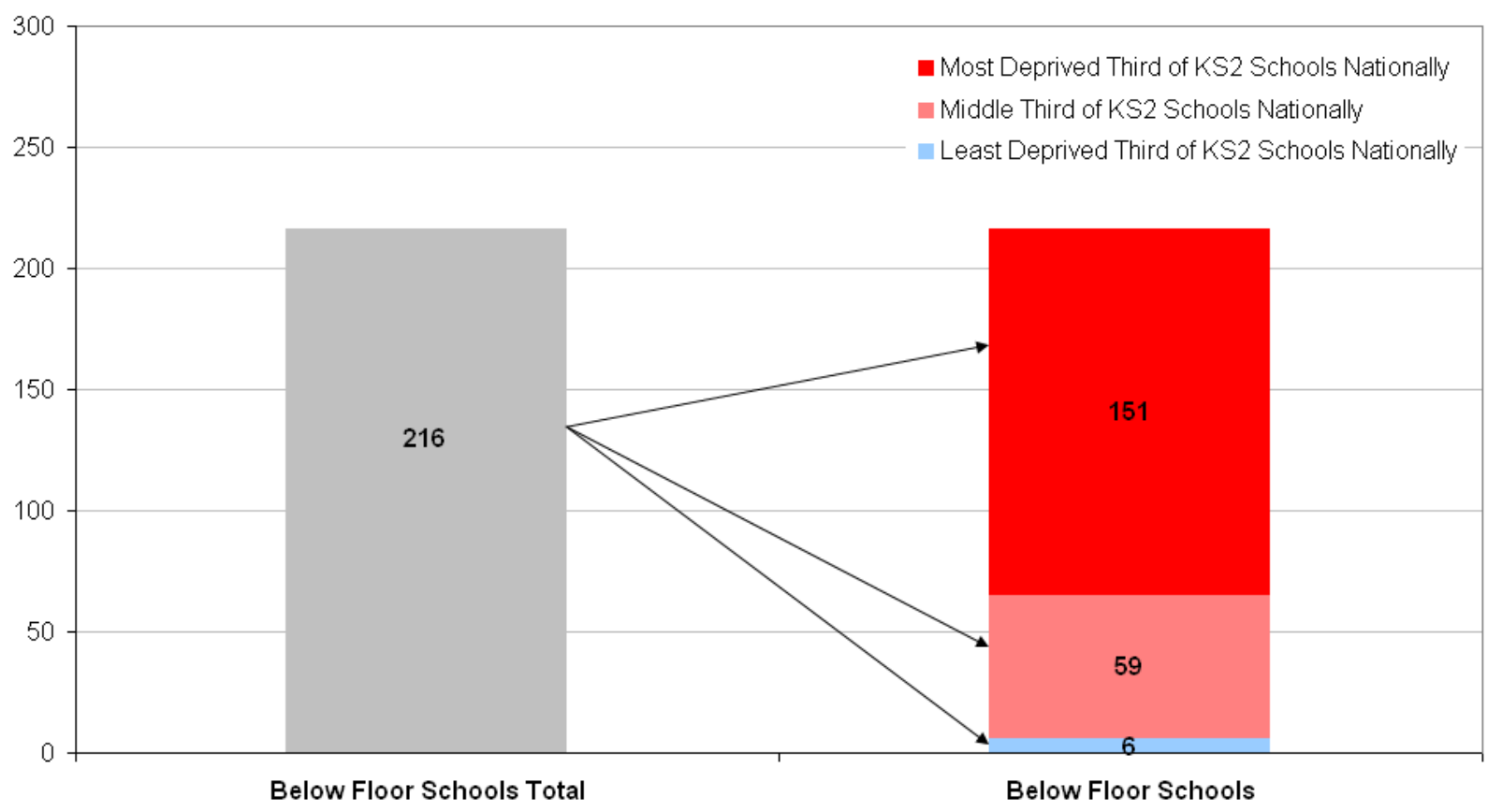

\section{Chart 1.2f}

KS4 Below Floor Schools Population: Ethnicity

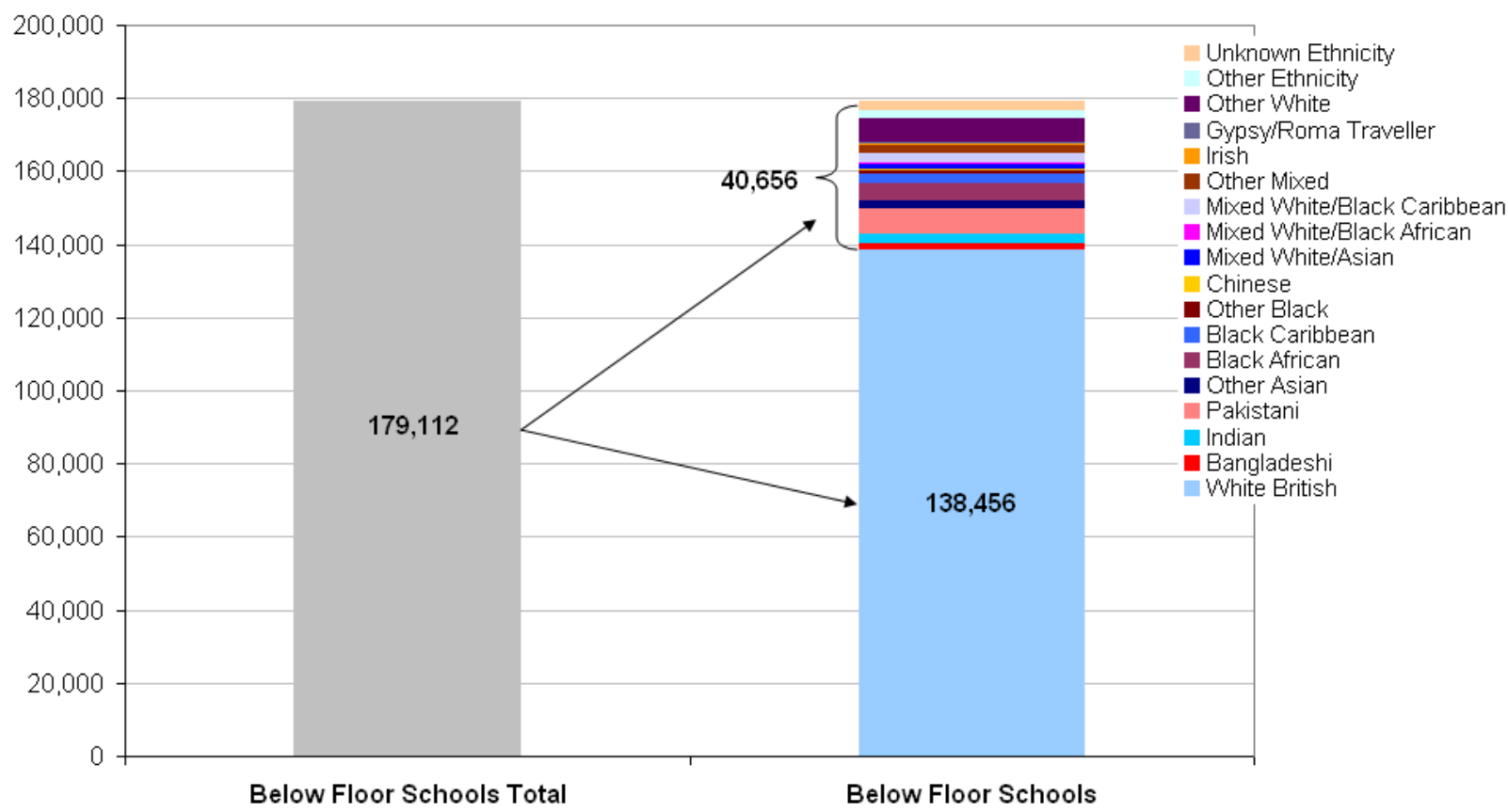




\section{Chart 1.2g}

KS4 Below Floor Schools Population: First language

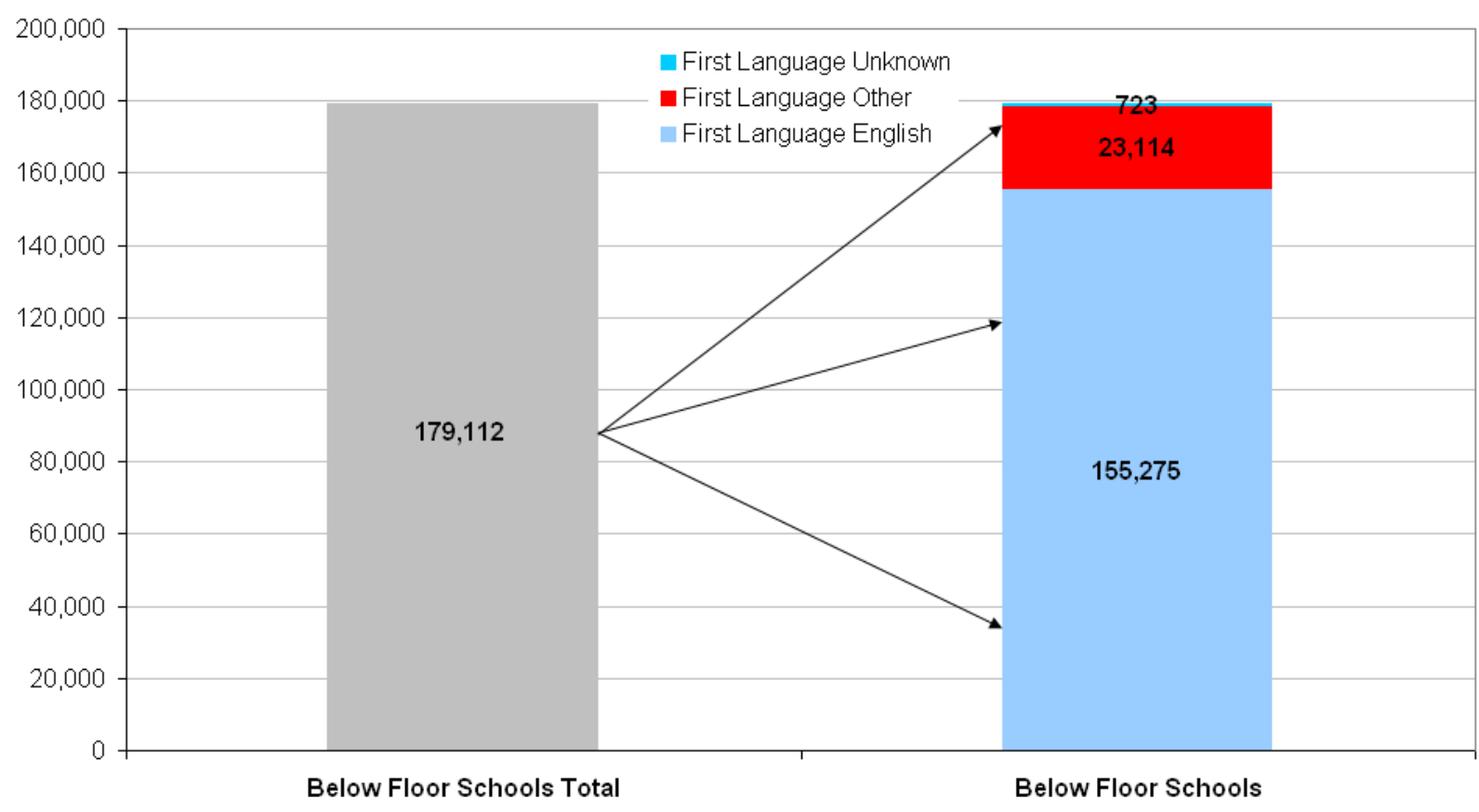

\section{Chart 1.2h}

KS4 Below Floor Schools Population: Special Educational Needs

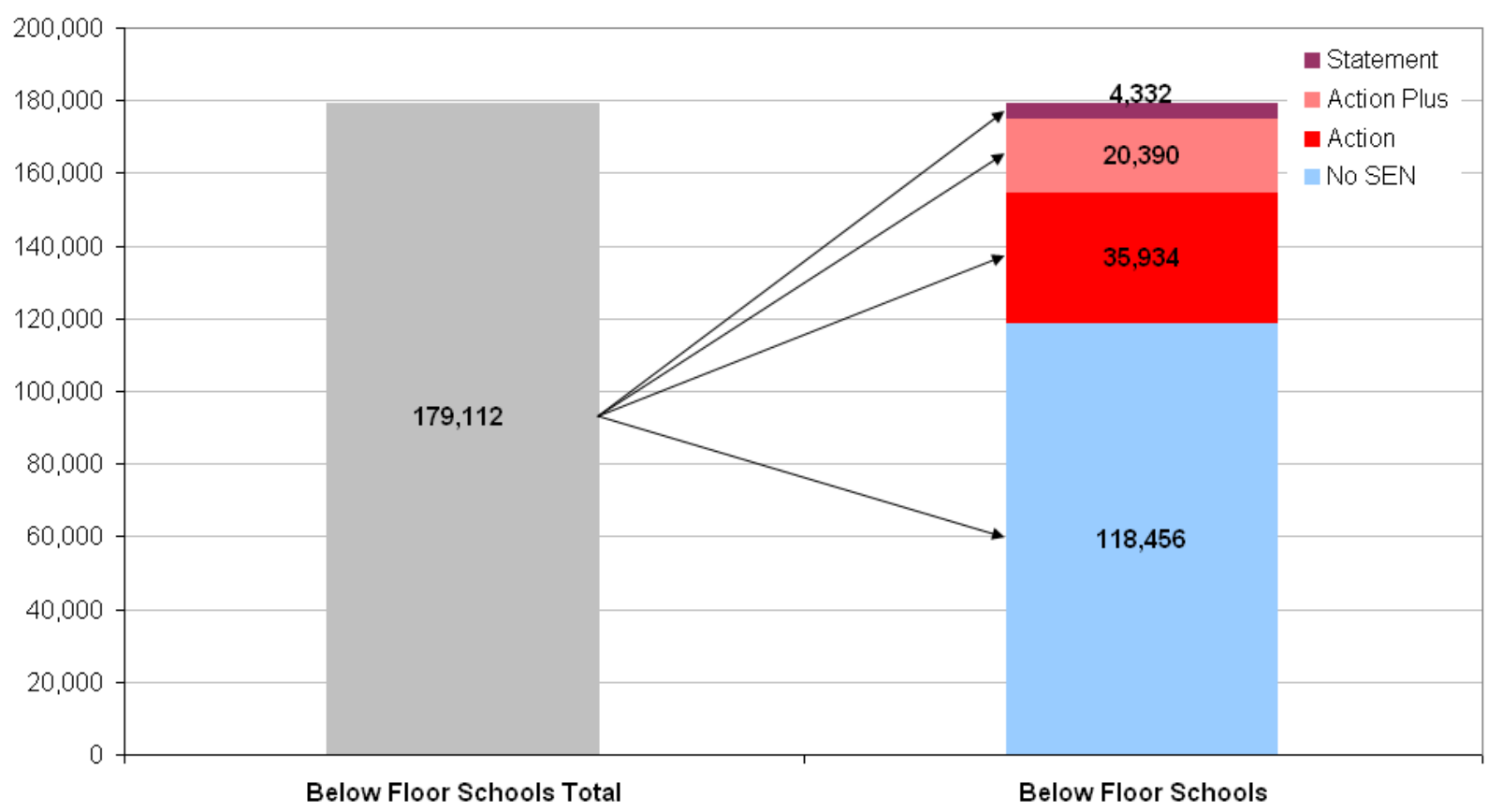




\section{Chart 1.2i}

KS4 Below Floor Schools: National Curriculum Year Group

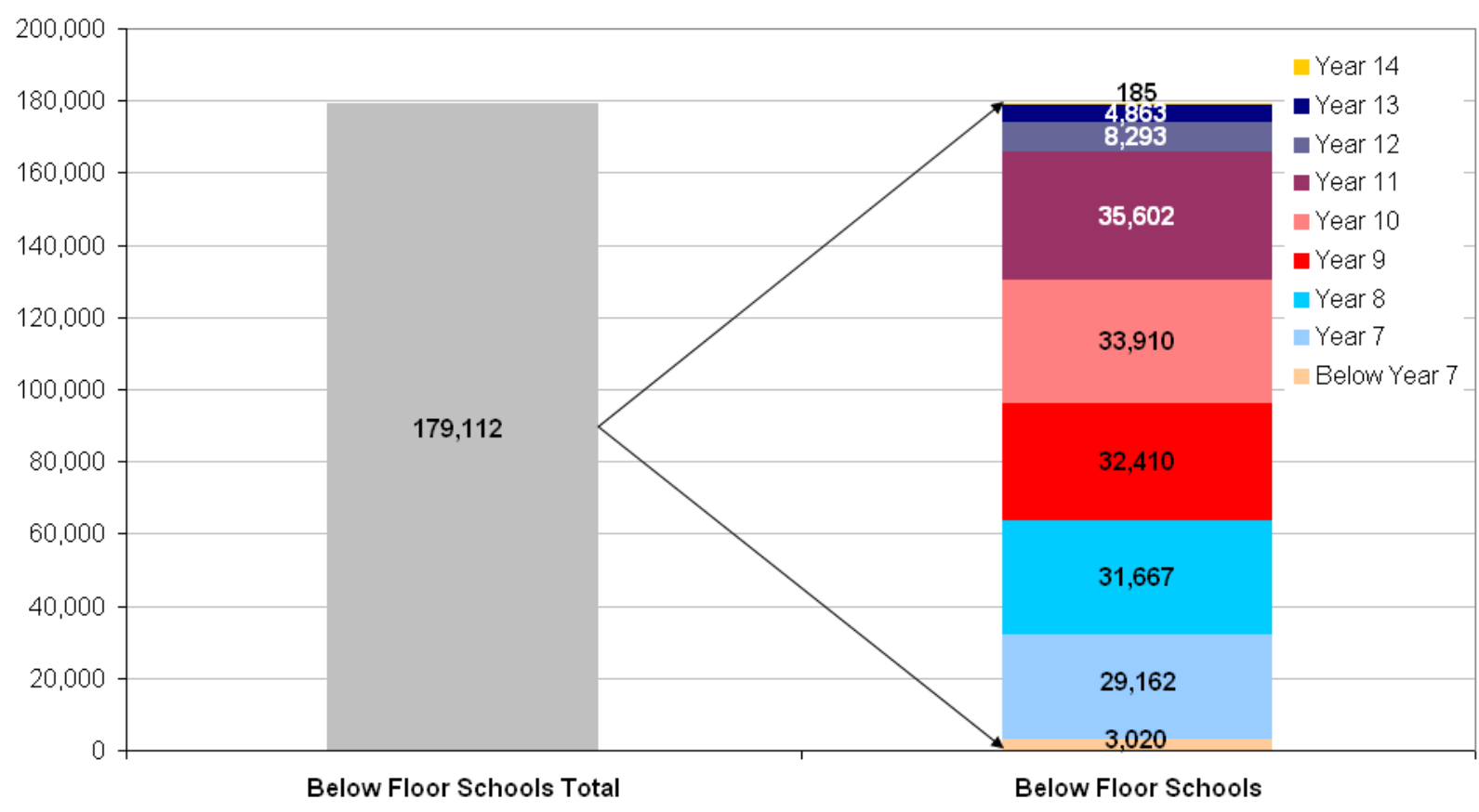




\section{Intake in Below Floor Schools Compared With Other Schools}

This chapter compares the characteristics of pupils in below floor schools with those of pupils in above floor schools to establish which groups of pupils are overrepresented in underperforming schools. Sections 2.1 and 2.2 contain analyses of KS2 and KS4 schools respectively, section 2.3 covers Looked After Children in below floor schools, and sections 2.4 and 2.5 focus on pupils eligible for free school meals within KS2 and KS4 schools.

\section{Key Findings}

- Deprived pupils (those eligible for free school meals and those living in areas of higher deprivation) were the most overrepresented groups in both primary and secondary below floor schools. Pupils in below floor schools live in more deprived areas than those in above floor schools both within the eligible for free school meals group and within those not eligible for FSM.

- Pupils eligible for free school meals made up $16 \%$ of those in above KS2 floor schools, but $28 \%$ of those in below floor schools and $33 \%$ of those in schools that were below floor standards in 2009 then boycotted the 2010 tests; in above KS4 floor schools, $14 \%$ of pupils were eligible for free school meals, compared with $27 \%$ of pupils in below floor schools.

- Overall, pupils of Black or minority ethnicity were distributed proportionately between KS2 below floor schools, KS4 below floor schools, and their above floor counterparts (KS2: 27\% compared with 25\%, KS4: $21 \%$ compared with $22 \%$ ); however, there were a higher proportion of BME pupils in schools below the KS2 floor standards in 2009 which then boycotted the 2010 tests (34\% compared with 25\%).

- Within the total BME population, there were individual ethnic groups with disproportionate representation in the below floor schools, with a tendency for overrepresentation of groups with low attainment, and underrepresentation of groups with above average attainment.

- Gypsy / Roma Traveller pupils and Pakistani pupils were substantially overrepresented in both primary and secondary below floor schools; to a lesser degree, Black African and Bangladeshi pupils were overrepresented in schools that were below the KS2 floor standards in 2009 then boycotted the 2010 tests.

- Irish pupils and Indian pupils were substantially underrepresented in both groups of below KS2 floor standard schools, and in below KS4 floor standard schools. Chinese pupils were also underrepresented in below KS4 floor standard schools.

- Higher proportions of pupils in below floor schools at both Key Stages were identified with special educational needs, compared with those in above floor schools (KS2: $26-28 \%$ compared with $21 \%$; KS4: $33 \%$ compared with $21 \%$ ). The stronger overrepresentation at KS4 was driven by higher proportions of pupils with SEN at school action level, or at school action plus level.

- Pupils whose first language is not English were overrepresented in schools that were below the KS2 floor standards in 2009 then boycotted the 2010 tests (24\% compared with $16 \%$ ), but were not overrepresented in schools below the $2010 \mathrm{KS} 2$ and KS4 floor standards. 
- Looked After Children are overrepresented in below floor schools at both Key Stages, although their total numbers are small. In the KS2 cohort, $0.5 \%$ of children in below floor schools were Looked After Children, compared with $0.3 \%$ in above floor schools; in the KS4 cohort, $0.8 \%$ of children in below floor schools were Looked After Children, compared with $0.5 \%$ in above floor schools.

- Schools in the East of England and the South East were overrepresented among KS2 below floor schools; those in Yorkshire and the Humber, the North East and the West Midlands were overrepresented among schools that were below the KS2 floor standards in 2009 then boycotted the 2010 tests.

- Schools in the Yorkshire and the Humber, East Midlands and the South East were overrepresented among KS4 below floor schools.

- Schools in Inner and Outer London and the North West were underrepresented among KS2 below floor schools; those in the East of England and the South West were underrepresented among schools that were below the KS2 floor standards in 2009 then boycotted the 2010 tests.

- Schools in Inner and Outer London and the South West were underrepresented among KS4 below floor schools.

- Separating the FSM and non-FSM populations in below and above floor schools, at both Key Stages, pupils with a special educational need are overrepresented amongst pupils with and without free school meals eligibility in below floor schools; this overrepresentation of SEN is stronger amongst non-FSM pupils.

- White British pupils are overrepresented in below floor schools among the FSM eligible population, but not among non-FSM pupils; this is the case at both Key Stages.

- At both Key Stages, pupils of Black and minority ethnicity, and those with a first language that is not English are both overrepresented in the non-FSM population within below floor schools, but underrepresented within the population of pupils eligible for free school meals in below floor schools. 


\subsection{Key Stage 2 Schools}

Charts 2.1a-2.1h illustrate the incidence of deprivation, Black and minority ethnic groups, pupils with a first language other than English, and special educational needs in KS2 schools, grouped into those above and below the floor standards. Charts 2.1i and 2.1j then show the share of schools above and below the floor in each geographic region, and according to their urban / rural classification.

The odds ratios in the tables beneath each chart give a standardised measure of how disproportional each characteristic is within the below floor schools groups, which can be compared across different characteristics. Odds ratios with values greater than 1 mean that the characteristic in question is more prevalent in below floor schools than in above floor schools; odds ratios of less than 1 mean that the characteristics is less prevalent in below floor schools than above floor schools.

For example, in chart 2.1a, the odds ratio for free school meals is 2.0; the odds of a pupil in a below floor school being eligible for free school meals are two times as high as the odds for a pupil in an above floor school. The corresponding odds ratio for schools that were below the floor standards in 2009 then boycotted the tests in 2010 is even higher at 2.5, meaning that pupils eligible for FSM are even more overrepresented in these schools compared with above floor schools than was the case for schools below the floor in 2010. Because the odds ratios are a standardised measure, it is possible to compare across different characteristics; in chart $2.1 \mathrm{~b}$, the odds ratio on Black or minority ethnic status for schools that were below the floor standards in 2009 then boycotted the tests in 2010 is 1.5 - this group is overrepresented in these schools compared with above floor schools, but not to as great an extent as pupils eligible for free school meals are. 


\section{Chart 2.1a}

\section{School and Area Deprivation in Below / Above KS2 Floor Schools}

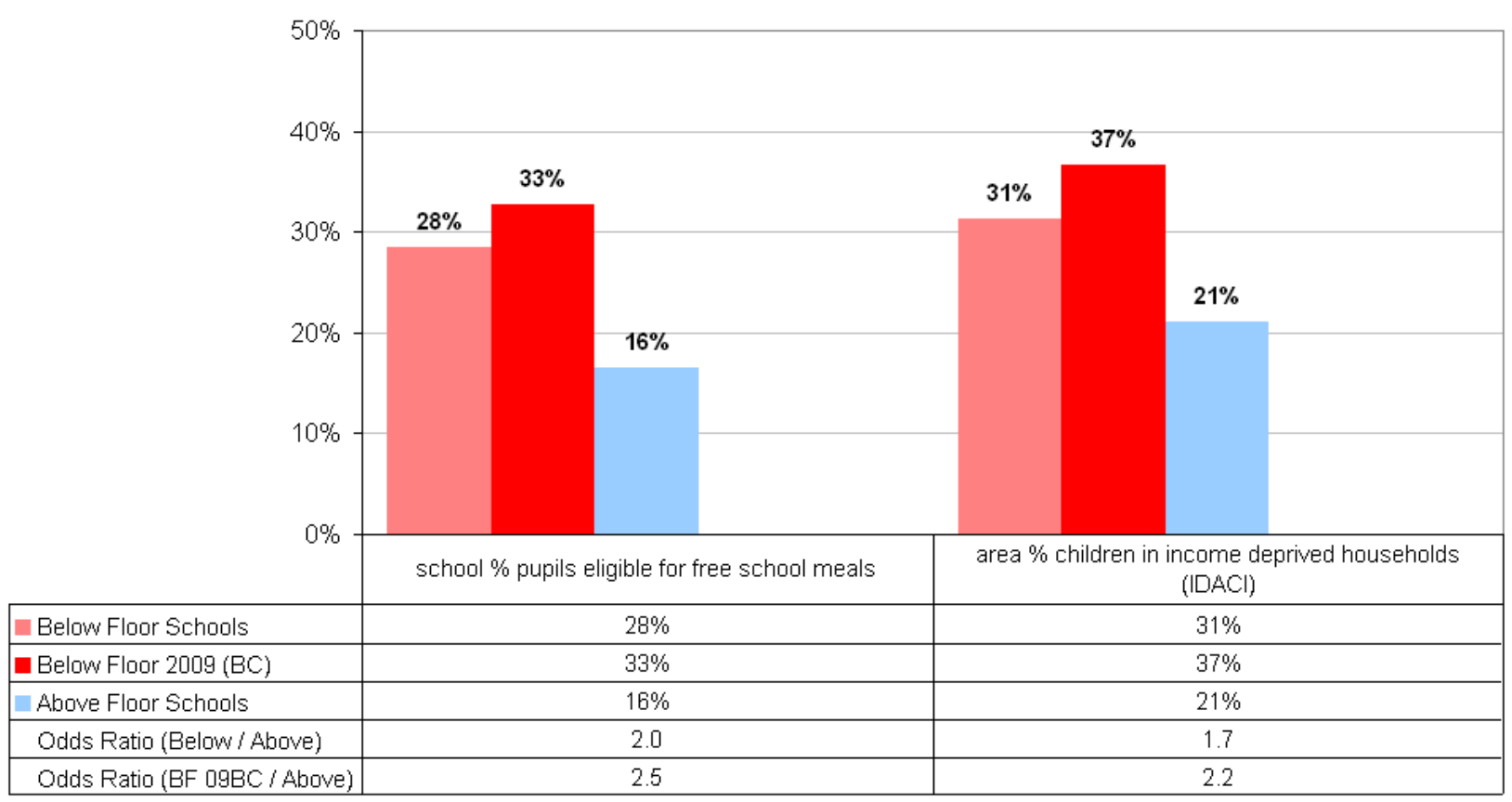

\section{Chart 2.1b}

\section{Black and Minority Ethnic Pupils in Below / Above KS2 Floor Schools}

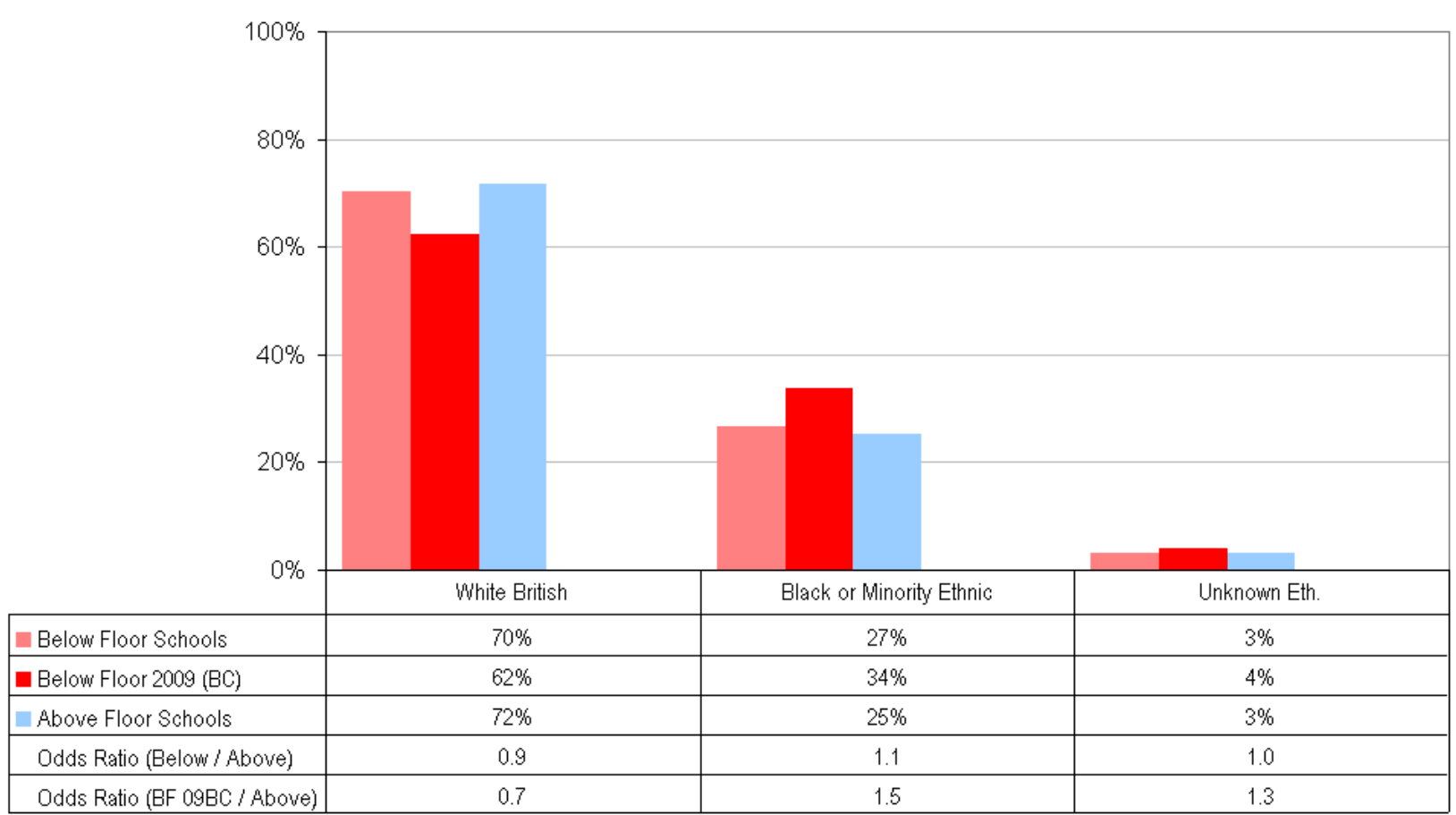




\section{Chart 2.1c}

Pupil Ethnicity in Below / Above KS2 Floor Schools (I)

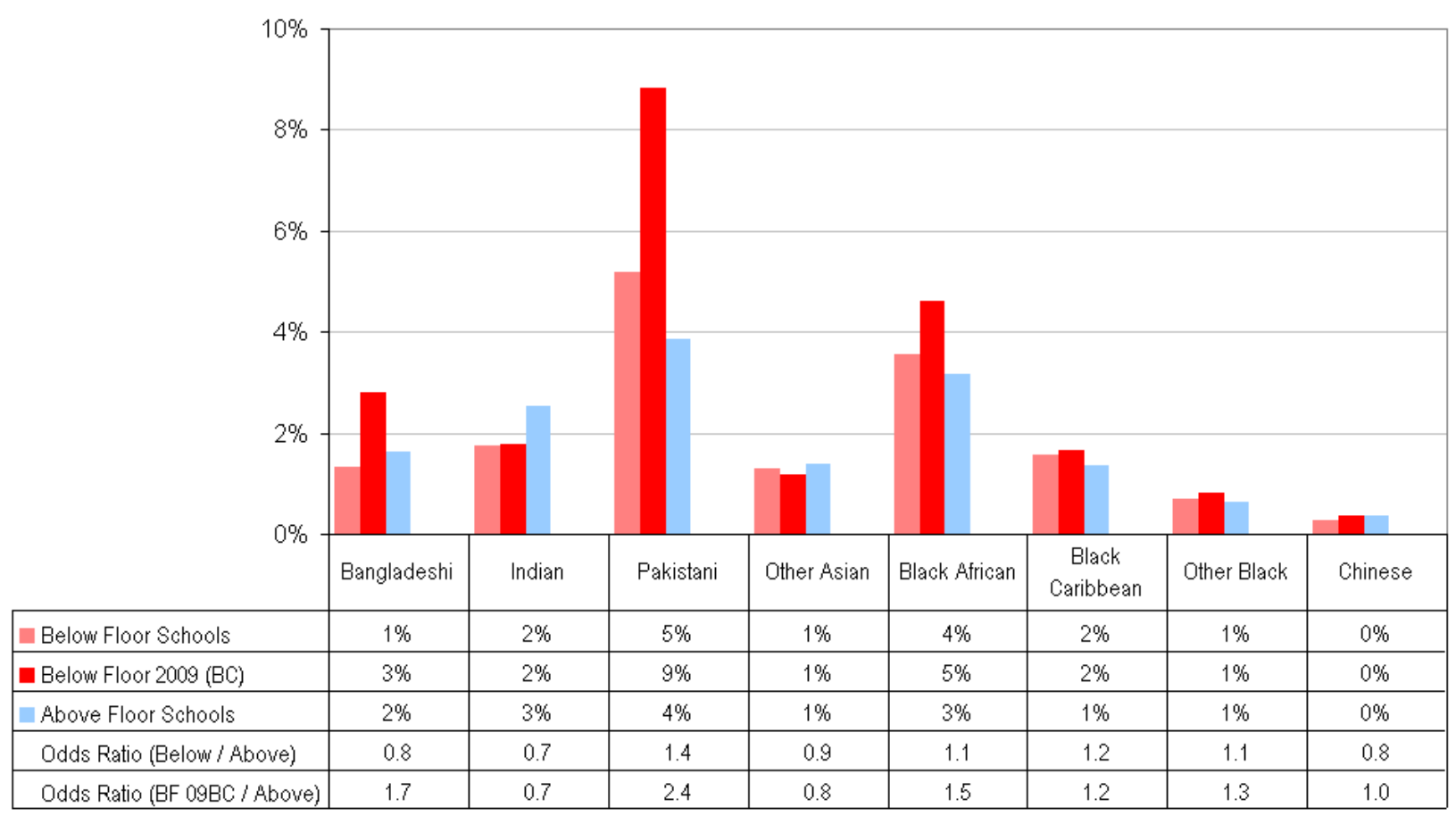

\section{Chart 2.1d}

Pupil Ethnicity in Below / Above KS2 Floor Schools (II)

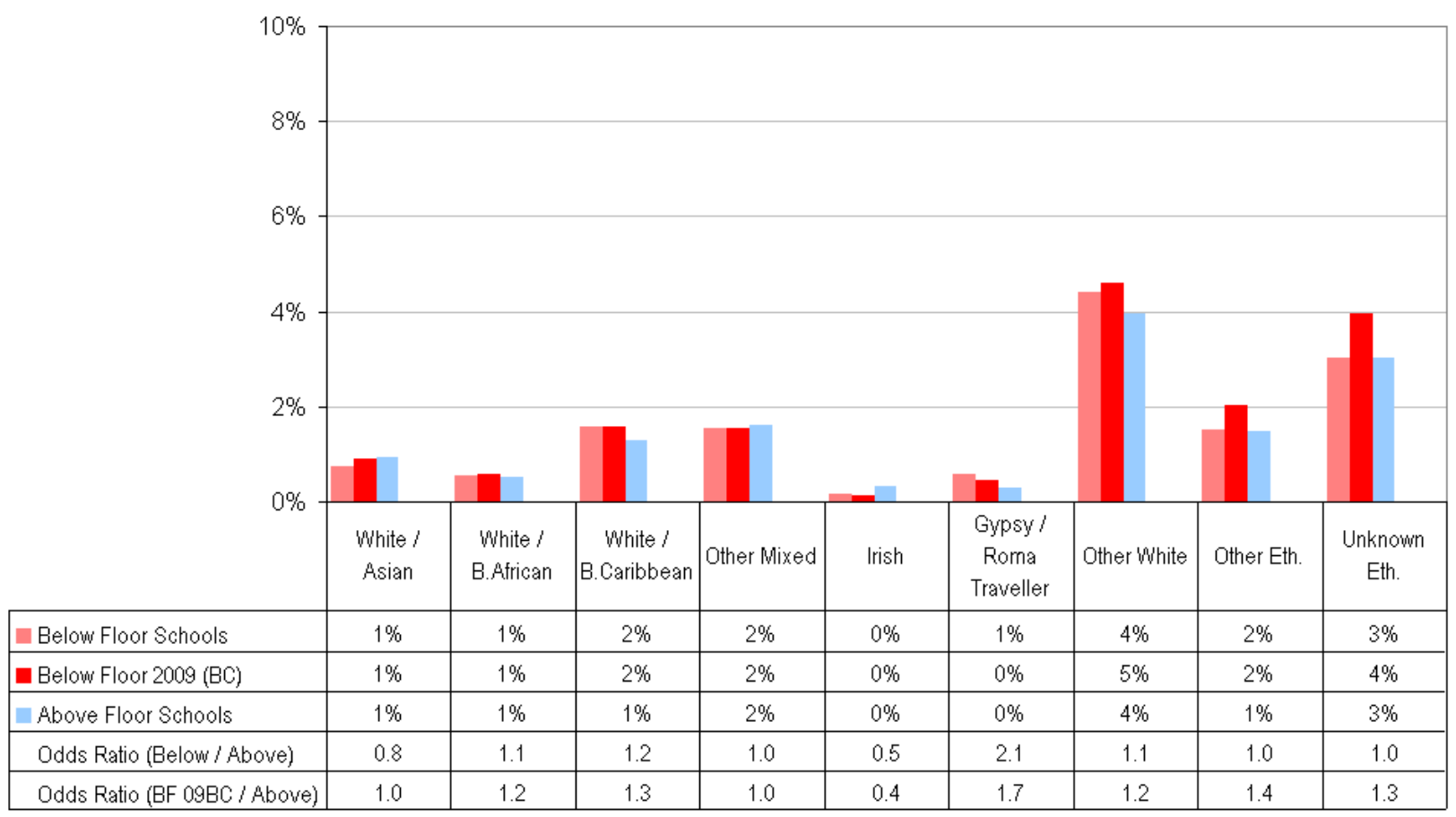




\section{Chart 2.1e}

\section{Pupil First Language in Below / Above KS2 Floor Schools}

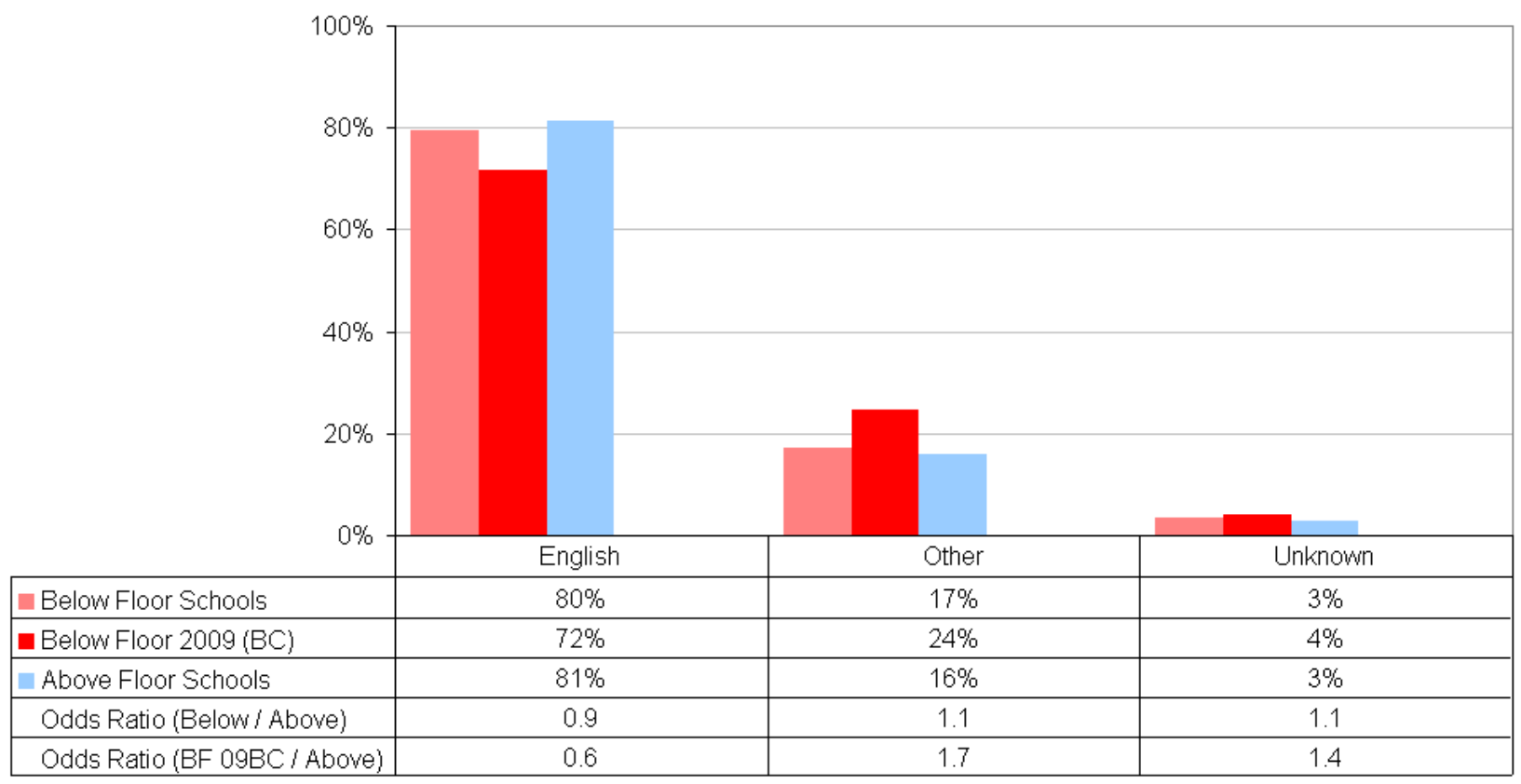

\section{Chart 2.1f}

\section{Special Educational Needs in Below / Above KS2 Floor Schools}

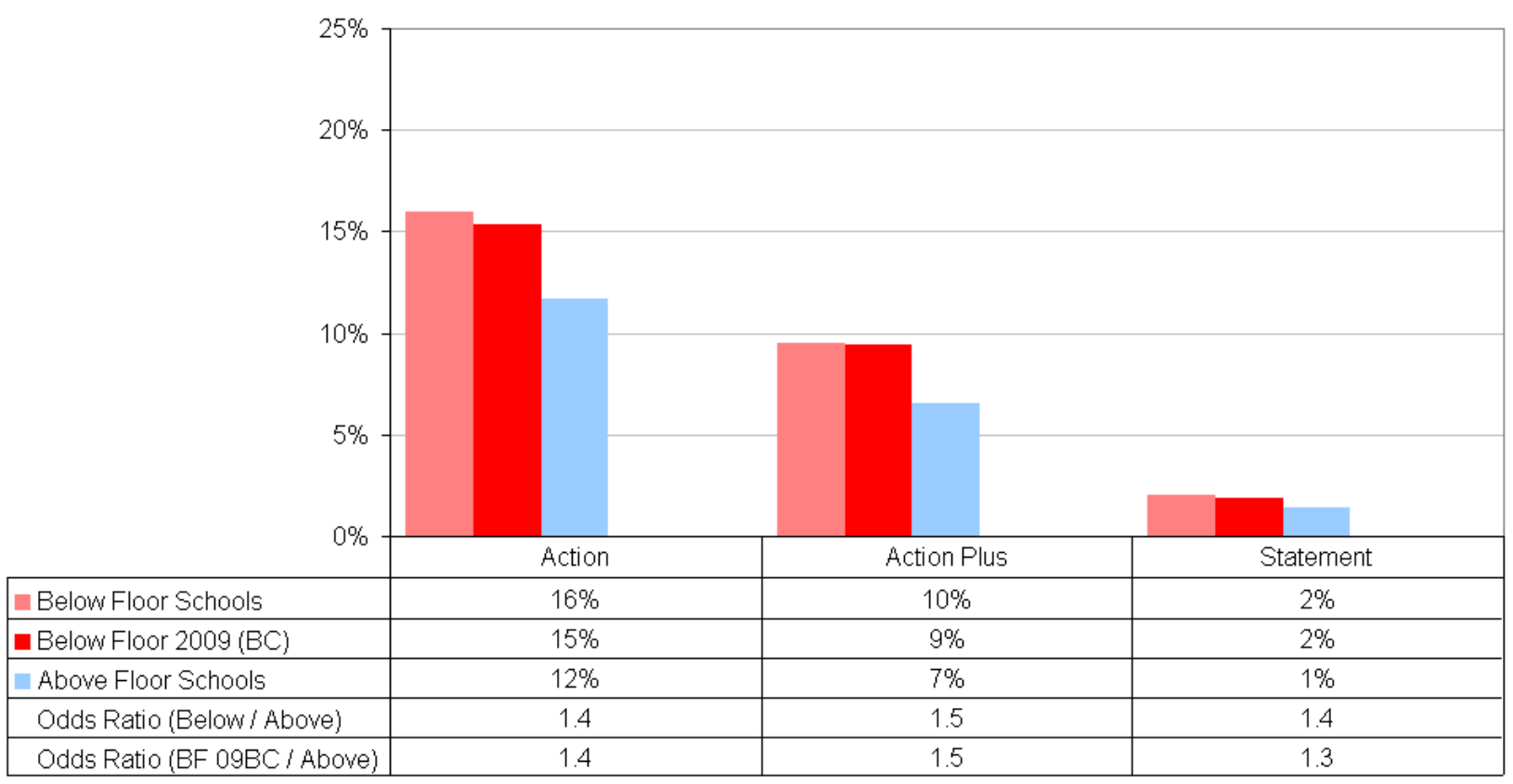




\section{Chart 2.1g}

Primary SEN Type (Action Plus and Statement) in Below / Above KS2 Floor Schools

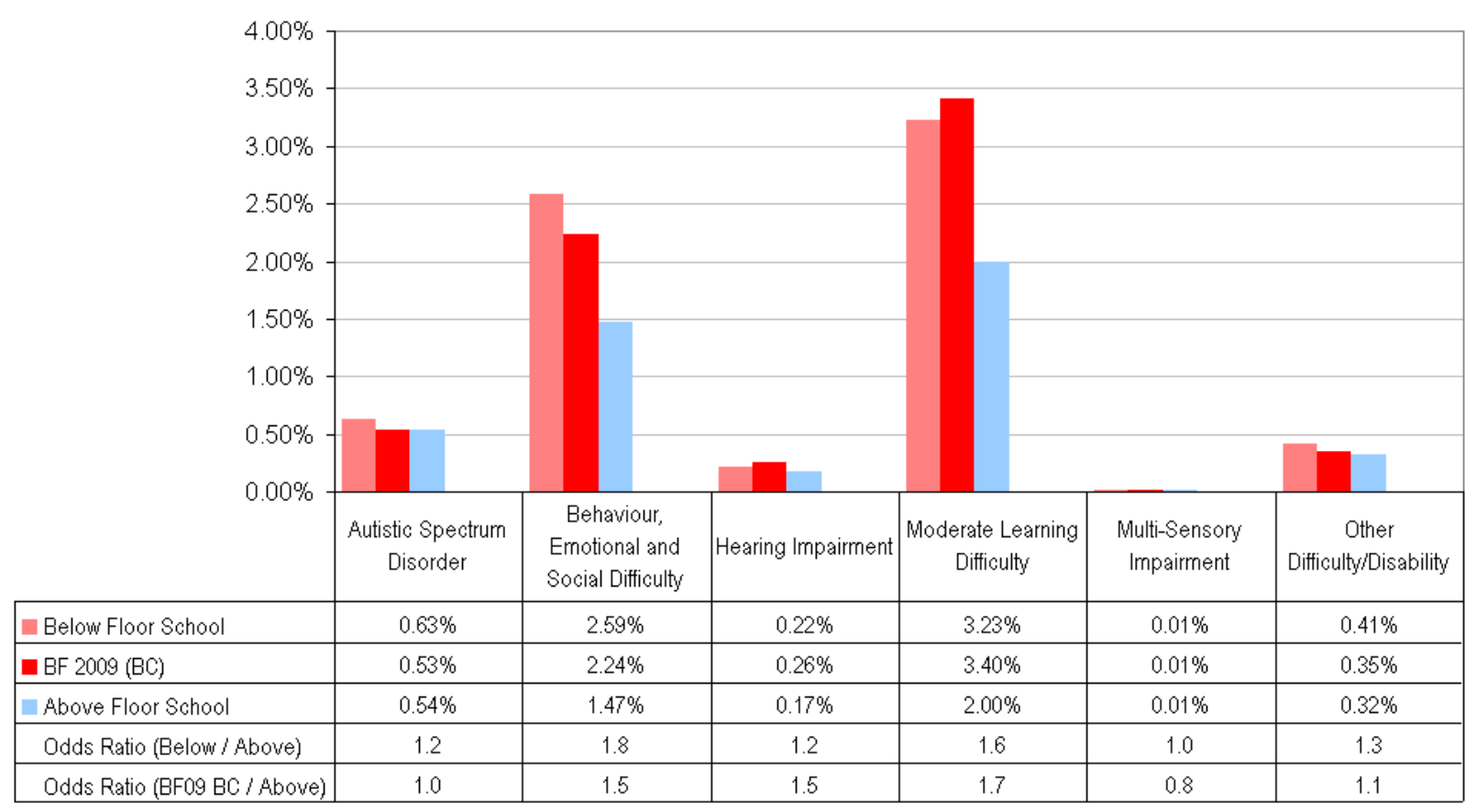

\section{Chart 2.1h}

Primary SEN Type (Action Plus and Statement) in Below / Above KS2 Floor Schools

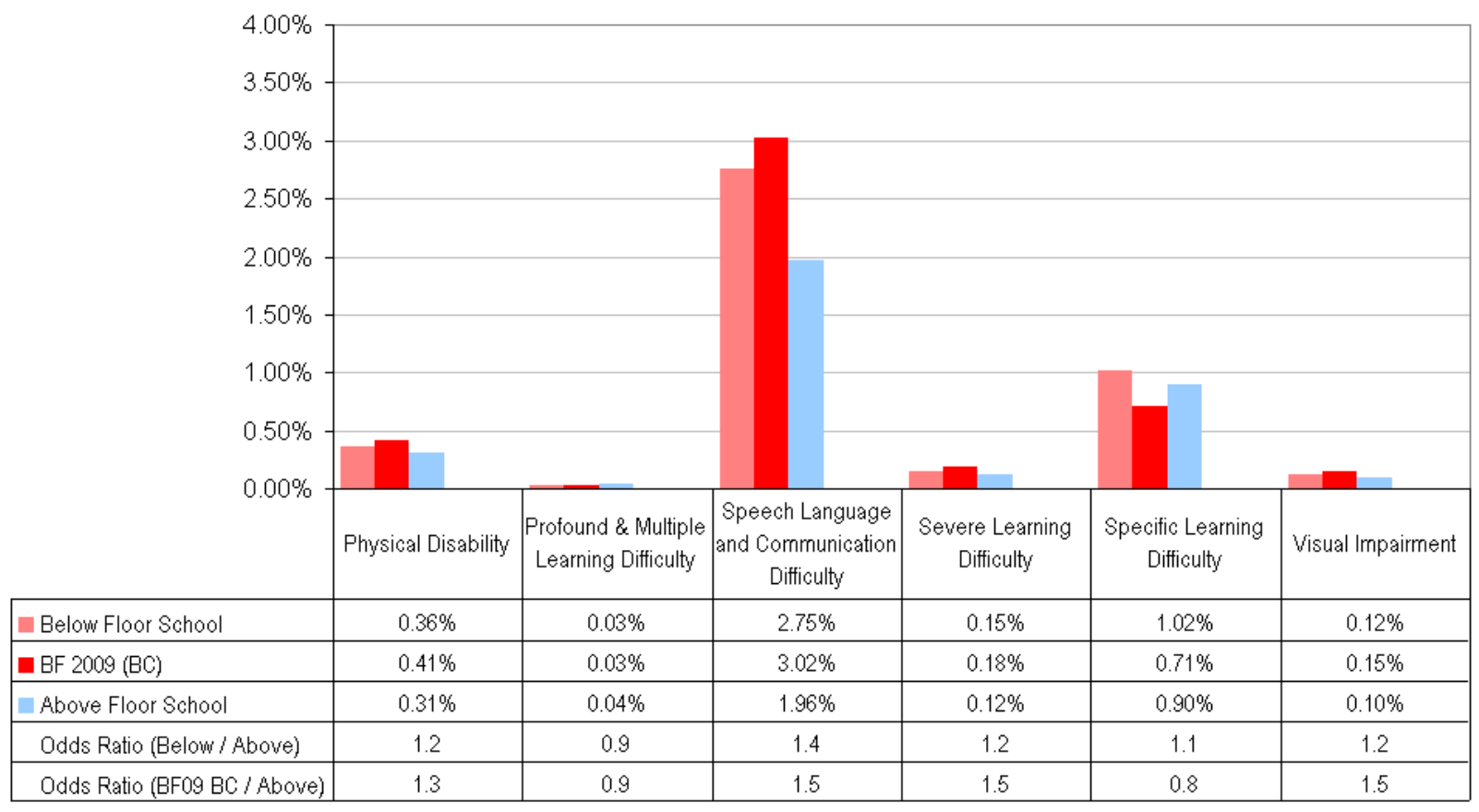




\section{Chart 2.1i}

\section{Regional Share of Below / Above KS2 Floor Schools}

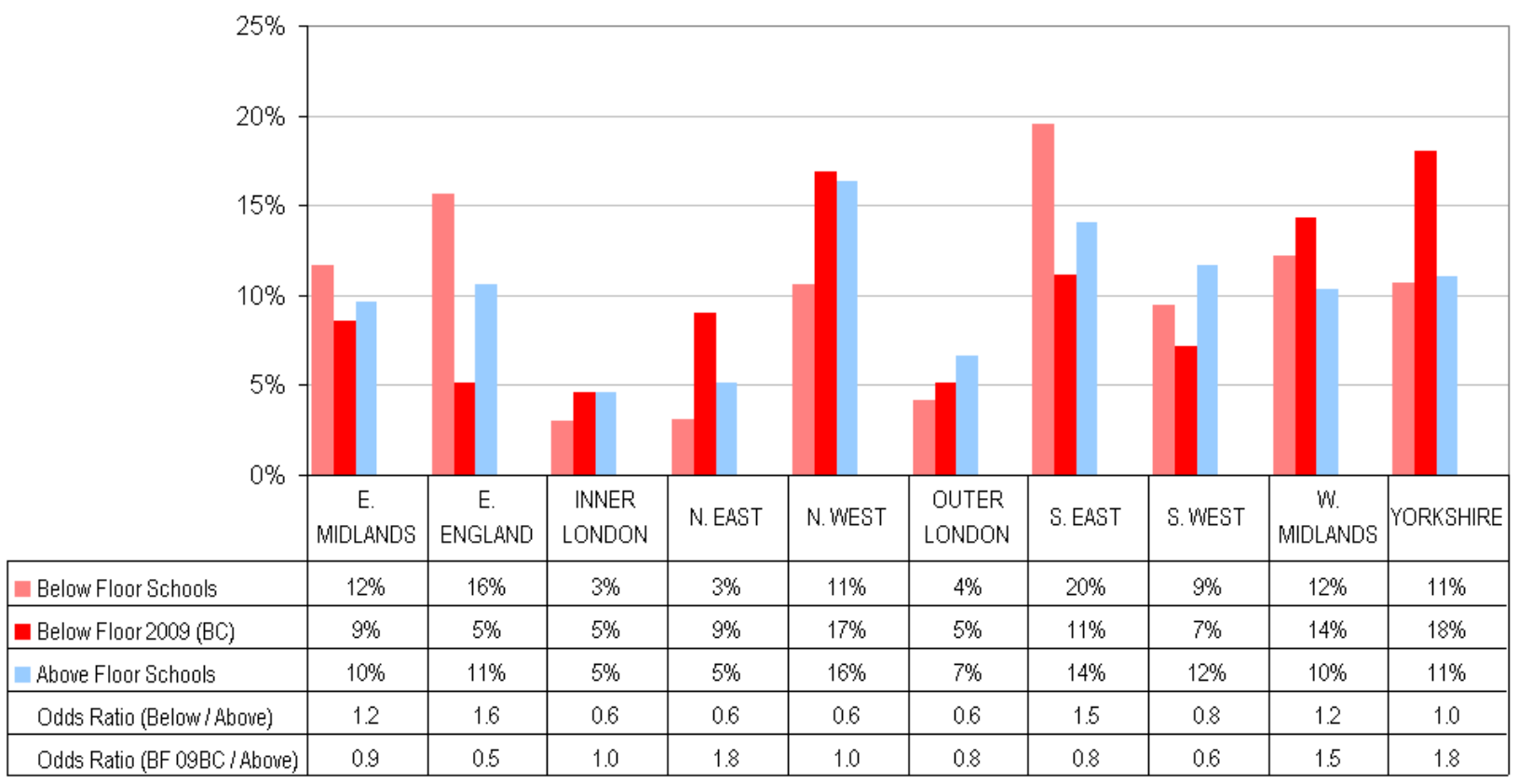

\section{Chart 2.1j}

Urban / Rural Classification of Below / Above KS2 Floor Schools

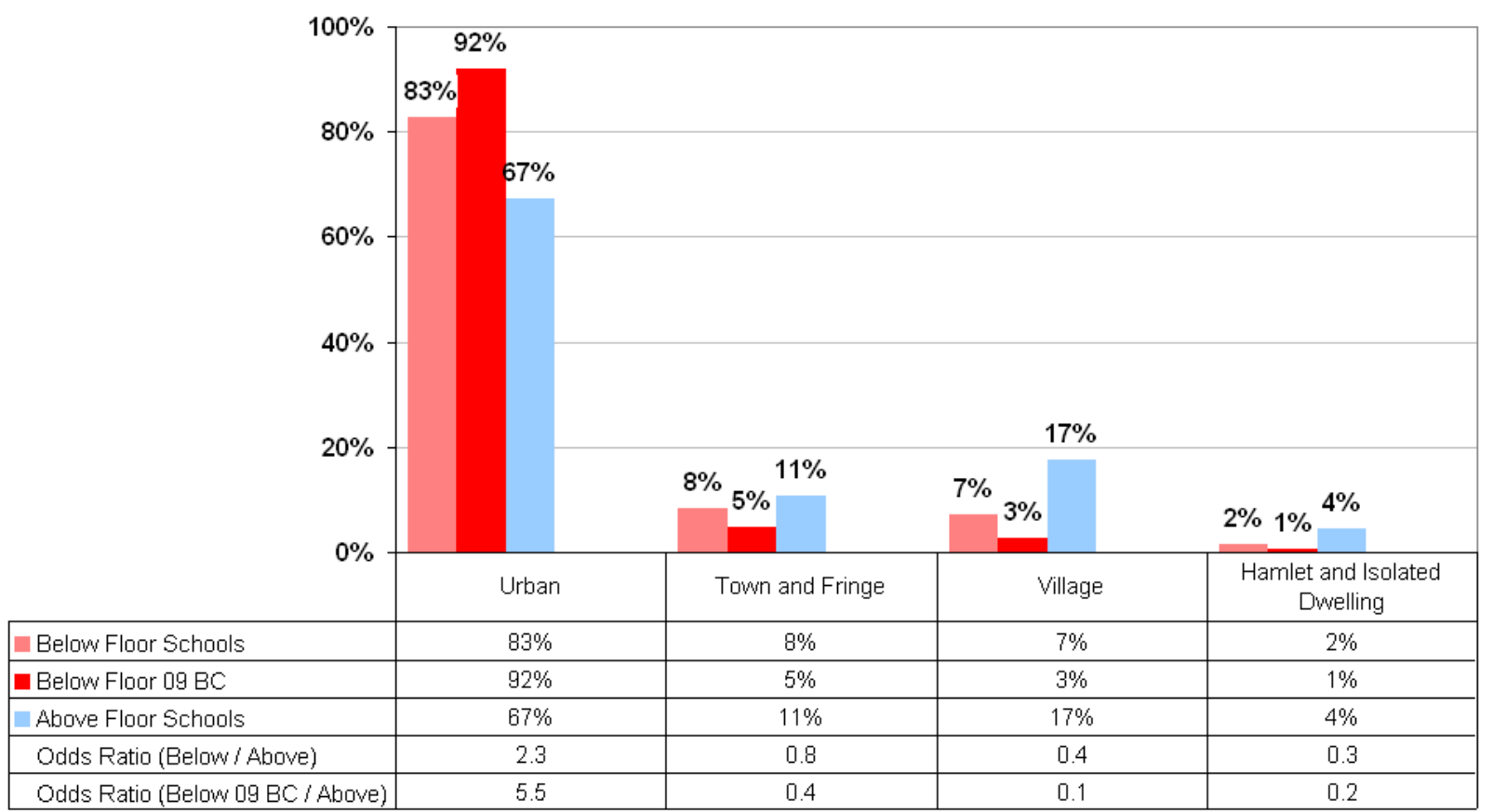




\subsection{Key Stage 4 Schools}

Charts 2.2a-2.2h chart the incidence of deprivation, Black and minority ethnic groups, pupils with a first language other than English, and special educational needs in KS4 schools, grouped into those above and below the floor standards. Charts $2.2 \mathrm{i}$ and $2.2 \mathrm{j}$ then show the share of schools above and below the floor in each geographic region, and according to their urban / rural classification.

\section{Chart 2.2a}

School and Area Deprivation in Below / Above KS4 Floor Schools

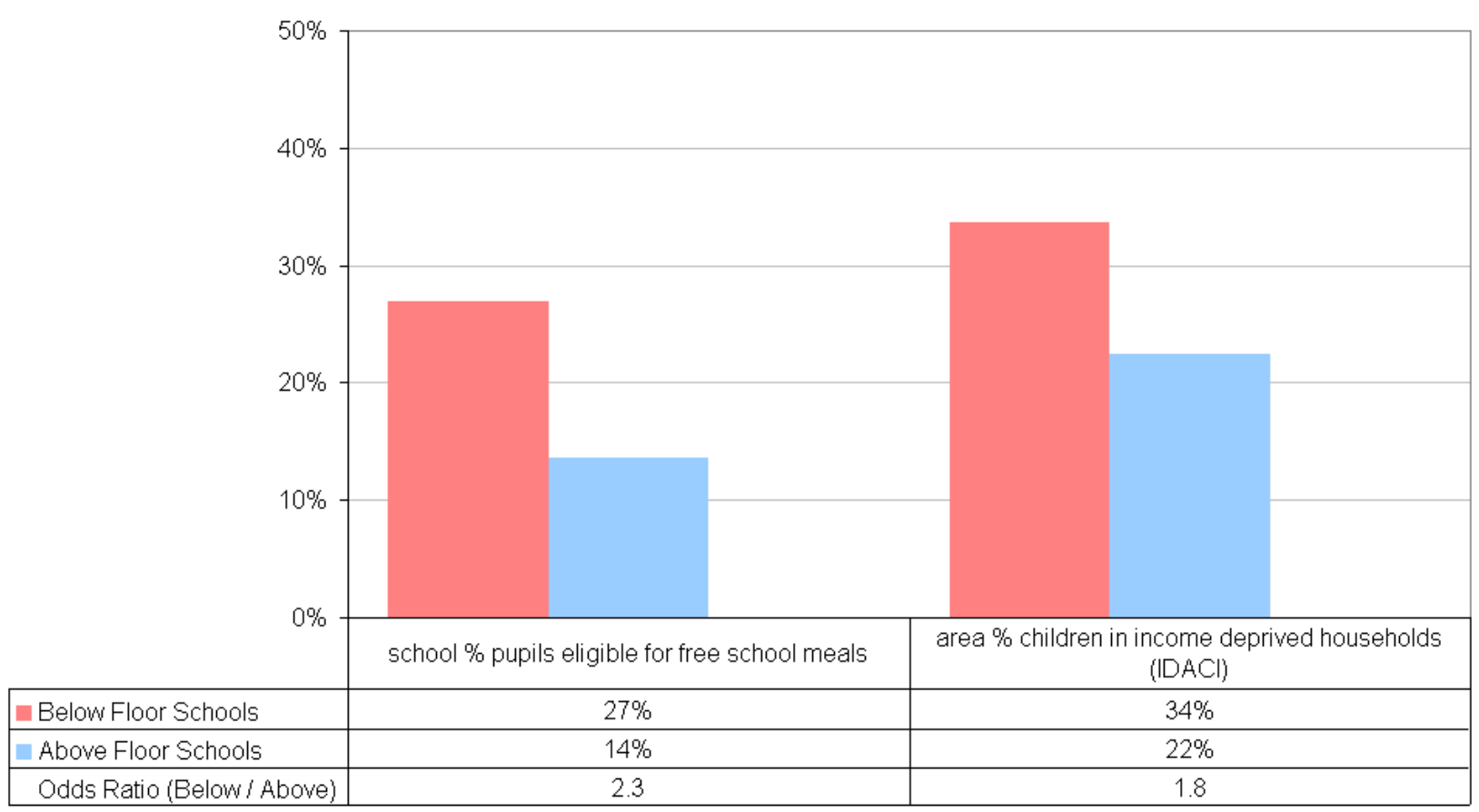




\section{Chart 2.2b}

\section{Black and Minority Ethnic Pupils in Below / Above KS4 Floor Schools}

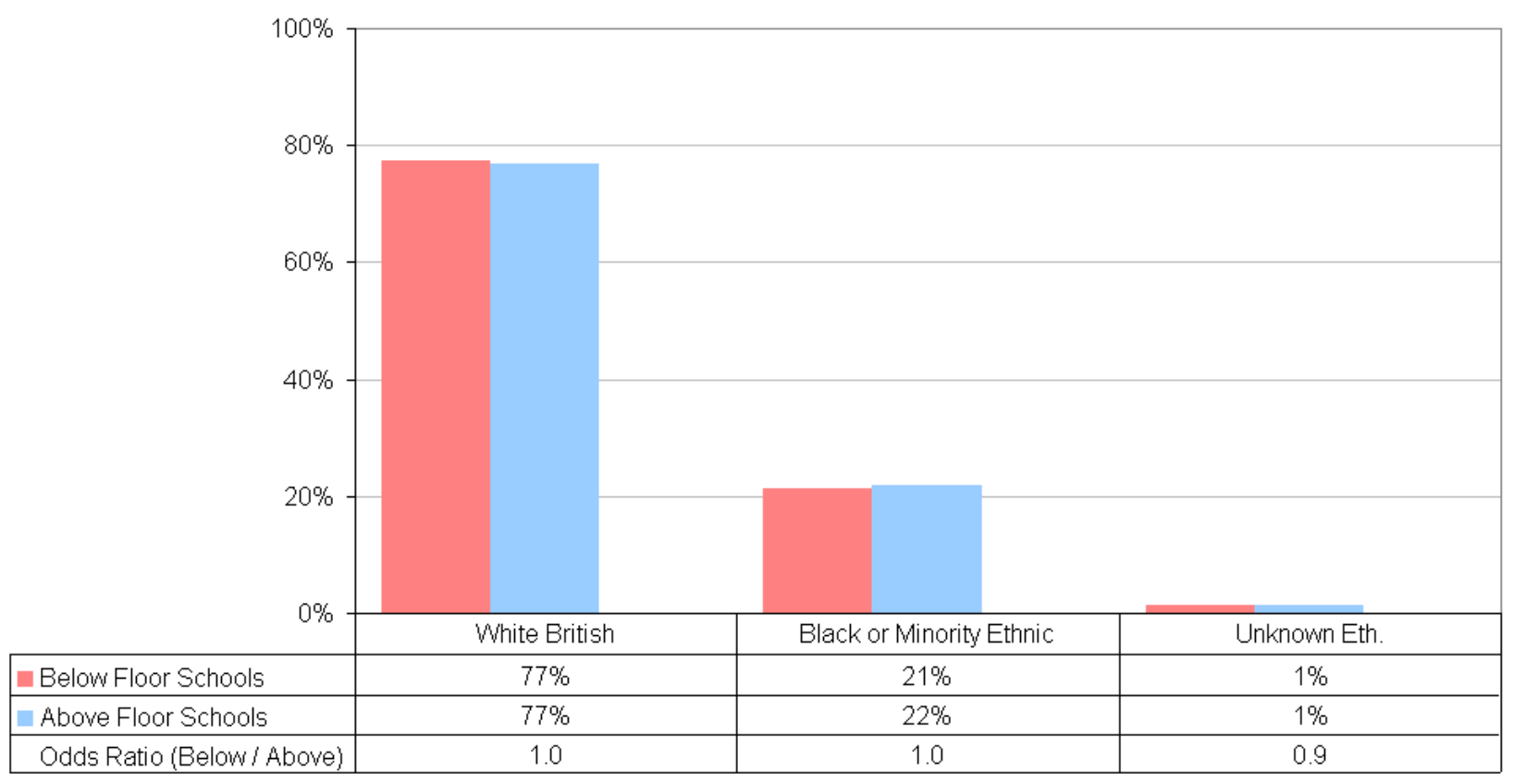

\section{Chart 2.2c}

Pupil Ethnicity in Below / Above KS4 Floor Schools (I)

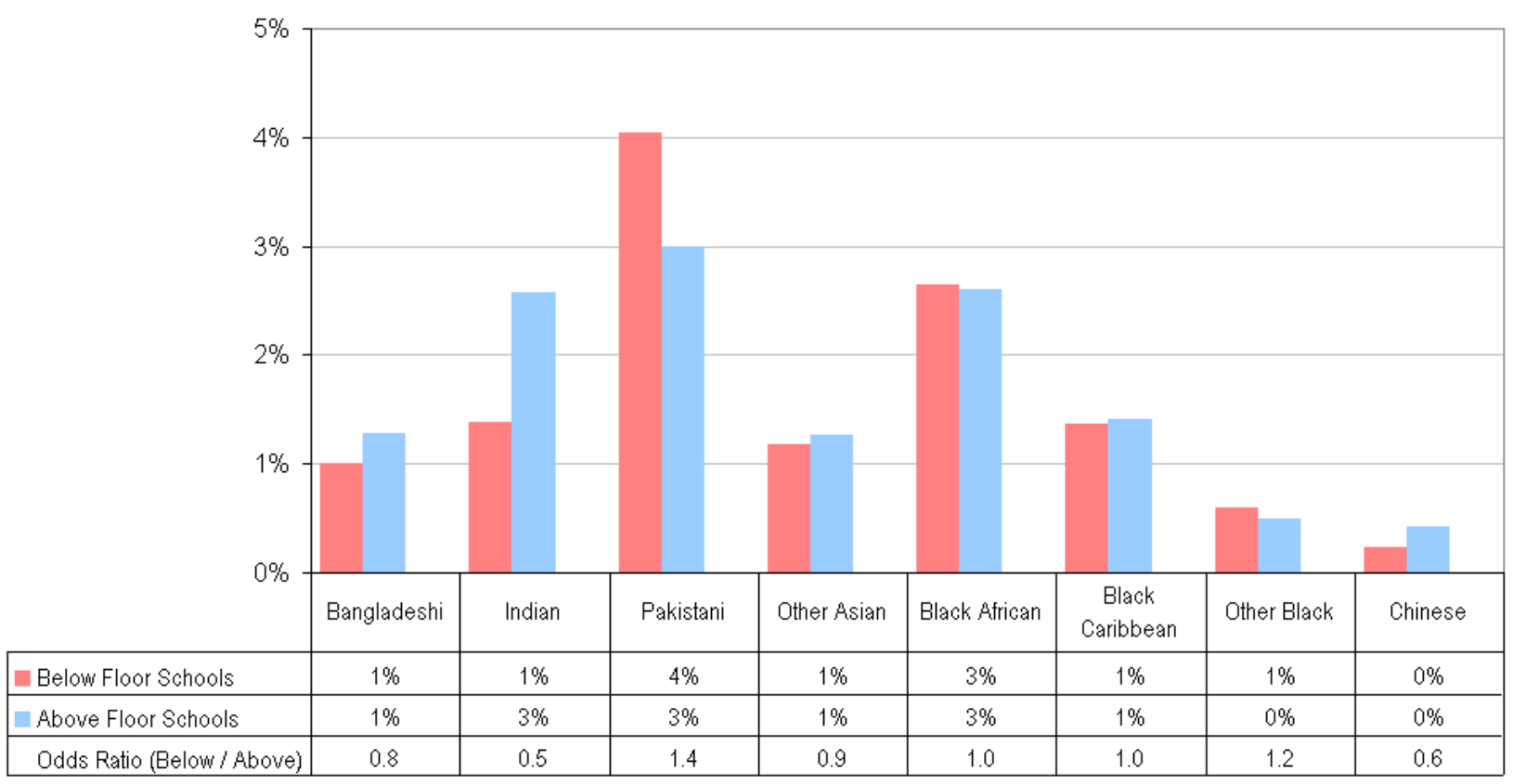




\section{Chart 2.2d}

\section{Pupil Ethnicity in Below / Above KS4 Floor Schools (II)}

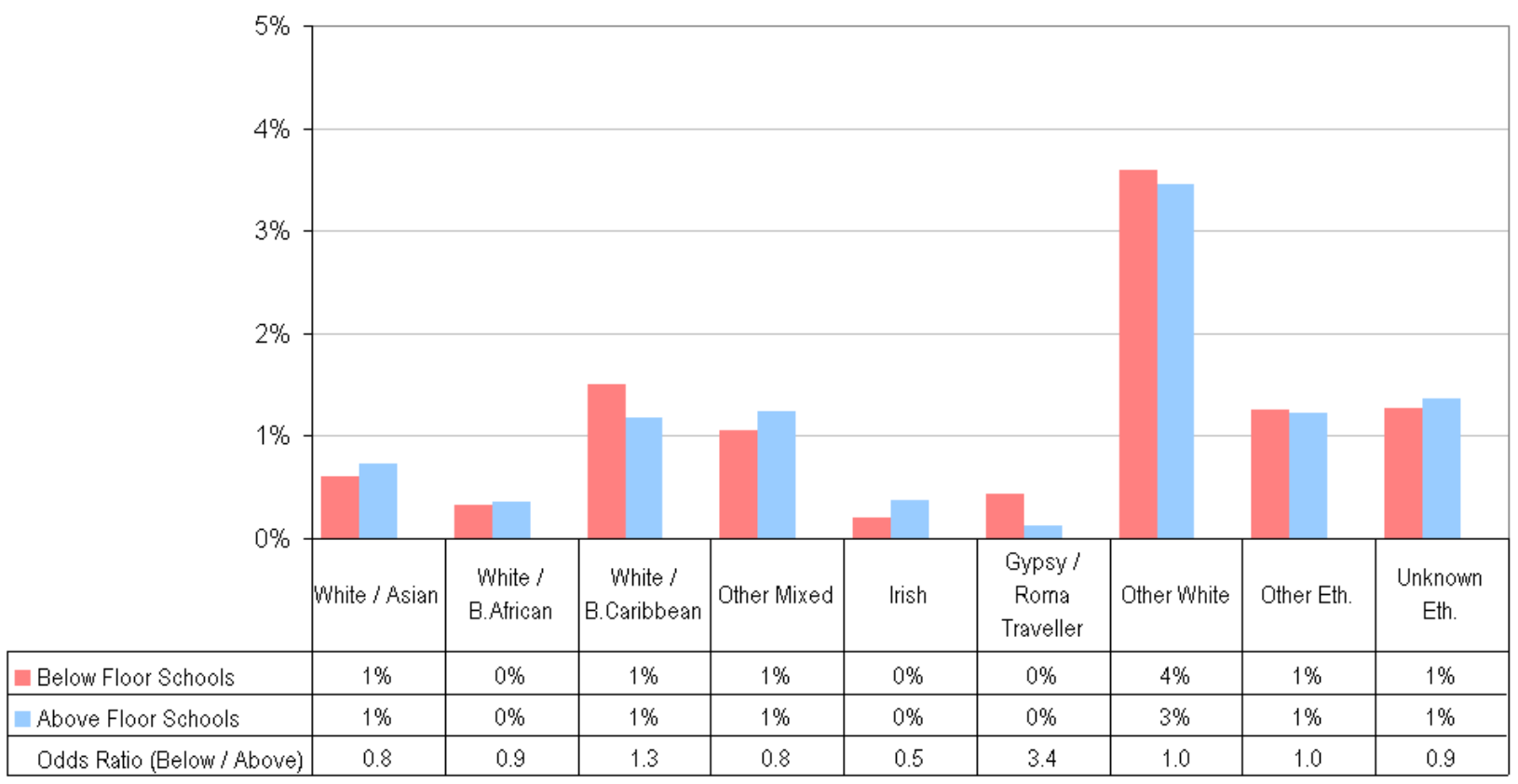

\section{Chart 2.2e}

Pupil First Language in Below / Above KS4 Floor Schools

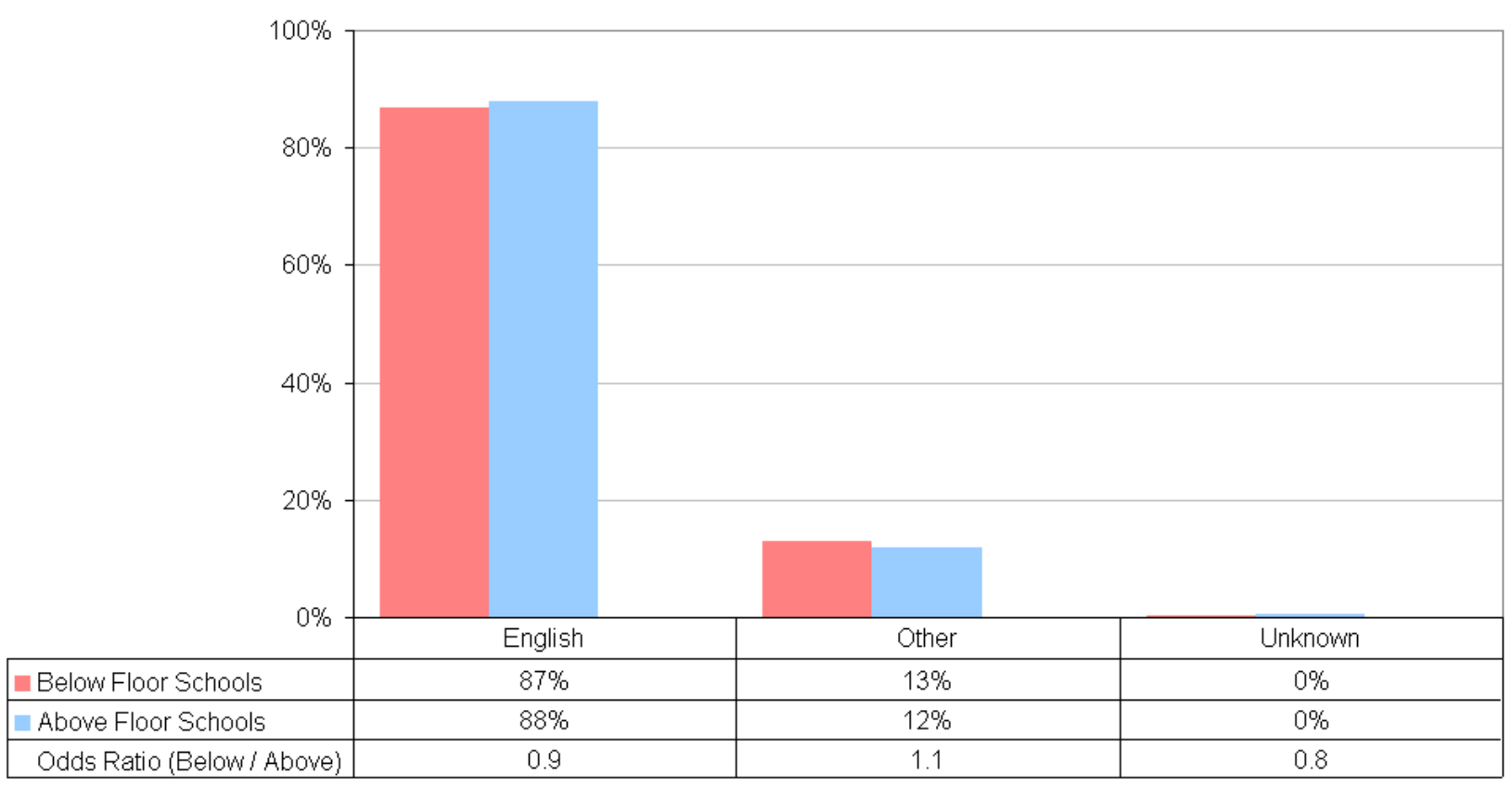




\section{Chart 2.2f}

\section{Special Educational Needs in Below / Above KS4 Floor Schools}

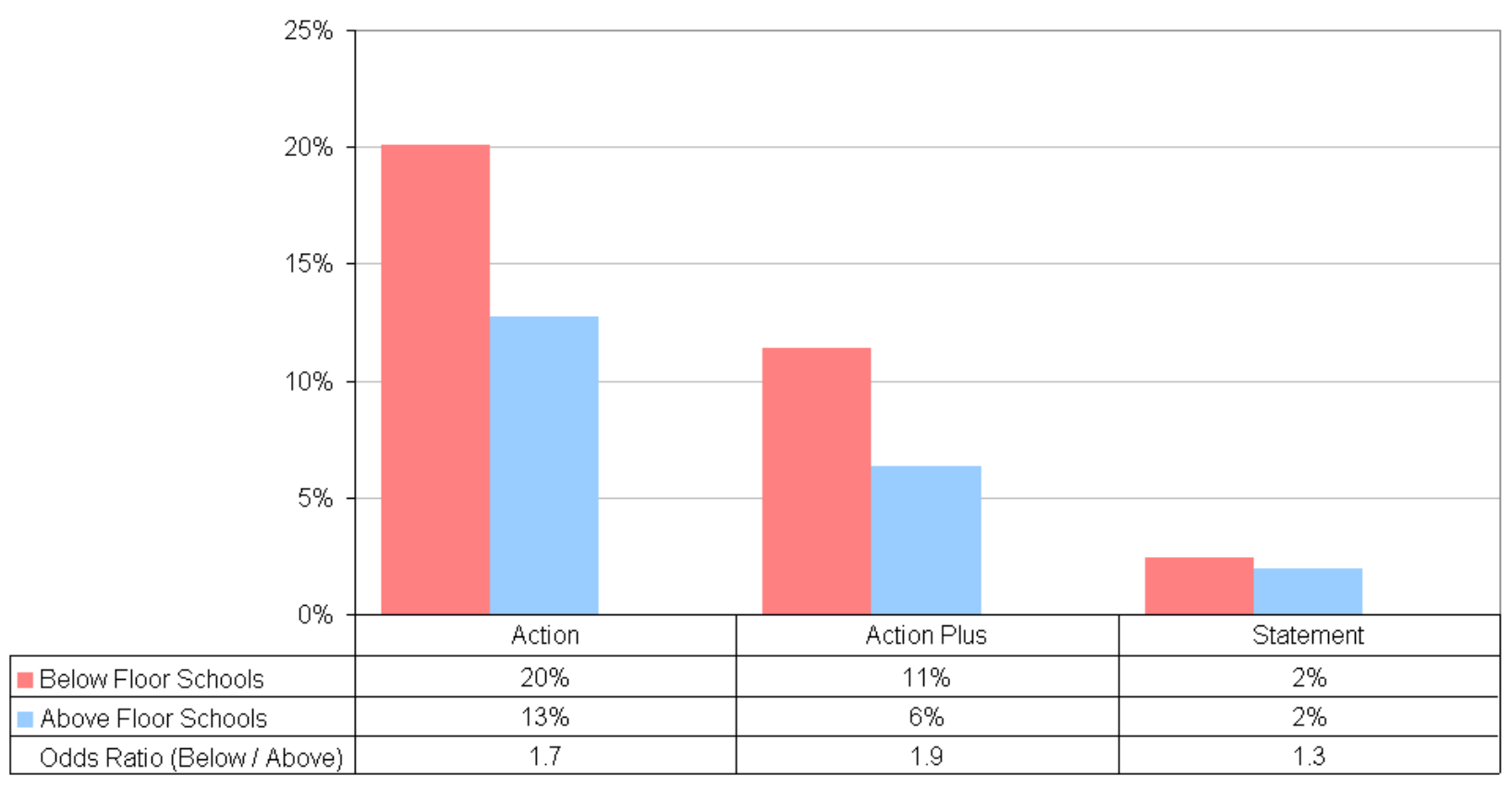

\section{Chart 2.2g}

Primary SEN Type (Action Plus and Statement) in Below / Above KS4 Floor Schools

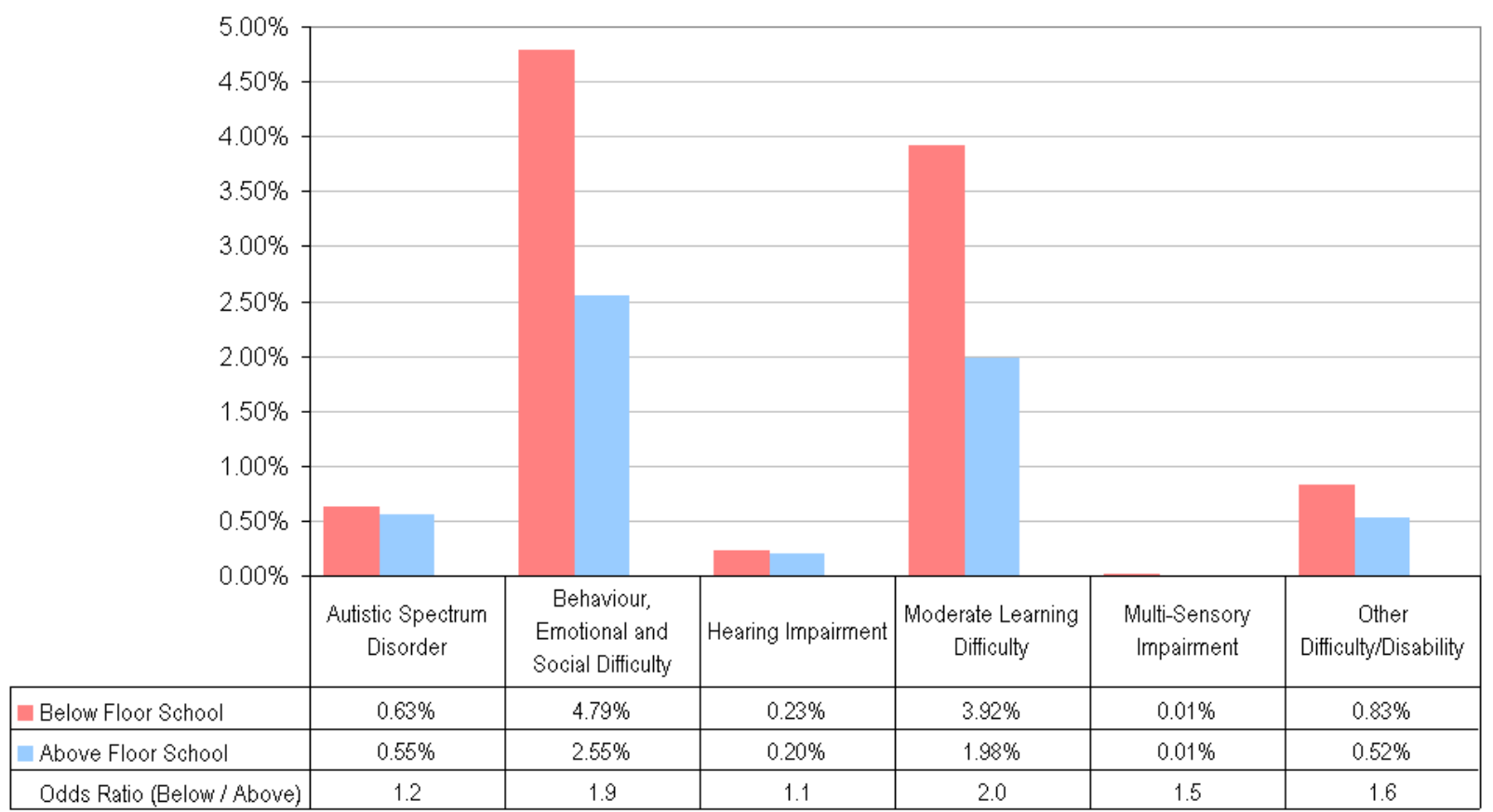




\section{Chart 2.2h}

Primary SEN Type (Action Plus and Statement) in Below / Above KS4 Floor Schools

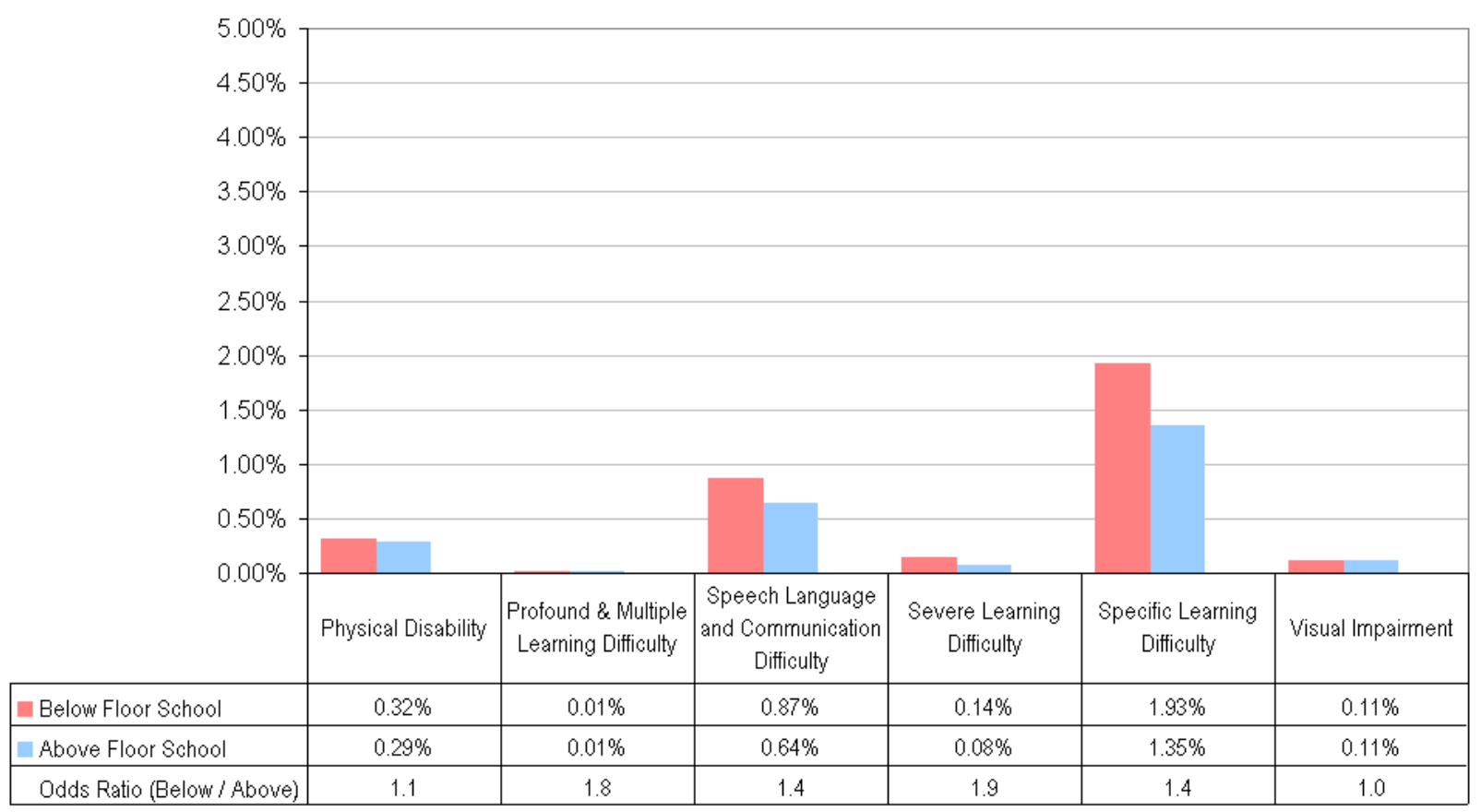

\section{Chart 2.2i}

Regional Share of Below / Above KS4 Floor Schools

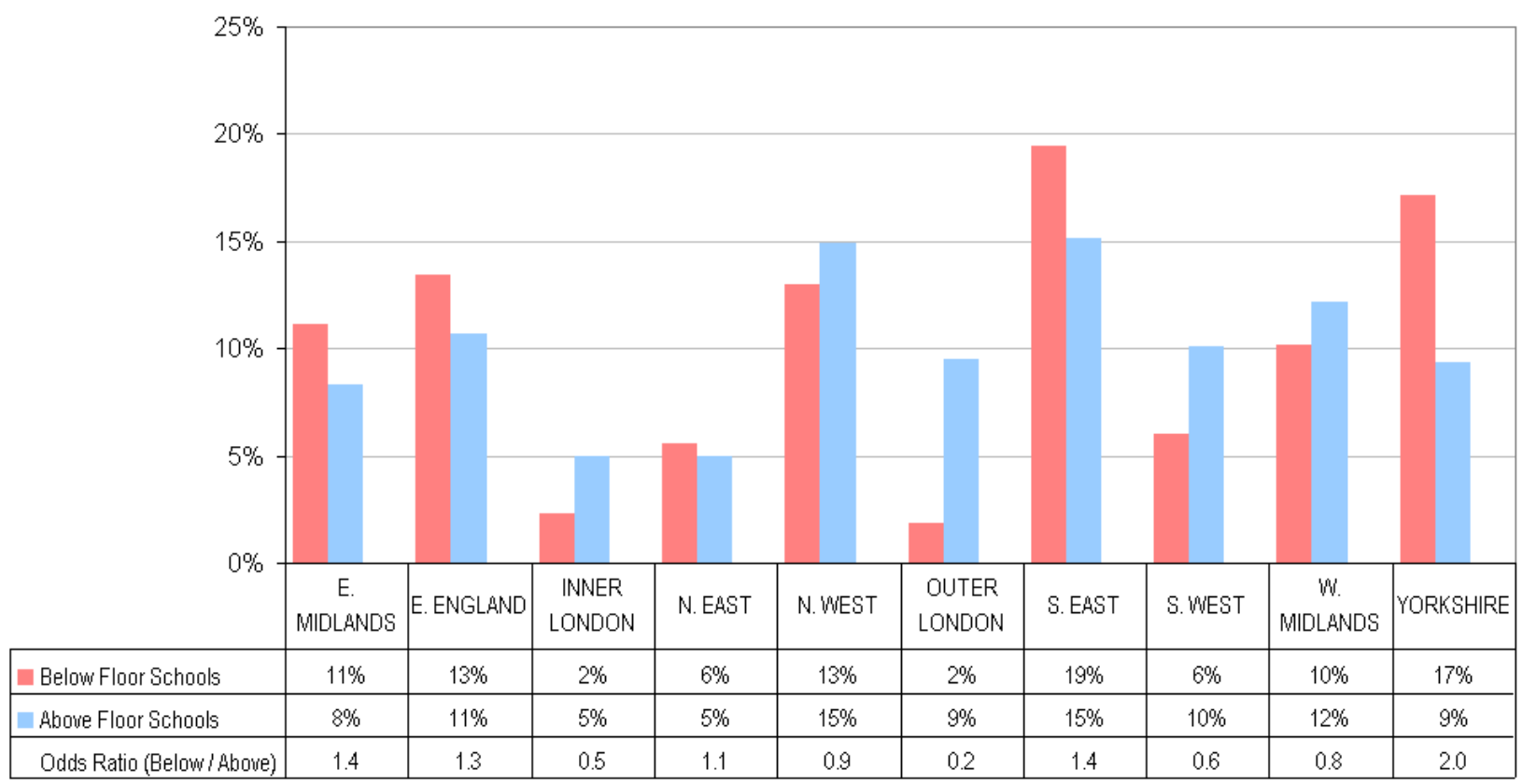




\section{Chart 2.2i}

Urban / Rural Classification of Below / Above KS4 Floor Schools

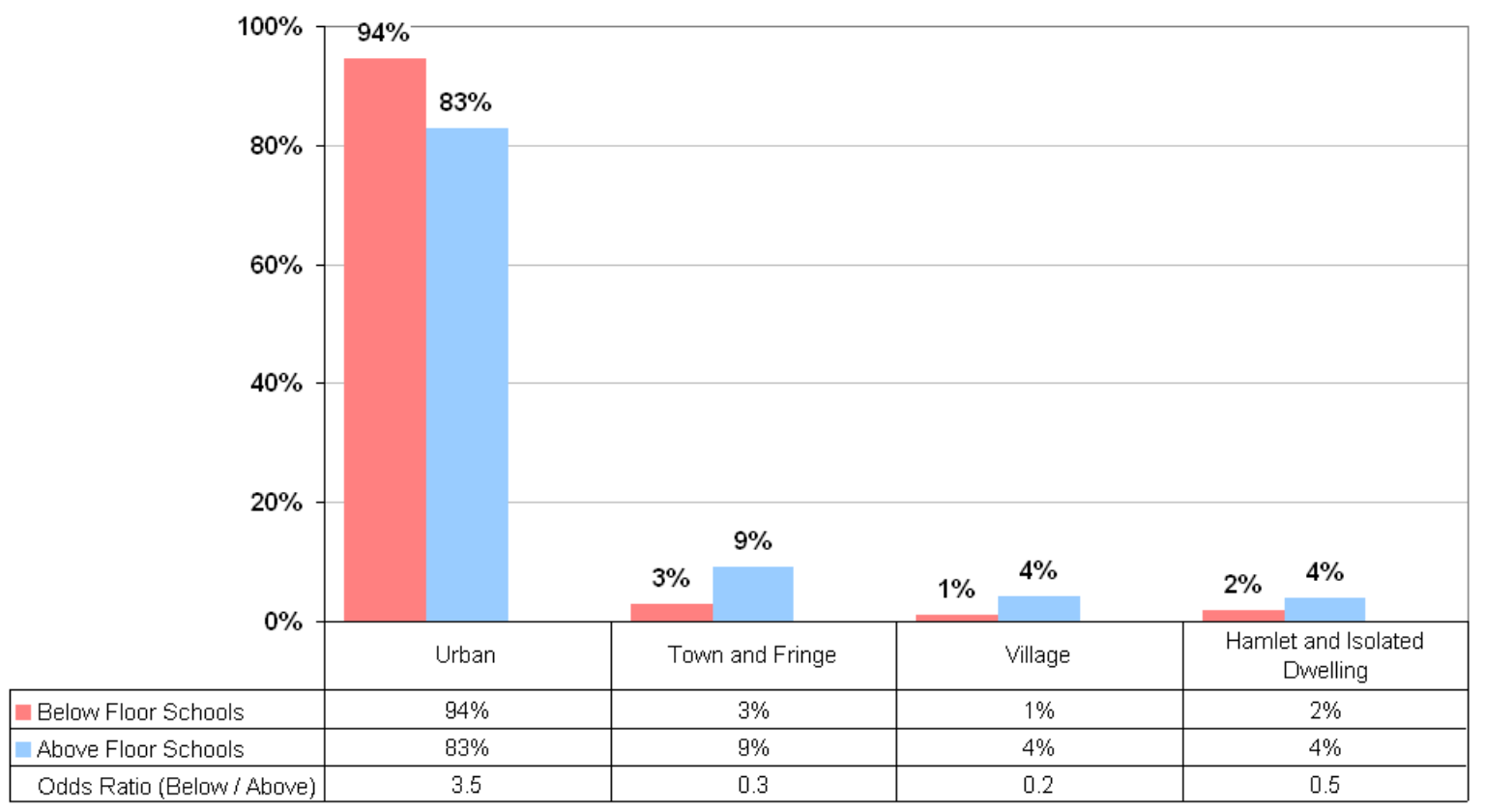




\subsection{Looked After Children in Below Floor Schools at KS2 and 4}

The following analysis gives the incidence of Looked After Children (LAC) in below and above floor schools. The populations shown here are the maintained mainstream schools cohorts at the end of Key Stages 2 and 4 in 2010; this differs from the previous analyses in sections 2.1 and 2.2 which included whole-school populations. For the purposes of this analysis, Looked After Children (LAC) are those children who had been continuously in care for 12 months or longer at $31^{\text {st }}$ March 2010; this excludes LAC who have been in care for a short period of time or those that are moving in and out of care or those who are looked after under an agreed series of short term placements. This analysis is sourced from DfE's matched CLA-NPD dataset.

\section{Chart 2.3a}

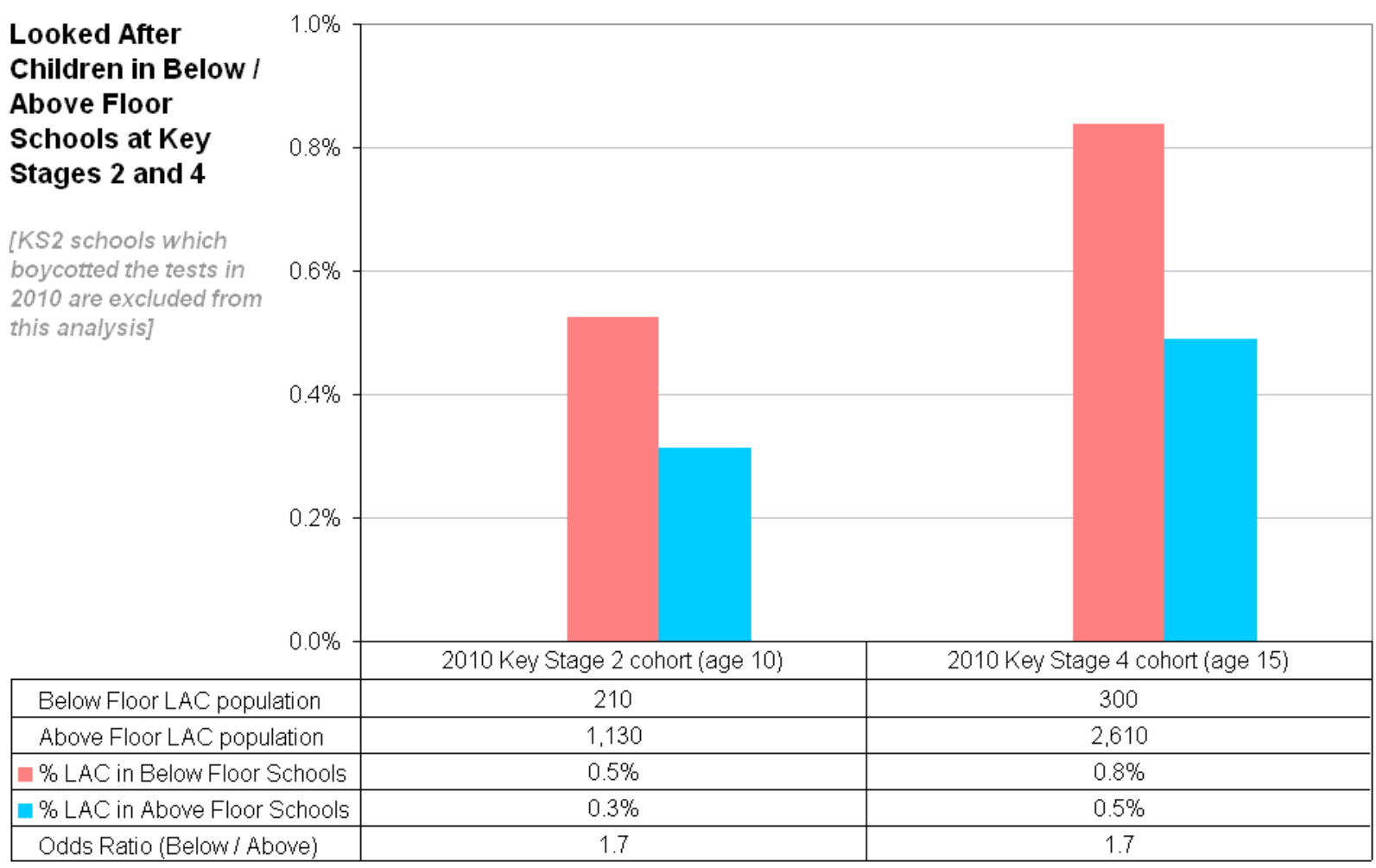




\subsection{FSM Eligible Pupils in Key Stage 2 Schools}

This section revisits the pupil characteristics presented in section 2.1, examining differences between pupils with and without free school meal eligibility, in below and above KS2 floor standard schools. Charts $2.4 \mathrm{a}-2.4 \mathrm{~g}$ present the average IDACI scores (\% of children living in deprived households in the area), and the percentages of pupils with Black or minority ethnicity, with a first language other than English, and with special educational needs, for the six combinations of FSM status and school performance group at Key Stage 2.

The odds ratios in the tables appearing beneath each chart represent the difference between pupils in below floor schools from those in above floor schools (as previously), but within each FSM category. For example, in chart 2.4f, the odds ratio on having a statement of SEN, for below floor schools compared with above floor schools, is 1.1 within pupils eligible for free school meals, but 1.4 within non-FSM pupils; thus special educational needs at statemented level are more overrepresented in below floor school amongst pupils without FSM, than among pupils eligible for FSM.

\section{Chart 2.4a}

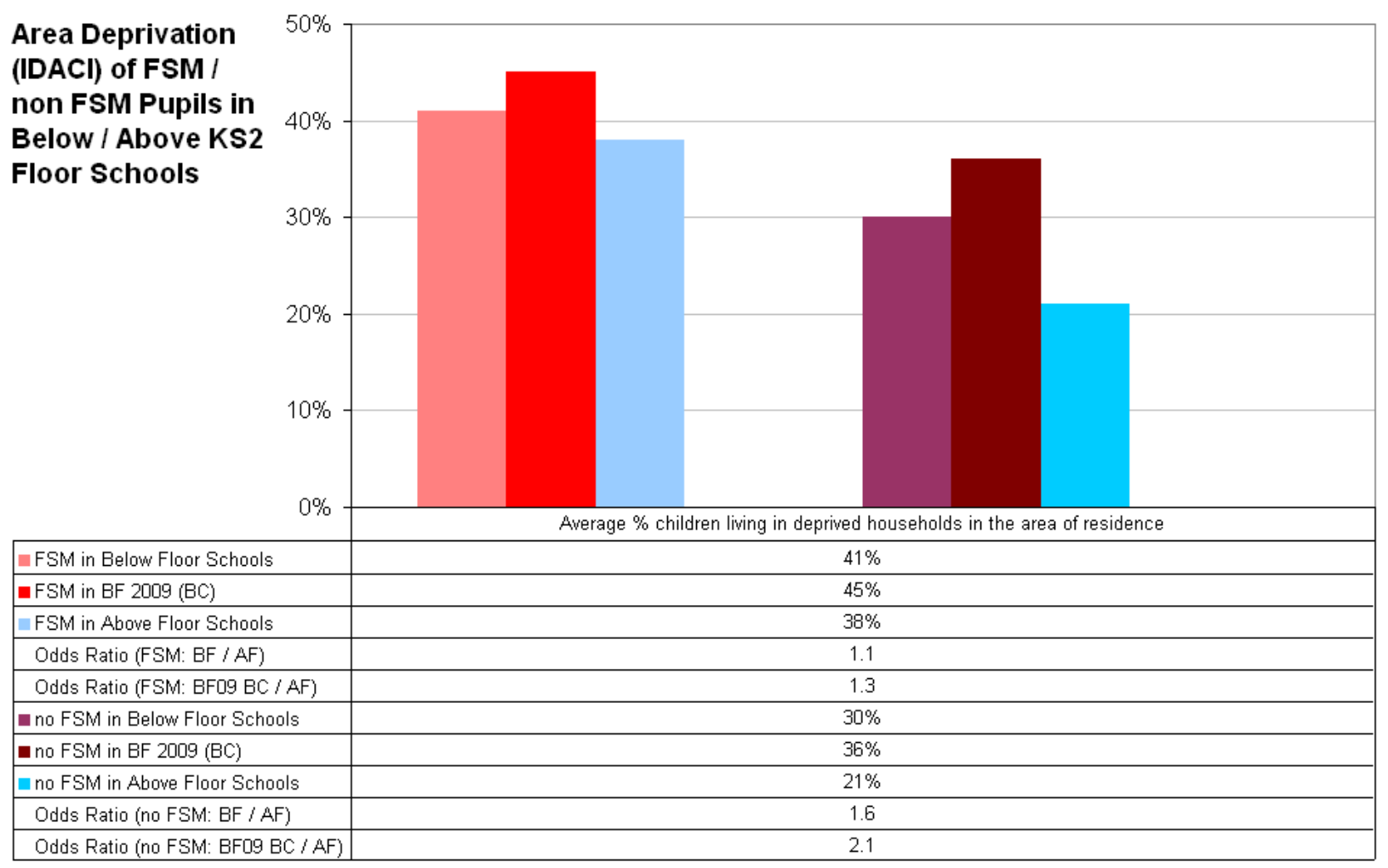




\section{Chart 2.4b}

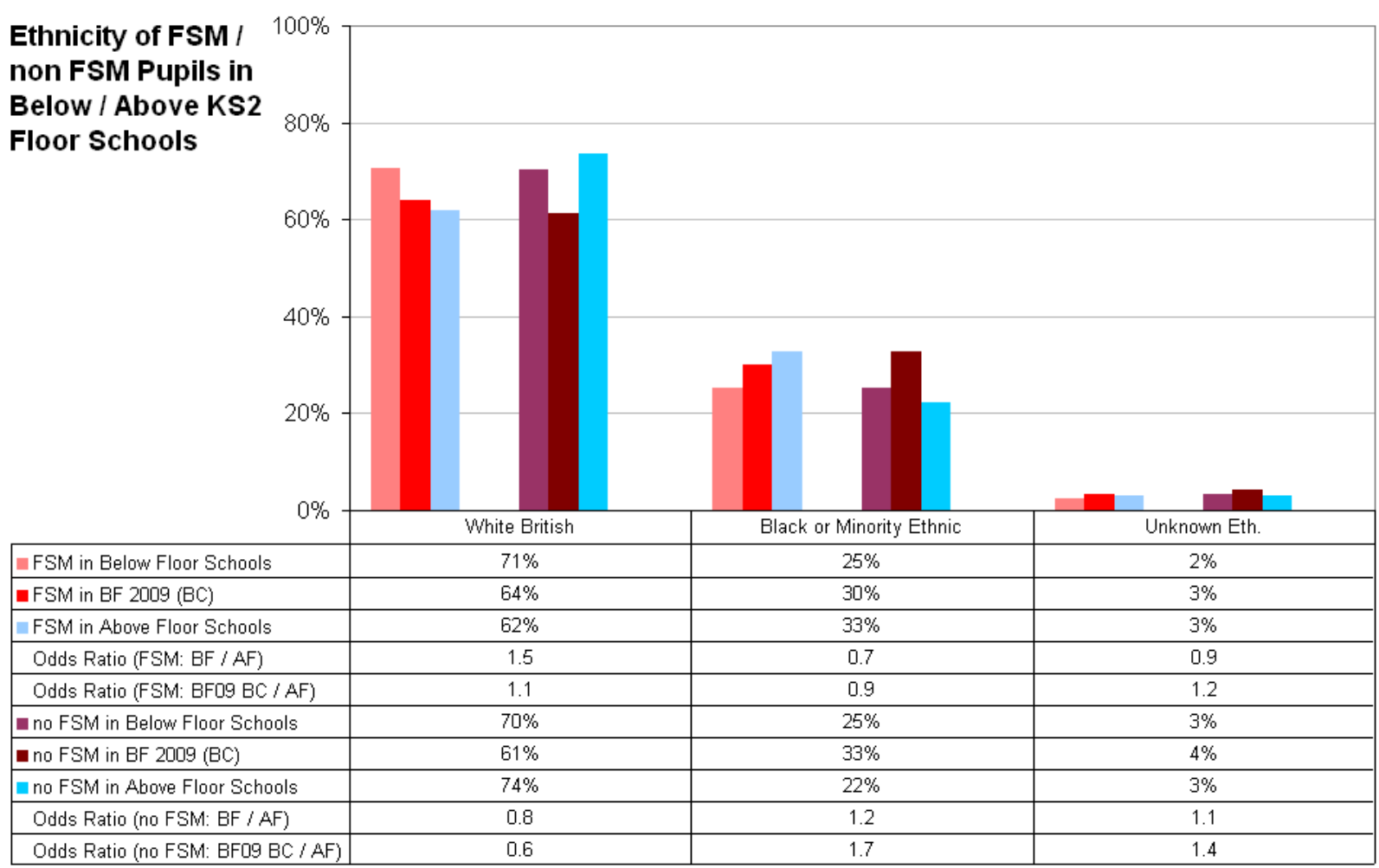

\section{Chart 2.4c}

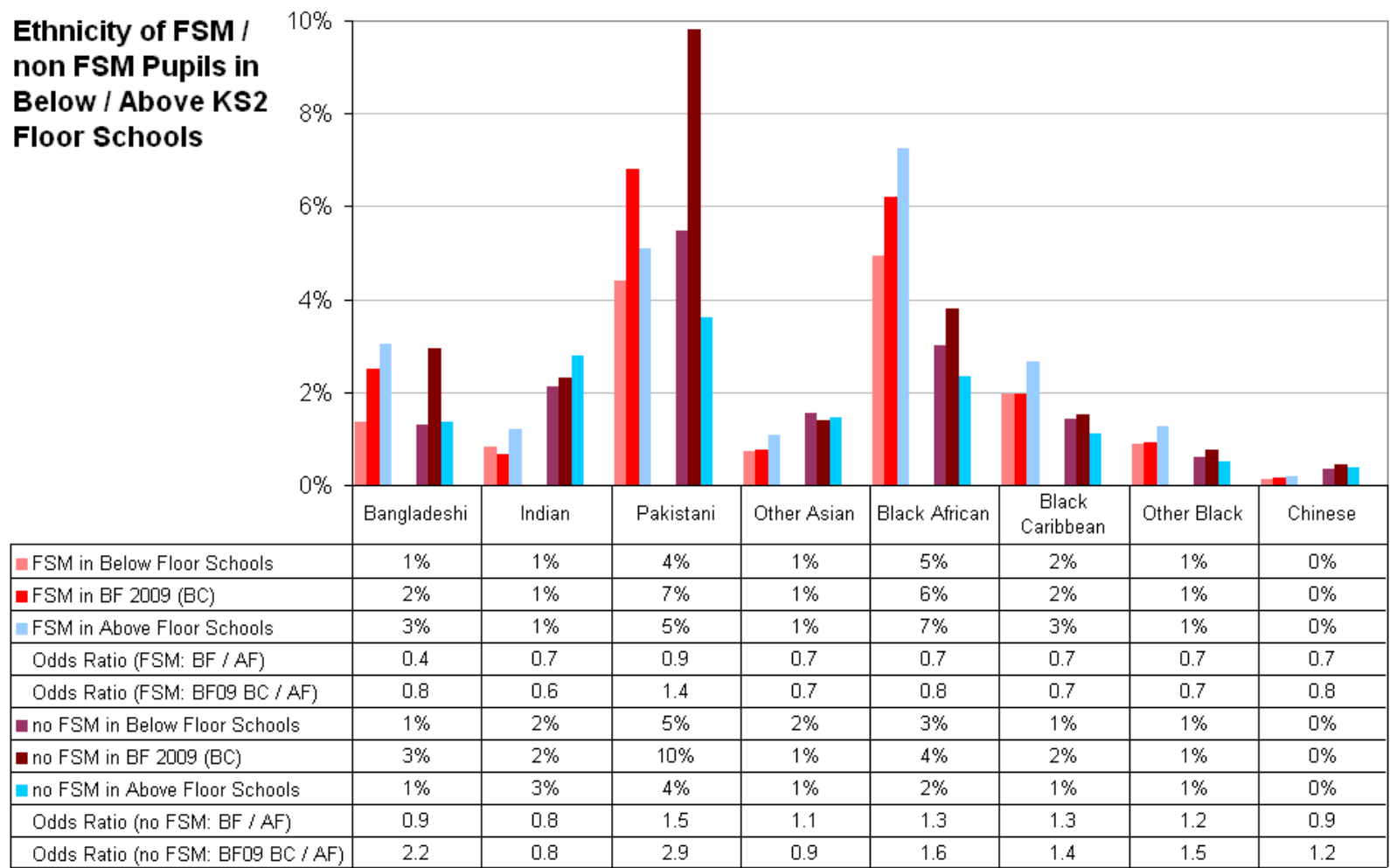


Chart 2.4d

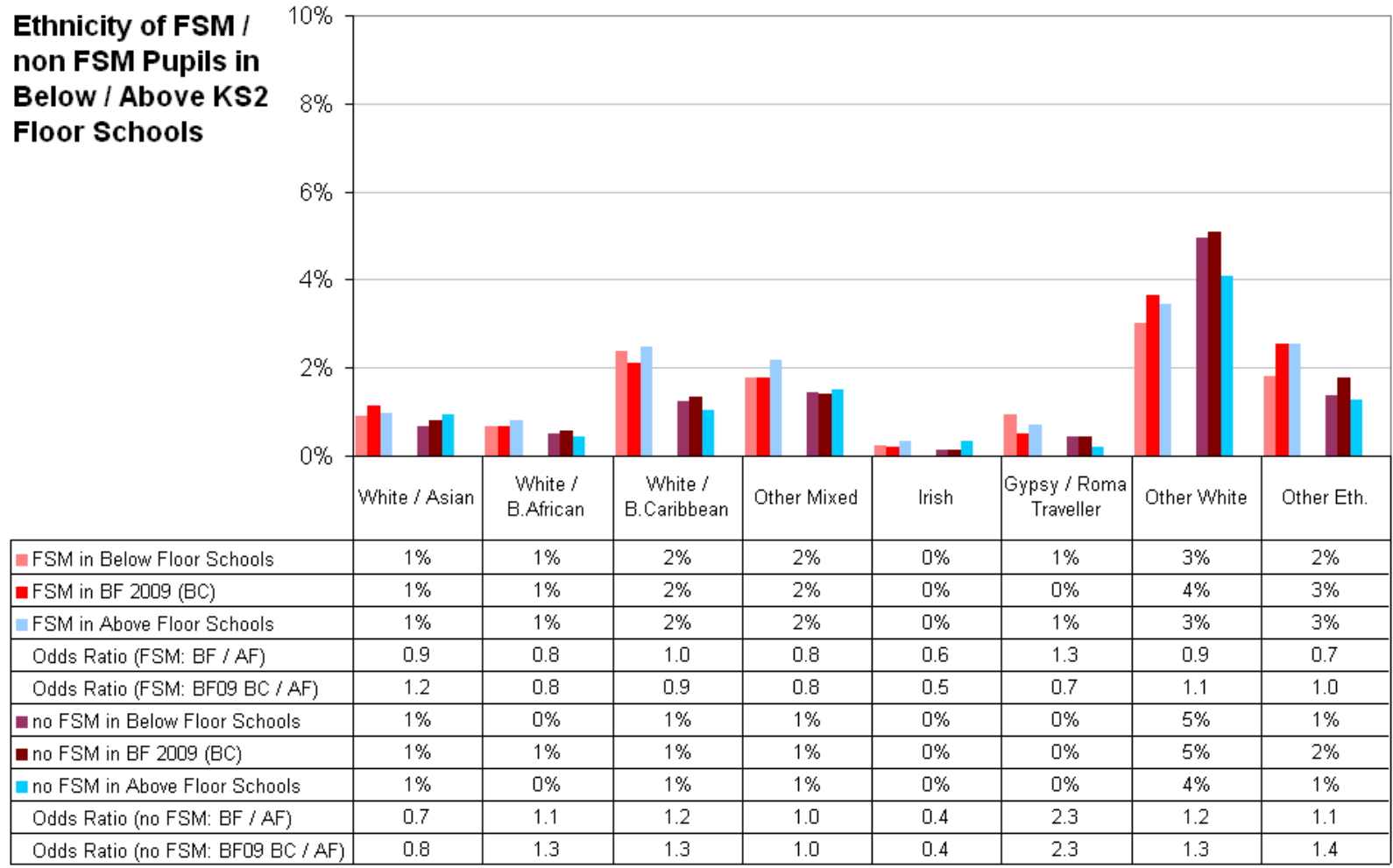


Chart 2.4e

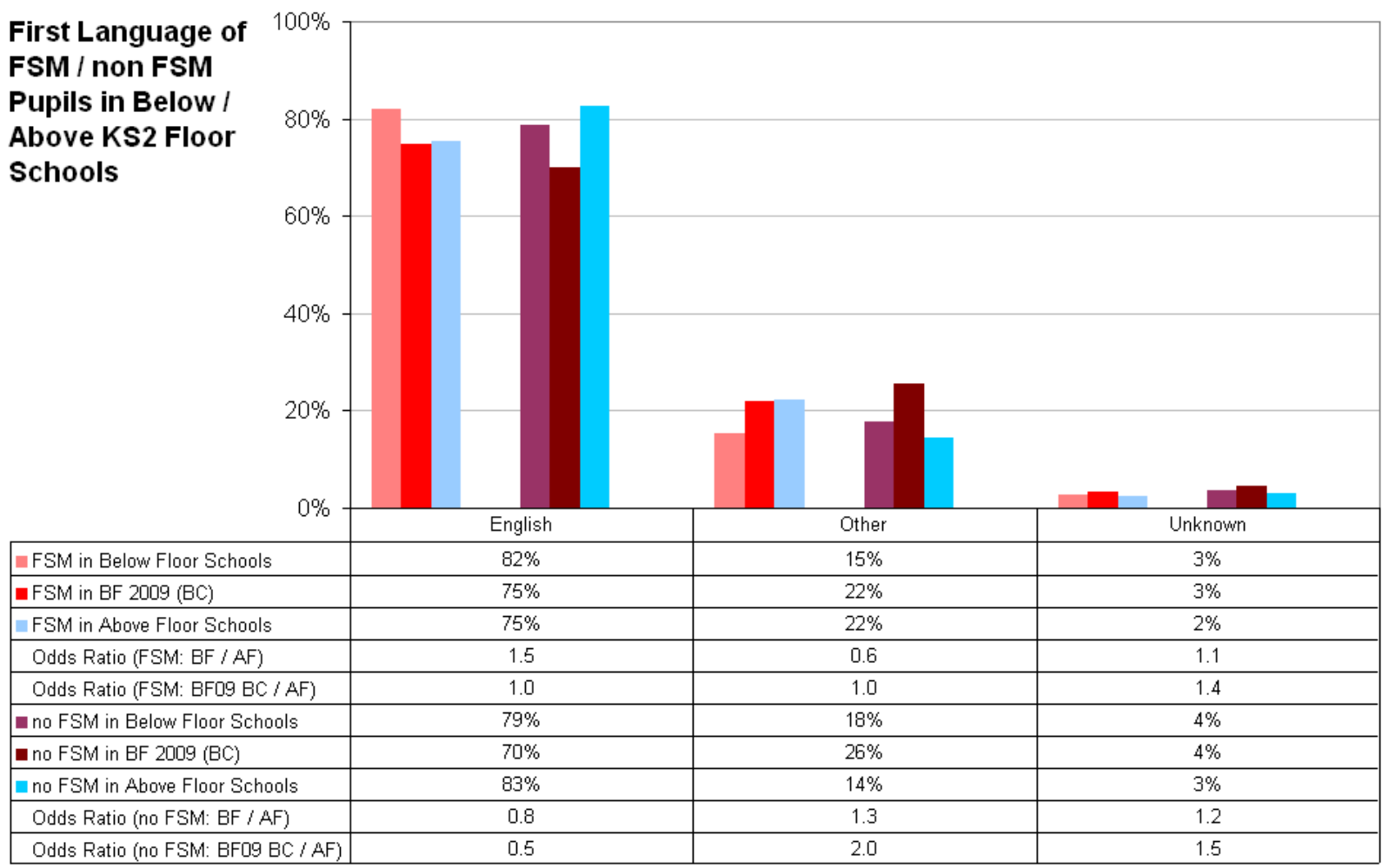

\section{Chart 2.4f}

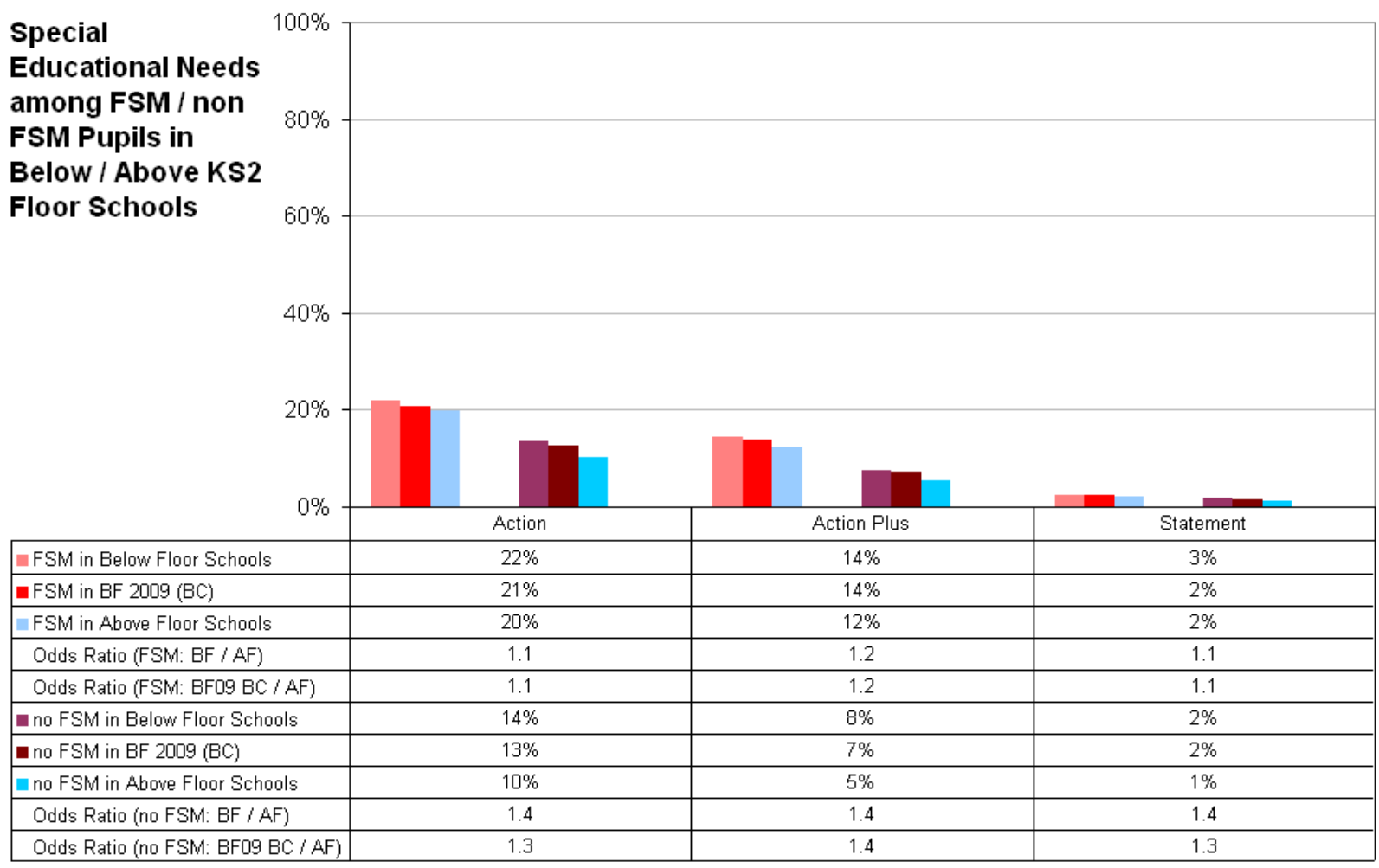




\section{Chart 2.4g}

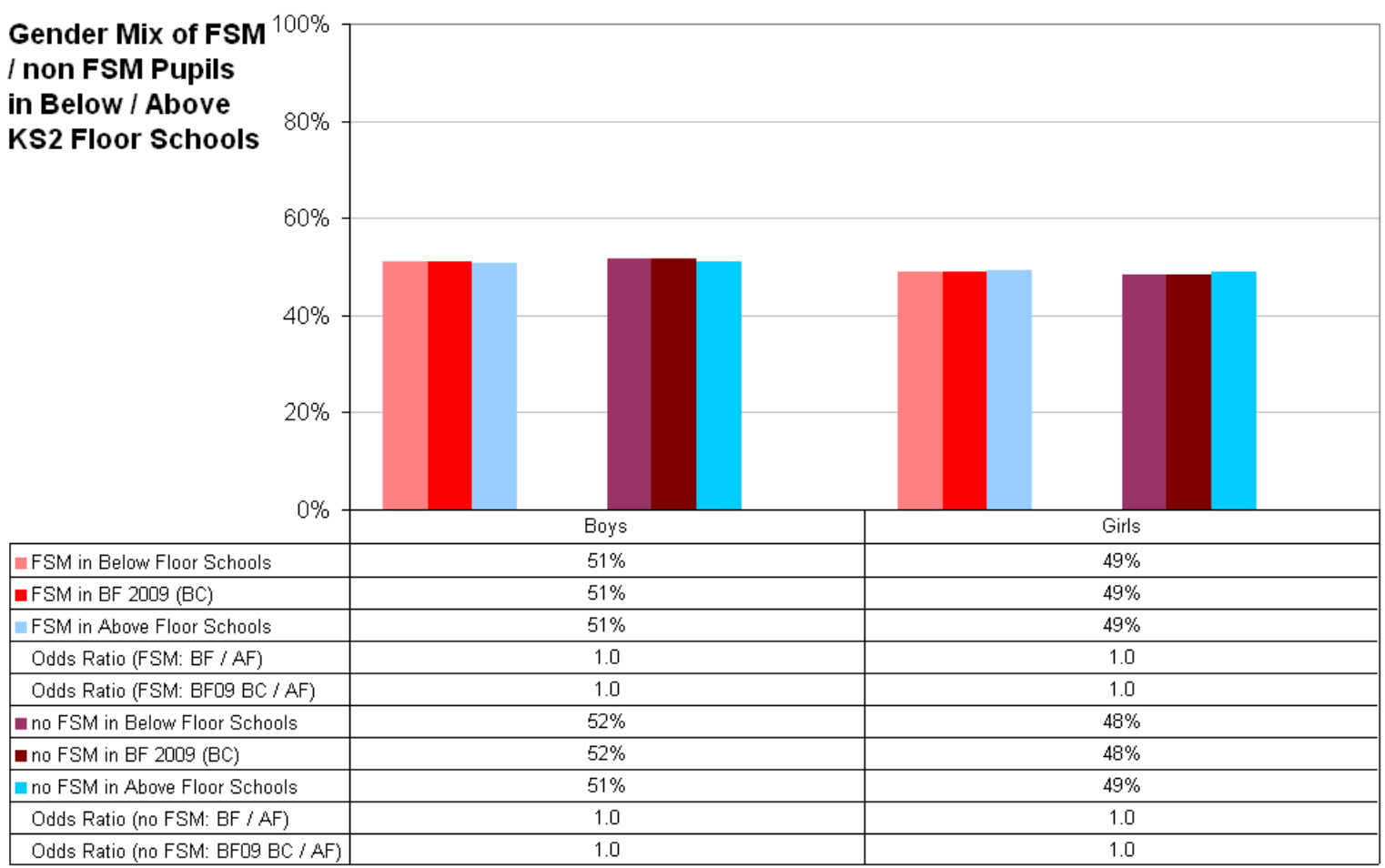




\subsection{FSM Eligible Pupils in Key Stage 4 Schools}

This section revisits the pupil characteristics presented in section 2.2, examining differences between pupils with and without free school meal eligibility, in below and above KS4 floor standard schools. Charts $2.5 \mathrm{a}-2.5 \mathrm{~g}$ present the average IDACI scores (\% of children living in deprived households in the area), and the percentages of pupils with Black or minority ethnicity, with a first language other than English, and with special educational needs, for the four combinations of FSM status and school performance group at Key Stage 4.

\section{Chart 2.5a}

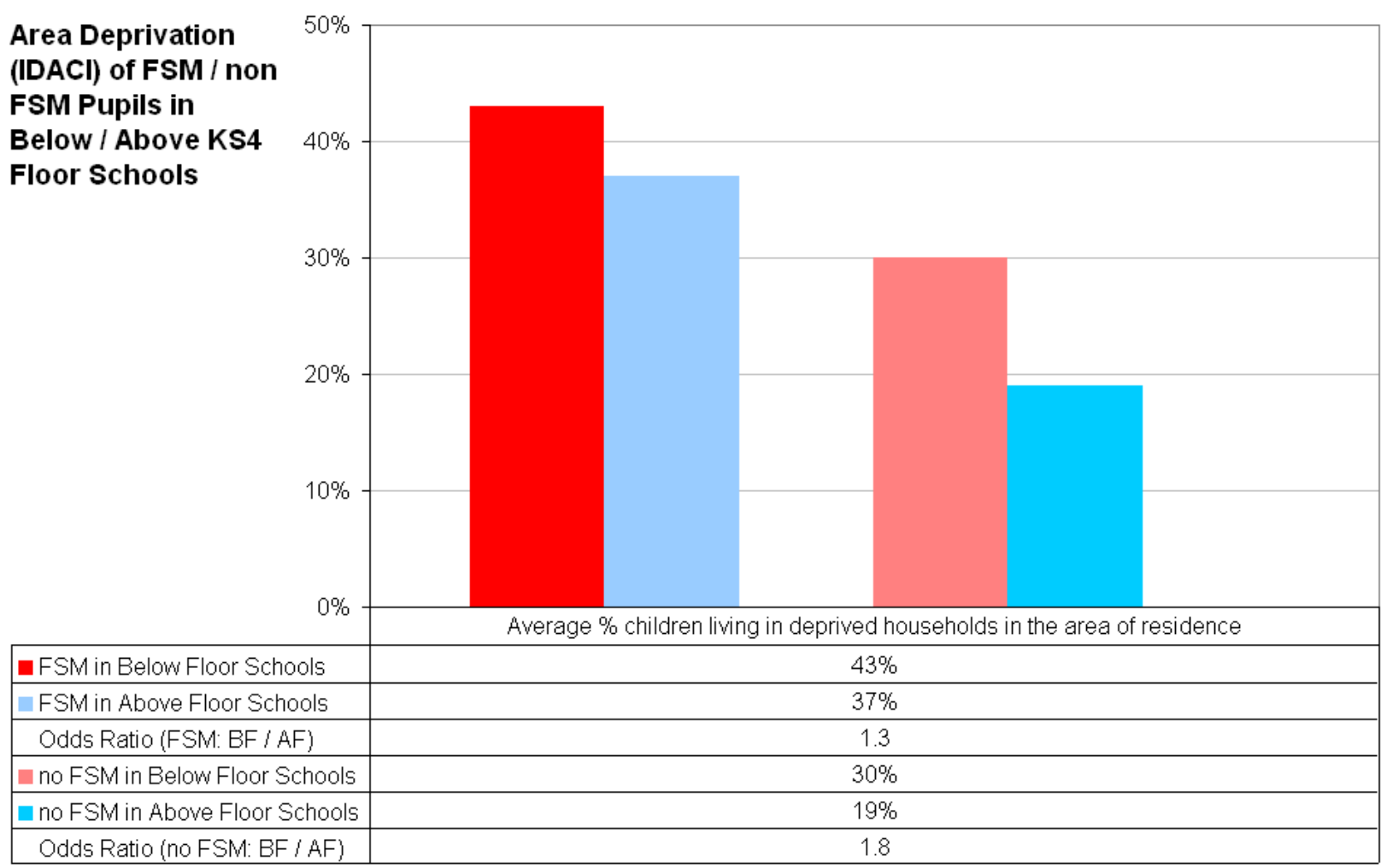


Chart 2.5b

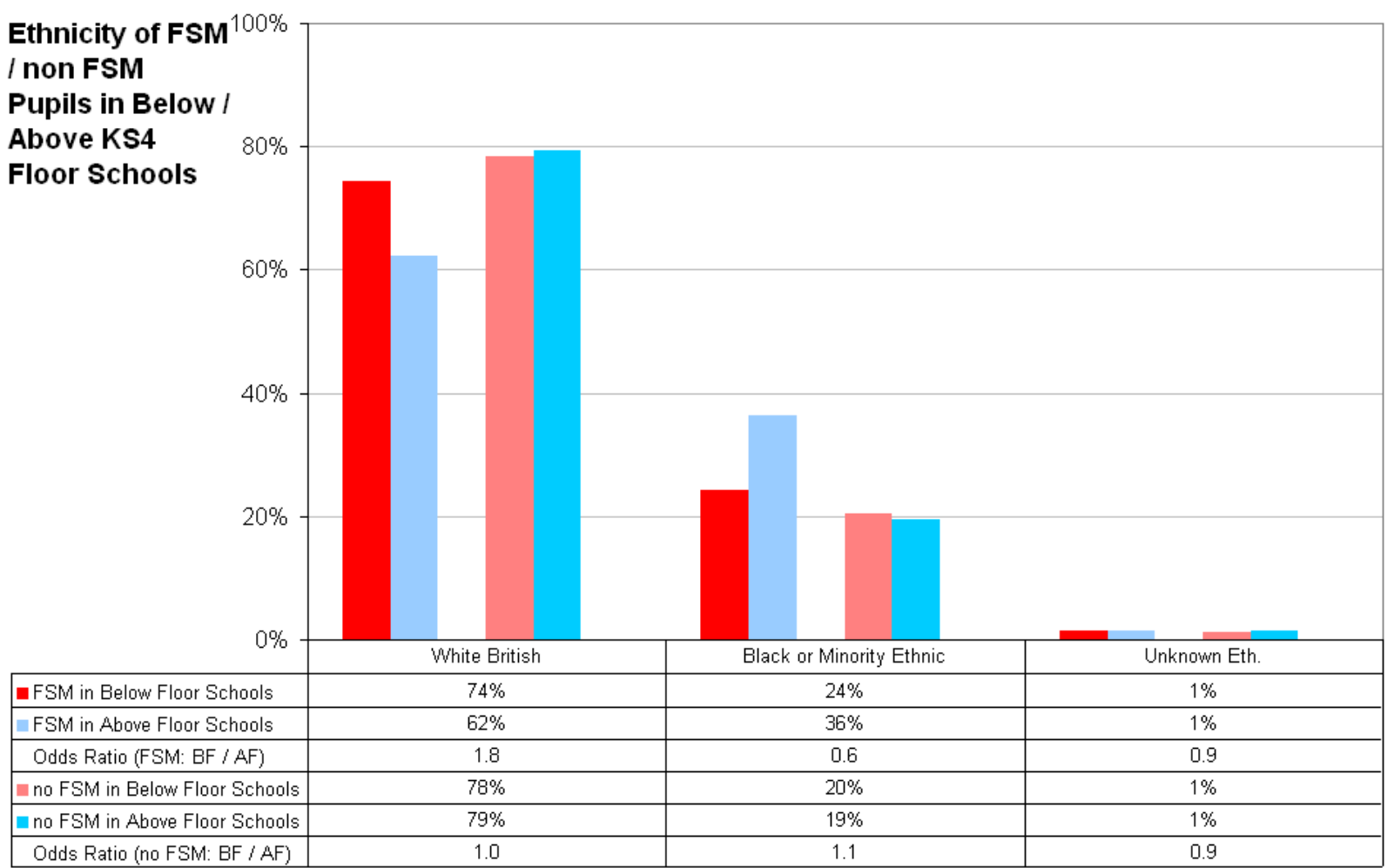

\section{Chart 2.5c}

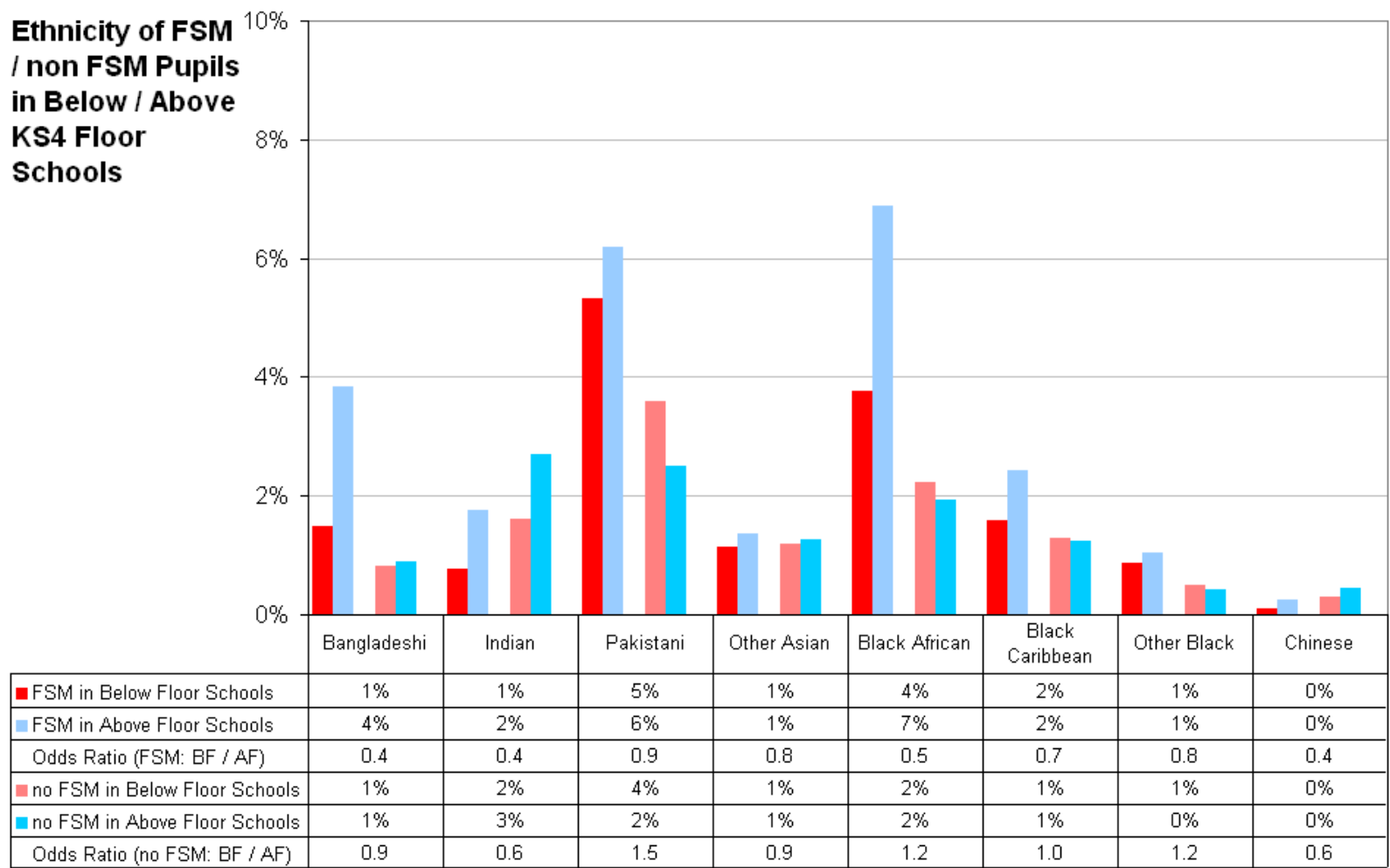




\section{Chart 2.5d}

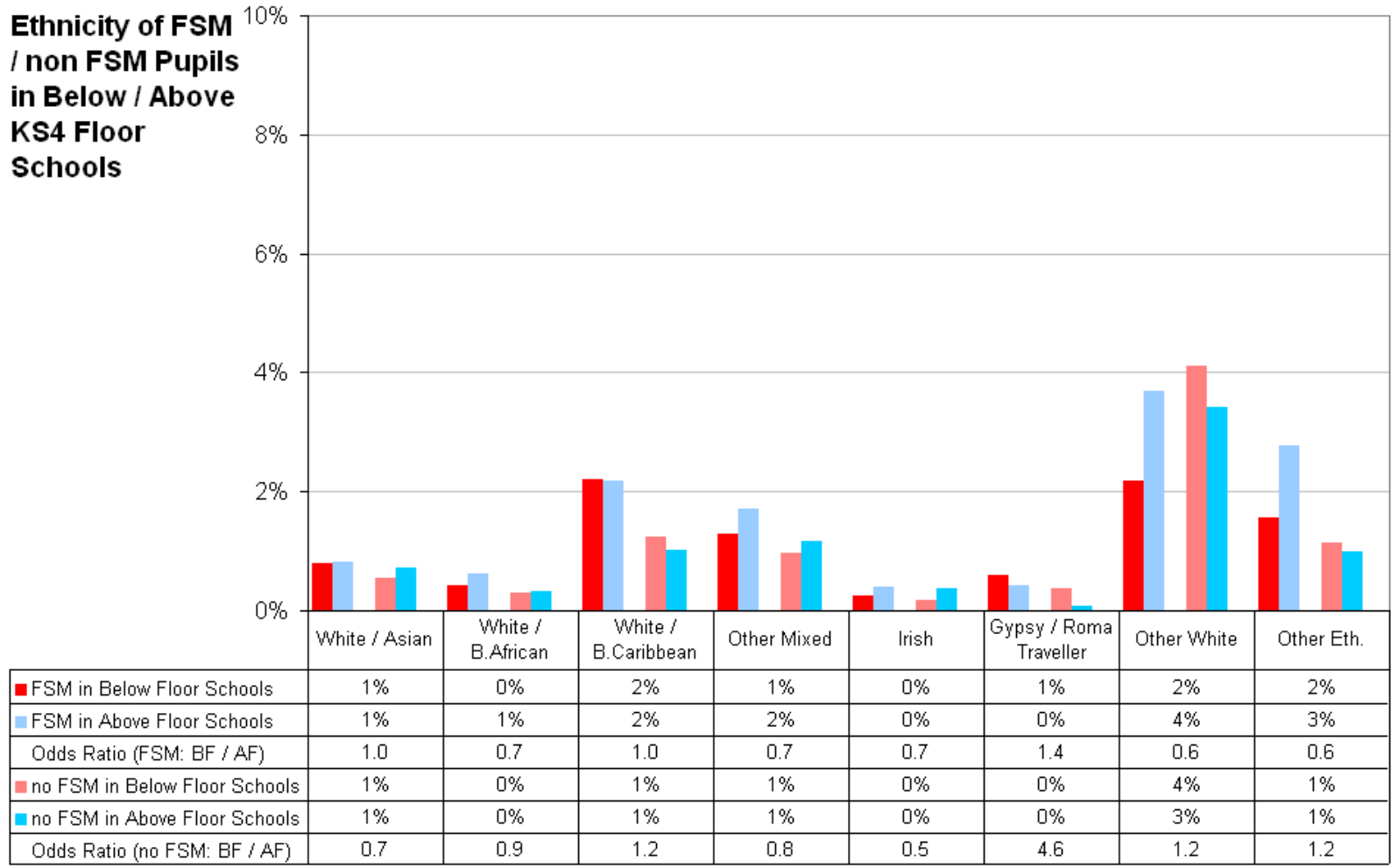

\section{Chart 2.5e}

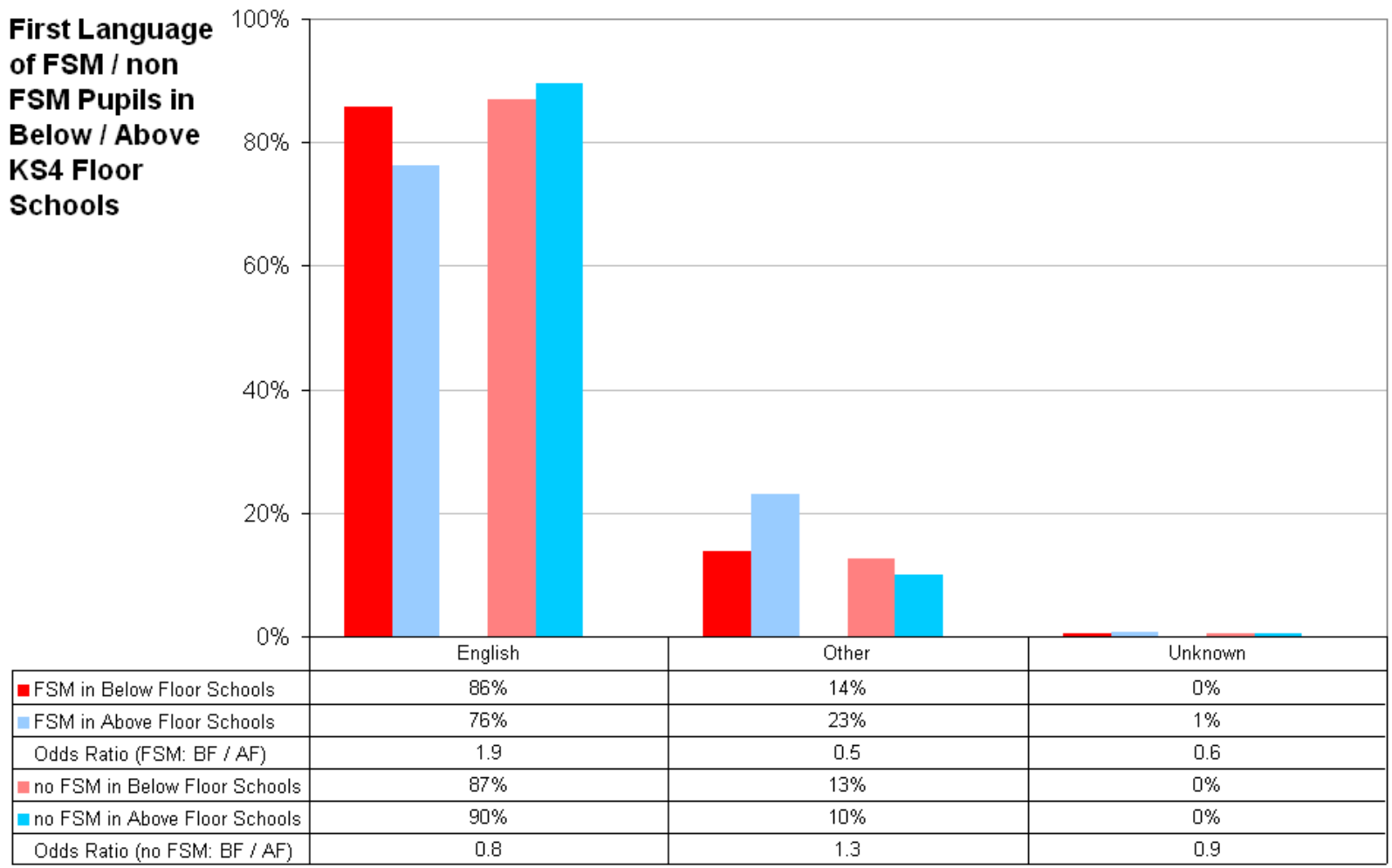




\section{Chart 2.5f}

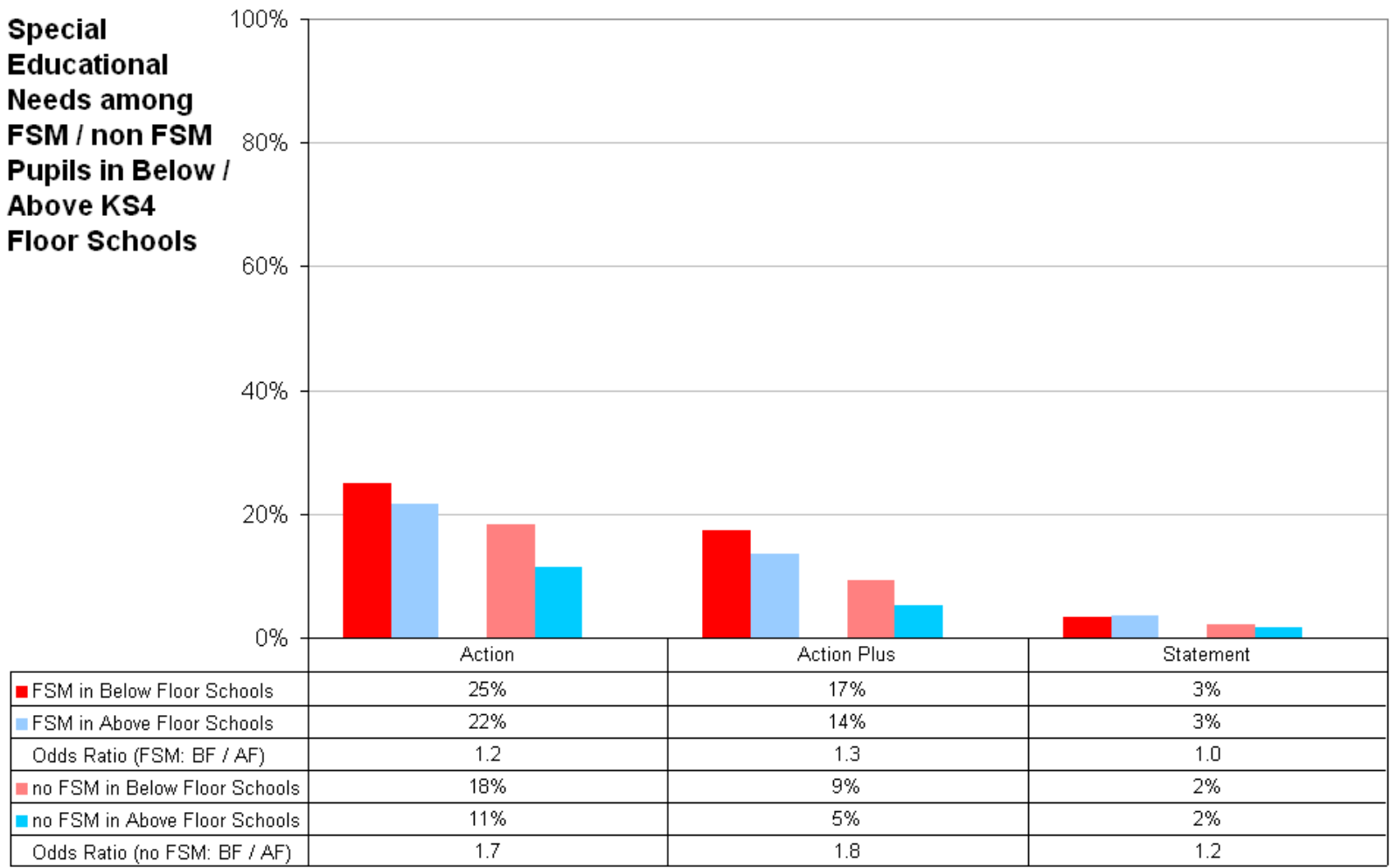

\section{Chart 2.5g}

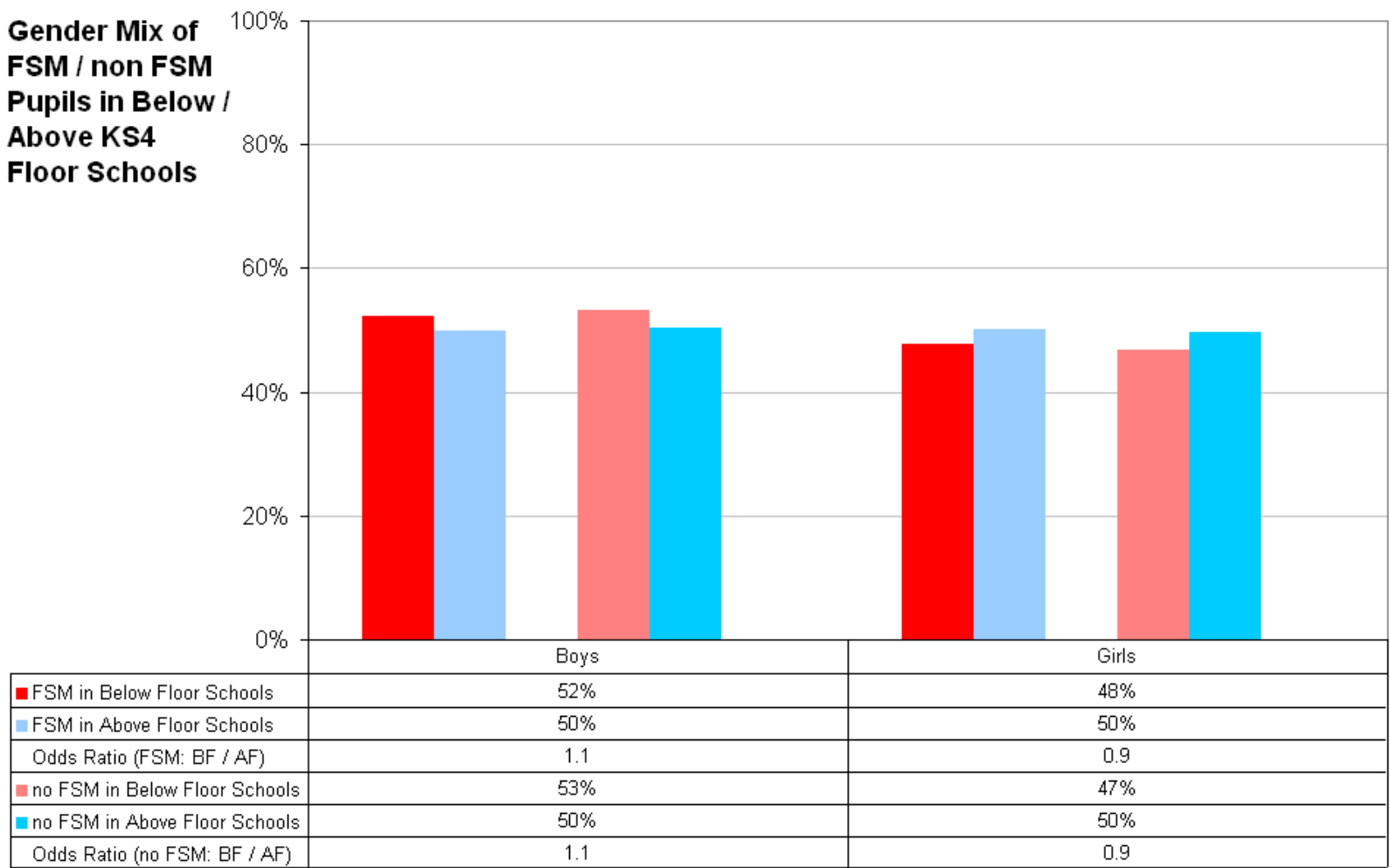




\section{Mobility, Attendance and Behaviour in Below Floor Schools}

This chapter examines pupil mobility between schools within the course of the Key Stages, levels of school attendance, and the incidence of fixed period exclusions, again comparing schools below the floor standards with other schools. Section 3.1 contains analyses for KS2 schools, with equivalents for KS4 schools appearing in section 3.2 .

\section{Key Findings}

- There is greater pupil mobility in below floor schools, with a markedly higher incidence of joining the school during the last two years of Key Stage 2 (primary schools) or Key Stage 4 (secondary schools), compared with above floor schools.

- Pupils in below floor schools (both primary and secondary) have consistently higher rates of absence than those in above floor schools, whether or not they are eligible for free school meals; this is reflected in overall absence, persistent absence and unauthorised absence measures.

- Fixed Period Exclusions (FPEs) are received by greater proportions of pupils in below floor schools at KS2 and KS4, than by their counterparts in above floor schools. The incidence of pupils with multiple exclusions within one academic year is also consistently higher in below floor schools, for pupils with and without free school meal eligibility.

\subsection{Key Stage 2 Schools}

\section{Chart 3.1a}

Mobility of Pupils in KS2 Schools - Pupils Joining During Year 6

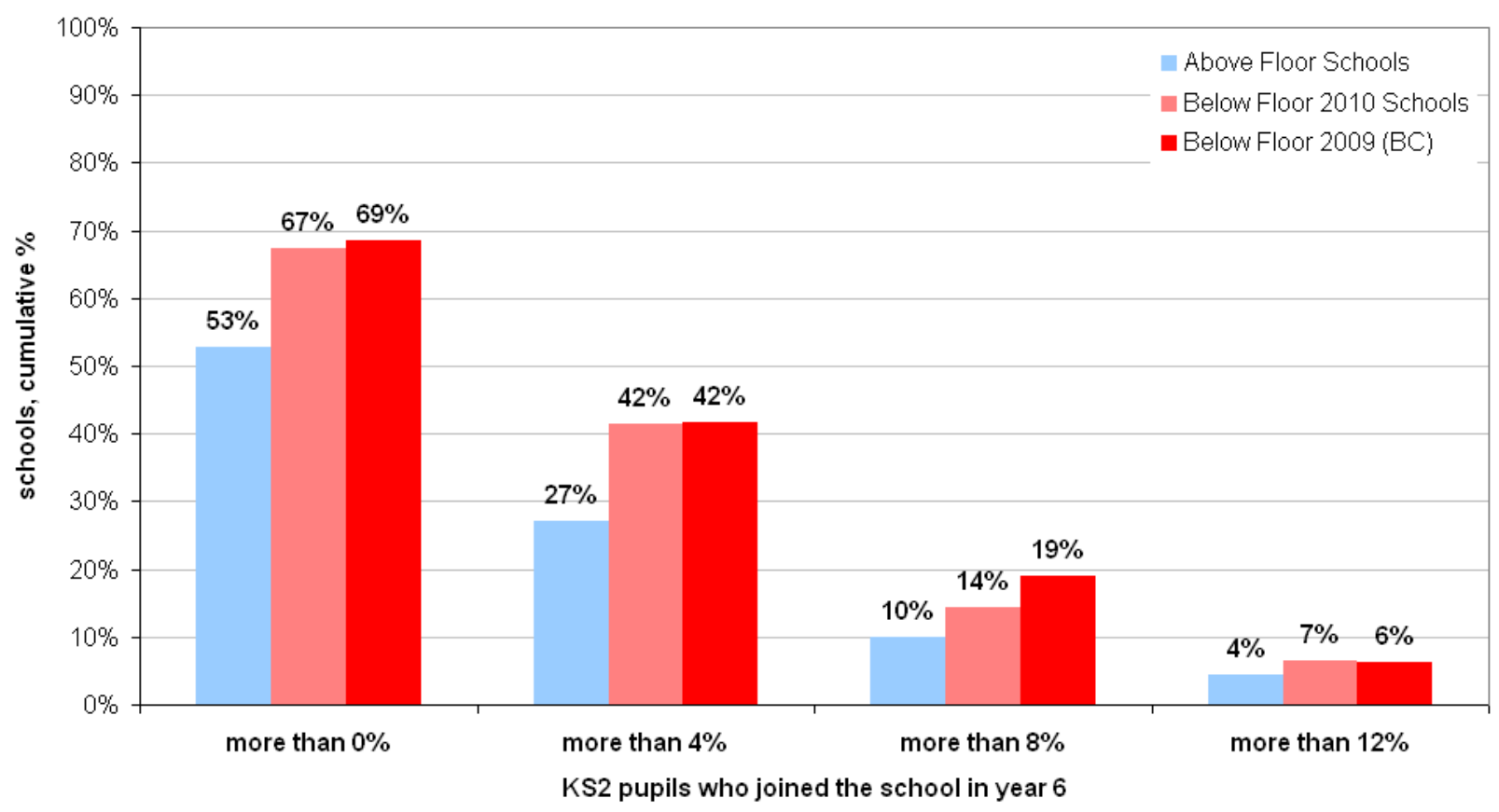




\section{Chart 3.1b}

Mobility of Pupils in KS2 Schools - Pupils Joining During Year 5

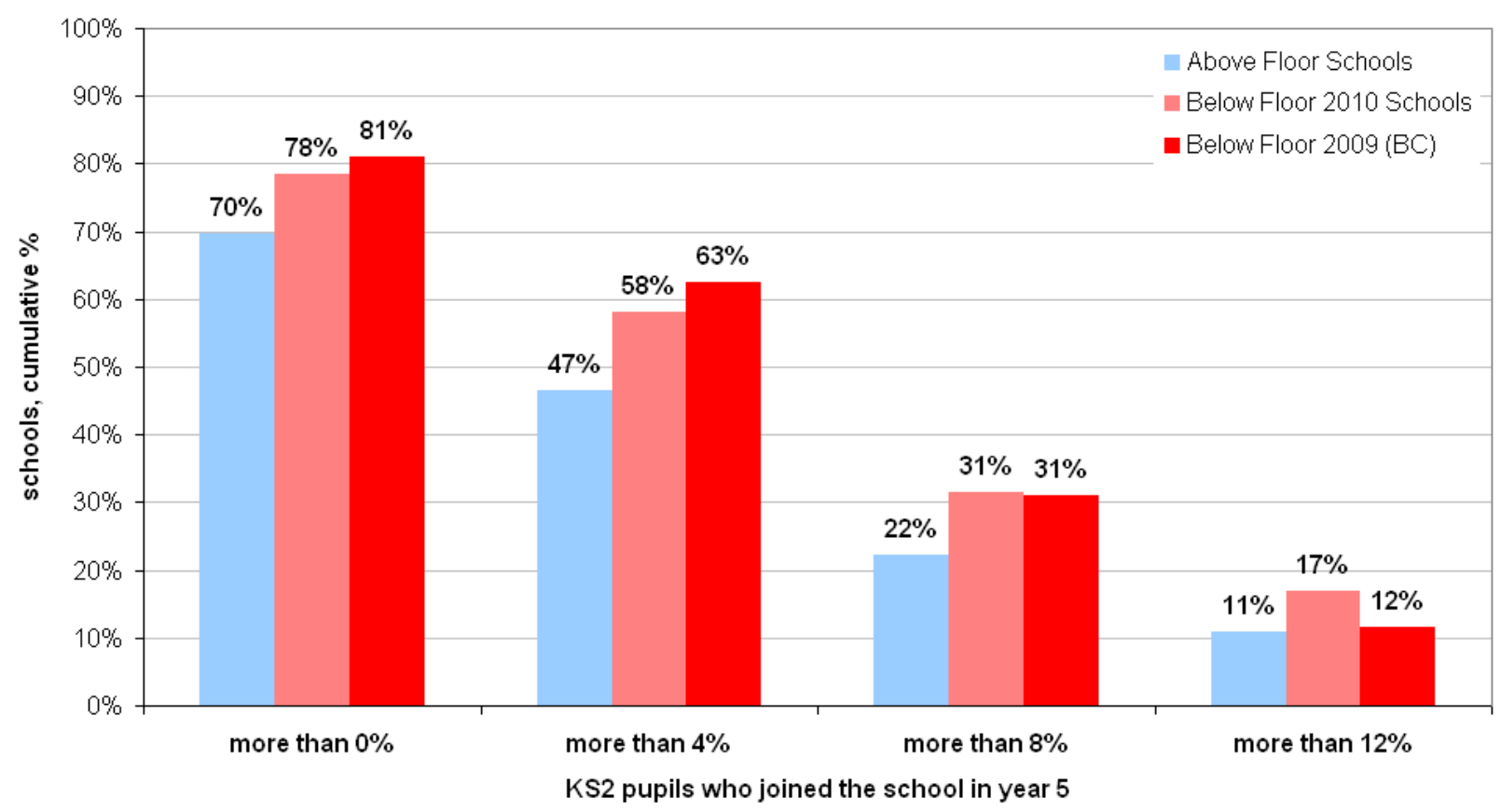

\section{Chart 3.1c}

Mobility of pupils in KS2 Schools - Pupils Joining During Years 3 or 4

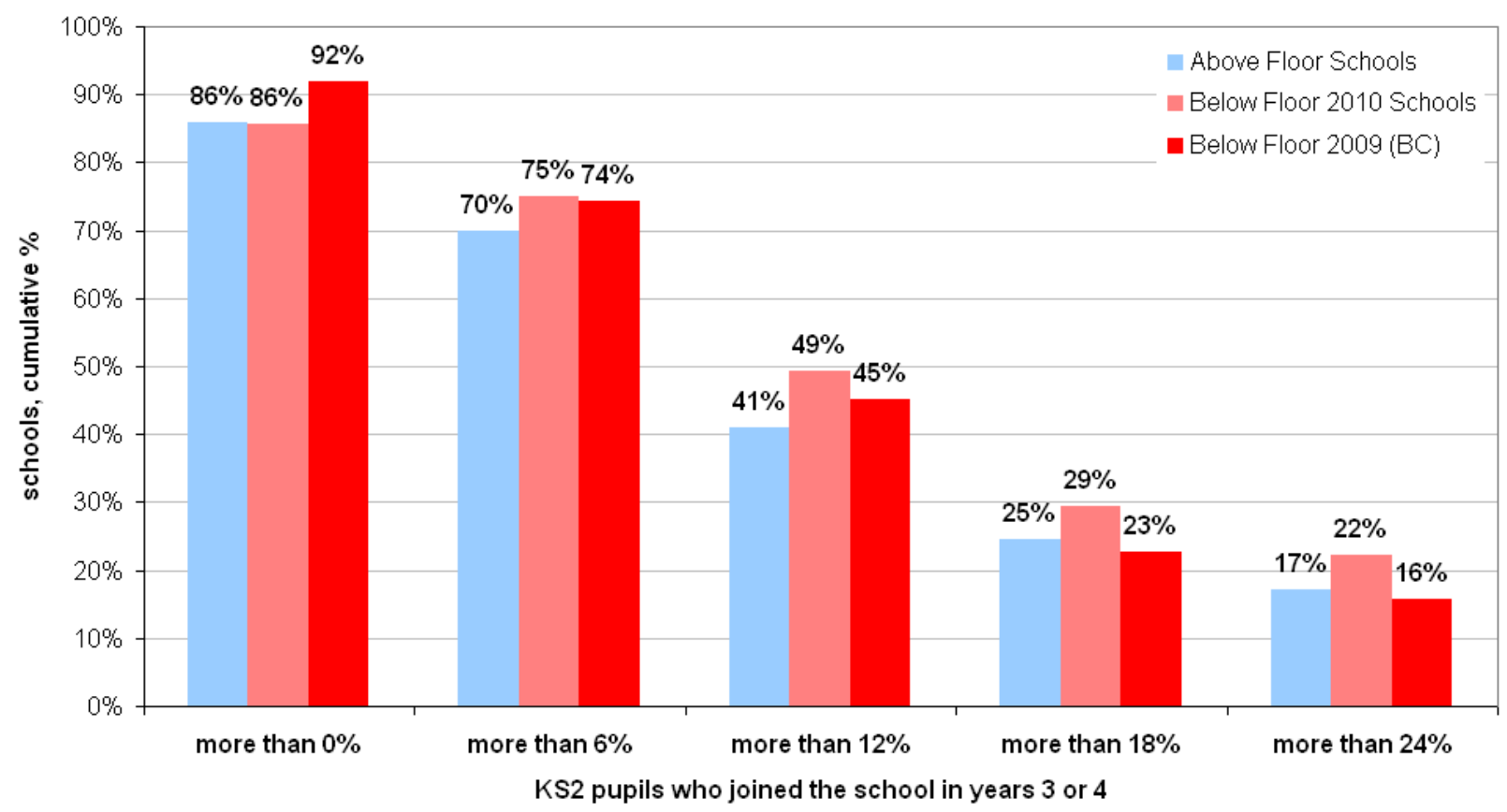




\section{Chart 3.1d}

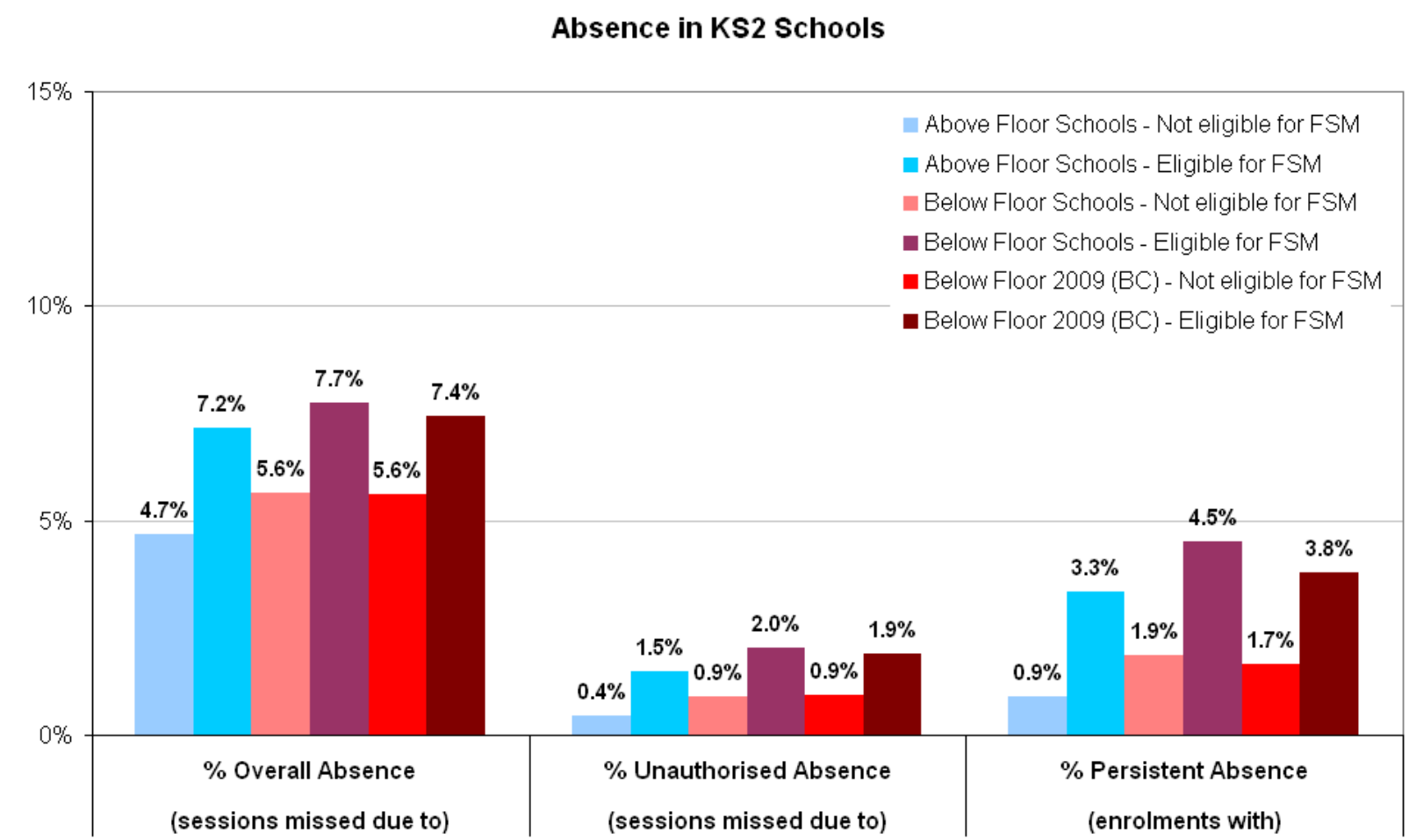

\section{Chart 3.1e}

Pupils with Fixed Period Exclusions in KS2 Schools

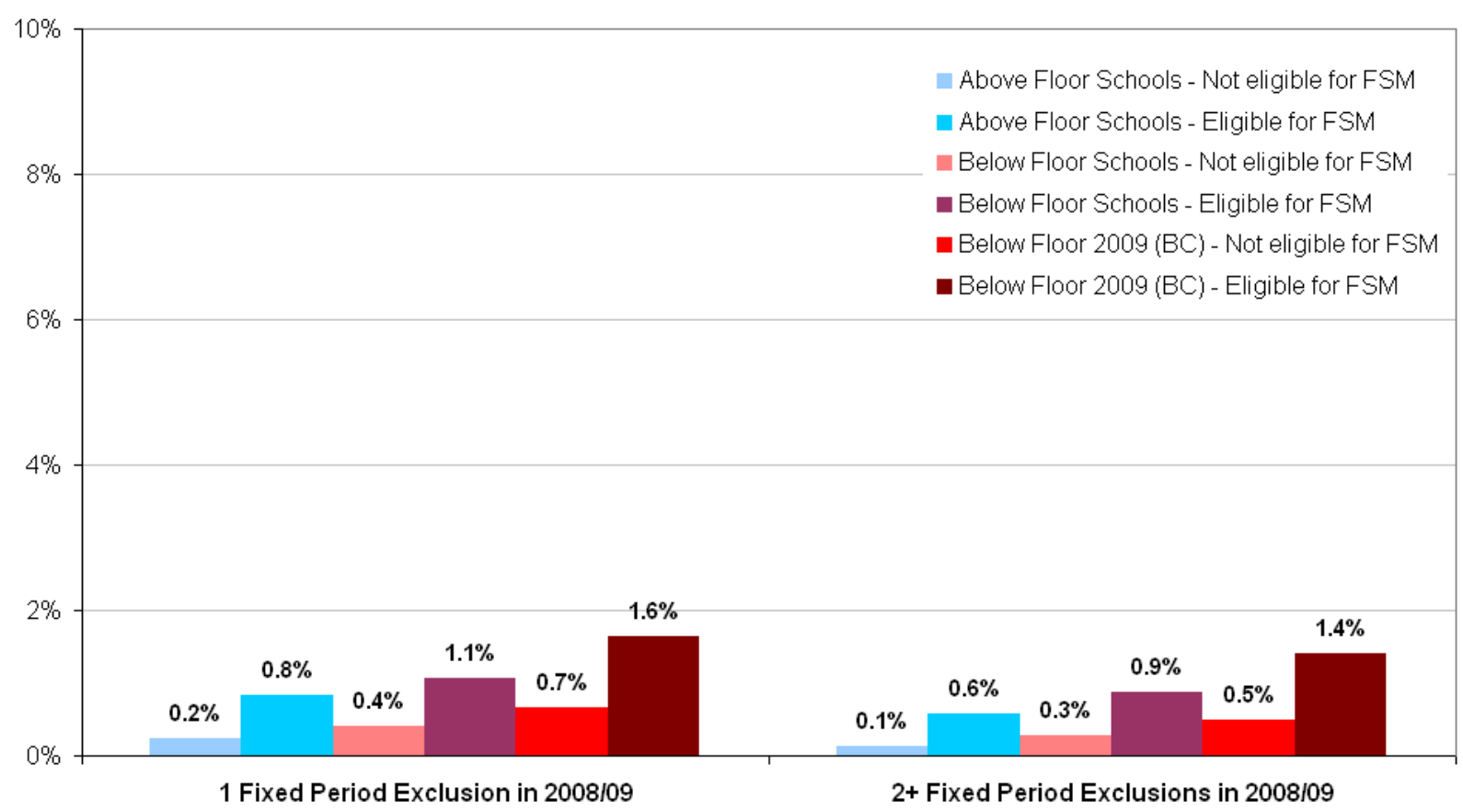




\subsection{Key Stage 4 Schools}

\section{Chart 3.2a}

Mobility of Pupils in KS4 Schools - Pupils Joining During KS4

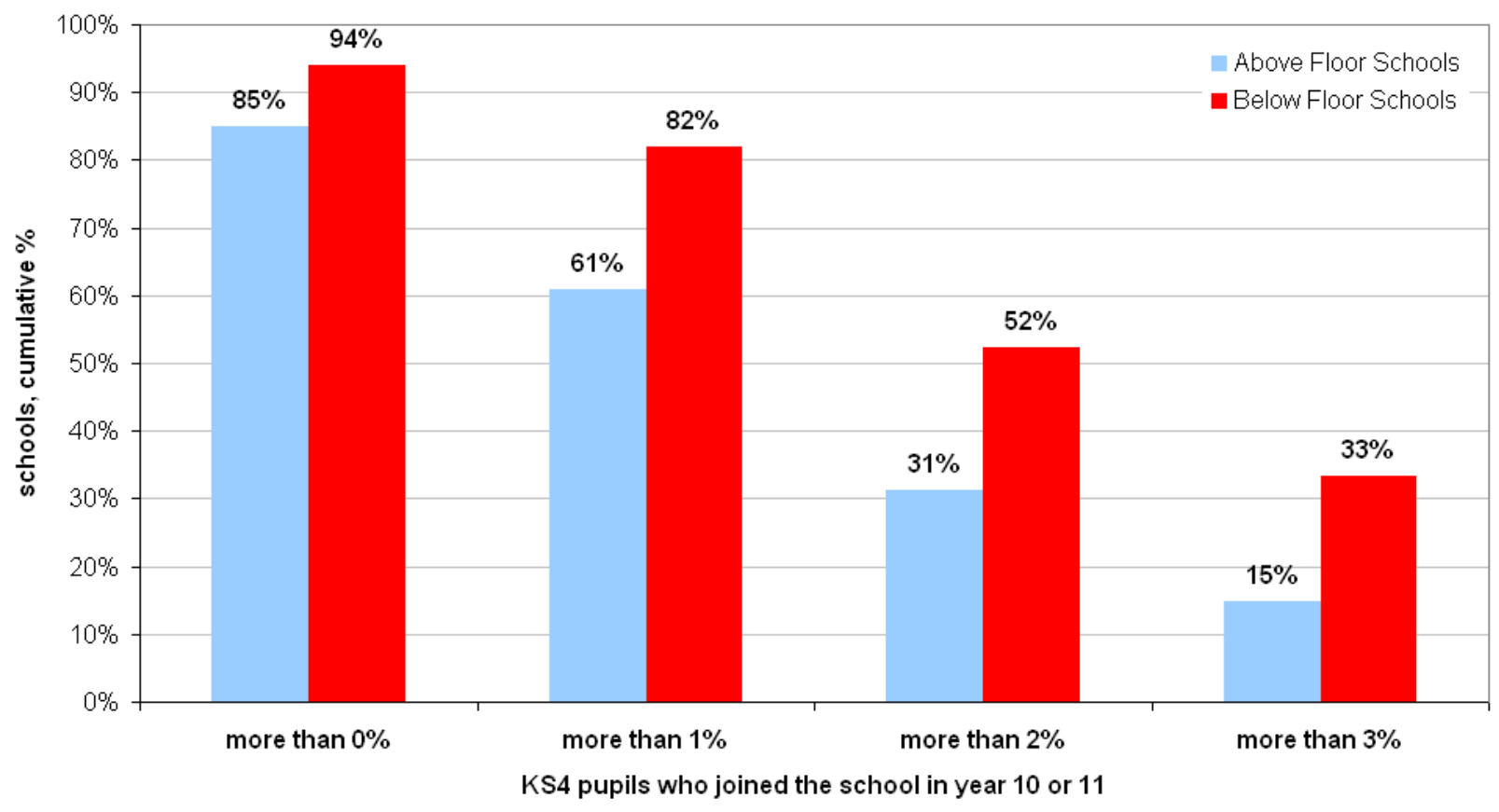

\section{Chart 3.2b}

Mobility of Pupils in KS4 Schools - Pupils Joining Mid-Year During KS3

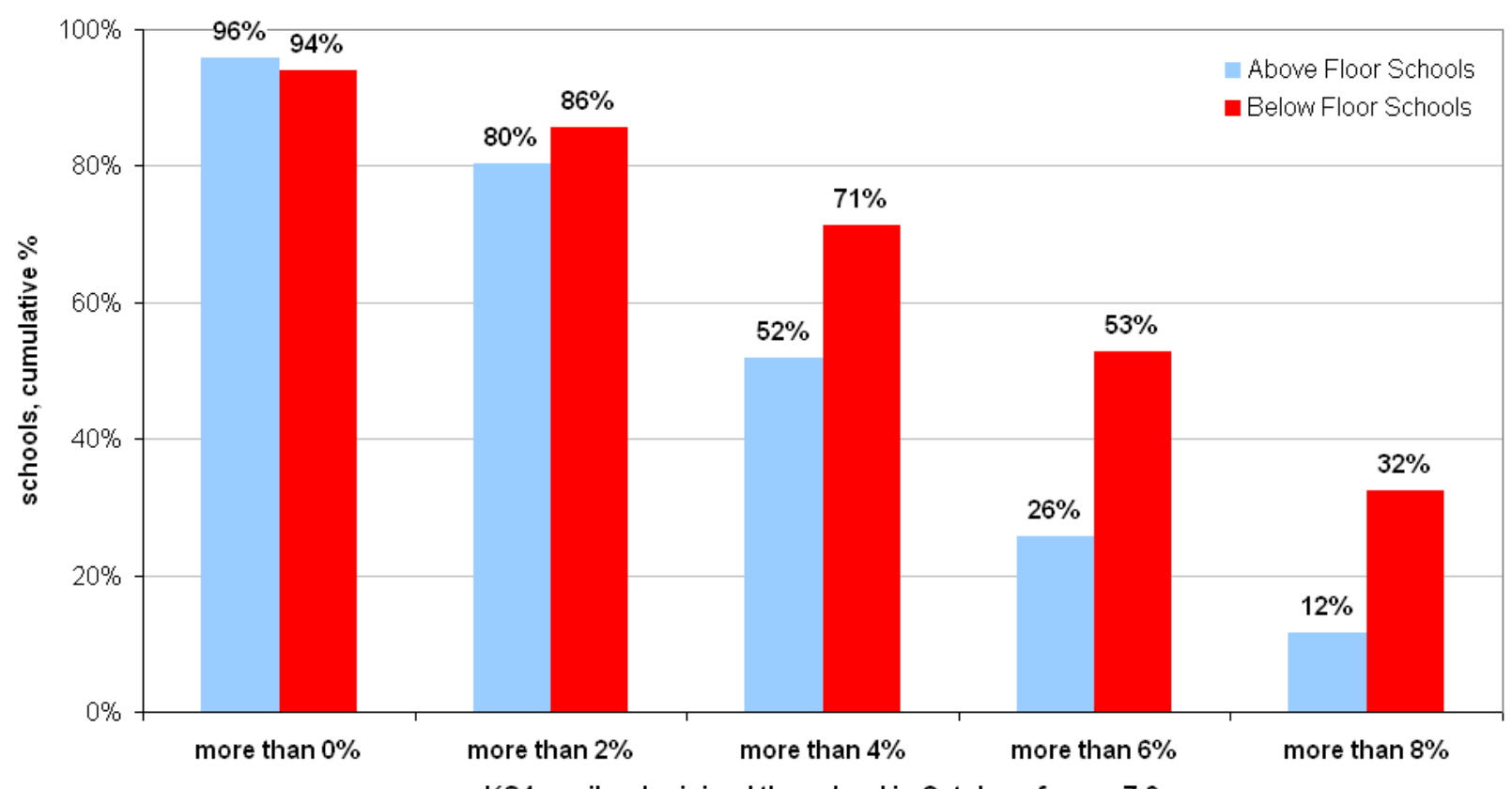

KS4 pupils who joined the school in Oct-Jun of years $7-9$ 


\section{Chart 3.2c}

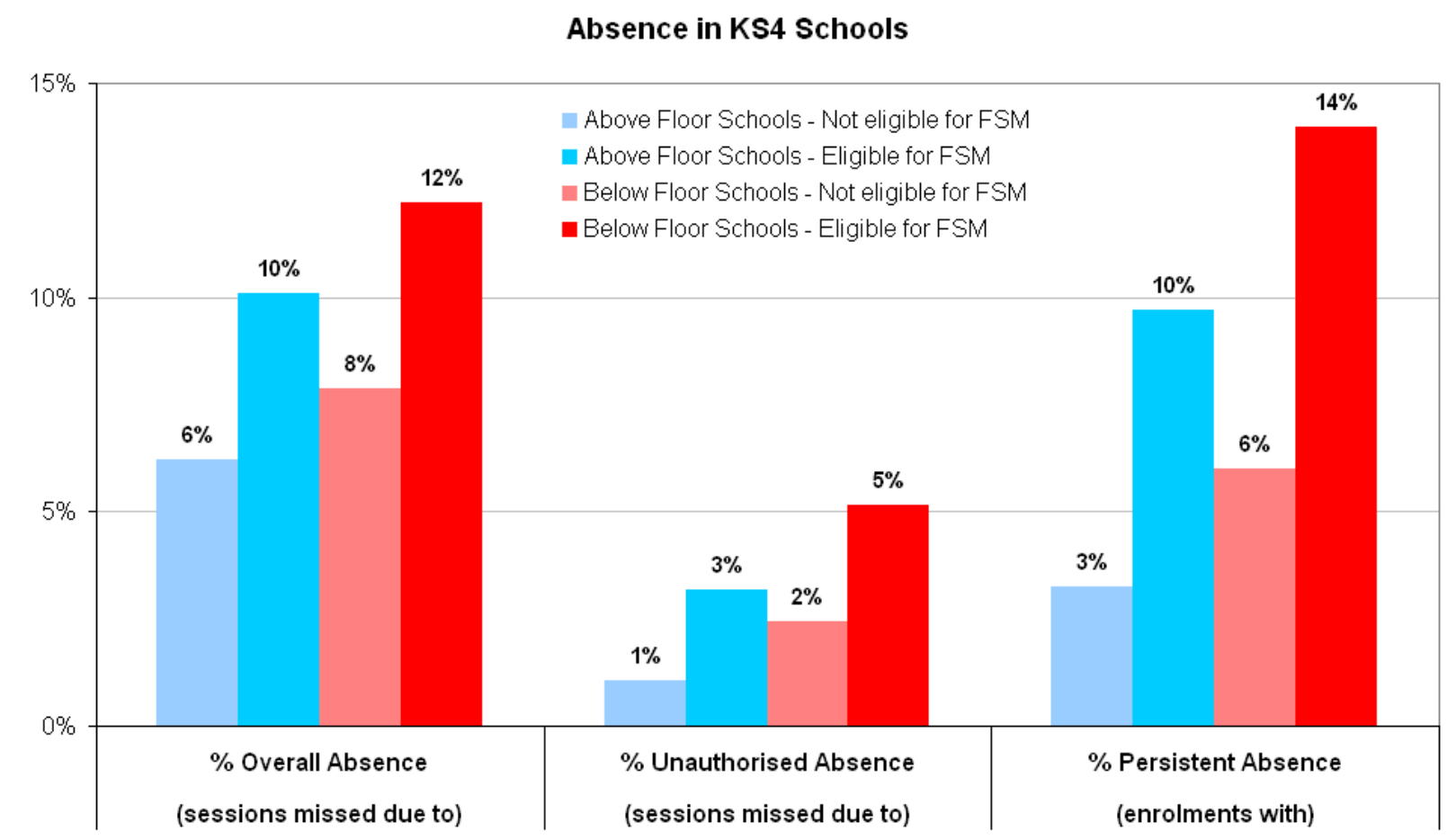

\section{Chart 3.2d}

Pupils with Fixed Period Exclusions in KS4 Schools

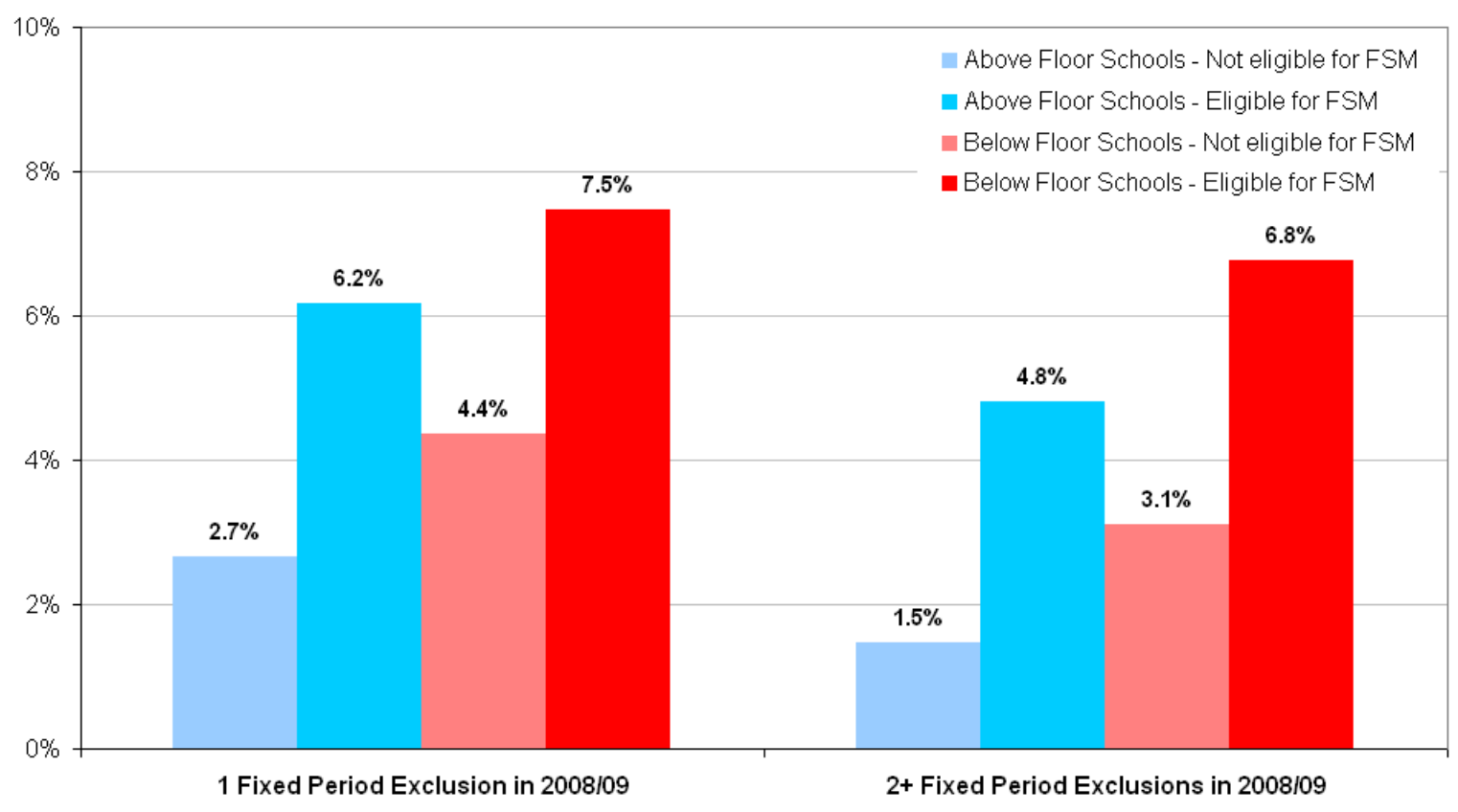




\section{Expenditure in Below Floor Schools}

This chapter compares the spending patterns of schools below and above the floor standards, assessing whether underperforming schools tend to use their resources in a different way from other schools.

\section{Key Findings}

- For primary schools with high rates of free school meals eligibility ( $\geq 35 \%)$, below floor schools have slightly lower per pupil spending than above floor schools; the reverse is true for schools with lower proportions of pupils eligible for FSM.

- Considering the allocation of school spending between categories such as teaching staff, back office and learning resources, primary schools have similar spending patterns whether they are above or below the floor standards.

- Per pupil school spending is slightly higher for below floor secondary schools compared with above floor schools, at all levels of FSM eligibility. However, above floor schools spend more on teaching staff and less on education support staff and back office expenses, compared with below floor schools; this is true both proportionally and in absolute per pupil spending.

\subsection{KS2 Schools}

\section{Chart 4.1a}

\section{Median Total Per Pupil Spend in KS2 Schools}

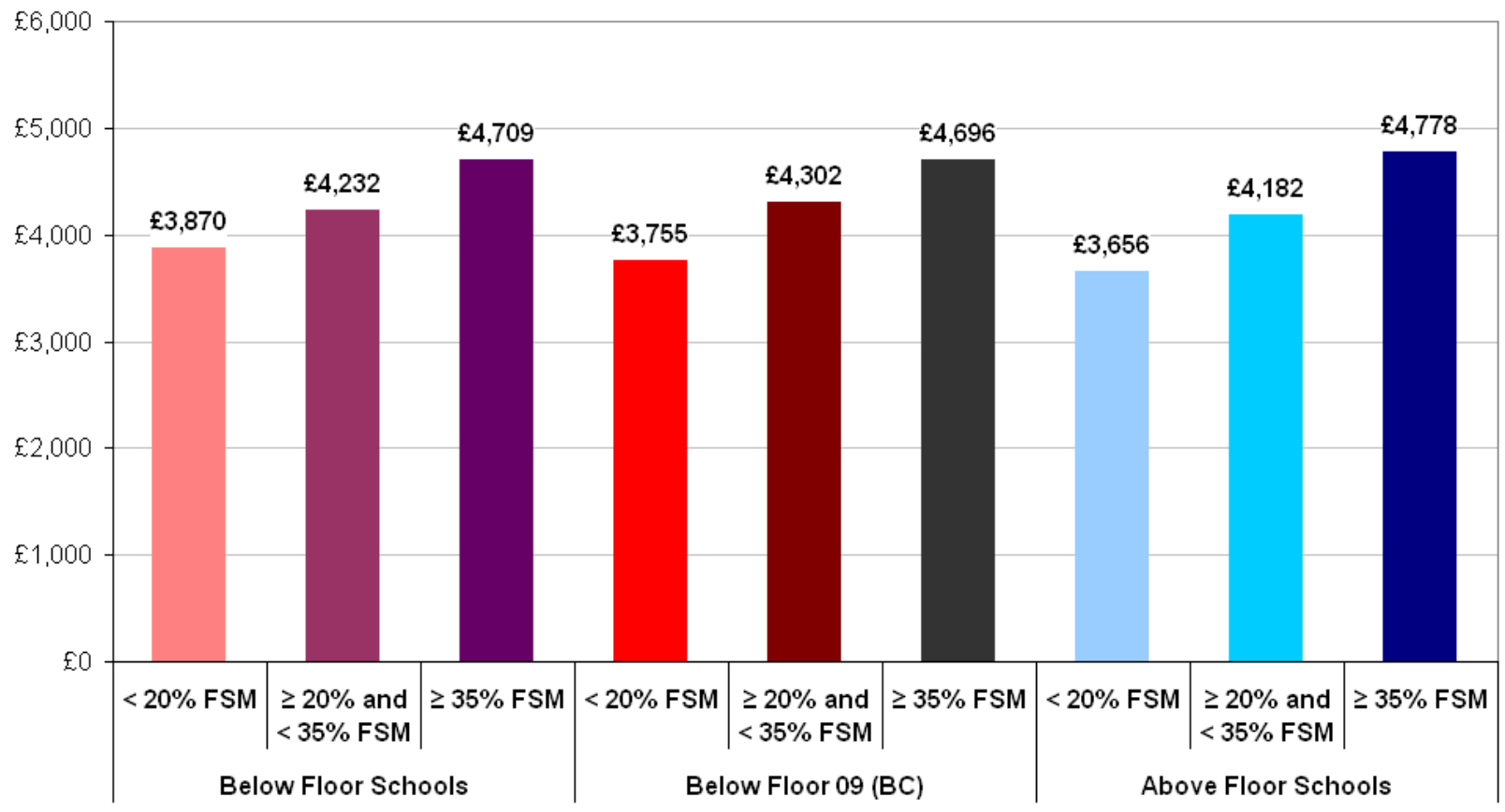




\section{Chart 4.1b}

KS2 School Spending Patterns (Proportion of Total Spend)

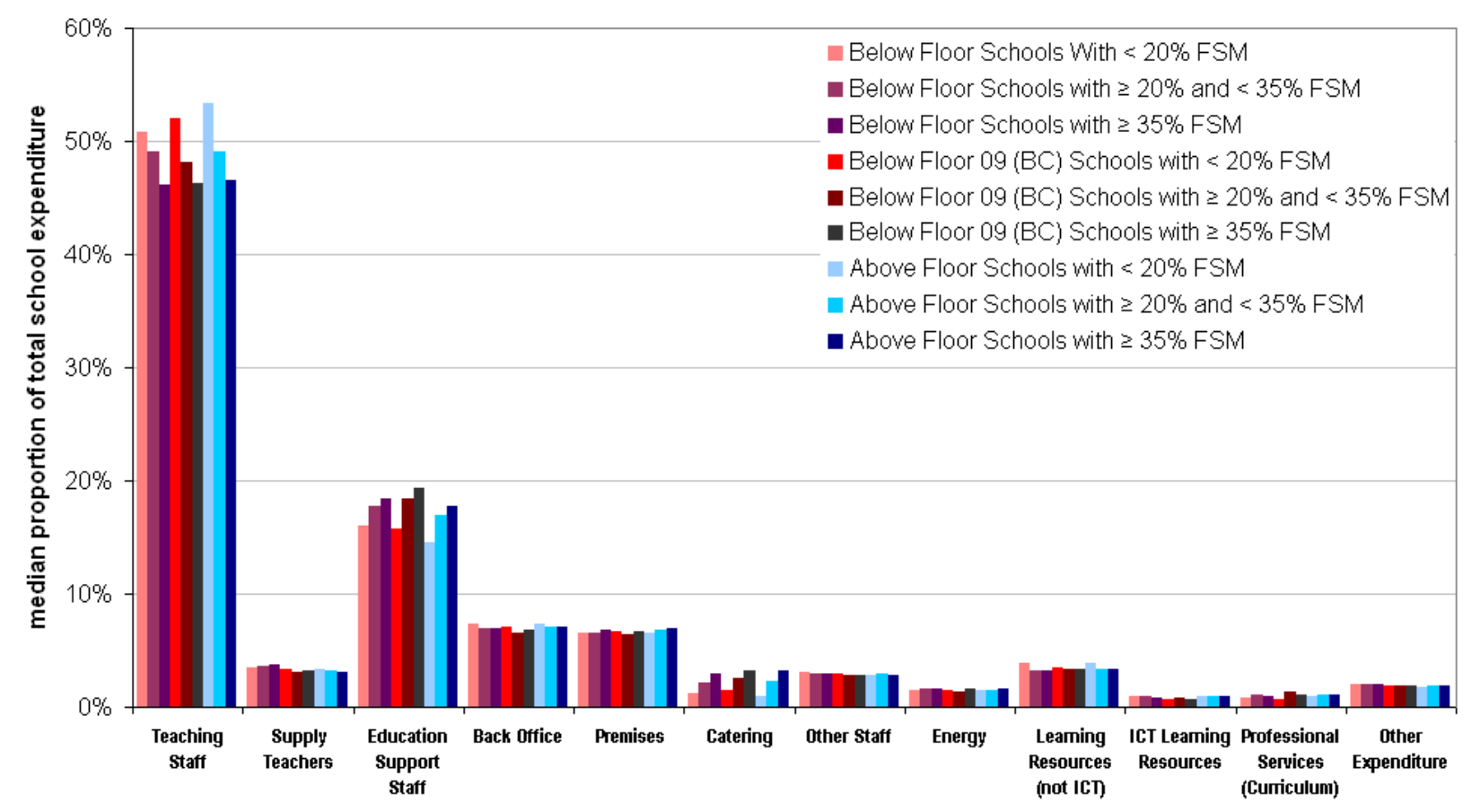

\section{Chart 4.1c}

\section{KS2 School Spending Patterns (Per Pupil Spend)}

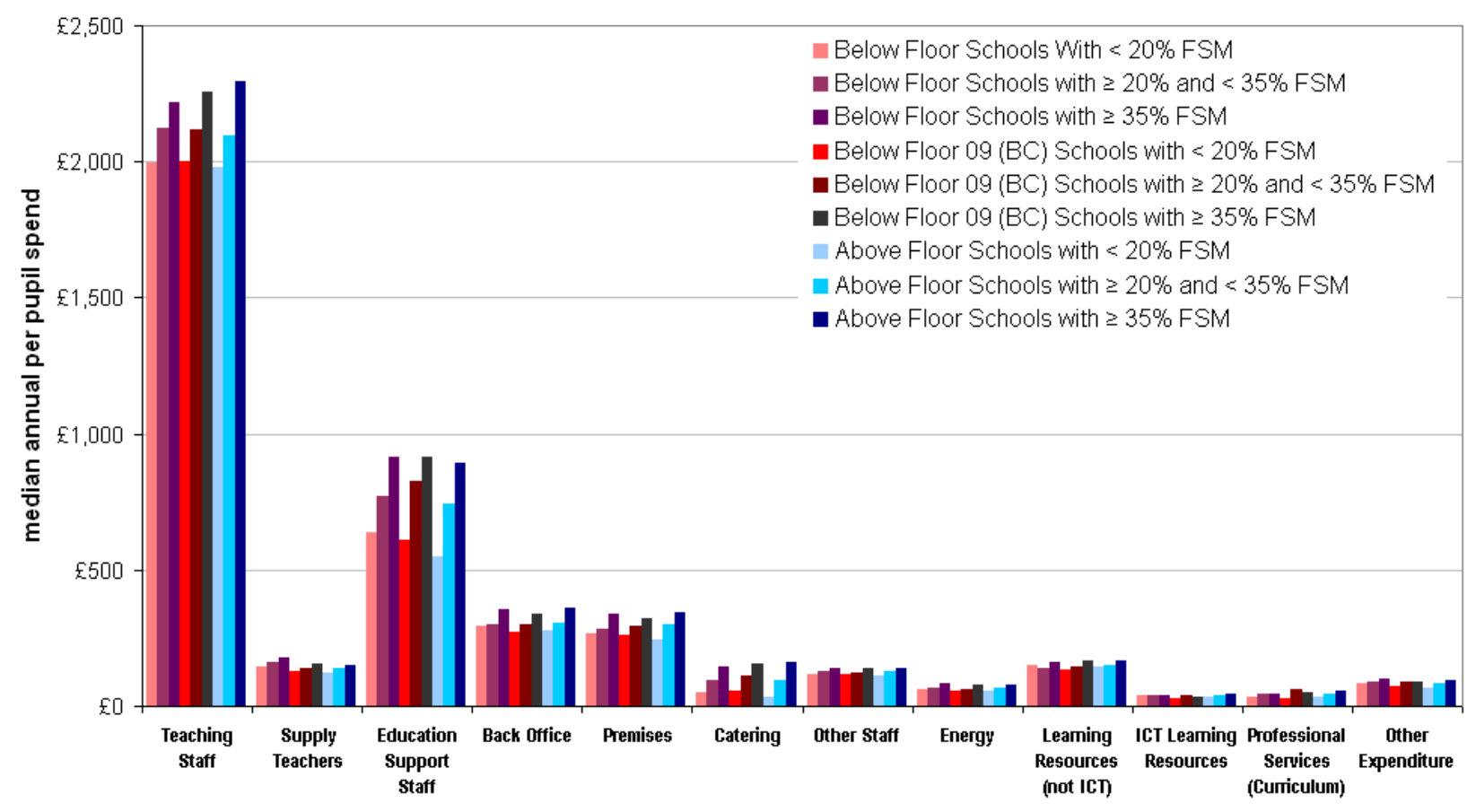




\subsection{KS4 Schools}

\section{Chart 4.2a}

\section{Median Total Per Pupil Spend in KS4 Schools}

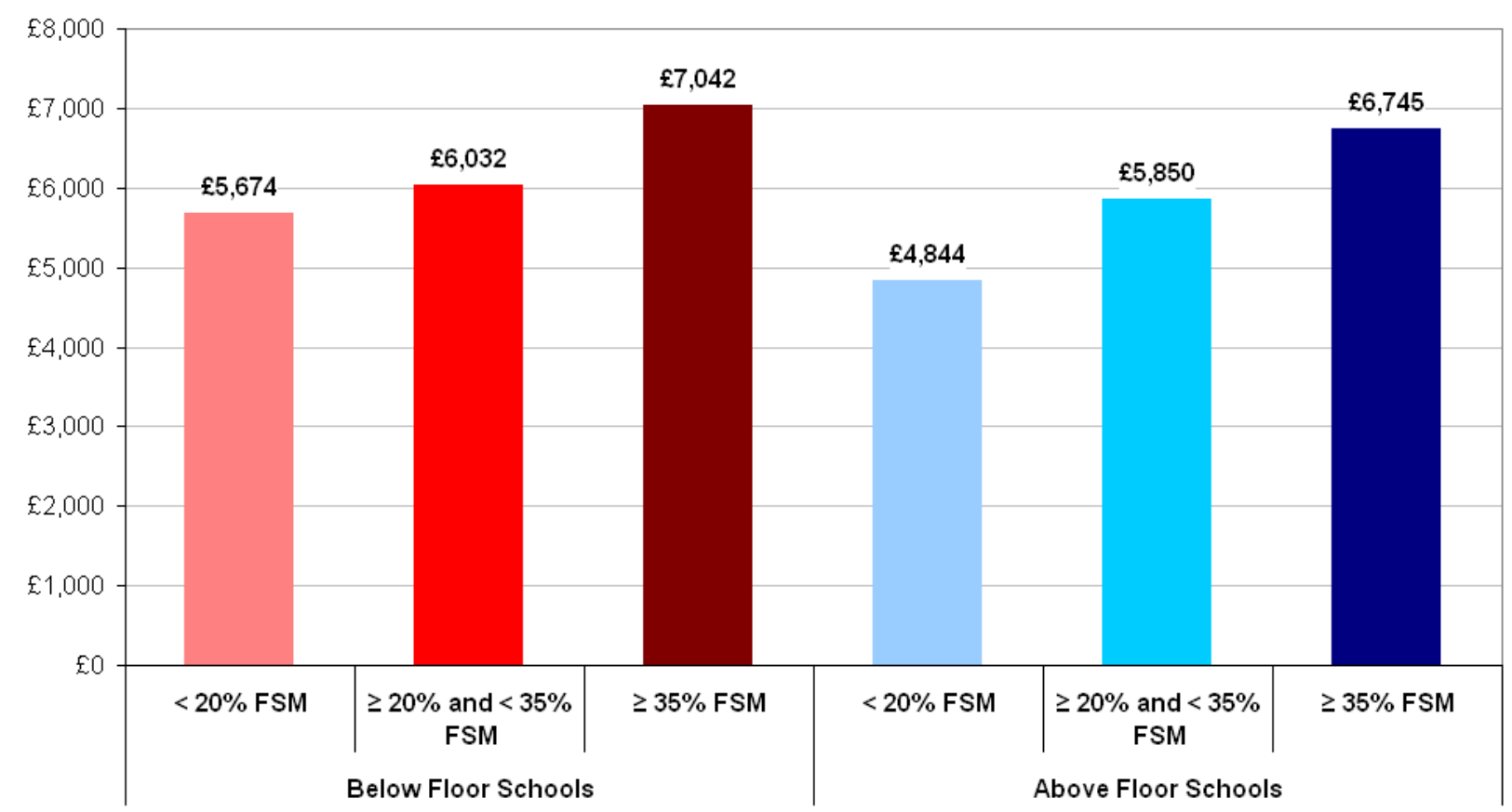

\section{Chart 4.2b}

KS4 School Spending Patterns (Proportion of Total Spend)

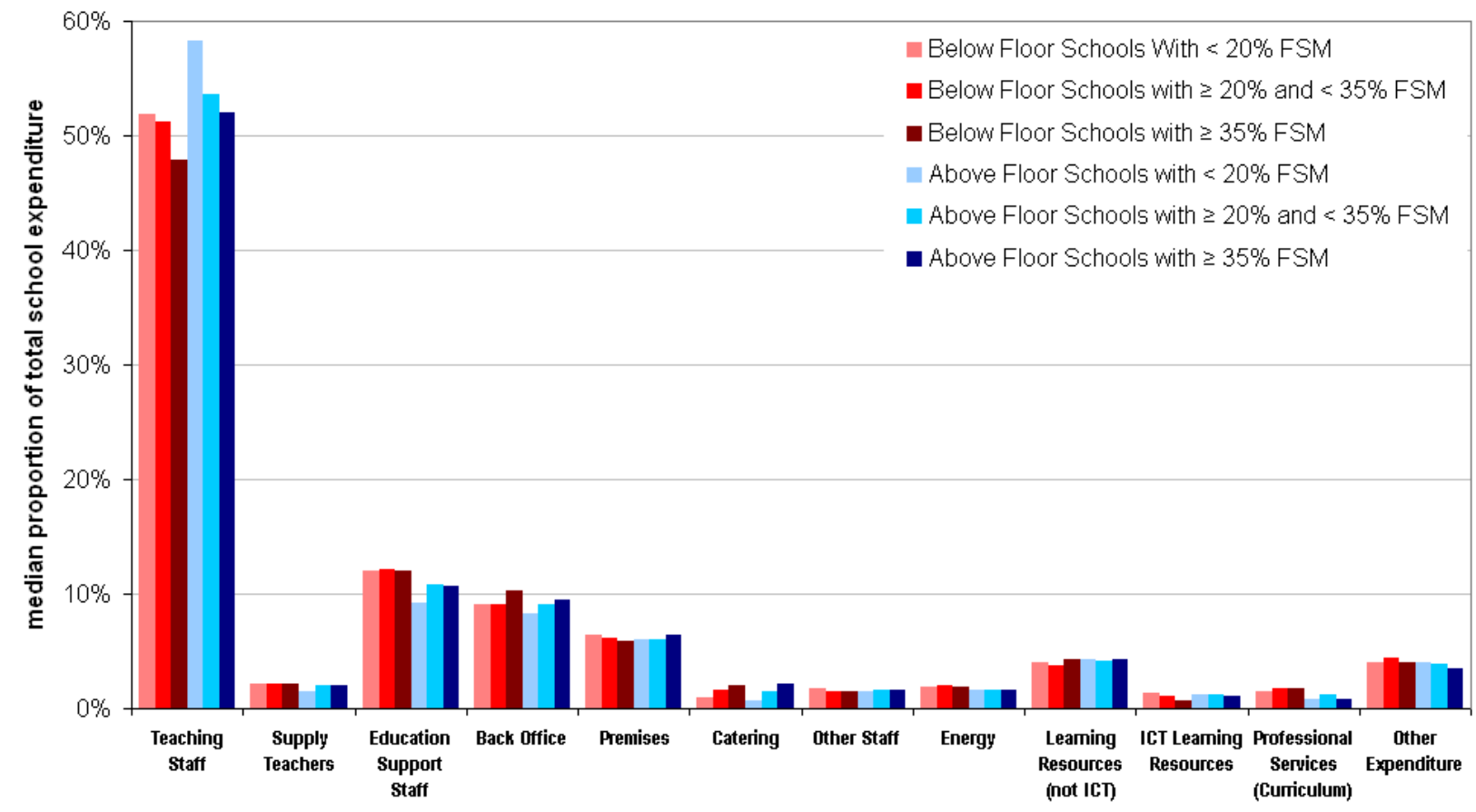




\section{Chart 4.2C}

\section{KS4 School Spending Patterns (Per Pupil Spend)}

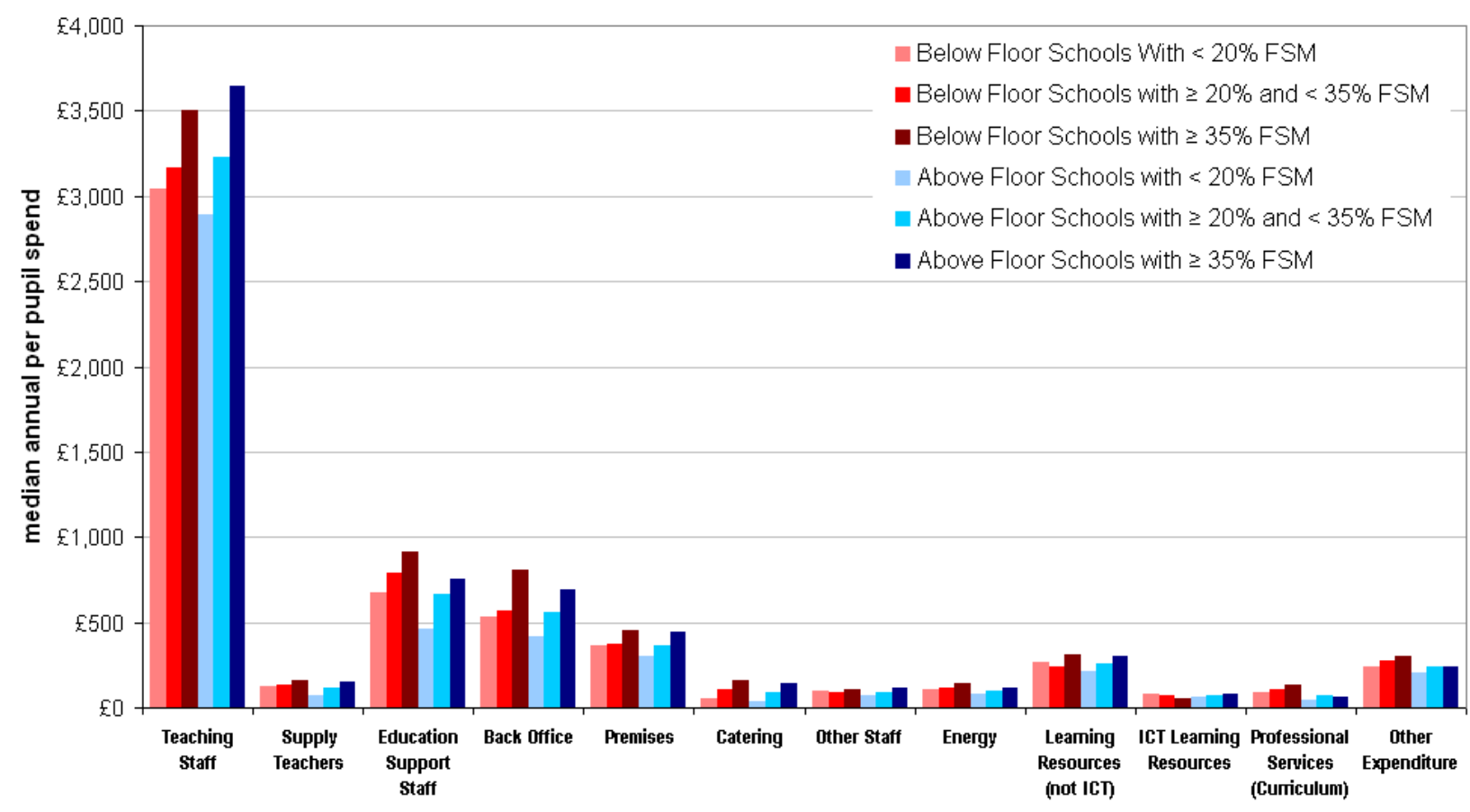




\section{Ofsted Judgements for Below Floor Schools}

This chapter reports the distributions of Ofsted overall effectiveness grades for below and above floor schools. The most recent inspection for each school as at the end of the 2009/10 academic year is used in the analysis - it's important to be aware that some of these inspection judgements will have been 2-3 years old at that time due to the inspection cycle, meaning that some will relate to an earlier inspection framework, and the schools' attainment and progress measures used to determine floor standards performance may have changed in the interim.

The overall effectiveness grade is based on a wide range of assessments about different aspects of a school, made according to the professional judgement of the lead inspector; these include assessments such as the quality of leadership and management, safeguarding, and how the school supports pupil health, the quality of provision, including the care, guidance and support for pupils, as well as the attainment and pupil progress assessments, of which the floor standards form one part. For this reason, overall effectiveness judgements may not correspond to individual attainment measures. However, the Ofsted inspection framework is expected to be revised with effect in January 2012 to reflect changes first proposed in the Schools White Paper which are now being taken forward as part of the Education Bill; the broad effect of the changes is expected to lead to a greater focus on teaching and its impact on pupil progress, which is likely to result in greater alignment with the floor standards.

\section{Key Findings}

- Below floor schools at both Key Stages typically have lower overall effectiveness judgements from Ofsted than above floor schools, with a greater proportion receiving satisfactory or inadequate grades, and a correspondingly smaller proportion receiving good or outstanding grades. 


\subsection{KS2 Schools}

\section{Chart 5.1a}

Latest Overall Effectiveness

Schools Below KS2 Floor 2010

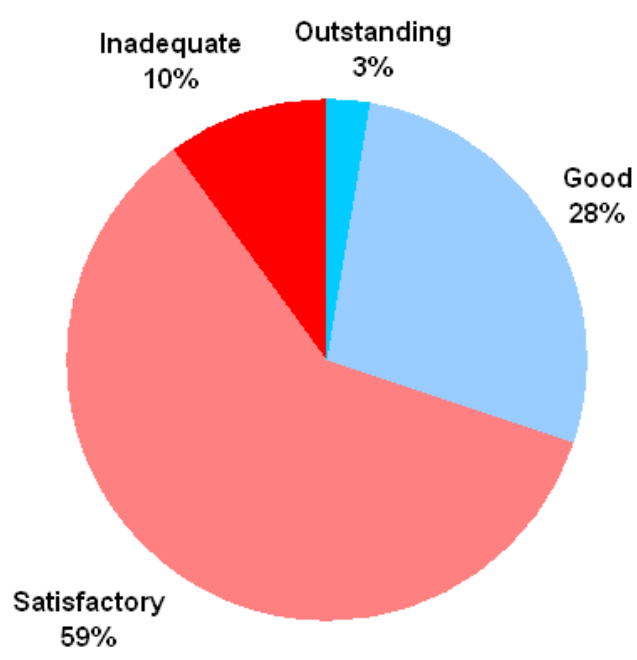

\section{Chart 5.1b}

Latest Overall Effectiveness

Below KS2 Floor 2009 (Boycott)

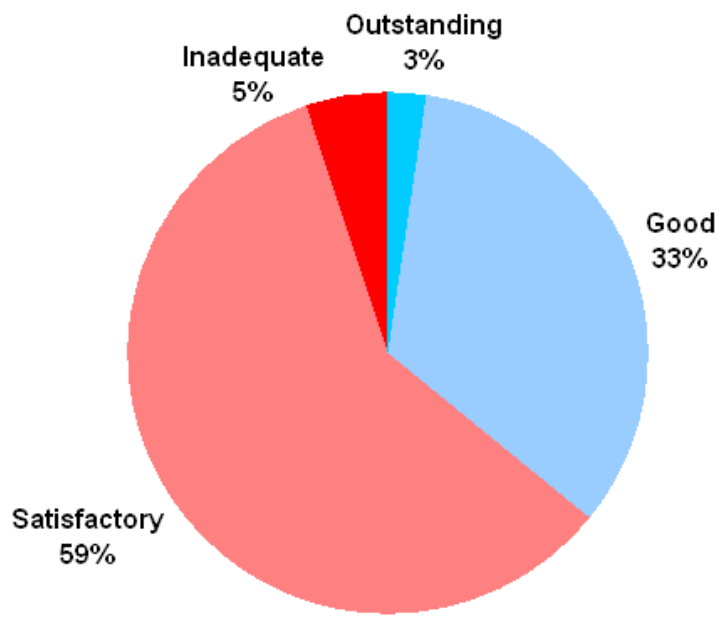




\section{Chart 5.1c}

\section{Latest Overall Effectiveness}

Schools Above KS2 Floor

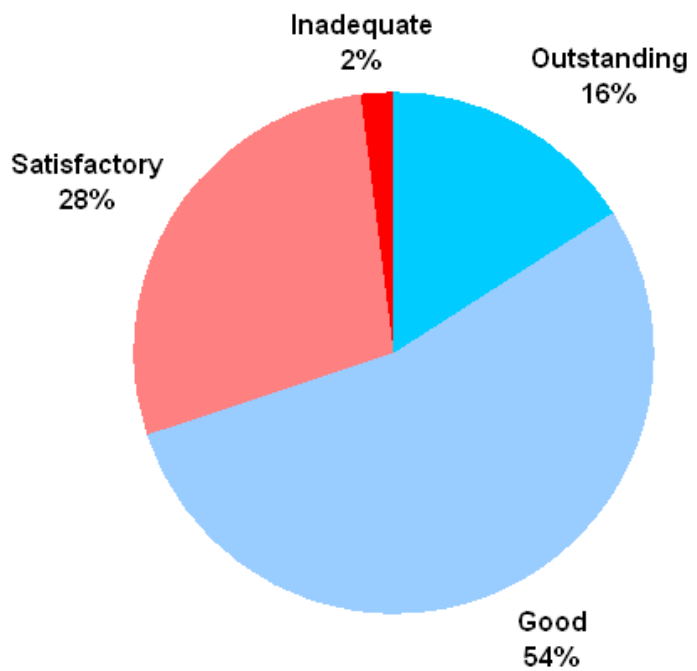




\subsection{KS4 Schools}

\section{Chart 5.2a}

Latest Overall Effectiveness

Schools Below KS4 Floor 2010

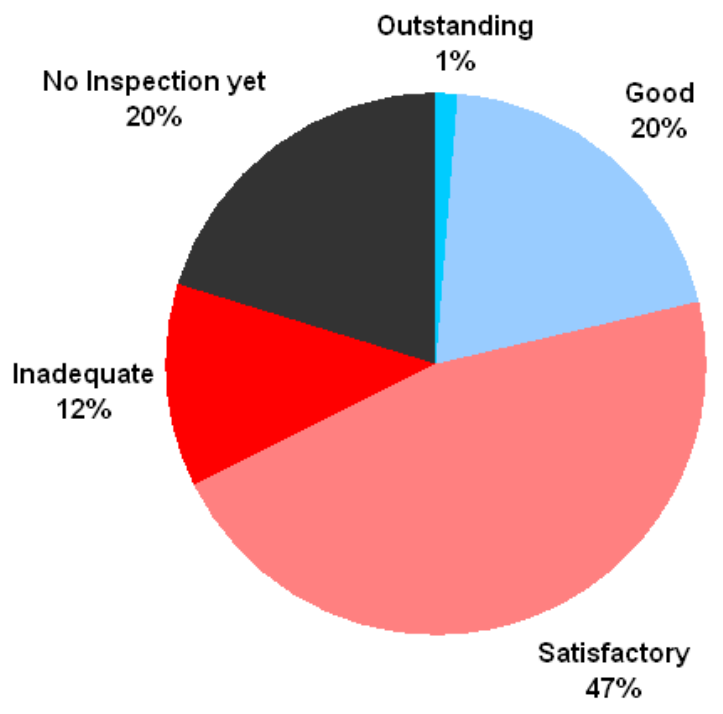

\section{Chart 5.2b}

Latest Overall Effectiveness

Schools Above KS4 Floor 2010

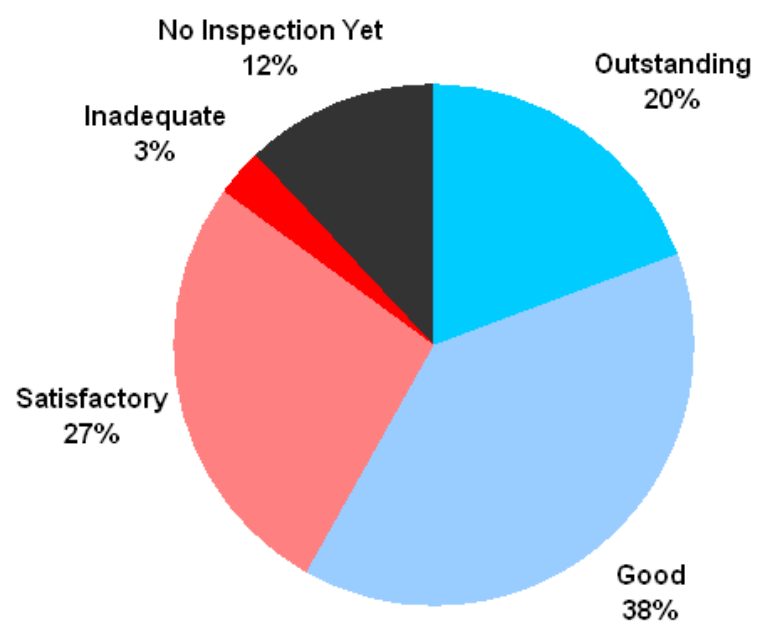




\section{Attainment and Progress in Below Floor Schools}

This chapter provides a comprehensive set of analyses of attainment and progress for below floor schools, at school group (below/above floor) level in sections 6.1 and 6.2 , and at school distribution level in sections 6.3 and 6.4. As with chapter 2, pupils eligible for free school meals and pupil deprivation form a key focus for the analyses. Additional analyses of attainment and progress at both Key Stages by pupil characteristics within below and above floor schools appear in annex B.

\section{Key Findings}

- On average, schools above the floor standards in 2010 have increased their attainment at KS2 over the last five years; this is in contrast to below floor schools, which have seen decreasing rates of achievement of the expected levels in English and maths, on average since 2008. Below floor schools that boycotted the tests in 2010 had large decreases in attainment from 2008 to 2009 on average.

- A similar pattern of trends for above and below floor schools is seen for the KS1-2 expected progress measure in English, although with decreases in English progress being less marked than the decreases in achievement of the expected level of attainment in below floor schools, but still important for below floor schools that boycotted the tests in 2010.

- A more positive picture is seen for KS 1-2 expected progress in maths, with all groups of schools broadly improving since 2006, although the increase has not been as steady in below floor schools (including those that boycotted the tests in 2010) as in above floor schools.

- At Key Stage 4, both above and below floor schools have seen steady increases in attainment of five good GCSEs (or equivalents) including GCSE English and maths. However, there remains a large gap in attainment between pupils who were eligible for free school meals in above floor schools and those who were not eligible for FSM, plus all pupils in below floor schools.

- Progress in English between Key Stages 2 and 4 has increased for both FSM eligible and non-FSM pupils in both above and below floor schools. Pupils eligible for FSM in above floor schools have similar progress rates on average to those not eligible for FSM in below floor schools, with a large gap in progress between these groups and pupils who are both eligible for FSM and attended a below floor school.

- A similar pattern of gaps is seen for KS2-4 progress in maths, but with much smaller improvements in below floor schools regardless of FSM eligibility. 


\subsection{KS2 Overview \& Trend}

\section{Chart 6.1a}

Attainment in KS2 Schools, 2006-2010

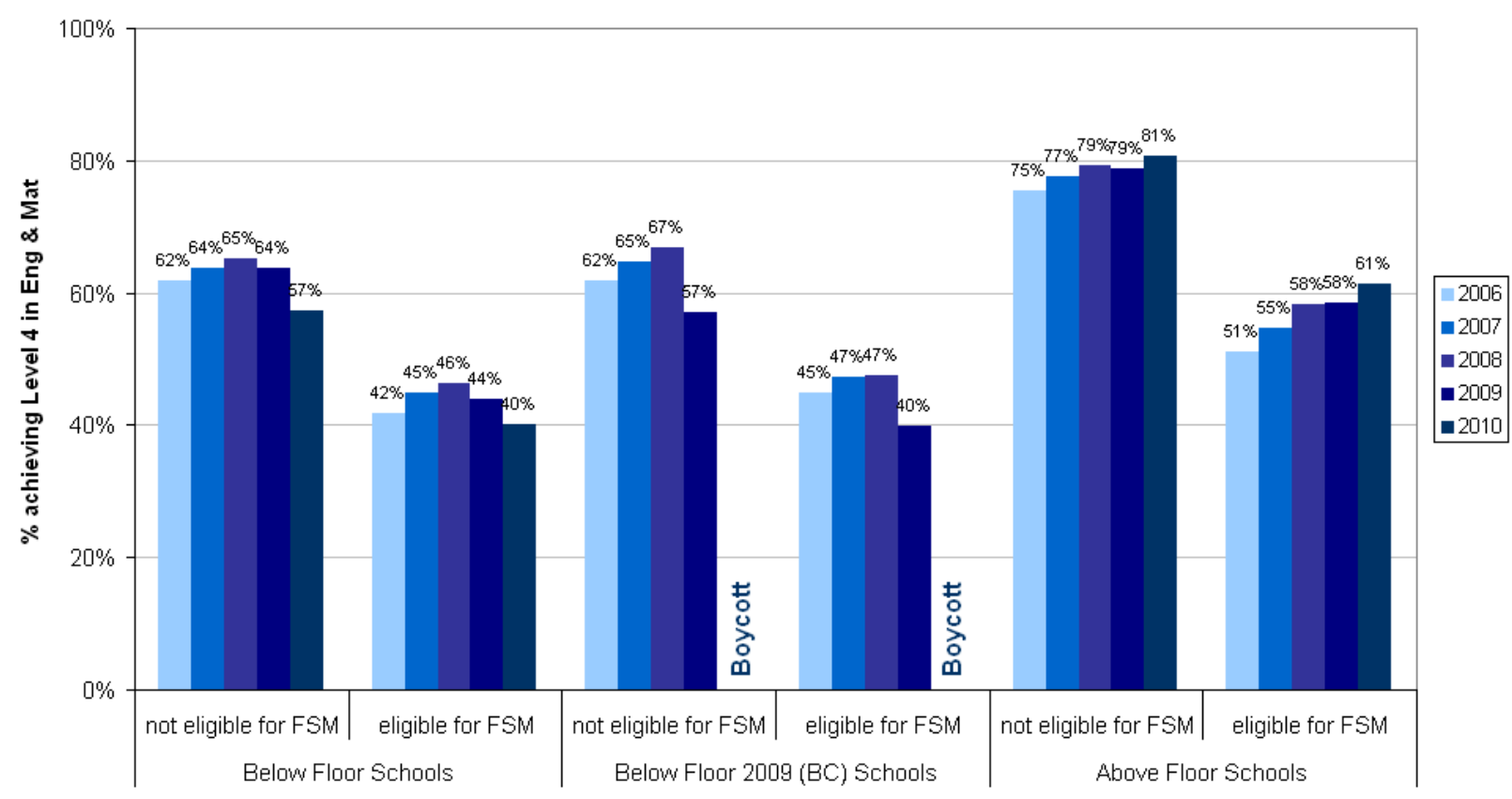

\section{Chart 6.1b}

English Progress in KS2 Schools, 2006-2010

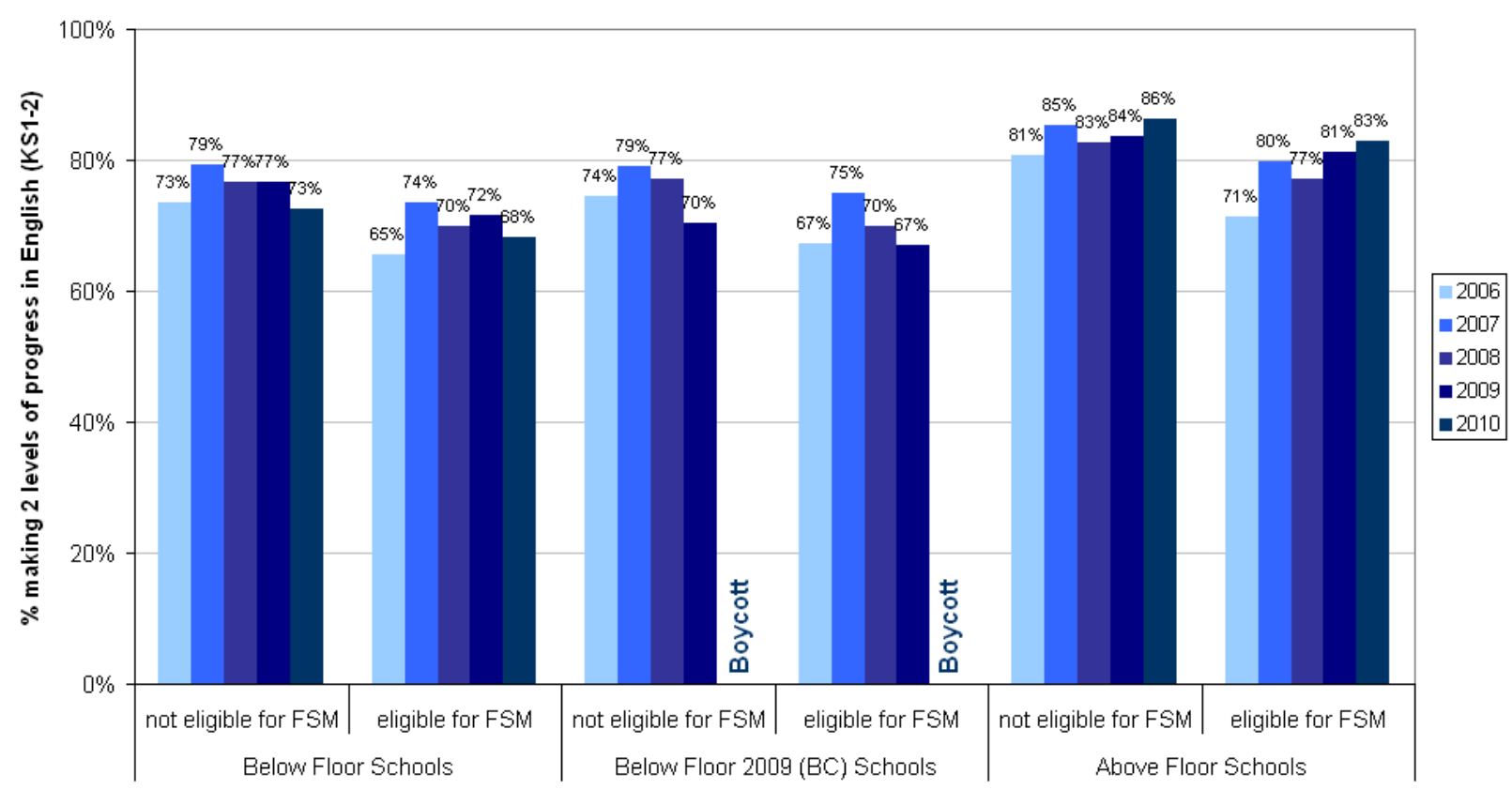




\section{Chart 6.1c}

Maths Progress in KS2 Schools, 2006-2010

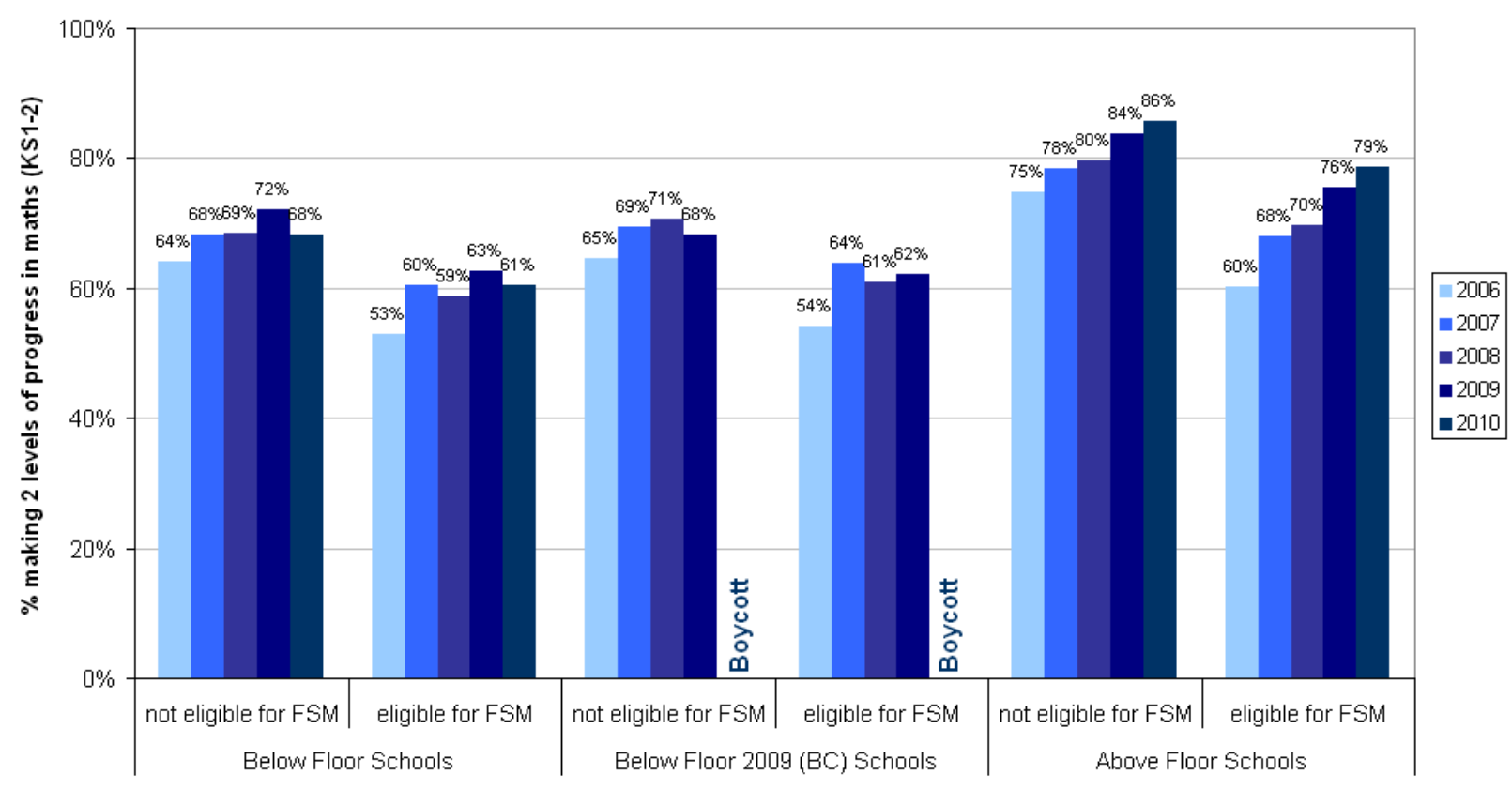




\subsection{KS4 Overview and Trend}

\section{Chart 6.2a}

Attainment in KS4 Schools, 2006-2010

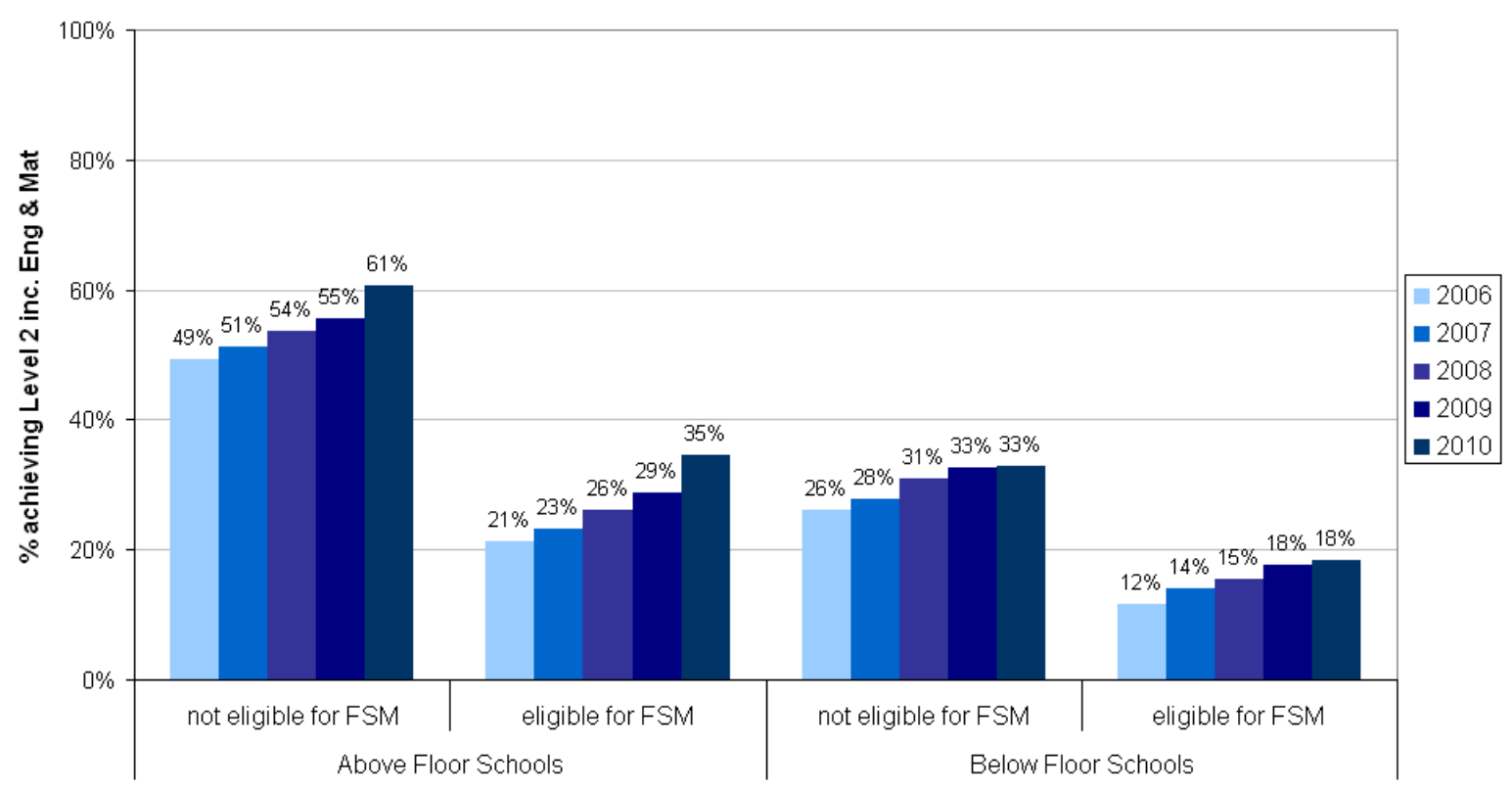

\section{Chart 6.2b}

English Progress in KS4 Schools, 2008-2010

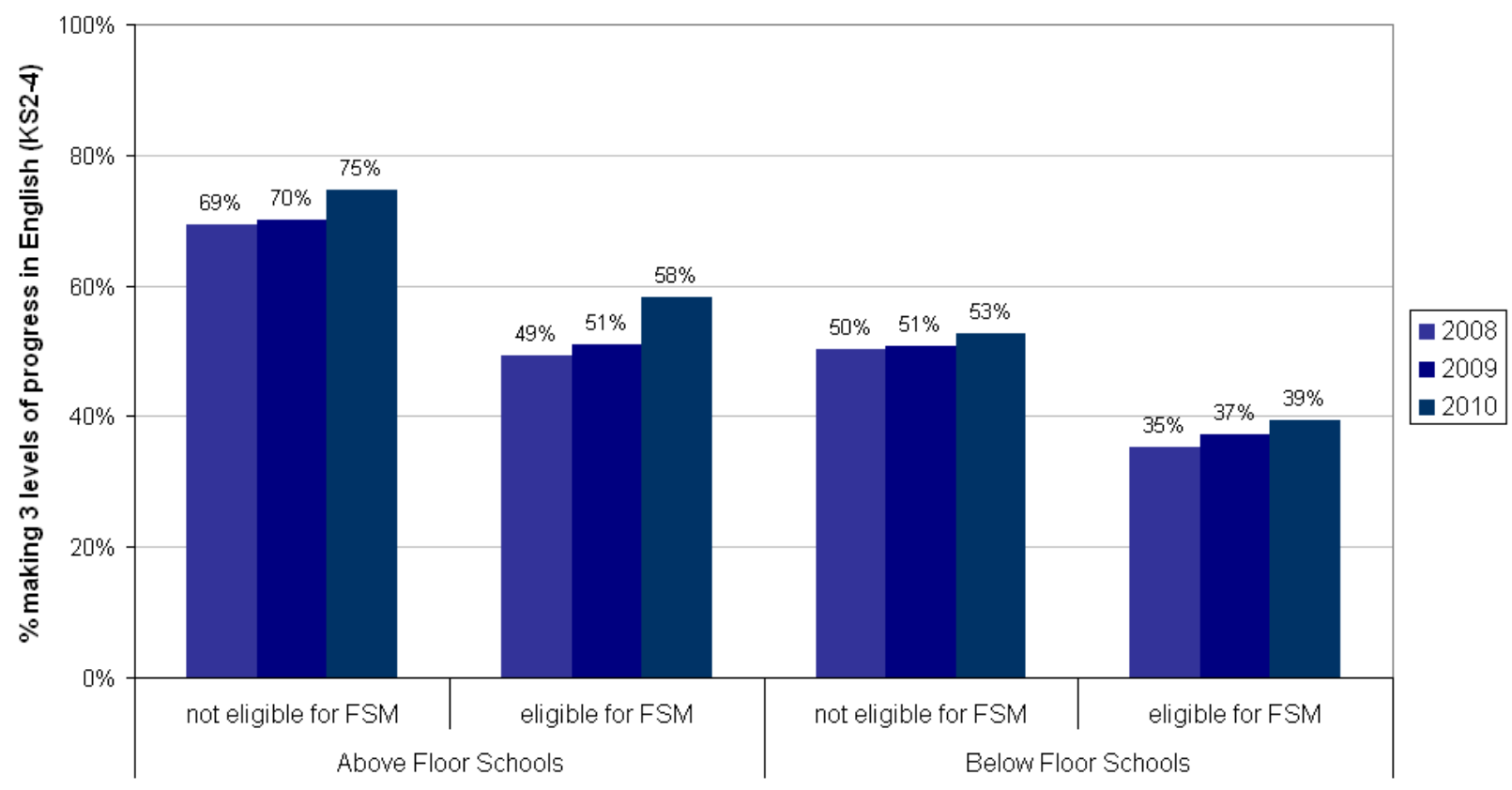




\section{Chart 6.2c}

Maths Progress in KS4 Schools, 2008-2010

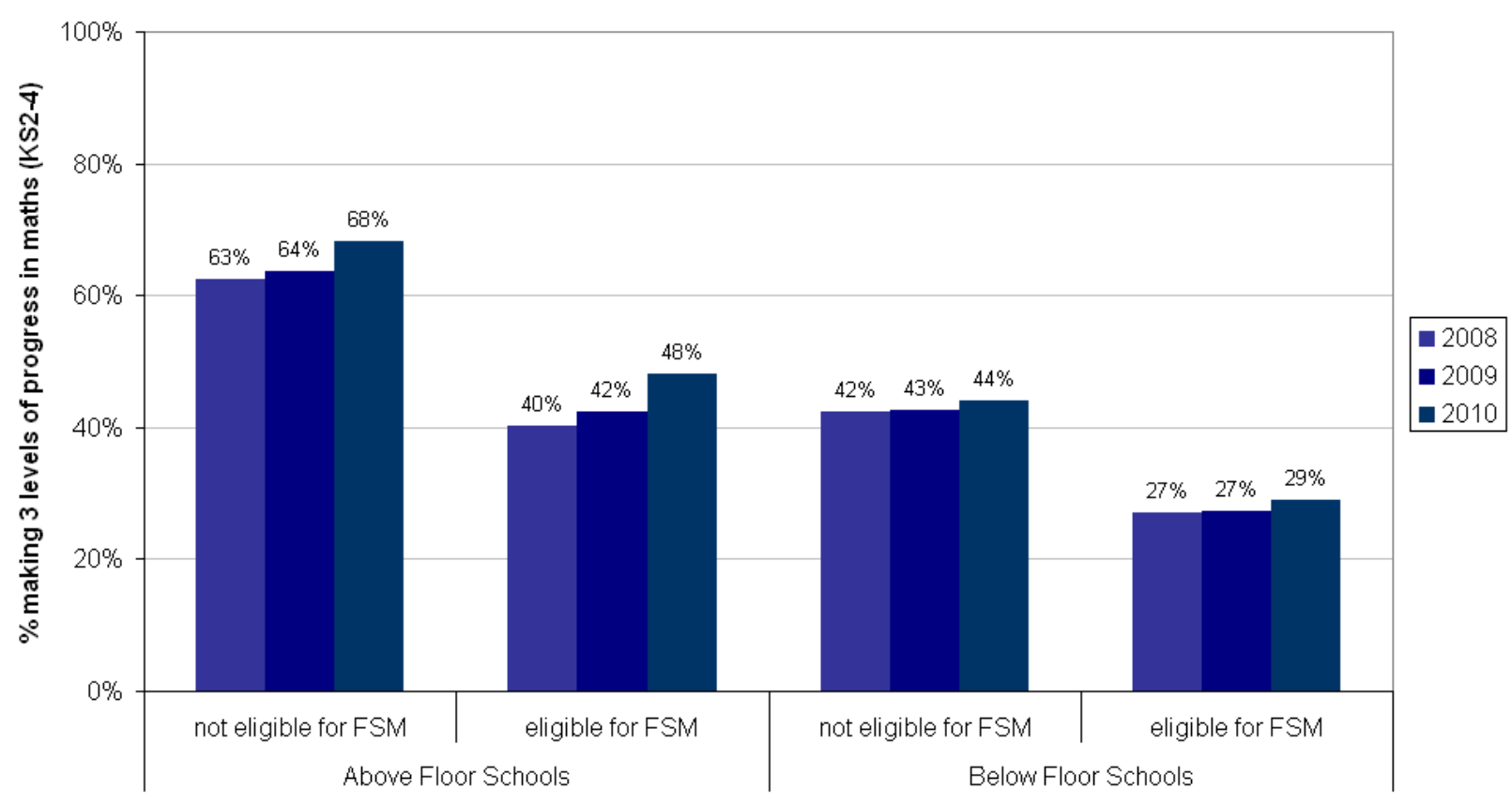




\subsection{KS2 Below Floor School Level Attainment Trajectories}

This section examines KS2 attainment at school level, comparing latest performance with the average change in performance over five years to reveal changes over time, or the trajectories followed by below floor schools and their above floor counterparts. For schools which boycotted the $2010 \mathrm{KS} 2$ tests, 2009 attainment is used as a proxy for 2010 performance.

\section{Key Findings}

- School level attainment is volatile from year to year due to the characteristics and prior attainment of the successive cohorts reaching the end of the Key Stage, as well as any changes in school effectiveness. Statistical significance testing of year-on-year changes and attainment changes averaged over several years can help to identify true underlying trends in performance.

- The majority of KS2 schools, both below and above floor standards, had no statistically significant year-on-year changes in attainment (expected level in English and maths) between 2006 and 2010 ( $p<0.05$ ). However, a larger minority of below floor schools had statistically significant year-on-year decreases in attainment than of above floor schools, and a smaller minority of below floor schools had statistically significant year-on-year improvements in attainment.

- The majority of schools below the floor standards at Key Stage 2, including those below the floor in 2009 which then boycotted the tests in 2010, have seen negative 5 year average changes (deteriorations) in attainment between 2006 and 2010. This contrasts with above floor schools, which were more evenly split between improving attainment on average, and deteriorating attainment.

Chart 6.3a categorises schools below and above the floor standards into attainment trajectories based on the direction, consistency, and statistical significance of yearon-year changes to each school's percentage of pupils achieving the expected level in English and maths. 


\section{Chart 6.3a}

KS2 School Trajectories for \% Achieving Level 4+ in Eng \& Mat

Based on Statistical Significance of Year-on-Year Changes for 2006-2010 $(p<0.05)$

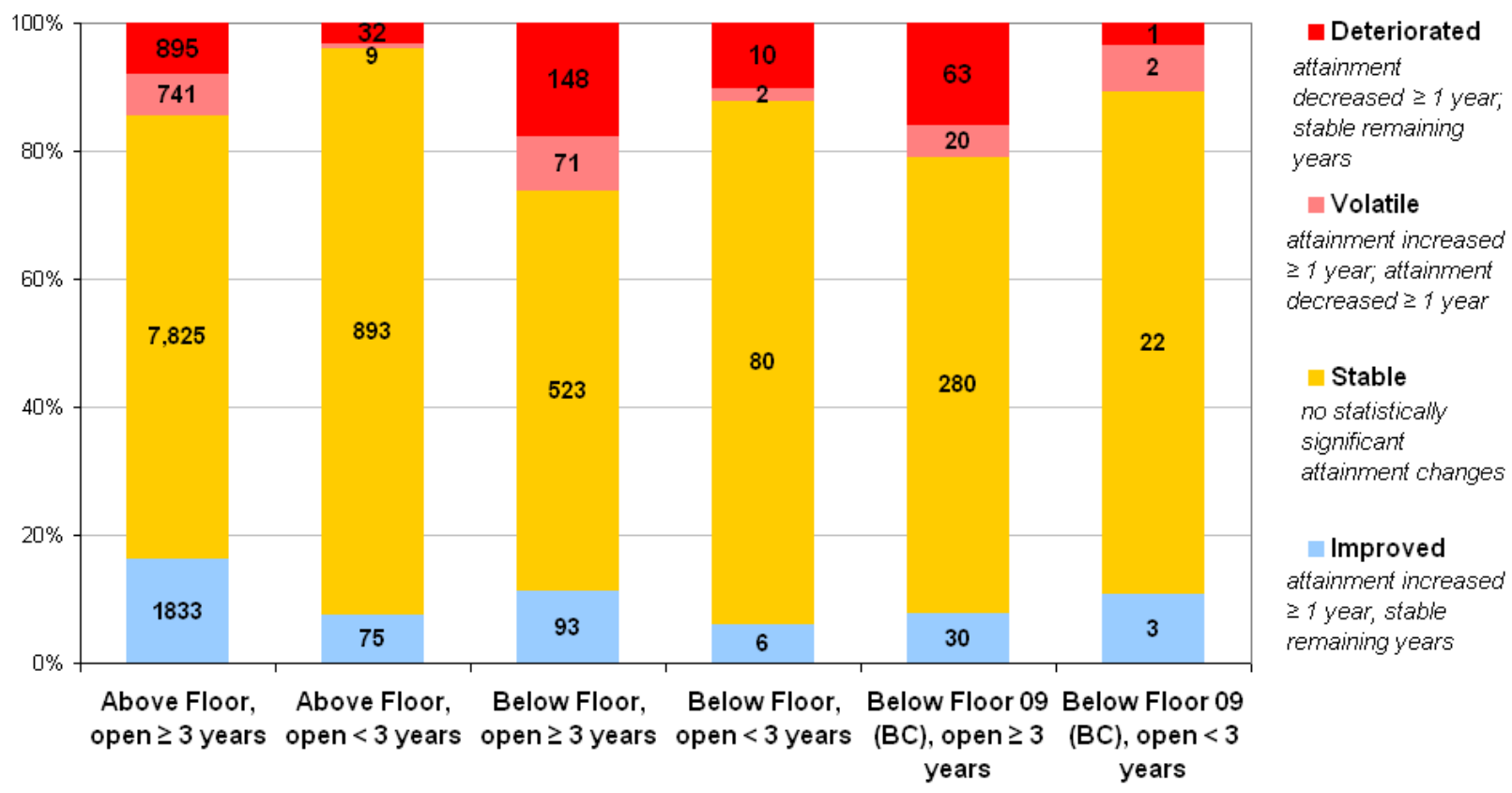

The scatter points in charts $6.3 \mathrm{a}$ and $6.3 \mathrm{~b}$ show the spread of schools within each geographic region, according to their percentage of children achieving the expected level in English and maths (vertical axis), and the average number of percentage points by which this measure has improved or deteriorated over five years (horizontal axis). Hence, schools in the top right of the chart have higher attainment that has improved on average; those in the bottom left have lower attainment that has deteriorated on average. Schools in the top left have higher attainment, but this has fallen on average; schools in the bottom right have lower attainment, but this has improved on average in the last 5 years.

Schools with fewer than two pairs of consecutive years with valid data over 20062010 are excluded, as are schools which have closed; this affects smaller schools disproportionately because their results are excluded in years where fewer than 11 pupils sat the KS2 tests. Average improvement over five years is used to smooth out the inherent volatility in school performance measures year-on-year, which are affected by the characteristics and prior attainment of the successive cohorts reaching the end of the Key Stage, as well as by school effectiveness. 


\section{Chart 6.3a}

\section{East Midlands KS2 Schools}

(Maintained Mainstream)

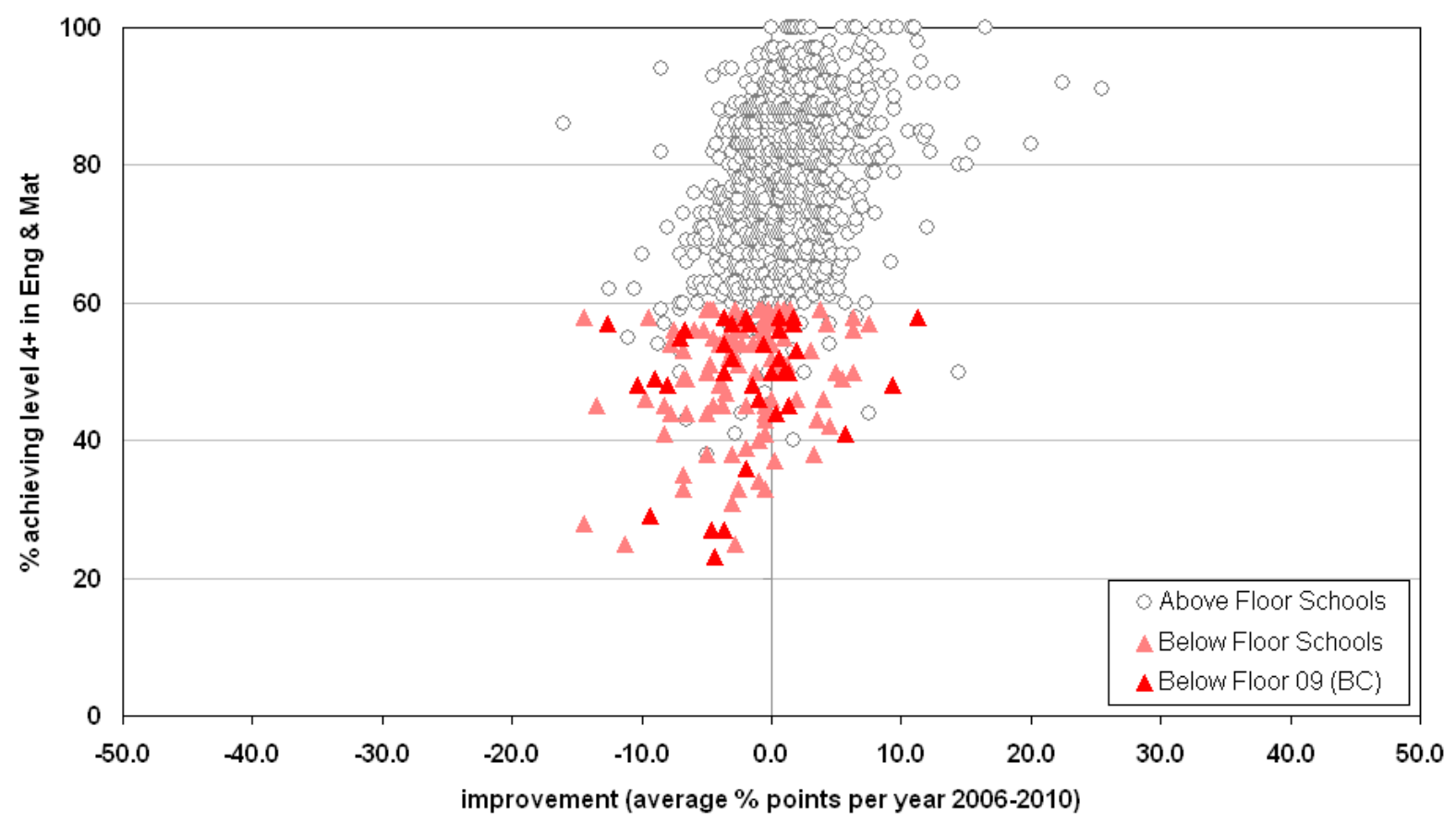

\section{Chart 6.3b}

East of England KS2 Schools

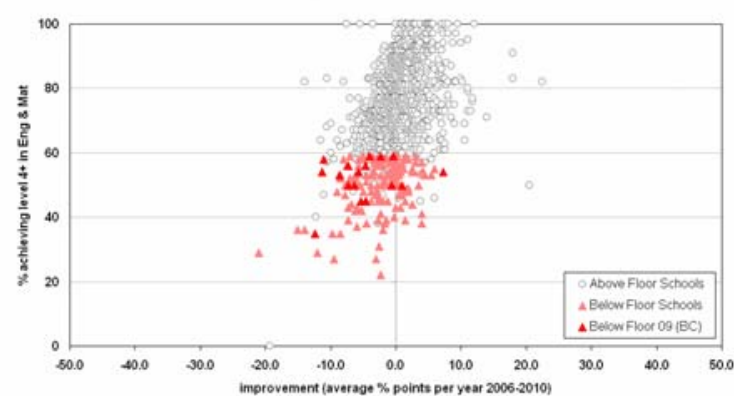

North East KS2 Schools

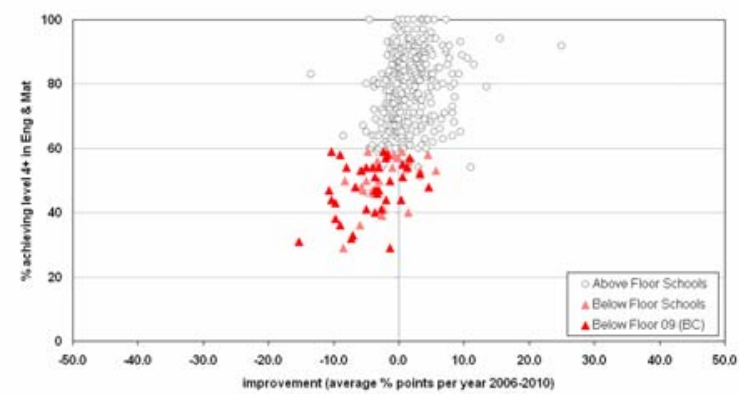

Inner London KS2 Schools

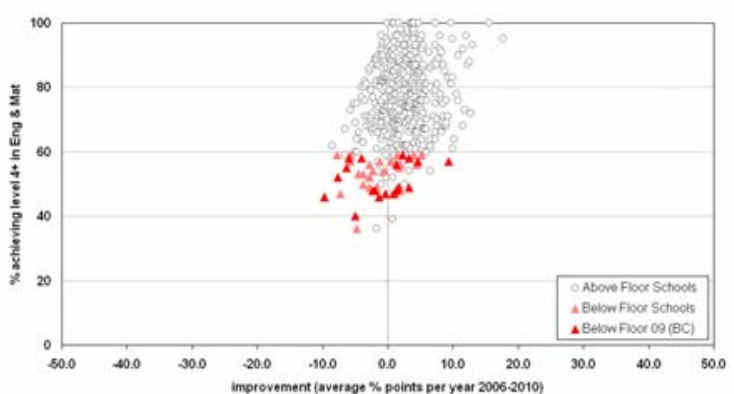

North West KS2 Schools

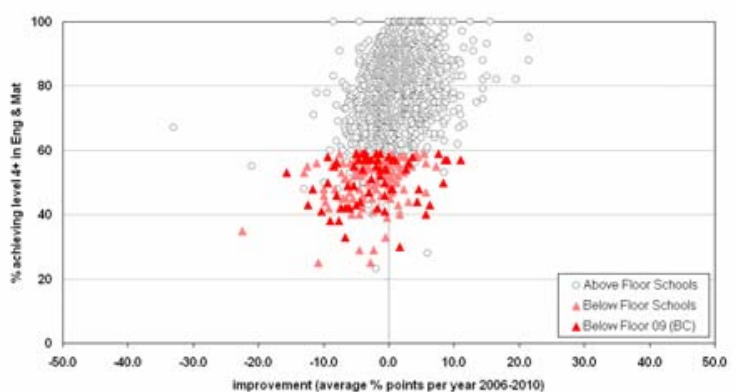


Outer London KS2 Schools

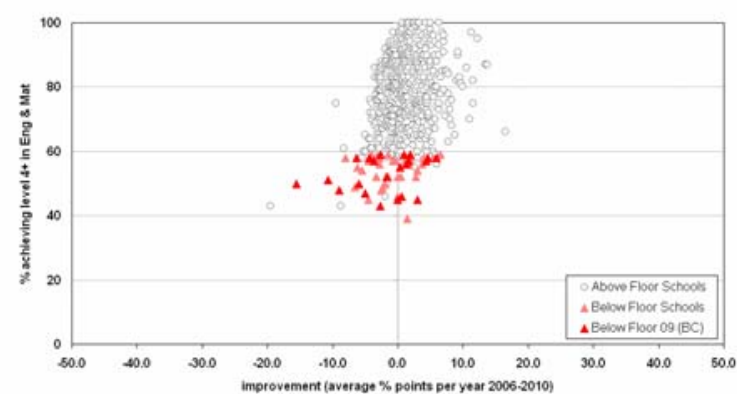

South West KS2 Schools

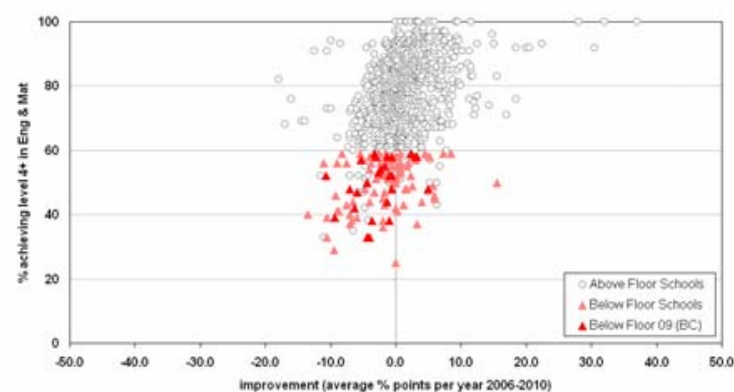

Yorkshire and the Humber KS2 Schools

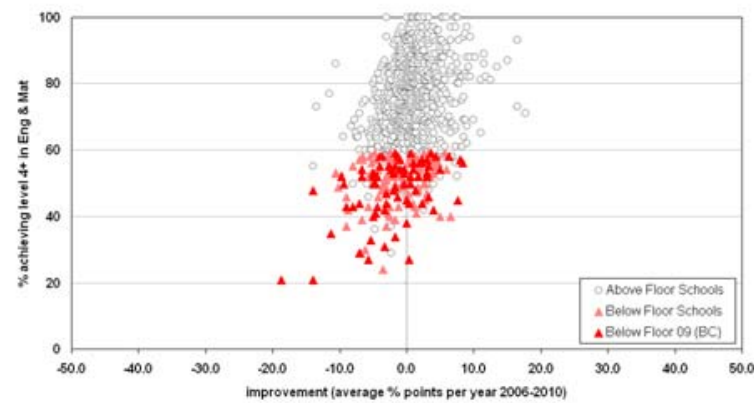

South East KS2 Schools

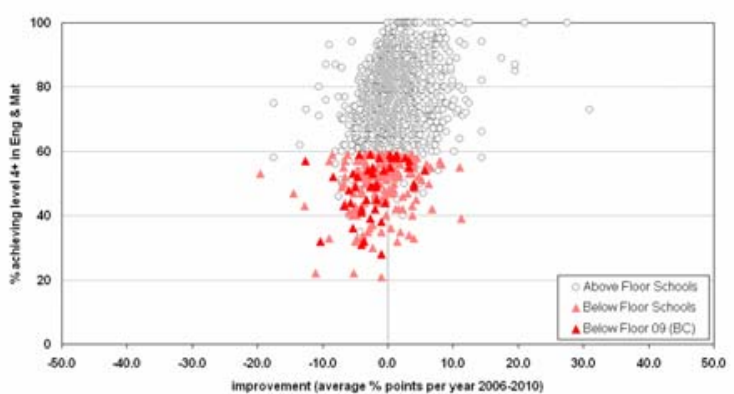

West Midlands KS2 Schools

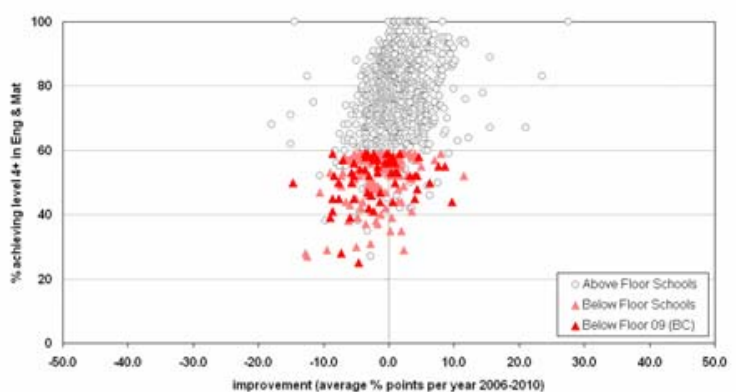




\subsection{KS4 Below Floor School Level Attainment Trajectories}

This section turns to KS4 attainment at school level, comparing latest performance with the average change in performance over five years to reveal changes over time, or the trajectories followed by below floor schools and their above floor counterparts.

\section{Key Findings}

- The majority of KS4 schools which have been open for at least 4 years, both below and above floor standards, were split evenly between having had no statistically significant year-on-year changes in attainment between 2006 and 2010 ( $p<0.05$ ), and having had statistically significant year-on-year improvements. However, among below floor schools, a larger minority had volatile results (both improvements and declines in attainment that were statistically significant) than was the case for above floor schools.

- In all regions, at least half of schools below the KS4 floor standards have seen positive 5 year average changes (improvements) in attainment between 2006 and 2010. All below floor schools in Inner and Outer London have improved KS4 attainment on average; as do the vast majority of above floor schools in each region.

Chart 6.4a categorises schools below and above the floor standards into attainment trajectories based on the direction, consistency, and statistical significance of yearon-year changes to each school's percentage achieving level 2 including GCSE English and maths.

\section{Chart 6.4a}

\section{KS4 School Trajectories for \% Achieving Level 2 inc Eng \& Mat \\ Based on Statistical Significance of Year-on-Year Changes for 2006-2010 $(p<0.05)$}

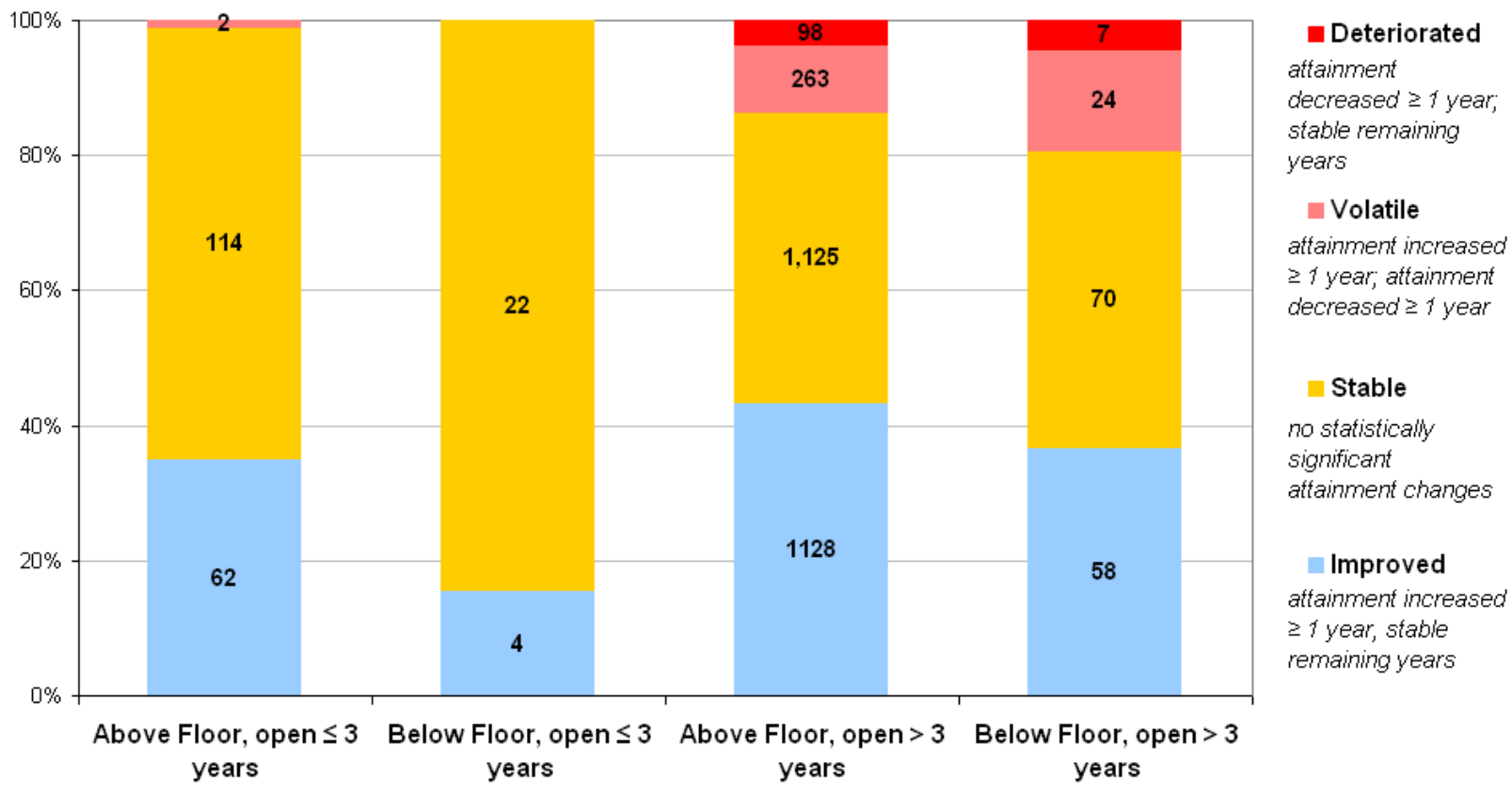

The scatter points in charts $6.4 b$ and $6.4 c$ show the spread of schools within each 
geographic region, according to their percentage of children achieving level 2 including GCSE English and maths (vertical axis), and the average number of percentage points by which this measure has improved or deteriorated over five years (horizontal axis). Hence, schools in the top right of the chart have higher attainment that has improved on average; those in the bottom left have lower attainment that has deteriorated on average. Schools in the top left have higher attainment, but this has fallen on average; schools in the bottom right have lower attainment, but this has improved on average in the last 5 years.

Schools with fewer than two pairs of consecutive years with valid data over 20062010 are excluded, as are schools which have closed. Average improvement over five years is used to smooth out the inherent volatility in school performance measures year-on-year, which are affected by the characteristics and prior attainment of the successive cohorts reaching the end of the Key Stage, as well as by school effectiveness.

\section{Chart 6.4b}

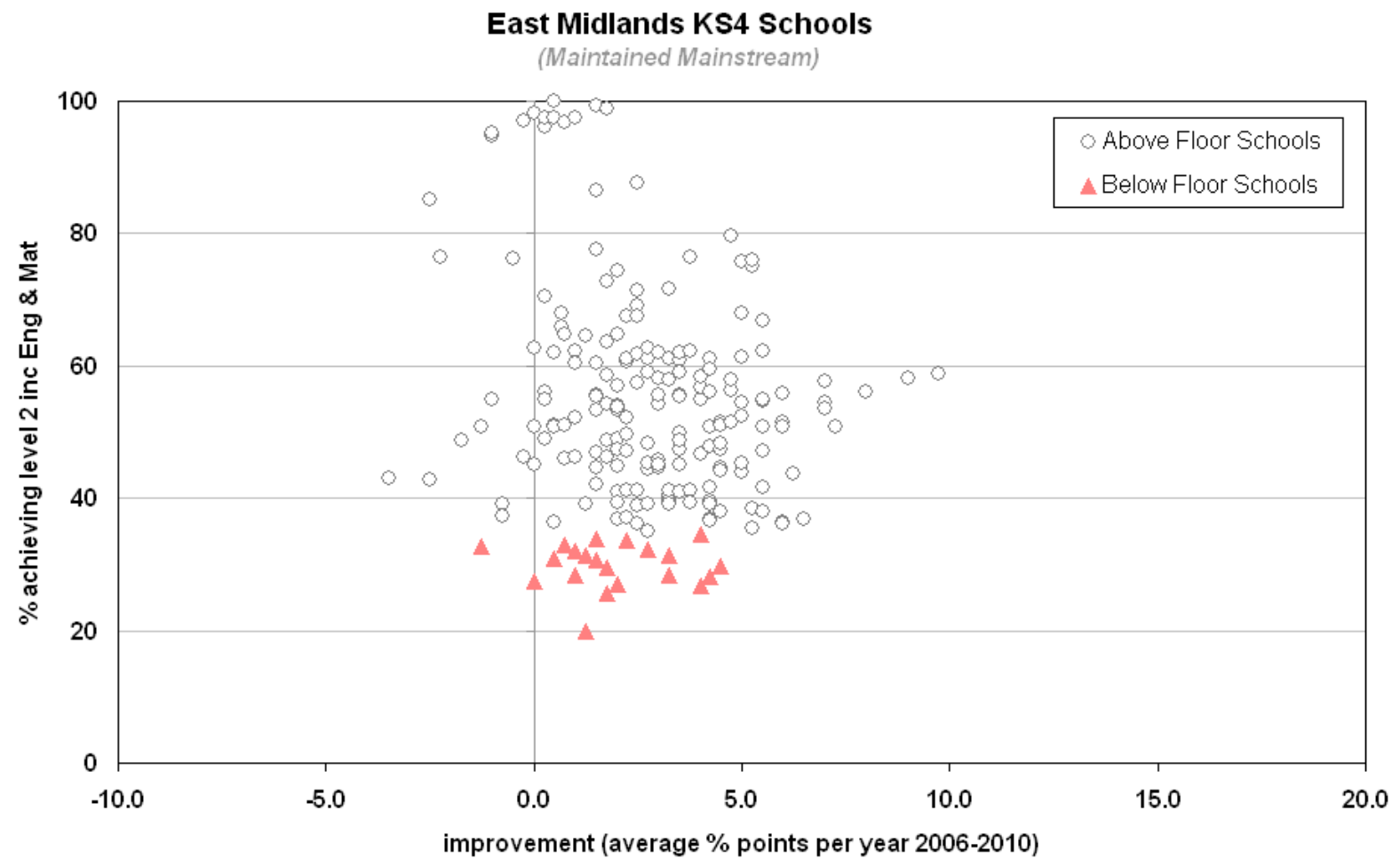

\section{Chart 6.4c}

East of England KS4 Schools

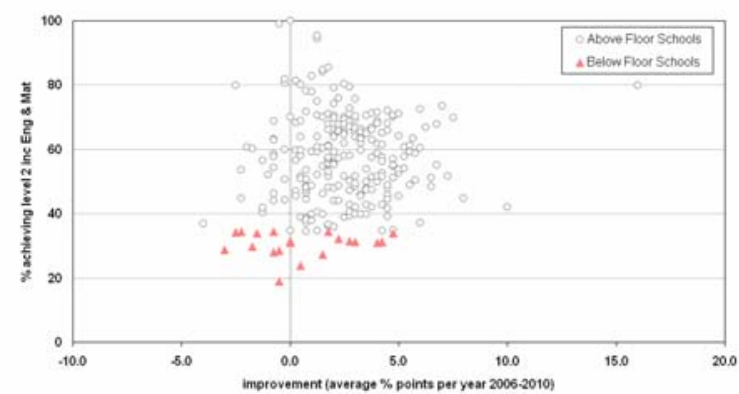

Inner London KS4 Schools

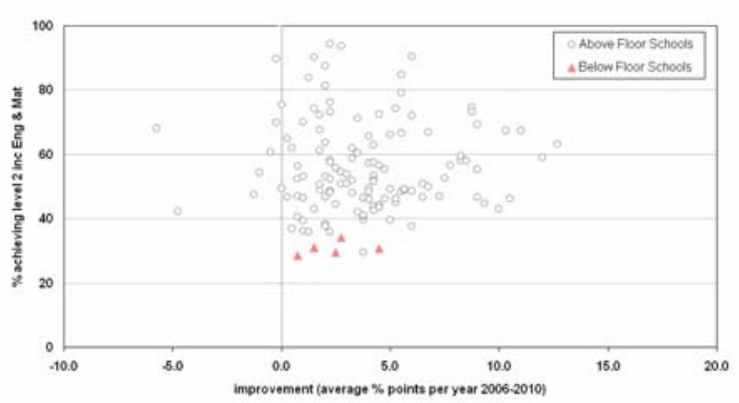



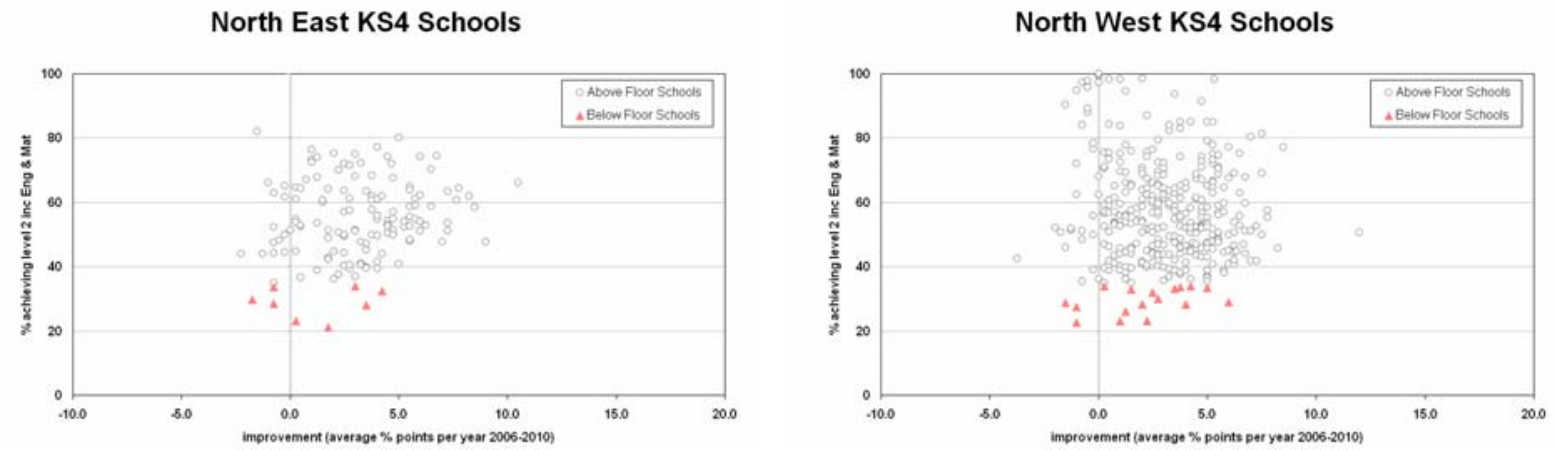

Outer London KS4 Schools
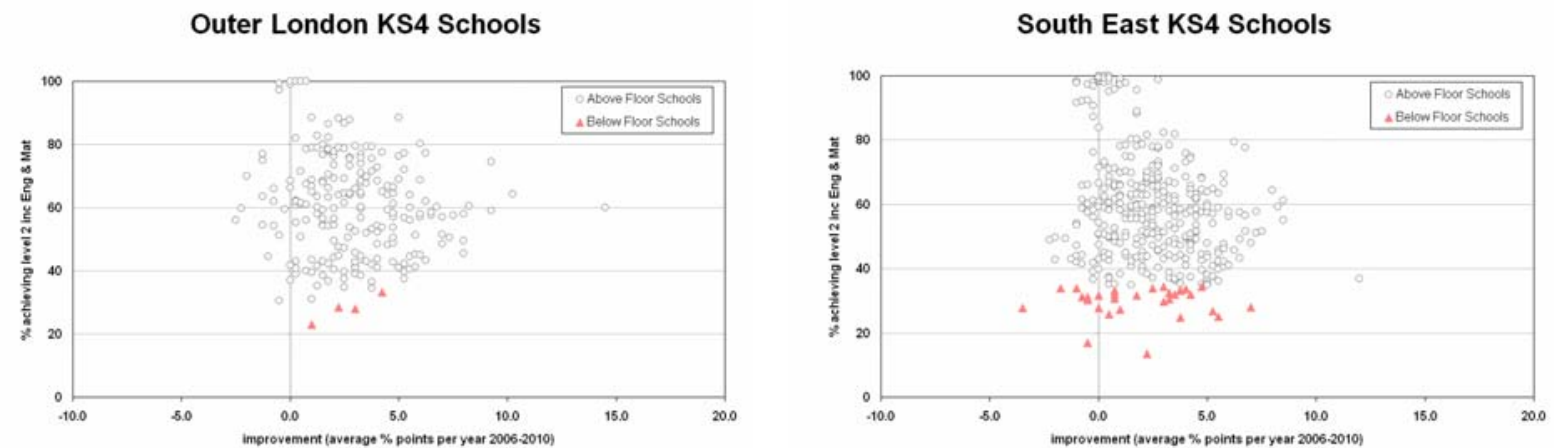

South West KS4 Schools

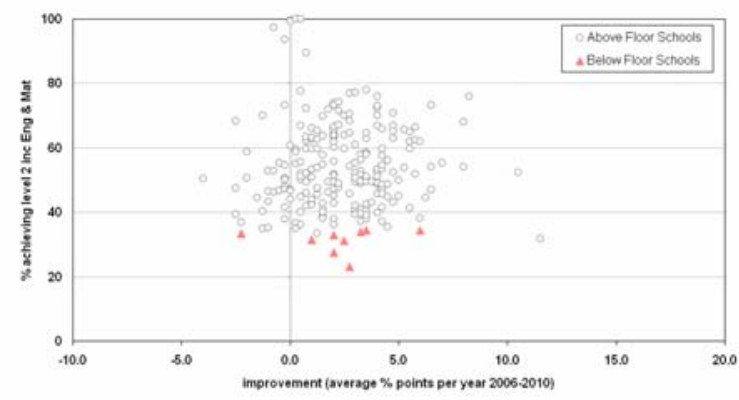

West Midlands KS4 Schools

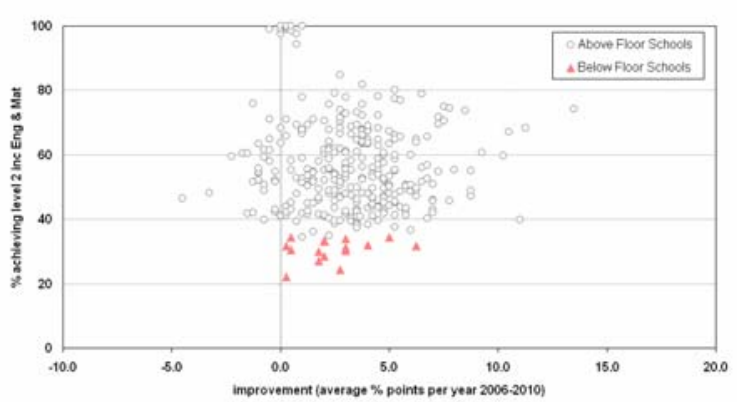

Yorkshire and the Humber KS4 Schools

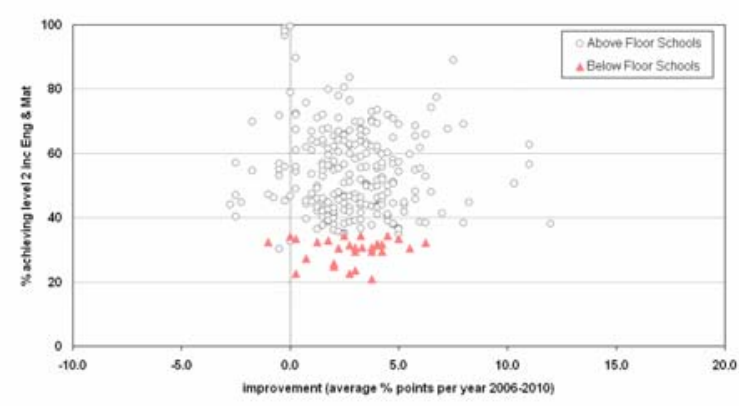




\section{Annex A: Additional Population Profile Information}

\section{Regional Pupil Characteristics Profile in Below KS2 Floor Schools}

All Pupils in Below KS2 Floor Schools by Region

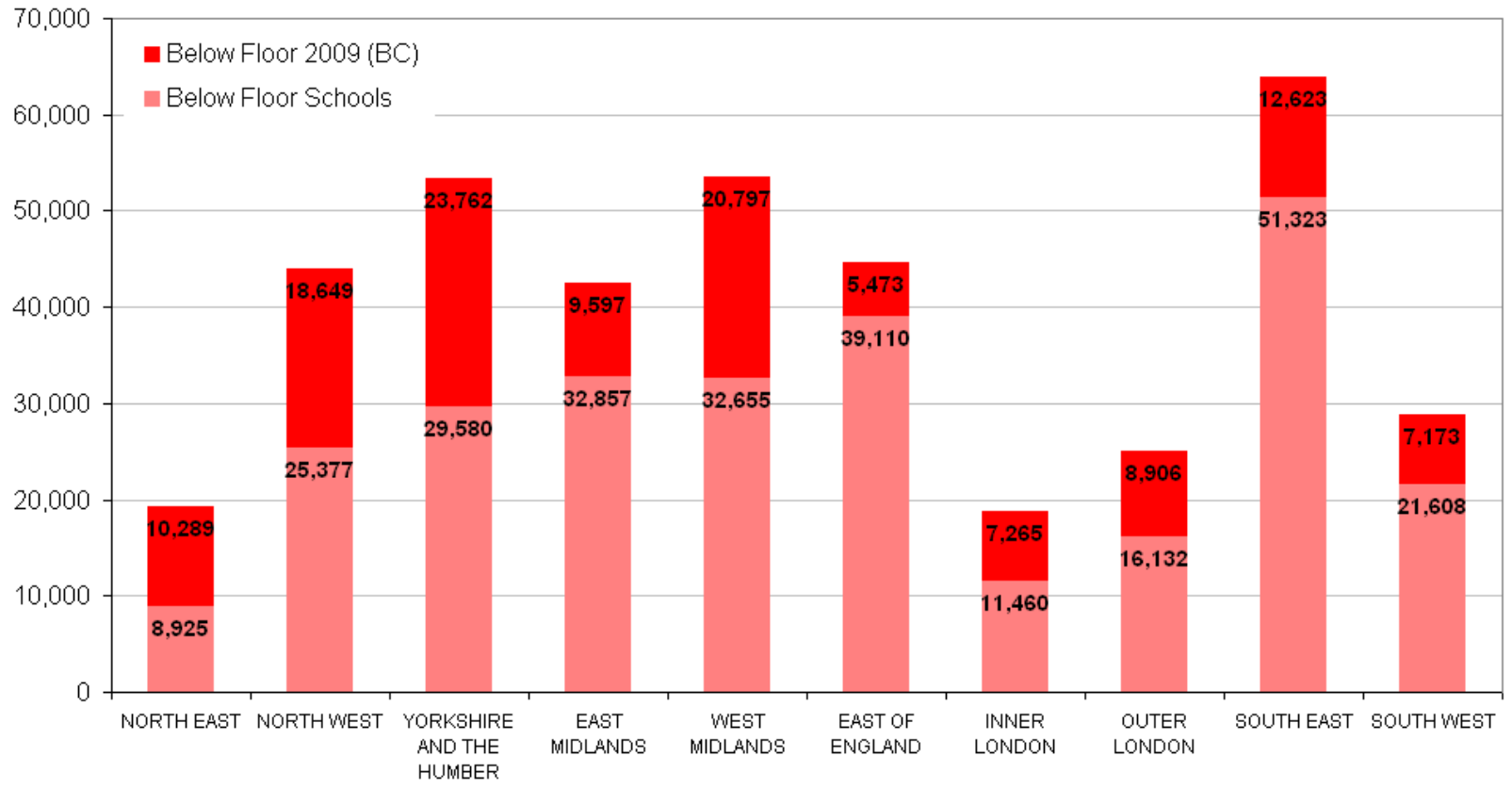

FSM Pupils in Below KS2 Floor Schools by Region

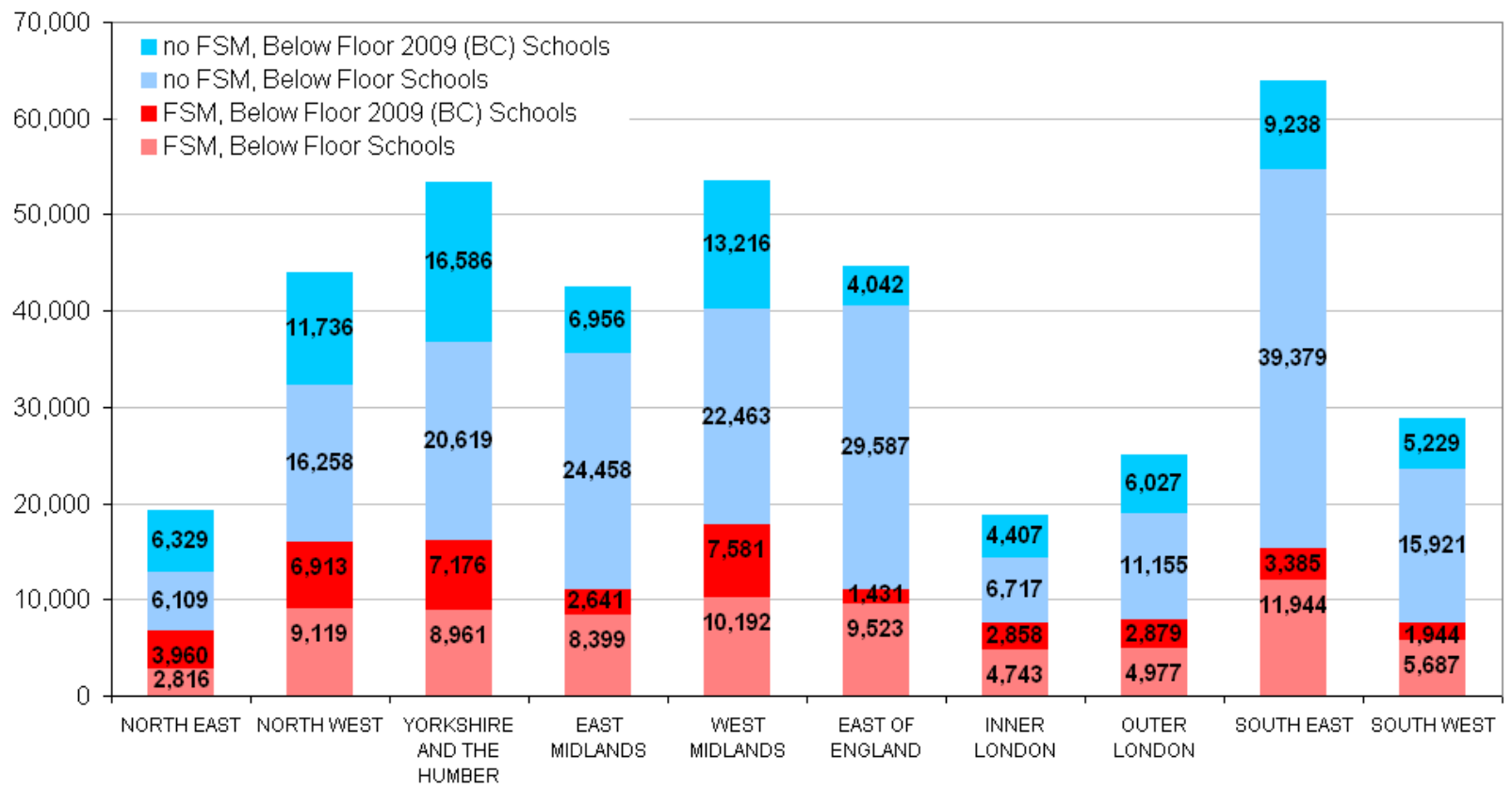




\section{Boys and Girls in Below KS2 Floor Schools by Region}

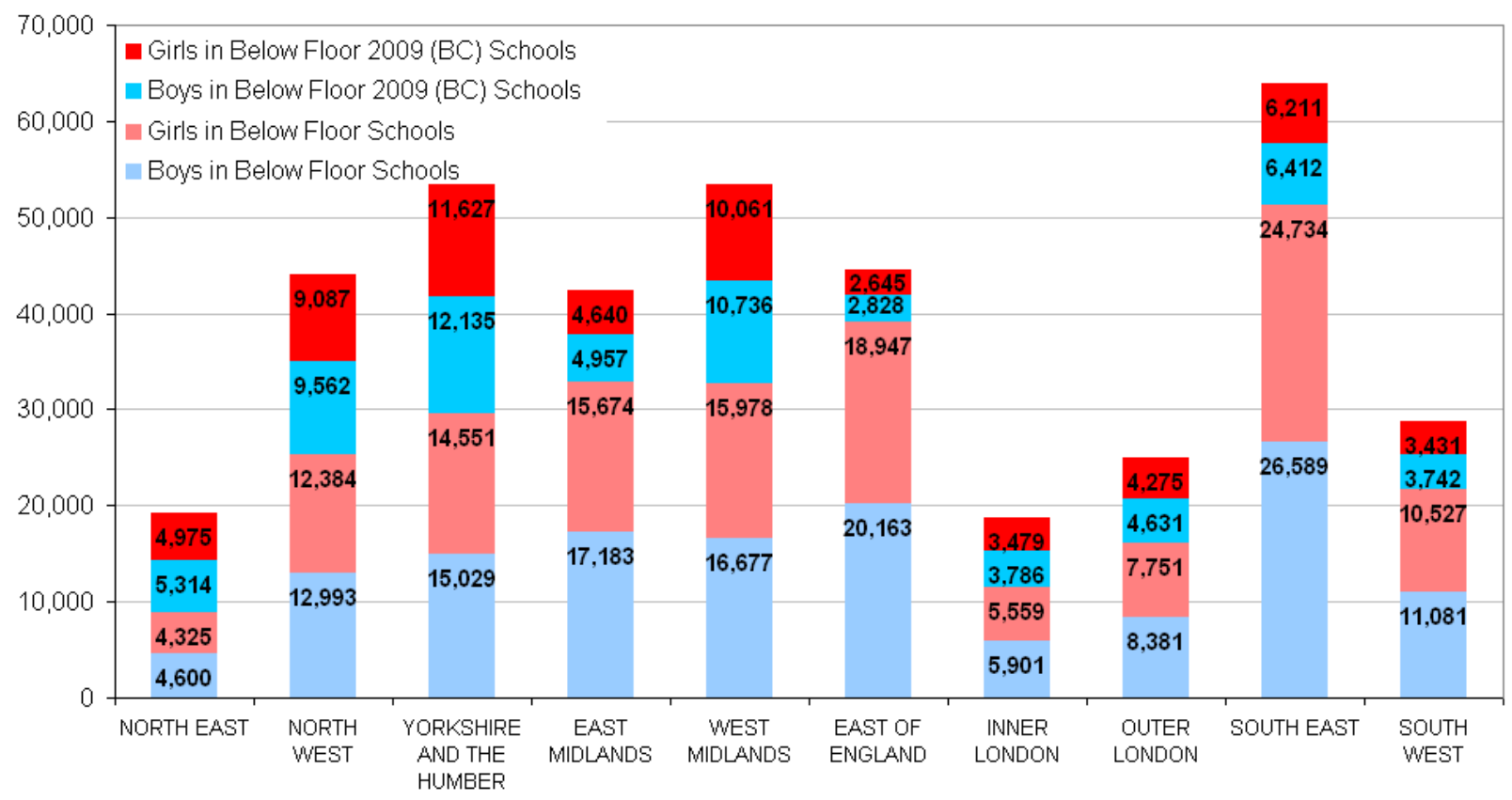

Underperforming Ethnic Minority Groups in Below KS2 Floor Schools

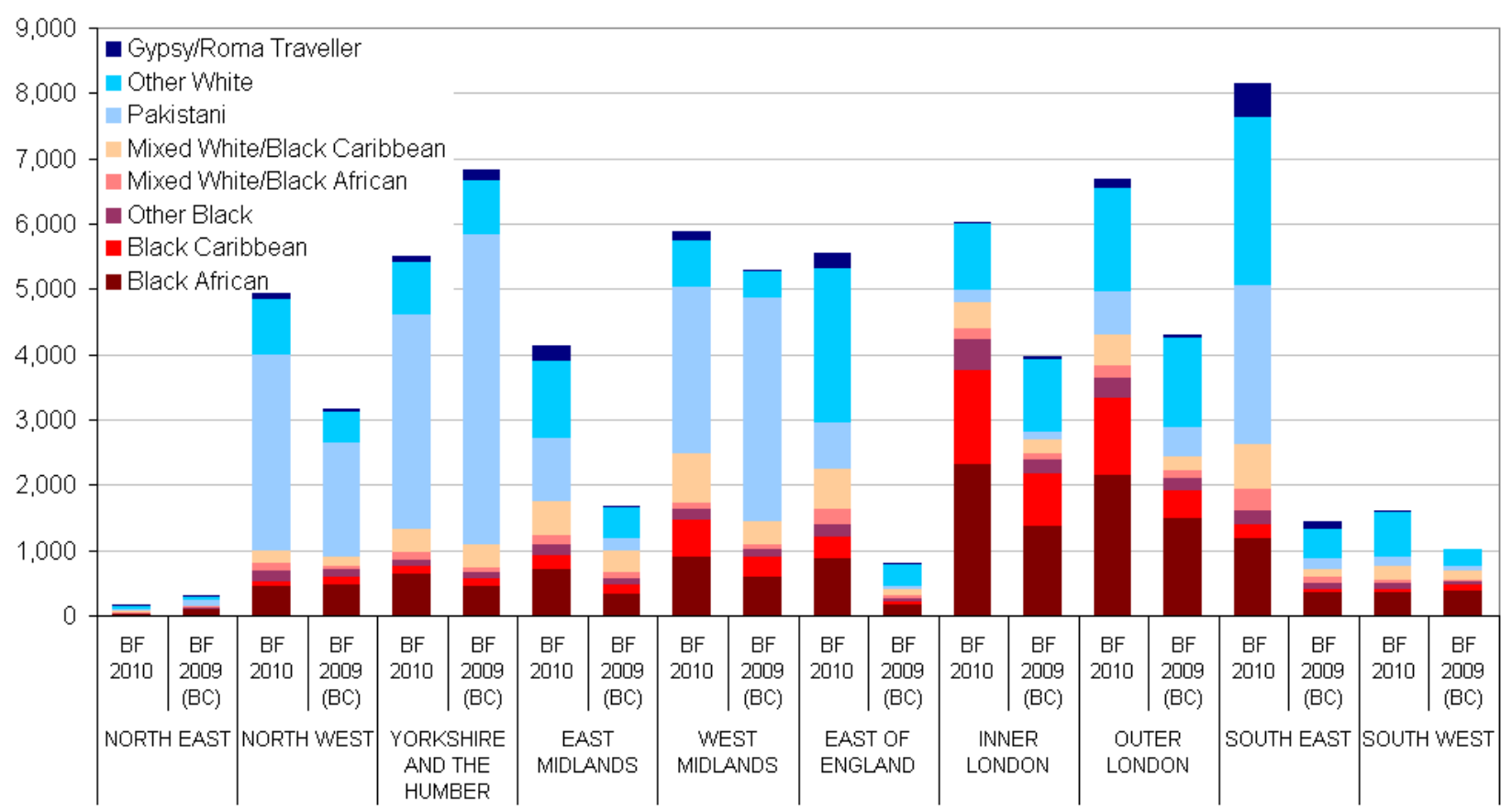




\section{Pupils with English as an Additional language in Below KS2 Floor Schools}

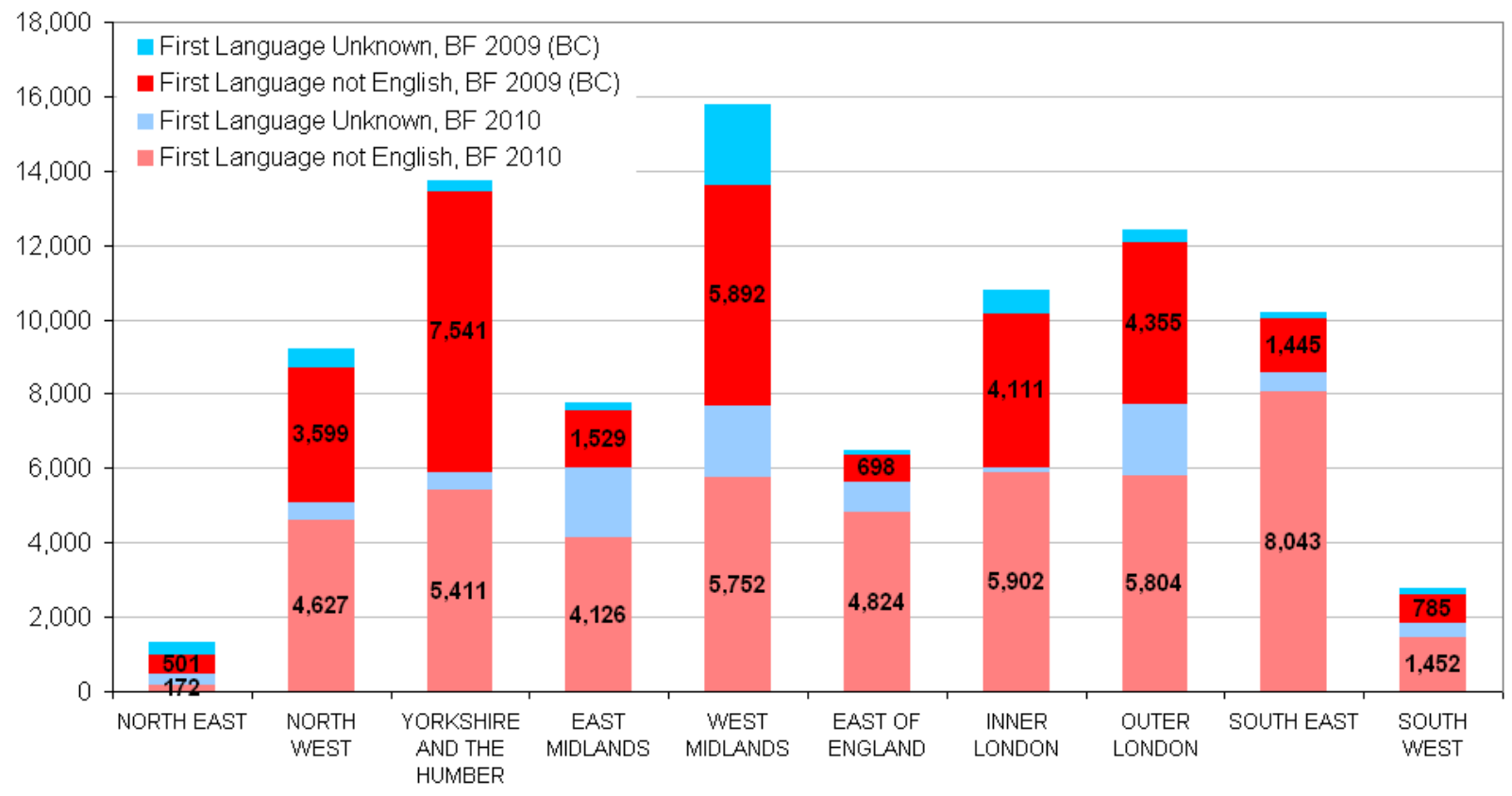

Pupils with Special Educational Needs in Below KS2 Floor Schools

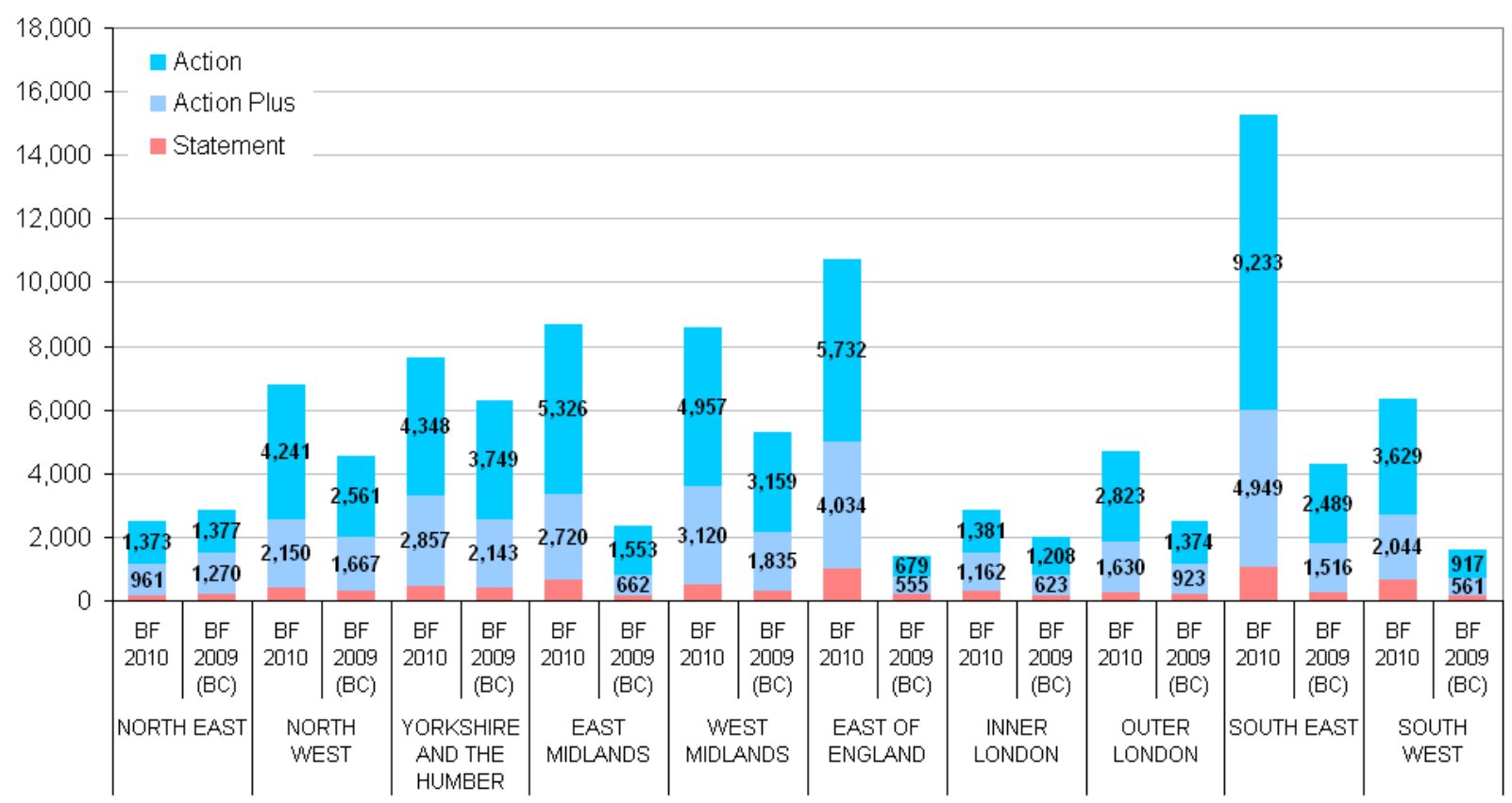


Below Floor KS2 Schools By IDACI Area Deprivation Band

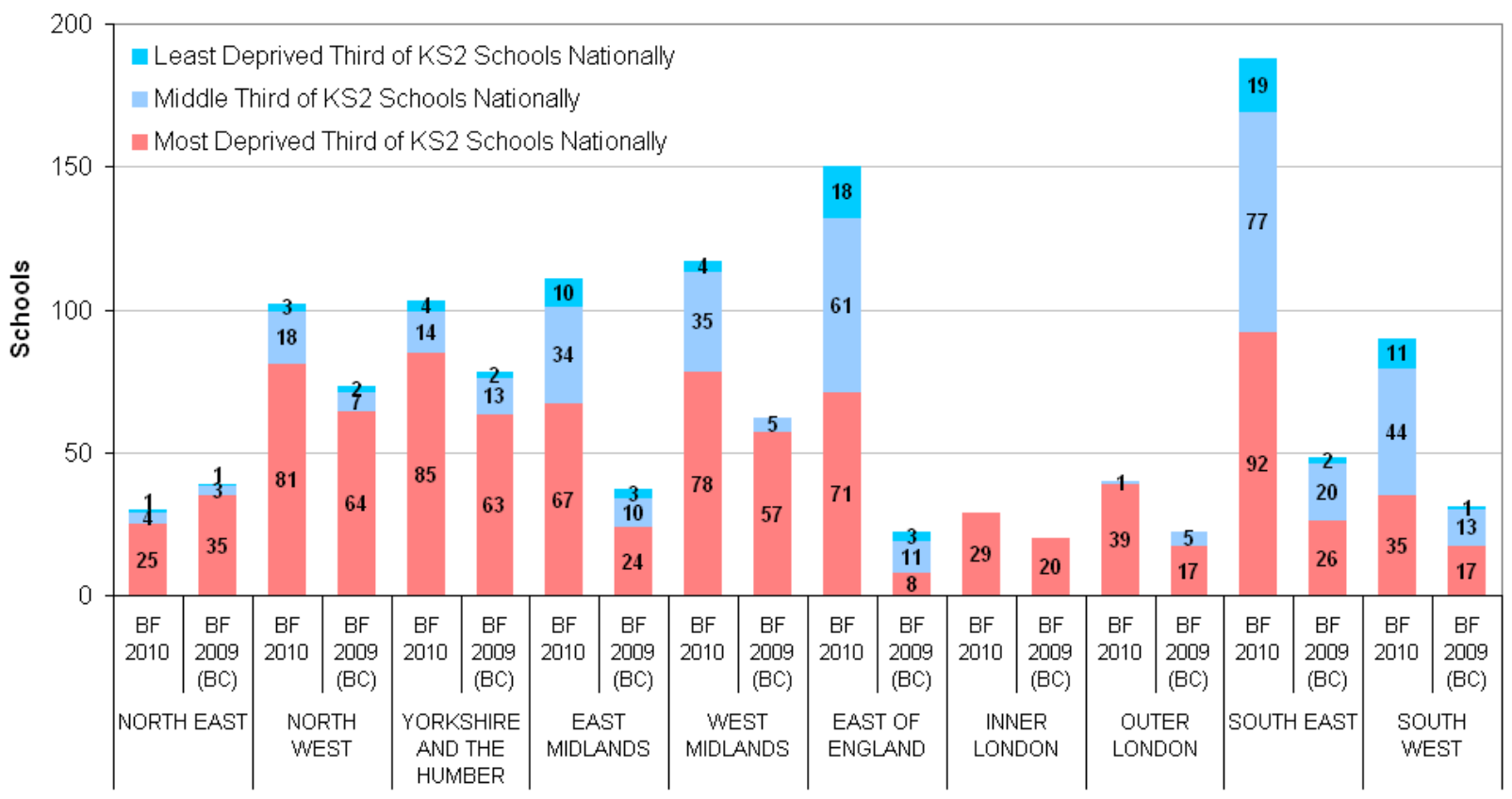

\section{Regional Pupil Characteristics Profile in Below KS4 Floor Schools}

All Pupils in Below KS4 Floor Schools by Region

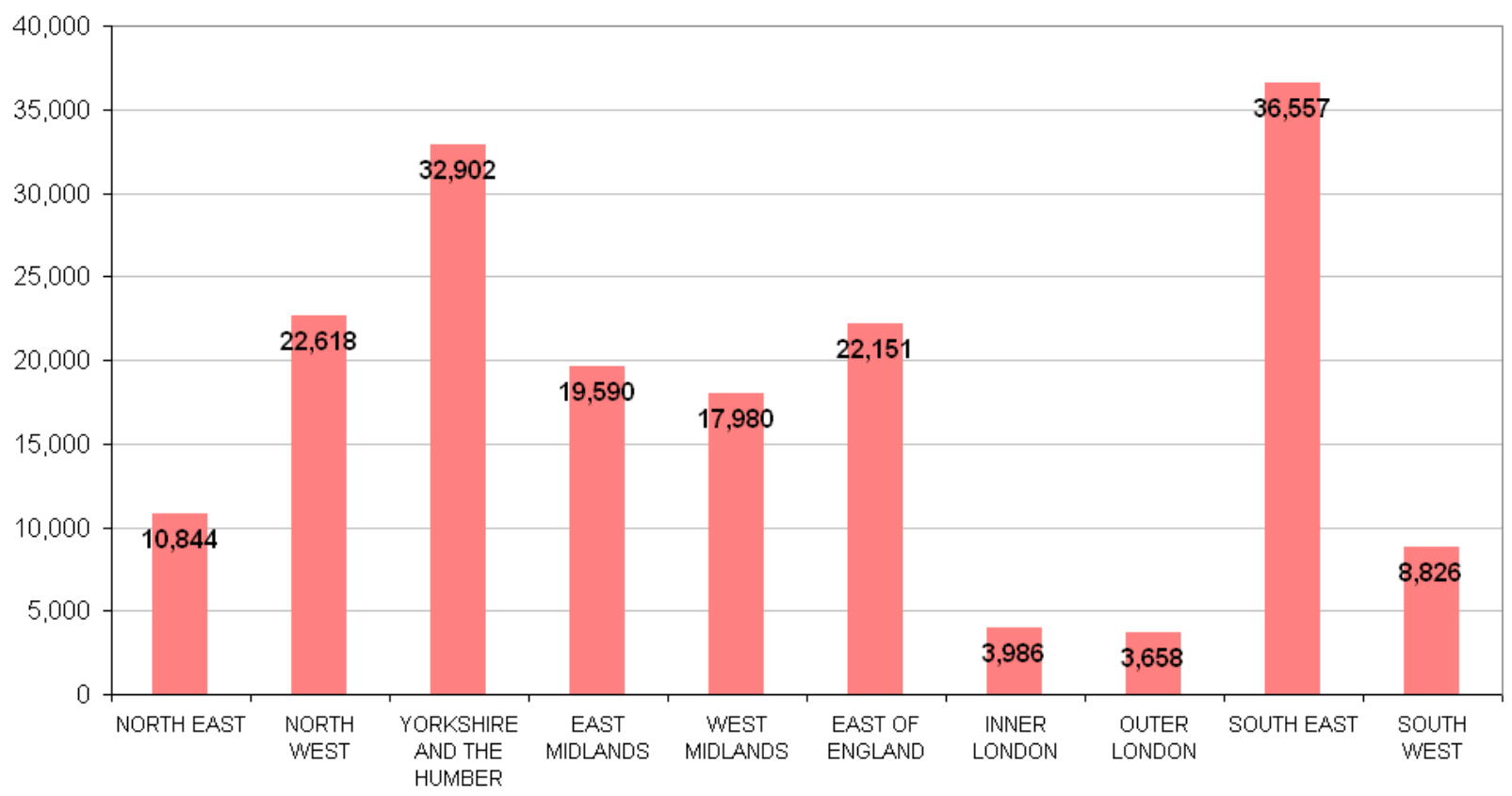


FSM Pupils in Below KS4 Floor Schools by Region

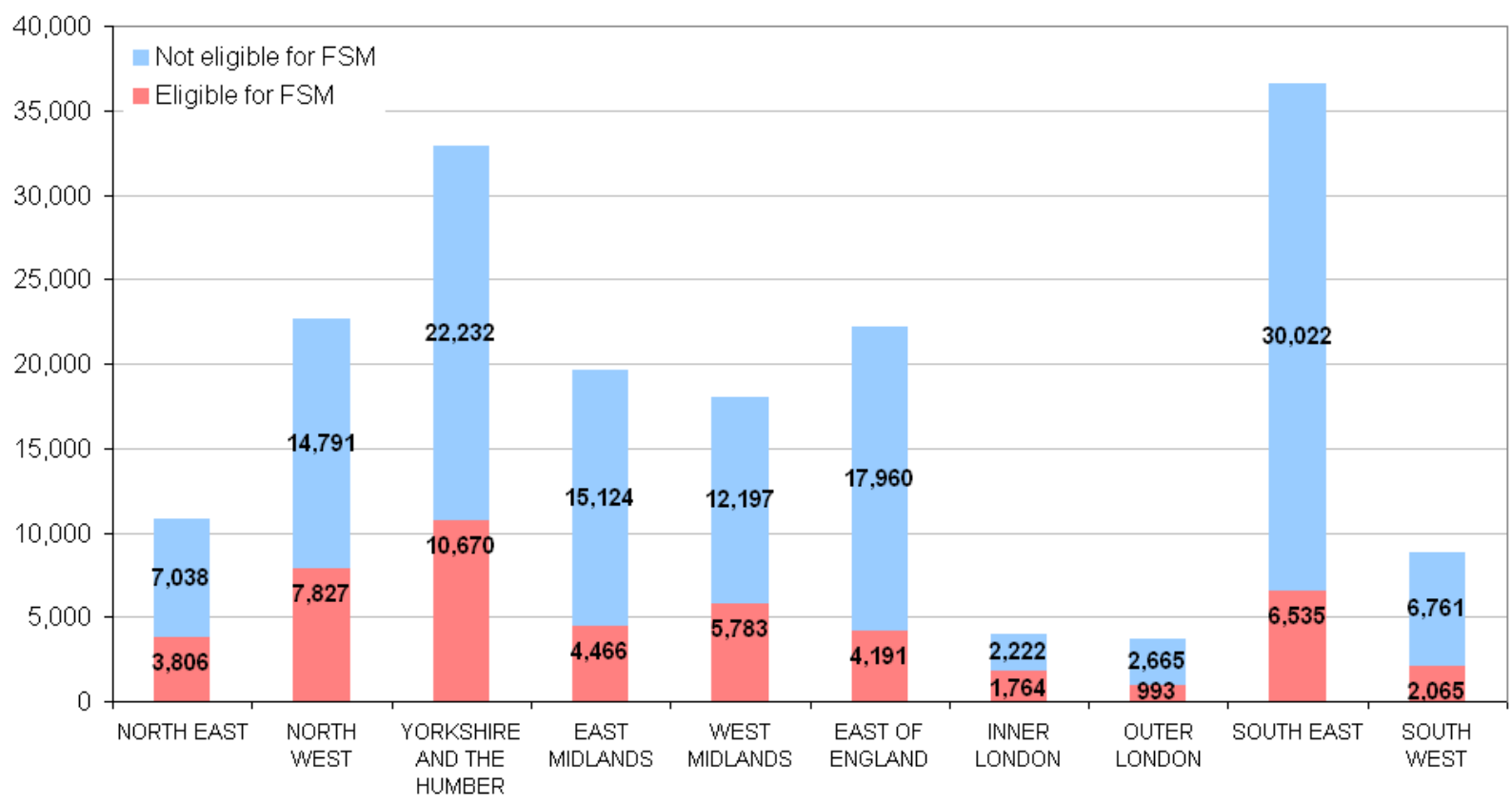

Boys and Girls in Below KS4 Floor Schools by Region

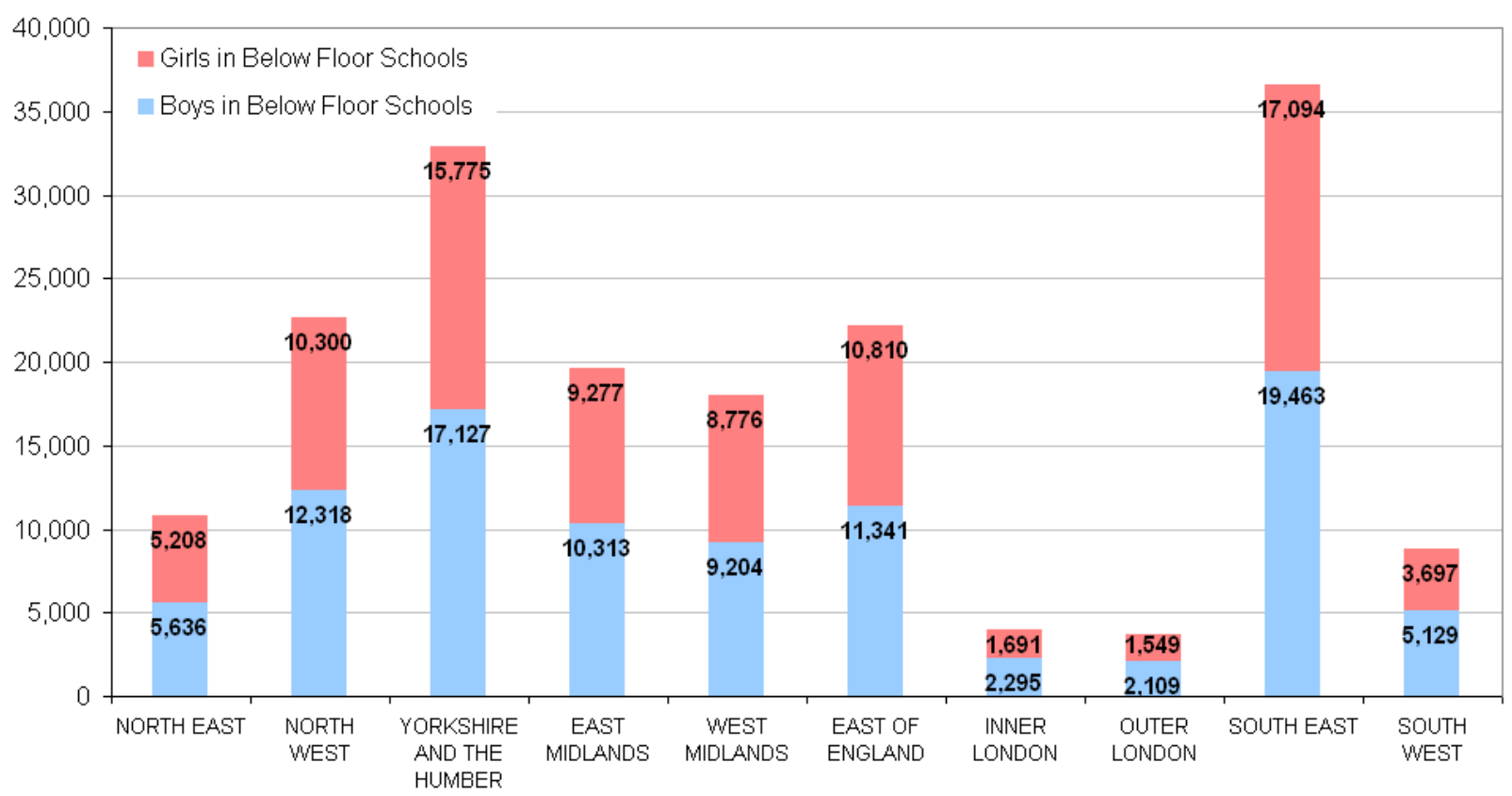


Underperforming Ethnic Minority Groups in Below KS4 Floor Schools

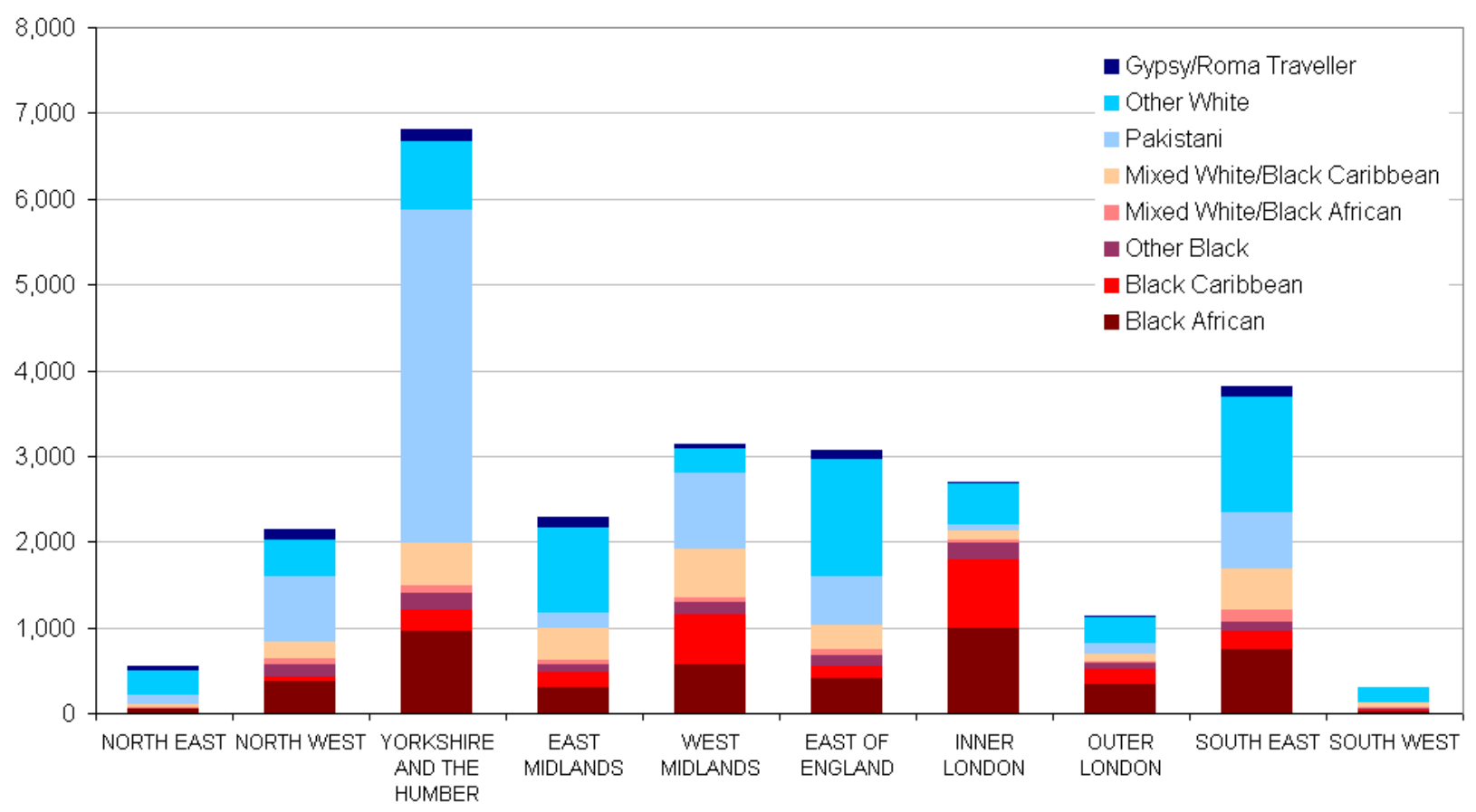

Pupils with English as an Additional language in Below KS4 Floor Schools

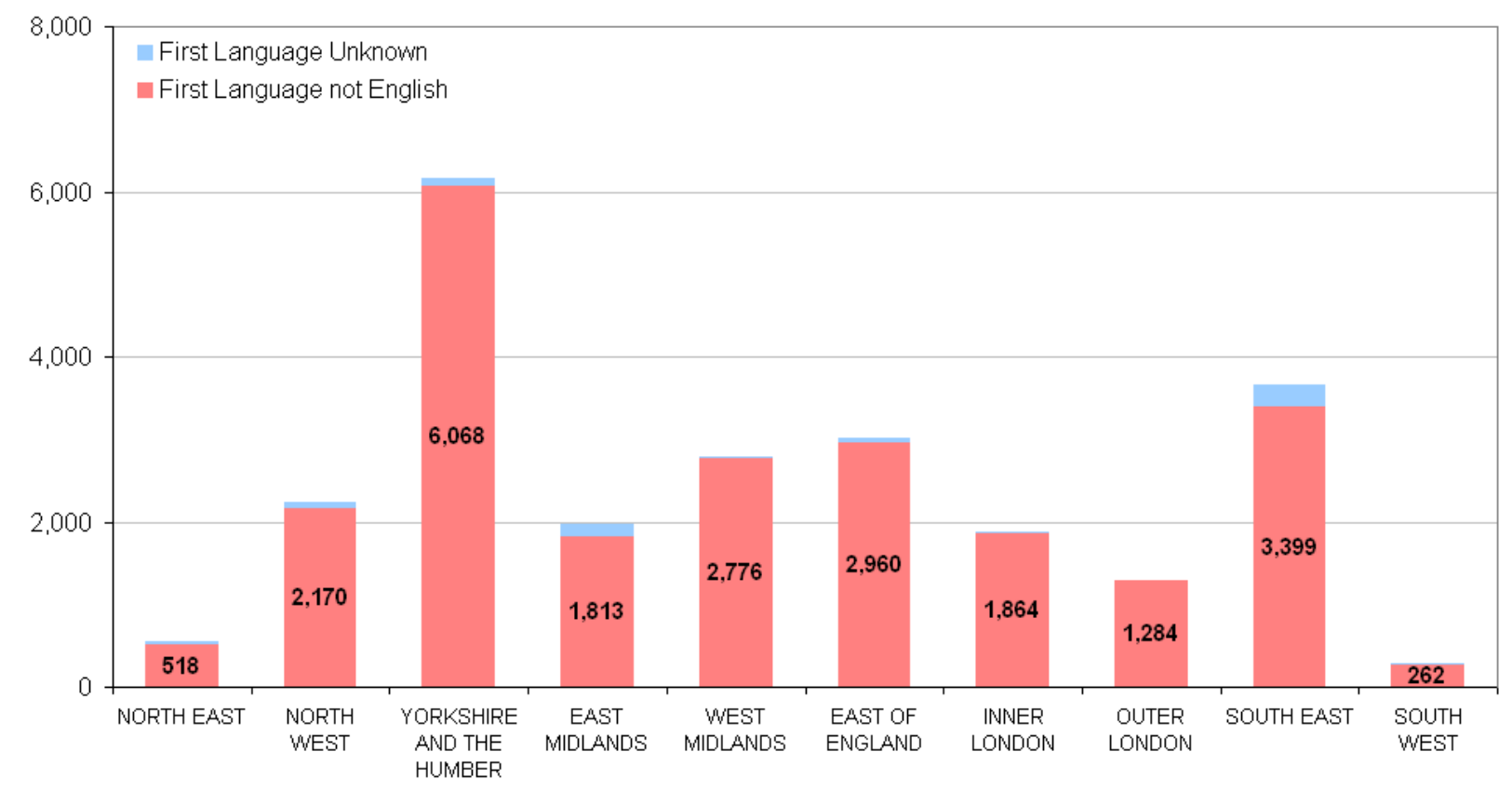




\section{Pupils with Special Educational Needs in Below KS4 Floor Schools}

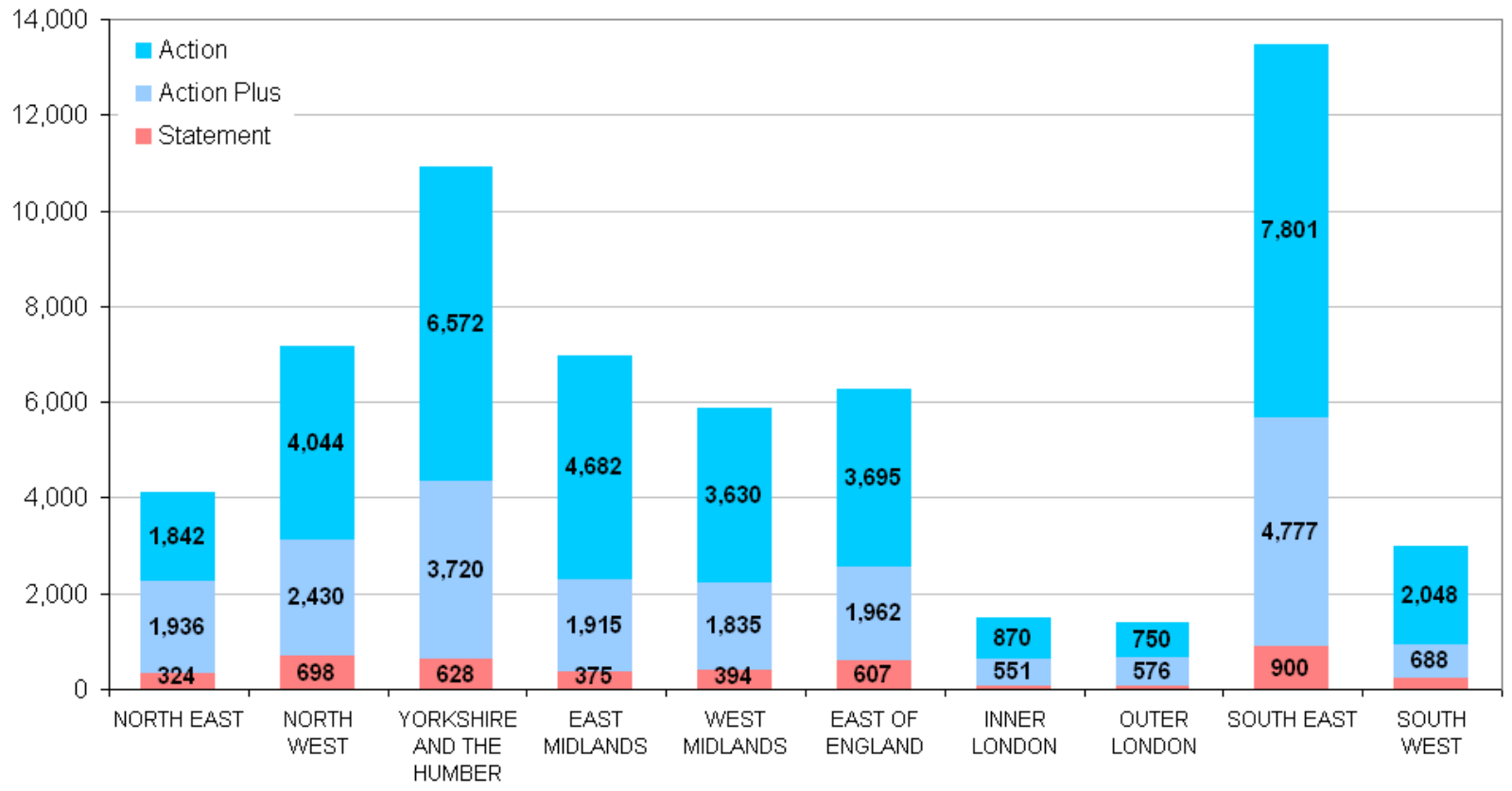

Below Floor KS4 Schools By IDACI Area Deprivation Band

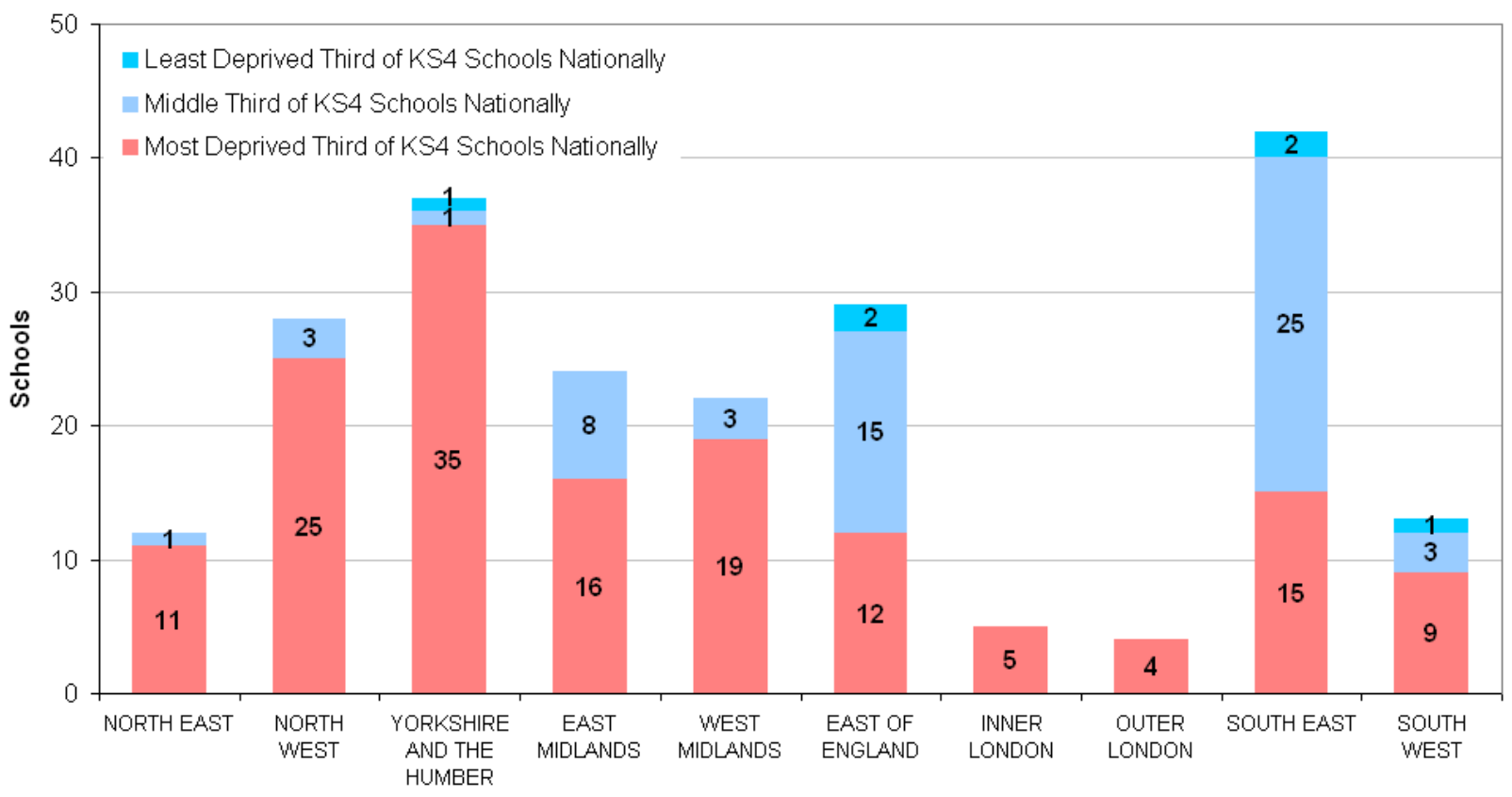


Detailed Population Profile: Key Stage 2 Schools Below the Floor Standards

\begin{tabular}{|c|c|c|c|c|c|c|c|c|c|c|c|c|c|c|c|c|c|c|c|c|c|c|c|}
\hline \multirow[b]{3}{*}{ Ethnicity } & \multirow[b]{3}{*}{ First Language } & \multirow[b]{3}{*}{ SEN Status } & \multirow[b]{3}{*}{ FSM Status } & \multicolumn{20}{|c|}{ Below Floor 2010} \\
\hline & & & & \multicolumn{2}{|c|}{$\begin{array}{c}\text { EAST } \\
\text { MIDLANDS }\end{array}$} & \multicolumn{2}{|c|}{$\begin{array}{l}\text { EAST OF } \\
\text { ENGLAND }\end{array}$} & \multicolumn{2}{|c|}{$\begin{array}{l}\text { INNNER } \\
\text { LONDON }\end{array}$} & \multicolumn{2}{|c|}{ NORTH EAST } & \multicolumn{2}{|c|}{ NORTH WEST } & \multicolumn{2}{|c|}{$\begin{array}{l}\text { OUTER } \\
\text { LONDON }\end{array}$} & \multicolumn{2}{|c|}{ SOUTH EAST } & SOUT & WEST & & ST & $\begin{array}{l}\text { YORK } \\
\text { AND } \\
\text { HUI }\end{array}$ & $\begin{array}{l}\text { SHIRE } \\
\text { THE } \\
\text { BER }\end{array}$ \\
\hline & & & & Girls & Boys & Girls & Boys & Girls & Boys & Girls & Boys & Girls & Boys & Girls & Boys & Girls & Boys & Girls & Boys & Girls & Boys & Girls & Boys \\
\hline \begin{tabular}{|l} 
Bangladeshi \\
\end{tabular} & English or Unclassified & No SEN & Not FSM & - & - & 15 & $x$ & $x$ & $x$ & $\mathrm{x}$ & $x$ & $x$ & $x$ & $\mathrm{x}$ & $x$ & $x$ & 15 & $\mathrm{x}$ & $x$ & $x$ & $x$ & $x$ & $x$ \\
\hline & & & FSM & $x$ & $x$ & $x$ & $x$ & $x$ & $x$ & - & - & $x$ & $x$ & $x$ & $x$ & $x$ & $x$ & - & - & $x$ & $x$ & - & $x$ \\
\hline & & SEN at Action / Plus & Not FSM & $x$ & - & - & $x$ & - & $x$ & - & $\mathrm{x}$ & $x$ & - & $x$ & $x$ & $x$ & $x$ & - & $x$ & - & - & $x$ & $\mathrm{x}$ \\
\hline & & & FSM & - & $x$ & - & $x$ & - & $x$ & - & - & - & - & - & - & - & - & - & - & - & $x$ & - & $\mathrm{x}$ \\
\hline & & Statemented SEN & Not FSM & $x$ & - & - & $x$ & $x$ & - & - & - & - & $x$ & - & $x$ & - & - & - & $x$ & - & - & - & - \\
\hline & & & FSM & & $x$ & - & - & 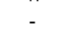 & - & - & - & - & - & - & - & - & - & - & $\hat{x}$ & - & - & - & $x$ \\
\hline & Other than English & No SEN & Not FSM & 56 & 48 & 162 & 151 & 234 & 207 & $x$ & $x$ & 77 & 75 & 53 & 67 & 163 & 138 & 52 & 56 & 90 & 55 & 79 & 82 \\
\hline & & & FSM & 35 & 18 & 64 & 37 & 146 & 150 & $x$ & - & 25 & 15 & 16 & 18 & 35 & 29 & $x$ & $x$ & 55 & 42 & 26 & 21 \\
\hline & & SEN at Action / Plus & Not FSM & 15 & 19 & 29 & 47 & 31 & 64 & - & $x$ & 12 & 22 & 18 & 21 & 30 & 44 & $x$ & $x$ & 16 & 25 & 15 & 16 \\
\hline & & & FSM & $x$ & $x$ & 12 & 19 & 45 & 56 & - & - & 10 & 11 & 13 & $x$ & $x$ & 12 & - & $x$ & 10 & 14 & $x$ & $x$ \\
\hline & & Statemented SEN & $\begin{array}{l}\text { Not FSM } \\
\text { FSM }\end{array}$ & $x$ & $x$ & $x$ & $\mathrm{x}$ & $\begin{array}{l}x \\
x\end{array}$ & $\begin{array}{l}x \\
x\end{array}$ & $x$ & - & $\mathrm{x}$ & $\bar{x}$ & $-\bar{x}$ & - & $x$ & $x$ & - & $\mathrm{x}$ & - & - & $x$ & $x$ \\
\hline Indian & English or Unclassified & No SEN & Not FSM & 32 & 45 & 33 & 23 & $\frac{n}{x}$ & $\frac{x}{10}$ & $x$ & $x$ & 10 & $\frac{x}{17}$ & $\frac{x}{25}$ & 37 & 55 & 50 & $x$ & 10 & 88 & $\frac{x}{91}$ & $\frac{x}{19}$ & 15 \\
\hline & & & FSM & $\mathrm{x}$ & $x$ & $\mathrm{x}$ & $x$ & $\mathrm{x}$ & $x$ & - & $\mathrm{x}$ & $\mathrm{x}$ & $x$ & $x$ & $x$ & $\mathrm{x}$ & $\mathrm{x}$ & - & $x$ & 15 & 10 & $\mathrm{x}$ & $\mathrm{x}$ \\
\hline & & SEN at Action / Plus & Not FSM & $x$ & $x$ & $x$ & $\mathrm{x}$ & - & $\mathrm{x}$ & - & $x$ & - & $x$ & $x$ & $x$ & $x$ & $x$ & - & $\mathrm{x}$ & 11 & 13 & - & $\mathrm{x}$ \\
\hline & & & FSM & $\hat{x}$ & $\hat{x}$ & $\hat{x}$ & $\hat{x}$ & - & $\mathrm{x}$ & - & . & $x$ & . & $x$ & $\hat{x}$ & $\hat{x}$ & $\hat{x}$ & - & - & $x$ & $\mathrm{x}$ & $x$ & $x$ \\
\hline & & Statemented SEN & Not FSM & - & $x$ & $x$ & - & - & $x$ & - & - & - & - & - & $x$ & - & $x$ & - & - & - & - & $x$ & $x$ \\
\hline & & & FSM & - & & & - & - & . & - & - & - & - & - & & - & & - & - & - & - & & \\
\hline & Other than English & No SEN & Not FSM & 217 & 261 & 175 & 147 & 37 & 41 & $x$ & $x$ & 75 & 81 & 199 & 188 & 244 & 308 & 51 & 41 & 367 & 381 & 49 & 52 \\
\hline & & & FSM & 35 & 28 & 14 & 16 & 17 & 27 & $x$ & $x$ & $x$ & $x$ & 23 & 19 & 28 & 24 & - & $\mathrm{x}$ & 44 & 53 & $x$ & $x$ \\
\hline & & SEN at Action / Plus & Not FSM & 34 & 55 & $x$ & 23 & $x$ & $x$ & $\hat{x}$ & $\hat{x}$ & $\mathrm{x}$ & 17 & 33 & 44 & 33 & 60 & $x$ & $\mathrm{x}$ & 43 & 87 & $\mathrm{x}$ & 11 \\
\hline & & & FSM & 13 & 15 & $\mathrm{x}$ & $x$ & $\mathrm{x}$ & 11 & - & $\mathrm{x}$ & $x$ & $\mathrm{x}$ & $\mathrm{x}$ & 11 & $\mathrm{x}$ & $x$ & - & $\mathrm{x}$ & 14 & 17 & $x$ & $x$ \\
\hline & & Statemented SEN & Not FSM & $\mathrm{x}$ & $\mathrm{x}$ & $\hat{x}$ & - & - & - & - & - & - & - & $\mathrm{x}$ & $x$ & $\hat{x}$ & $x$ & - & $x$ & $\mathrm{x}$ & $x$ & $x$ & $x$ \\
\hline & & 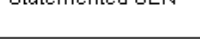 & FSM & $n$ & $\hat{x}$ & $n$ & - & - & - & - & - & - & - & . & $\hat{x}$ & $n$ & $n$ & - & 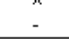 & . & $\hat{x}$ & $n$ & $n$ \\
\hline Pakistani & English or Unclassified & No SEN & Not FSM & 17 & 25 & 21 & 18 & $x$ & $x$ & $x$ & $x$ & 90 & 99 & 24 & 26 & 60 & 55 & $x$ & $x$ & 74 & 55 & 105 & 79 \\
\hline & & & FSM & 11 & $x$ & $x$ & $x$ & - & $x$ & - & - & 25 & 26 & $x$ & $x$ & $x$ & $x$ & - & - & 21 & 23 & 22 & 17 \\
\hline & & SEN at Action / Plus & Not FSM & $x$ & $x$ & $x$ & $x$ & - & $x$ & - & $x$ & $x$ & 23 & $x$ & 13 & $x$ & 12 & $x$ & $x$ & $x$ & 16 & 13 & 18 \\
\hline & & & FSM & $\hat{x}$ & $\hat{x}$ & $x$ & $x$ & - & $\hat{x}$ & - & - & $\hat{x}$ & $x$ & $\hat{x}$ & $\mathrm{x}$ & $x$ & $\mathrm{x}$ & . & - & $\hat{x}$ & 11 & $\mathrm{x}$ & $\mathrm{x}$ \\
\hline & & Statemented SEN & Not FSM & $x$ & $x$ & $x$ & $x$ & $x$ & $x$ & - & - & $x$ & $x$ & - & $x$ & $x$ & $x$ & - & - & - & $x$ & $x$ & $x$ \\
\hline & & & FSM & - & - & & & & & - & - & - & $x$ & - & & & & - & - & - & - & - & $x$ \\
\hline & Other than English & No SEN & Not FSM & 219 & 242 & 178 & 169 & 56 & 37 & $x$ & $\mathrm{x}$ & 771 & 723 & 179 & 160 & 796 & 696 & 25 & 40 & 616 & 542 & 943 & 850 \\
\hline & & & FSM & 85 & 85 & 66 & 53 & 19 & 20 & $x$ & - & 228 & 186 & 41 & 30 & 121 & 100 & 11 & 12 & 313 & 225 & 231 & 191 \\
\hline & & SEN at Action / Plus & Not FSM & 57 & 101 & 41 & 71 & $\mathrm{x}$ & $\mathrm{x}$ & $\mathrm{x}$ & - & 225 & 308 & 47 & 61 & 139 & 235 & $x$ & $x$ & 127 & 237 & 212 & 331 \\
\hline & & & FSM & 30 & 48 & 25 & 35 & 13 & 10 & - & $x$ & 86 & 122 & 16 & 34 & 33 & 78 & $x$ & $x$ & 112 & 154 & 97 & 116 \\
\hline & & Statemented SEN & Not FSM & $\mathrm{x}$ & $x$ & $x$ & $x$ & $\mathrm{x}$ & $x$ & - & $\hat{x}$ & 13 & 23 & - & $x$ & 18 & 28 & - & $\hat{x}$ & $x$ & 13 & $x$ & 21 \\
\hline & & & & & $x$ & $x$ & $x$ & - & $x$ & - & - & $x$ & $x$ & $x$ & $x$ & $\mathrm{x}$ & $x$ & - & - & $x$ & $x$ & $x$ & $x$ \\
\hline Other Asian & English or Unclassified & No SEN & Not FSM & 17 & 15 & 20 & 27 & 11 & 10 & $x$ & $x$ & 13 & 12 & 35 & 38 & 30 & 28 & $x$ & $x$ & 21 & 18 & 17 & 17 \\
\hline & & & FSM & $x$ & $x$ & $x$ & $x$ & $x$ & $x$ & - & - & $x$ & $x$ & $x$ & $x$ & $x$ & $x$ & - & $x$ & $x$ & $x$ & $x$ & $x$ \\
\hline & & SEN at Action / Plus & Not FSM & $x$ & $x$ & $x$ & $x$ & $x$ & $x$ & $x$ & - & $x$ & $x$ & $x$ & 10 & $x$ & $x$ & - & $x$ & $x$ & $x$ & $x$ & $x$ \\
\hline & & & FSM & $x$ & $x$ & - & $x$ & $x$ & - & - & - & $x$ & $x$ & - & $x$ & $x$ & $x$ & - & - & $x$ & $x$ & - & $x$ \\
\hline & & Statemented SEN & Not FSM & - & - & - & - & - & $x$ & - & $x$ & - & - & - & - & - & - & - & - & - & - & - & $x$ \\
\hline & & & FSM & - & - & - & - & - & - & - & - & - & - & - & - & - & - & - & - & - & - & - & - \\
\hline & Other than English & No SEN & Not FSM & 80 & 71 & 113 & 103 & 43 & 56 & 15 & $x$ & 40 & 43 & 201 & 201 & 425 & 350 & 40 & 35 & 108 & 105 & 74 & 72 \\
\hline & & & FSM & $\mathrm{x}$ & 13 & $\mathrm{x}$ & 15 & 25 & 20 & $x$ & $\mathrm{x}$ & 14 & 11 & 34 & 39 & 29 & 28 & - & $x$ & 32 & 27 & 25 & 21 \\
\hline & & SEN at Action / Plus & Not FsM & $\hat{x}$ & 16 & $\hat{x}$ & 22 & $x$ & 14 & $\hat{x}$ & $\hat{x}$ & $x$ & $x$ & 38 & 58 & 24 & 70 & $x$ & $\hat{15}$ & $x$ & 19 & $x$ & 16 \\
\hline & & & FSM & - & $\mathrm{x}$ & $\mathrm{x}$ & $x$ & $\mathrm{x}$ & $x$ & - & - & $x$ & $\hat{x}$ & 17 & 26 & $\mathrm{x}$ & $\mathrm{x}$ & - & - & $\mathrm{x}$ & $x$ & $x$ & $x$ \\
\hline & & Statemented SEN & Not FSM & $x$ & $x$ & $x$ & - & - & - & - & $x$ & - & - & $x$ & - & - & $x$ & - & - & - & - & $x$ & $x$ \\
\hline & & & FSM & ${ }^{\prime}$ & & & . & - & $x$ & - & - & - & - & - & $x$ & - & - & - & - & $\mathrm{x}$ & $x$ & . & $\mathrm{x}$ \\
\hline
\end{tabular}

"x" represents 1-9 pupils, suppressed to protect confidentiality " "-" represents zero pupils 
Detailed Population Profile: Key Stage 2 Schools Below the Floor Standards ...continued

\begin{tabular}{|c|c|c|c|c|c|c|c|c|c|c|c|c|c|c|c|c|c|c|c|c|c|c|c|}
\hline \multirow[b]{3}{*}{ Ethnicity } & \multirow[b]{3}{*}{ First Language } & \multirow[b]{3}{*}{ SEN Status } & \multirow[b]{3}{*}{ FSM Status } & \multicolumn{20}{|c|}{ Below Floor 2010} \\
\hline & & & & \multicolumn{2}{|c|}{$\begin{array}{c}\text { EAST } \\
\text { MIDLANDS }\end{array}$} & \multicolumn{2}{|c|}{$\begin{array}{l}\text { EAST OF } \\
\text { ENGLAND }\end{array}$} & \multicolumn{2}{|c|}{$\begin{array}{l}\text { INNER } \\
\text { LONDON }\end{array}$} & \multicolumn{2}{|c|}{ NORTH EAST } & \multicolumn{2}{|c|}{ NORTH WEST } & \multicolumn{2}{|c|}{$\begin{array}{l}\text { OUTER } \\
\text { LONDON }\end{array}$} & \multicolumn{2}{|c|}{ SOUTH EAST } & SOUT & WEST & W & ST & $\begin{array}{l}\text { YORK } \\
\text { AND } \\
\text { HUI }\end{array}$ & $\begin{array}{l}\text { SHRE } \\
\text { THE } \\
\text { BER }\end{array}$ \\
\hline & & & & Girls & Boys & Girls & Boys & Girls & Boys & Girls & Boys & Girls & Boys & Girls & Boys & Girls & Boys & Girls & Boys & Girls & Boys & Girls & Boys \\
\hline Black African & English or Unclassified & No SEN & Not FSM & 60 & 52 & 146 & 137 & 186 & 144 & $x$ & - & 34 & $\frac{10}{35}$ & 282 & 195 & 160 & 123 & 17 & 11 & 79 & 47 & 49 & 45 \\
\hline & & & FSM & 32 & 15 & 21 & 18 & 79 & 61 & - & $x$ & 25 & 13 & 61 & 63 & 21 & 23 & $\mathrm{x}$ & $x$ & 28 & 20 & 17 & 18 \\
\hline & & SEN at Action / Plus & NotFSM & $\mathrm{x}$ & 17 & 17 & 34 & 29 & 35 & - & - & $x$ & $\mathrm{x}$ & 35 & 86 & 21 & 33 & $\mathrm{x}$ & $\mathrm{x}$ & $\mathrm{x}$ & 13 & $x$ & 12 \\
\hline & & & FSM & $x$ & 10 & $x$ & $x$ & 12 & 30 & $x$ & $x$ & $x$ & $x$ & 17 & 32 & $x$ & $x$ & $x$ & $x$ & $x$ & 11 & $x$ & $x$ \\
\hline & & Statemented SEN & Not FSM & $x$ & - & $\mathrm{x}$ & $x$ & $\mathrm{x}$ & 10 & - & - & - & - & $x$ & $x$ & $\mathrm{x}$ & $x$ & - & $\mathrm{x}$ & $x$ & - & $\mathrm{x}$ & $\mathrm{x}$ \\
\hline & & & FSM & - & $x$ & - & $\mathrm{x}$ & - & 13 & - & - & - & $x$ & - & $\mathrm{x}$ & - & - & - & - & - & - & - & $x$ \\
\hline & Other than English & No SEN & Not FSM & 128 & 123 & 152 & 156 & 360 & 320 & $x$ & $x$ & 60 & 43 & 253 & 233 & 241 & 205 & 57 & 56 & 142 & 124 & 120 & 89 \\
\hline & & & FSM & 74 & 67 & 48 & 34 & 311 & 319 & $\mathrm{x}$ & $\mathrm{x}$ & 79 & 72 & 275 & 205 & 89 & 73 & 68 & 66 & 164 & 137 & 82 & 56 \\
\hline & & SEN at Action / Plus & NotFSM & 19 & 33 & 20 & 45 & 53 & 106 & $x$ & - & 12 & 19 & 58 & 91 & 32 & 71 & $x$ & $\mathrm{x}$ & 14 & 29 & 14 & 34 \\
\hline & & & FSM & 18 & 36 & 11 & 14 & 83 & 121 & . & - & 12 & 23 & 81 & 147 & 24 & 34 & 15 & 20 & 21 & 42 & 28 & 35 \\
\hline & & Statemented SEN & Not FSM & - & $x$ & - & $x$ & $x$ & 12 & - & - & $x$ & - & $x$ & $x$ & $x$ & $x$ & $x$ & $\mathrm{x}$ & - & $x$ & - & $x$ \\
\hline & & & FSM & $x$ & $x$ & - & $x$ & $x$ & 18 & - & - & - & - & $x$ & 10 & $x$ & $x$ & - & $x$ & - & $x$ & $x$ & $x$ \\
\hline Black Caribbean & English or Unclassified & No SEN & Not FSM & 53 & 51 & 103 & $\frac{1}{68}$ & 340 & 252 & $x$ & $x$ & 13 & 12 & 274 & 250 & $\frac{1}{47}$ & $\frac{1}{47}$ & 17 & $\frac{n}{x}$ & 141 & 124 & $\frac{1}{38}$ & $\frac{n}{19}$ \\
\hline & & & FSM & 24 & 12 & 30 & 33 & 165 & 146 & $\hat{x}$ & $x$ & $\mathrm{x}$ & 11 & 120 & 105 & 23 & 21 & $\mathrm{x}$ & $\hat{x}$ & 65 & 68 & 16 & $x$ \\
\hline & & SEN at Action / Plus & NotFSM & 13 & 30 & 14 & 31 & 79 & 123 & . & $\hat{x}$ & $\hat{x}$ & $x$ & 86 & 164 & 21 & 31 & $\hat{x}$ & $\hat{x}$ & 21 & 56 & $\mathrm{x}$ & $\hat{x}$ \\
\hline & & & FSM & $\mathrm{x}$ & 16 & 17 & 16 & 71 & 112 & - & $\mathrm{x}$ & $\mathrm{x}$ & $\mathrm{x}$ & 60 & 106 & $x$ & 15 & $\mathrm{x}$ & $x$ & 32 & 42 & $x$ & $\mathrm{x}$ \\
\hline & & Statemented SEN & Not FSM & - & $x$ & $x$ & $x$ & $x$ & 18 & - & - & - & - & $x$ & $x$ & $\mathrm{x}$ & $x$ & $\mathrm{x}$ & $x$ & $x$ & $x$ & - & $\mathrm{x}$ \\
\hline & & & FSM & . & $x$ & . & $x$ & $x$ & 19 & . & : & . & - & $x$ & $x$ & . & 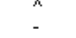 & . & $x^{x}$ & $\hat{x}$ & $\begin{array}{l}x \\
x\end{array}$ & . & $x$ \\
\hline & Other than English & No SEN & Not FSM & $x$ & $x$ & $x$ & $x$ & 20 & 25 & - & - & $x$ & $x$ & $x$ & $x$ & $x$ & $x$ & - & $\mathrm{x}$ & $x$ & $x$ & - & $\mathrm{x}$ \\
\hline & & & FSM & . & $\hat{x}$ & $\hat{x}$ & . & 12 & 12 & - & - & . & $\hat{x}$ & $\hat{x}$ & $\hat{x}$ & $\hat{x}$ & . & - & . & $\hat{x}$ & $\hat{x}$ & $\mathrm{x}$ & $\hat{x}$ \\
\hline & & SEN at Action / Plus & NotFSM & $x$ & $\mathrm{x}$ & . & $x$ & $\mathrm{x}$ & 17 & - & - & $x$ & - & $x$ & - & $x$ & $x$ & - & - & $x$ & $x$ & - & $x$ \\
\hline & & & FSM & $\hat{x}$ & - & - & - & $\hat{x}$ & $x$ & - & - & $\mathrm{x}$ & - & $\mathrm{x}$ & $x$ & $\hat{x}$ & - & - & - & - & $\mathrm{x}$ & - & - \\
\hline & & Statemented SEN & Not FSM & - & - & - & $x$ & - & $x$ & - & - & - & - & - & - & - & - & - & - & - & - & $x$ & $x$ \\
\hline & & Salementer SEIV & FSM & - & - & - & . & - & - & - & . & - & . & - & - & - & . & - & . & . & - & . & . \\
\hline Other Black & English or Unclassified & No SEN & Not FSM & 22 & 15 & 36 & 35 & 85 & 66 & $x$ & $x$ & 28 & 33 & 54 & 54 & 32 & 30 & 12 & 11 & 21 & 20 & 13 & 11 \\
\hline & & & FSM & 12 & 18 & 10 & $\mathrm{x}$ & 40 & 34 & $\hat{x}$ & - & 23 & 13 & 26 & 25 & 10 & $x$ & $\mathrm{x}$ & $x$ & 16 & 27 & $x$ & $x$ \\
\hline & & SEN at Action / Plus & NotFSM & $x$ & 11 & $\mathrm{x}$ & 17 & 14 & 24 & - & $x$ & $\mathrm{x}$ & 14 & 10 & 16 & $\mathrm{x}$ & 10 & $\mathrm{x}$ & $\mathrm{x}$ & $x$ & 17 & $x$ & $\mathrm{x}$ \\
\hline & & & FSM & $x$ & 13 & $\mathrm{x}$ & $x$ & $x$ & 24 & - & $\mathrm{x}$ & $\mathrm{x}$ & $x$ & $x$ & 23 & $\mathrm{x}$ & $x$ & $\mathrm{x}$ & $\mathrm{x}$ & $\mathrm{x}$ & 12 & - & $\mathrm{x}$ \\
\hline & & Statemented SEN & Not FSM & . & - & $x$ & - & $\mathrm{x}$ & $x$ & - & - & $\mathrm{x}$ & $\mathrm{x}$ & $\mathrm{x}$ & - & - & - & - & $\mathrm{x}$ & - & $x$ & - & $x$ \\
\hline & & & FSM & $x$ & - & . & - & $\mathrm{x}$ & $\mathrm{x}$ & - & - & -. & - & - & $x$ & - & $x$ & - & $x$ & - & - & - & - \\
\hline & Other than English & No SEN & Not FSM & 15 & 19 & 22 & 19 & 41 & 34 & - & - & 10 & 13 & 17 & 11 & 35 & 44 & $x$ & $x$ & 15 & $\mathrm{x}$ & 11 & 11 \\
\hline & & & FSM & $\mathrm{x}$ & $\mathrm{x}$ & $\mathrm{x}$ & $x$ & 25 & 31 & - & - & $\mathrm{x}$ & $\mathrm{x}$ & 21 & 12 & $\mathrm{x}$ & 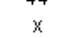 & $\hat{-}$ & $\hat{x}$ & $\mathrm{x}$ & $\hat{x}$ & $\mathrm{x}$ & $x$ \\
\hline & & SEN at Action / Plus & NotFSM & $\hat{x}$ & $\hat{x}$ & $\mathrm{x}$ & $\hat{x}$ & $x$ & 12 & $x$ & - & - & $\mathrm{x}$ & $x$ & 10 & $\mathrm{x}$ & 12 & $x$ & - & $\mathrm{x}$ & $\mathrm{x}$ & $\mathrm{x}$ & $x$ \\
\hline & & & FSM & . & $\mathrm{x}$ & . & $\hat{x}$ & $\hat{x}$ & 13 & . & . & $x$ & $\hat{x}$ & $\hat{x}$ & 10 & $\hat{x}$ & $x$ & $\hat{x}$ & $x$ & $\hat{x}$ & $\hat{x}$ & $\hat{x}$ & $\hat{x}$ \\
\hline & & Statemented SEN & Not FSM & - & - & - & $x$ & $x$ & $\mathrm{x}$ & - & - & - & - & - & - & $x$ & - & - & - & - & - & - & - \\
\hline & & & FSM & - & - & - & $x$ & - & $x$ & - & - & - & - & - & - & - & $x$ & - & - & - & - & - & - \\
\hline Chinese & English or Unclassified & No SEN & Not FSM & $x$ & $x$ & $x$ & $x$ & $x$ & $x$ & $x$ & - & $x$ & $x$ & - & $x$ & $x$ & $x$ & $x$ & $x$ & $x$ & $x$ & $x$ & $x$ \\
\hline & & & FSM & - & - & $x$ & - & - & - & - & - & $x$ & - & $x$ & - & $x$ & - & $x$ & - & $x$ & $x$ & $x$ & . \\
\hline & & SEN at Action / Plus & Not FSM & - & - & - & $x$ & - & $x$ & . & . & - & $x$ & $\hat{x}$ & - & $\hat{x}$ & . & . & . & - & $\hat{x}$ & - & . \\
\hline & & & & - & $x$ & - & $\hat{x}$ & - & - & - & - & - & - & - & - & - & - & - & - & - & - & - & - \\
\hline & & Statemented SEN & Not FSM & - & - & $x$ & - & - & - & - & . & - & - & - & - & $x$ & - & - & - & - & - & - & - \\
\hline & & & FSM & - & - & - & - & - & - & . & . & - & - & . & - & - & - & - & . & - & - & - & - \\
\hline & Other than English & No SEN & Not FSM & 19 & 20 & 31 & 34 & 39 & 36 & $x$ & $x$ & 40 & 30 & $x$ & 17 & 56 & 41 & 12 & $x$ & 21 & 24 & 31 & 16 \\
\hline & & & FSM & $x$ & - & $x$ & $x^{34}$ & 19 & 18 & . & . & $\begin{array}{c}40 \\
x\end{array}$ & $x$ & $x$ & $x$ & $x$ & $x$ & $x$ & $x$ & $x$ & ${ }_{x}^{24}$ & $x$ & $x$ \\
\hline & & SEN at Action / Plus & NotFSM & $\mathrm{x}$ & $x$ & $\mathrm{x}$ & $x$ & $\mathrm{x}$ & $x$ & $x$ & $x$ & $\mathrm{x}$ & $x$ & - & $x$ & $x$ & $x$ & & $x$ & $\mathrm{x}$ & $\mathrm{x}$ & $\mathrm{x}$ & $x$ \\
\hline & & & FSM & . & 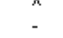 & $\hat{x}$ & . & $\hat{x}$ & $\hat{x}$ & . & $\therefore$ & . & $\hat{-}$ & - & $\hat{x}$ & $\hat{x}$ & $\hat{x}$ & - & . &. & $\therefore$ & . & $\hat{x}$ \\
\hline & & Statemented SEN & Not FSM & - & - & - & $x$ & - & - & - & - & - & - & - & . & - & $\hat{x}$ & - & - & - & $x$ & - & . \\
\hline
\end{tabular}

"x" represents 1-9 pupils, suppressed to protect confidentiality " "-" represents zero pupils 
Detailed Population Profile: Key Stage 2 Schools Below the Floor Standards ...continued

\begin{tabular}{|c|c|c|c|c|c|c|c|c|c|c|c|c|c|c|c|c|c|c|c|c|c|c|c|}
\hline \multirow[b]{3}{*}{ Ethnicity } & \multirow[b]{3}{*}{ First Language } & \multirow[b]{3}{*}{ SEN Status } & \multirow[b]{3}{*}{ FSM Status } & \multicolumn{20}{|c|}{ Below Floor 2010} \\
\hline & & & & \multicolumn{2}{|c|}{$\begin{array}{c}\text { EAST } \\
\text { MIDLANDS }\end{array}$} & \multicolumn{2}{|c|}{$\begin{array}{l}\text { EAST OF } \\
\text { ENGLAND }\end{array}$} & \multicolumn{2}{|c|}{$\begin{array}{l}\text { INNER } \\
\text { LONDON }\end{array}$} & \multicolumn{2}{|c|}{ NORTH EAST } & \multicolumn{2}{|c|}{ NORTH WEST } & \multicolumn{2}{|c|}{$\begin{array}{l}\text { OUTER } \\
\text { LONDON }\end{array}$} & \multicolumn{2}{|c|}{ SOUTHEAST } & SOUTH & WEST & MIDL & STT & & $\begin{array}{l}\text { SHIRE } \\
\text { THE } \\
\text { BER }\end{array}$ \\
\hline & & & & Girls & Boys & Girls & Boys & Girls & Boys & Girls & Boys & Girls & Boys & Girls & Boys & Girls & Boys & Girls & Boys & Girls & Boys & Girls & Boys \\
\hline White \& Asian & English or Unclassified & No SEN & Not FSM & 42 & 58 & 65 & 72 & 13 & 14 & $x$ & $x$ & 38 & 28 & 25 & 30 & 113 & 102 & 19 & 25 & 53 & 54 & 48 & 53 \\
\hline & & & FSM & 20 & 18 & 24 & 15 & $\mathrm{x}$ & $\mathrm{x}$ & $\mathrm{x}$ & $x$ & 29 & 20 & 15 & $x$ & 27 & 24 & $\mathrm{x}$ & 11 & 50 & 39 & 33 & 40 \\
\hline & & SEN at Action / Plus & Not FSM & $x$ & $x$ & $x$ & 11 & $\mathrm{x}$ & $x$ & $x$ & - & $x$ & 11 & $x$ & $x$ & 12 & 28 & $\mathrm{x}$ & $x$ & $x$ & 18 & $\mathrm{x}$ & 14 \\
\hline & & & FSM & $x$ & 13 & $\mathrm{x}$ & 15 & $x$ & $x$ &. & $x$ & $\mathrm{x}$ & 17 & $\mathrm{x}$ & $\hat{x}$ & $\mathrm{x}$ & 13 & $x$ & $x$ & 17 & 27 & $\mathrm{x}$ & 25 \\
\hline & & Statemented SEN & Not FSM & $\mathrm{x}$ & $x$ & $x$ & - & - & $\mathrm{x}$ & - & - & $x$ & $x$ & $\mathrm{x}$ & - & $\mathrm{x}$ & 10 & - & $\mathrm{x}$ & - & $x$ & - & $x$ \\
\hline & & & FSM & - & - & - & - & - & - & - & - & - & - & - & $x$ & - & $x$ & - & - & - & $x$ & - & $x$ \\
\hline & Other than English & No SEN & Not FSM & 10 & 12 & 22 & 16 & 10 & $x$ & $x$ & - & $x$ & $x$ & 20 & 13 & 31 & 21 & $x$ & $x$ & $x$ & $x$ & 12 & 12 \\
\hline & & & FSM & $x$ & $x$ & $x$ & $x$ & $x$ & $x$ & - & - & $x$ & $x$ & 10 & $x$ & $x$ & 12 & $x$ & - & $x$ & $x$ & $x$ & $x$ \\
\hline & & SEN at Action / Plus & Not FSM & $x$ & - & $\mathrm{x}$ & $\mathrm{x}$ & $x$ & $\mathrm{x}$ & - & - & - & $\mathrm{x}$ & $x$ & $\mathrm{x}$ & $\mathrm{x}$ & $x$ & $x$ & $x$ & $\mathrm{x}$ & $x$ & $\mathrm{x}$ & $x$ \\
\hline & & & FSM & - & $x$ & $x$ & $x$ & $x$ & $\mathrm{x}$ & - & - & - & - & $\mathrm{x}$ & $\mathrm{x}$ & - & $x$ & - & - & $\mathrm{x}$ & $\mathrm{x}$ & $\mathrm{x}$ & $\mathrm{x}$ \\
\hline & & Statemented SEN & Not FSM & - & . & - & - & - & - & - & - & - & - & - & . & - & $x$ & - & $\mathrm{x}$ & - & . & - &. \\
\hline & & & FSM & - & - & - & - & - & $x$ & - & - & - & - & - & - & $\mathrm{x}$ & & - & & 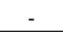 & 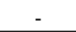 & - & $x$ \\
\hline White \& Black African & English or Unclassified & No SEN & Not FSM & 33 & 33 & 59 & 42 & 25 & 17 & $x$ & $x$ & 28 & 23 & 34 & 29 & 81 & 67 & $x$ & 13 & 25 & 16 & 27 & 22 \\
\hline & & & FSM & $x$ & $x$ & 23 & 27 & 15 & $x$ & $x$ & $x$ & 16 & $x$ & 17 & 12 & 28 & 30 & $x$ & 10 & 13 & $x$ & 19 & $x$ \\
\hline & & SEN at Action / Plus & Not FSM & $x$ & 16 & $x$ & 11 & $x$ & 12 & $x$ & - & $x$ & $x$ & $x$ & 12 & 11 & 21 & $x$ & $x$ & $x$ & $x$ & $x$ & $x$ \\
\hline & & & FSM & $x$ & $x$ & 11 & 20 & $\mathrm{x}$ & $\mathrm{x}$ & - & - & $\mathrm{x}$ & $\mathrm{x}$ & $\mathrm{x}$ & $\mathrm{x}$ & 11 & 12 & $\mathrm{x}$ & $\mathrm{x}$ & $x$ & $x$ & $\mathrm{x}$ & $\mathrm{x}$ \\
\hline & & Statemented SEN & Not FSM & - & $x$ & - & - & - & $x$ & - & $x$ & - & - & - & - & - & $x$ & - & - & - & $\mathrm{x}$ & - & - \\
\hline & & & FSM & $x$ & $\mathrm{x}$ & - & - & - & - & - & - & $x$ & $x$ & - & $x$ & - & $\hat{x}$ & - & - & - & - & - & - \\
\hline & Other than English & No SEN & Not FSM & 10 & $x$ & 11 & 13 & 13 & 17 & - & - & $x$ & $x$ & 20 & $x$ & 18 & 23 & - & $\mathrm{x}$ & $x$ & $x$ & $x$ & $x$ \\
\hline & & & FSM & $x$ & $x$ & $x$ & $x$ & $x$ & $x$ & $x$ & - & $x$ & $x$ & 10 & $x$ & $x$ & $x$ & $x$ & $x$ & $x$ & $x$ & $x$ & $\mathrm{x}$ \\
\hline & & SEN at Action / Plus & Not FSM & $x$ & $x$ & $x$ & $x$ & $x$ & $x$ & - & - & - & - & $x$ & $x$ & $x$ & $x$ & - & - & - & $x$ & $x$ & $x$ \\
\hline & & & FSM & $\mathrm{x}$ & - & $\mathrm{x}$ & $\mathrm{x}$ & $\mathrm{x}$ & $\mathrm{x}$ & - & - & $\mathrm{x}$ & - & $\mathrm{x}$ & $\mathrm{x}$ & $\mathrm{x}$ & $\mathrm{x}$ & - & $\mathrm{x}$ & - & - & - & $\mathrm{x}$ \\
\hline & & Statemented SEN & Not FSM & - & - & - & - & - & - & - & - & - & - & - & - & - & $\mathrm{x}$ & - & - & - & - & - & - \\
\hline & & & FSM & & & & & & $x$ & - & - & - & - & - & & - & & & & & & & \\
\hline White \& Elack Caribbean & English or Unclassified & No SEN & Not FSM & 127 & 122 & 150 & 125 & 95 & 51 & $x$ & $x$ & 46 & 32 & 102 & 109 & 170 & 141 & 54 & 37 & 157 & 124 & 95 & 55 \\
\hline & & & FSM & 78 & 61 & 95 & 65 & 69 & 64 & $x$ & $x$ & 30 & 17 & 64 & 42 & 93 & 73 & 49 & 22 & 138 & 97 & 60 & 48 \\
\hline & & SEN at Action / Plus & Not FSM & 30 & 41 & 25 & 50 & 19 & 31 & - & - & $x$ & 12 & 23 & 45 & 23 & 71 & 10 & 12 & 26 & 56 & 14 & 28 \\
\hline & & & FSM & 19 & 35 & 35 & 46 & 20 & 32 & - & - & 11 & 17 & 31 & 46 & 37 & 60 & $x$ & 20 & 41 & 86 & 11 & 36 \\
\hline & & Statemented SEN & Not FSM & $x$ & - & $x$ & $x$ & - & $x$ & - & - & $x$ & $x$ & $x$ & $\mathrm{x}$ & $x$ & $x$ & $\mathrm{x}$ & - & $x$ & $x$ & - & $x$ \\
\hline & & & FSM & $x$ & $x$ & $\mathrm{x}$ & $\mathrm{x}$ & $x$ & $x$ & - & $x$ & $\mathrm{x}$ & $x$ & $\mathrm{x}$ & $\hat{x}$ & $\hat{x}$ & $x$ & - & $x$ &. & $\mathrm{x}$ & - & $\mathrm{x}$ \\
\hline & Other than English & No SEN & Not FSM & $x$ & $x$ & $\mathrm{x}$ & $x$ & $\mathrm{x}$ & $x$ & - & - & $x$ & $x$ & $\mathrm{x}$ & $x$ & - & $x$ & - & $x$ & $\mathrm{x}$ & - & $x$ & $\mathrm{x}$ \\
\hline & & & FSM & $x$ & . & $\mathrm{x}$ & $x$ & $x$ & - & - & - & - & $x$ & - & . & - & - & - & - & . & - & - & . \\
\hline & & SEN at Action / Plus & Not FSM & - & $x$ & - & $x$ & $x$ & $x$ & - & - & - & - & - & $x$ & - & $x$ & - & - & $x$ & - & - & $x$ \\
\hline & & & FSM & - & - & $x$ & - & $x$ & $x$ & - & - & - & - & - & $x$ & $x$ & - & - & - & - & - & - & - \\
\hline & & Statemented SEN & Not FSM & - & - & - & - & - & - & - & - & - & - & - & $\hat{-}$ & - & - & - & - & - & - & - & - \\
\hline & & 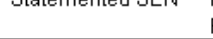 & FSM & . & . & - & - & . & . & . & . & . & . & . & . & - & - & . & . & - & - & . & . \\
\hline Other Mixed & English or Unclassified & No SEN & Not FSM & 86 & 76 & 121 & 108 & 63 & 73 & 10 & $x$ & 66 & 59 & 93 & 91 & 160 & 170 & 42 & 34 & 103 & 89 & 63 & 67 \\
\hline & & & FSM & 46 & 34 & 48 & 35 & 40 & 34 & $x$ & $x$ & 42 & 32 & 41 & 36 & 53 & 33 & 27 & 24 & 61 & 49 & 45 & 44 \\
\hline & & SEN at Action / Plus & Not FSM & 11 & 22 & 21 & 40 & 16 & 25 & $x$ & $x$ & $x$ & 21 & 16 & 43 & 35 & 56 & $x$ & 12 & $x$ & 32 & 10 & 14 \\
\hline & & & FSM & 13 & 19 & 23 & 19 & 16 & 16 & $\mathrm{x}$ & - & 15 & 32 & 22 & 32 & 24 & 40 & $\mathrm{x}$ & $x$ & 11 & 42 & 11 & 22 \\
\hline & & Statemented SEN & Not FSM & $x$ & $x$ & $x$ & $x$ & $x$ & $x$ & - & - & - & $x$ & $x$ & $x$ & $x$ & 10 & $x$ & $x$ & $x$ & $x$ & - & - \\
\hline & & 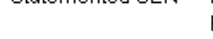 & FSM & $x$ & $x$ & $\mathrm{x}$ & $\mathrm{x}$ & $x$ & $\mathrm{x}$ & - & - & - & - & $\mathrm{x}$ & $\mathrm{x}$ & . & - & . & . & $\mathrm{x}$ & $\hat{x}$ & - & - \\
\hline & Other than English & No SEN & Not FSM & 16 & 16 & 56 & 60 & 29 & 43 & $x$ & $x$ & 32 & 29 & 43 & 34 & 78 & 89 & 17 & 18 & 13 & 15 & 20 & 28 \\
\hline & & & FSM & $\mathrm{x}$ & $x$ & 10 & $x$ & 24 & 23 & - & $\mathrm{x}$ & $x$ & 12 & 15 & 13 & $x$ & 19 & - & - & 10 & $x$ & $x$ & $x$ \\
\hline & & SEN at Action / Plus & NotFSM & $\mathrm{x}$ & 10 & $x$ & $x$ & $x$ & 13 & - & - & $x$ & $x$ & $x$ & 10 & 13 & 24 & $x$ & $x$ & $x$ & $x$ & $x$ & - \\
\hline & & & FSM & $x$ & $x$ & $\mathrm{x}$ & $x$ & $\mathrm{x}$ & $x$ & - & - & $x$ & $x$ & $x$ & $x$ & $x$ & $\mathrm{x}$ & - & - & - & - & - & $\mathrm{x}$ \\
\hline & & Statemented SEN & Not FSM & - & - & - & - & $x$ & $x$ & - & - & - & - & $x$ & - & - & $\mathrm{x}$ & - & - & - & - & - & - \\
\hline & & & FSM & - & - & - & $x$ & - & $x$ & - & - & - & - & - & - & - & - & - & - & - & - & - & - \\
\hline
\end{tabular}

"x" represents 1-9 pupils, suppressed to protect confidentiality " "-" represents zero pupils 
Detailed Population Profile: Key Stage 2 Schools Below the Floor Standards ...continued

\begin{tabular}{|c|c|c|c|c|c|c|c|c|c|c|c|c|c|c|c|c|c|c|c|c|c|c|c|}
\hline \multirow[b]{3}{*}{ Ethnicity } & \multirow[b]{3}{*}{ First Language } & \multirow[b]{3}{*}{ SEN Status } & \multirow[b]{3}{*}{ FSM Status } & \multicolumn{20}{|c|}{ Below Floor 2010} \\
\hline & & & & \multicolumn{2}{|c|}{$\begin{array}{l}\text { EAST } \\
\text { MIDLANDS }\end{array}$} & \multicolumn{2}{|c|}{$\begin{array}{l}\text { EAST OF } \\
\text { ENGLAND }\end{array}$} & \multicolumn{2}{|c|}{$\begin{array}{l}\text { INNNER } \\
\text { LONDON }\end{array}$} & \multicolumn{2}{|c|}{ NORTH EAST } & \multicolumn{2}{|c|}{ NORTH WEST } & \multicolumn{2}{|c|}{$\begin{array}{l}\text { OUTER } \\
\text { LONDON }\end{array}$} & \multicolumn{2}{|c|}{ SOUTH EAST } & SOUT & WEST & WIDL & ST & $\begin{array}{l}\text { YORL } \\
\text { ANL } \\
\text { HU }\end{array}$ & $\begin{array}{l}\text { SHIRE } \\
\text { THE } \\
\text { BER }\end{array}$ \\
\hline & & & & Girls & Boys & Girls & Boys & Girls & Boys & Girls & Boys & Girls & Boys & Girls & Boys & Girls & Boys & Girls & Boys & Girls & Boys & Girls & Boys \\
\hline White British & English or Unclassified & No SEN & Not FSM & 7037 & 6499 & 8934 & 7953 & 466 & 429 & 2327 & 2051 & 4784 & 4275 & 1449 & 1221 & 11141 & 9823 & 5506 & 4744 & 6259 & 5471 & 6221 & 5515 \\
\hline & & & FSM & 2065 & 1634 & 2451 & 1803 & 268 & 188 & 872 & 658 & 2374 & 1909 & 469 & 365 & 2875 & 2118 & 1659 & 1196 & 2181 & 1708 & 2401 & 1885 \\
\hline & & SEN at Action / Plus & Not FSM & 1315 & 2576 & 1718 & 3279 & 82 & 149 & 397 & 772 & 744 & 1436 & 350 & 636 & 2478 & 4686 & 1109 & 2087 & 1097 & 2192 & 1017 & 1930 \\
\hline & & & FSM & 976 & 1533 & 1119 & 1743 & 96 & 157 & 397 & 682 & 992 & 1627 & 317 & 410 & 1720 & 2486 & 730 & 1179 & 992 & 1505 & 972 & 1603 \\
\hline & & Statemented SEN & Not FSM & 81 & 255 & 123 & 419 & $\mathrm{x}$ & 40 & 32 & 72 & 30 & 124 & 17 & 49 & 131 & 462 & 88 & 292 & 63 & 170 & 48 & 114 \\
\hline & & & FSM & 59 & 148 & 79 & 220 & $x$ & 26 & 18 & 34 & 38 & 98 & 11 & 24 & 54 & 160 & 56 & 145 & 47 & 105 & 40 & 93 \\
\hline & Other than English & No SEN & Not FSM & 16 & 21 & 23 & 23 & 12 & 18 & $x$ & $x$ & 13 & 11 & 11 & 16 & 51 & 46 & 12 & $x$ & $x$ & 13 & $x$ & 10 \\
\hline & & & FSM & $x$ & $x$ & $x$ & $x$ & 11 & 11 & - & - & $x$ & $x$ & $x$ & $x$ & 10 & $x$ & $x$ & $x$ & $\mathrm{x}$ & $x$ & $x$ & $x$ \\
\hline & & SEN at Action / Plus & Not FSM & $x$ & $x$ & $x$ & $x$ & $x$ & $x$ & $x$ & - & $x$ & $x$ & $x$ & $x$ & 11 & 14 & $x$ & - & $x$ & $x$ & $x$ & $x$ \\
\hline & & & FSM & $x$ & $x$ & $x$ & $x$ & $x$ & - & - & - & - & - & $x$ & $x$ & $\mathrm{x}$ & 12 & $x$ & $x$ & $x$ & $x$ & - & $x$ \\
\hline & & Statemented SEN & Not FSM & $x$ & $x$ & - & $\bar{x}$ & $x$ & - & - & - & - & - & - & $x$ & $x$ & $x$ & - & - & - & $x$ & $x$ & $\begin{array}{c}10 \\
x\end{array}$ \\
\hline Irish & English or Unclassified & No SEN & Not FSM & 11 & $x$ & 19 & $x$ & 12 & $x$ & $x$ & $x$ & 10 & $x$ & $x$ & 12 & 25 & 16 & $x$ & $x$ & $x$ & 12 & $\frac{x}{x}$ & $\frac{x}{x}$ \\
\hline & & & FSM & $x$ & $x$ & $x$ & $x$ & $x$ & $x$ & $x$ & - & $x$ & $x$ & $x$ & $x$ & $x$ & $x$ & $x$ & $x$ & $x$ & $x$ & $x$ & $x$ \\
\hline & & SEN at Action / Plus & Not FSM & $x$ & $x$ & $x$ & 10 & - & $x$ & - & - & $x$ & $x$ & $x$ & $x$ & $x$ & 10 & $x$ & $x$ & $x$ & $x$ & - & $x$ \\
\hline & & & FSM & $\hat{x}$ & $\hat{x}$ & $\hat{x}$ & $\mathrm{x}$ & $x$ & $\mathrm{x}$ & - & $x$ & $\hat{x}$ & $\hat{x}$ & $x$ & $\hat{x}$ & $\hat{x}$ & $x$ & - & $\mathrm{x}$ & . & $\hat{x}$ & $x$ & $x$ \\
\hline & & Statemented SEN & Not FSM & - & - & - & $x$ & - & - & - & - & - & - & $x$ & $x$ & - & $x$ & - & - & - & $x$ & - & - \\
\hline & & & FSM & - & - & $x$ & $x$ & $x$ & - & - & - & - & - & - & - & - & - & - & - & - & $x$ & - & - \\
\hline & Other than English & No SEN & Not FSM & - & - & - & - & - & $x$ & - & - & $x$ & - & $x$ & - & - & - & $x$ & - & - & - & - & $x$ \\
\hline & & & FSM & - & - & - & - & - & - & - & - & - & - & $x$ & - & - & - & - & - & - & - & - & - \\
\hline & & SEN at Action / Plus & Not FSM & - & $x$ & - & - & - & - & - & - & - & - & - & - & $x$ & - & - & - & - & - & - & - \\
\hline & & & FSM & - & - & - & - & - & - & - & - & - & - & - & - & - & - & - & - & - & - & - & - \\
\hline & & Statemented SEN & Not FSM & - & - & - & - & - & - & - & - & - & - & - & - & - & - & $x$ & - & - & - & - & - \\
\hline & & 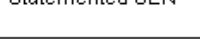 & FSM & - & - & - & - & - & - & - & - & - & - & - & - & - & - & $\therefore$ & - & - & - & - & - \\
\hline Gypsy/ Roma Traveller & English or Unclassified & No SEN & Not FSM & 11 & 15 & 29 & 18 & $x$ & $x$ & $x$ & - & 19 & 23 & 17 & 23 & 51 & 50 & $x$ & $x$ & 16 & 10 & $x$ & 11 \\
\hline & & & FSM & $x$ & $x$ & 23 & 25 & $x$ & - & $x$ & $x$ & 13 & $x$ & 14 & 13 & 50 & 40 & $x$ & $x$ & 17 & 20 & $x$ & $x$ \\
\hline & & SEN at Action / Plus & Not FSM & 13 & 15 & 13 & 14 & - & - & $x$ & $x$ & $x$ & $x$ & $x$ & 10 & 25 & 61 & $x$ & $x$ & $x$ & $x$ & - & $x$ \\
\hline & & & FSM & $x$ & 10 & 30 & 23 & $x$ & $x$ & . & $x$ & 12 & $\hat{x}$ & 18 & 17 & 42 & 81 & $\hat{x}$ & $\hat{x}$ & 18 & 28 & $x$ & $x$ \\
\hline & & Statemented SEN & Not FSM & - & - & - & $x$ & - & - & - & - & - & - & $x$ & $x$ & $x$ & $x$ & - & $x$ & - & - & - & $x$ \\
\hline & & & FSM & - & $x$ & $x$ & $\hat{x}$ & - & - & - & - & $x$ & $x$ & $\hat{x}$ & $\hat{x}$ & $\hat{x}$ & $\hat{x}$ & - & $\hat{x}$ & $x$ & - & - & . \\
\hline & Other than English & No SEN & Not FSM & 52 & 65 & 10 & $x$ & - & $x$ & - & - & $x$ & $x$ & $x$ & $x$ & 25 & 36 & $x$ & $x$ & $x$ & $\mathrm{x}$ & 13 & 13 \\
\hline & & & FSM & $x$ & $x$ & $x$ & - & $x$ & $x$ & - & - & $x$ & - & - & $x$ & 10 & $x$ & - & - & $x$ & $x$ & $x$ & - \\
\hline & & SEN at Action / Plus & Not FSM & $x$ & 11 & 13 & $x$ & - & - & - & - & $\mathrm{x}$ & $x$ & $x$ & $\mathrm{x}$ & $\mathrm{x}$ & 17 & - & - & - & $\mathrm{x}$ & $\mathrm{x}$ & 10 \\
\hline & & & FSM & $x$ & $x$ & $x$ & $x$ & - & $x$ & - & $x$ & $x$ & $x$ & $\mathrm{x}$ & - & $x$ & $x$ & - & - & 13 & 10 & $x$ & - \\
\hline & & Statemented SEN & Not FSM & - & - & - & - & - & - & - & - & - & - & - & - & $x$ & $x$ & - & - & - & - & $x$ & $x$ \\
\hline & & & FSM & - & $\mathrm{x}$ & & - & - & - & - & - & - & - & - & & & & & & & - & & \\
\hline Other White & English or Unclassified & No SEN & Not FSM & 91 & 92 & 199 & 198 & 32 & 33 & $x$ & $x$ & 137 & 111 & 87 & 108 & 332 & 273 & 75 & 60 & 49 & 39 & 79 & 93 \\
\hline & & & FSM & 44 & 32 & 47 & 49 & 16 & 18 & - & $x$ & 77 & 58 & 40 & 24 & 73 & 72 & 25 & 15 & 16 & 16 & 14 & 15 \\
\hline & & SEN at Action / Plus & Not FSM & 15 & 23 & 38 & 60 & $x$ & $\mathrm{x}$ & - & $x$ & 10 & 32 & 26 & 26 & 46 & 100 & 11 & 18 & $x$ & 16 & $x$ & $x$ \\
\hline & & & FSM & 19 & 17 & 29 & 37 & $\mathrm{x}$ & $\mathrm{x}$ & $x$ & $x$ & 17 & 53 & $\mathrm{x}$ & 14 & 26 & 64 & $x$ & 10 & 11 & 12 & $\mathrm{x}$ & $x$ \\
\hline & & Statemented SEN & Not FSM & $x$ & $x$ & $x$ & $x$ & $x$ & $x$ & - & - & $x$ & $x$ & - & $x$ & $x$ & 14 & - & $x$ & - & $x$ & - & $x$ \\
\hline & & & FSM & - & $x$ & $\mathrm{x}$ & $x$ & - & $\mathrm{x}$ & - & - & $\mathrm{x}$ & $x$ & - & $x$ & $x$ & $\mathrm{x}$ & - & $x$ & - & - & - & $x$ \\
\hline & Other than English & No SEN & Not FSM & 360 & 285 & 607 & 588 & 226 & 227 & $x$ & 13 & 135 & 109 & 356 & 343 & 561 & 547 & 173 & 152 & 190 & 180 & 197 & 195 \\
\hline & & & FSM & 25 & 22 & 62 & 53 & 143 & 114 & $\mathrm{x}$ & $\mathrm{x}$ & 16 & 12 & 134 & 115 & 62 & 46 & $x$ & 11 & 20 & 23 & 21 & 16 \\
\hline & & SEN at Action / Plus & Not FsM & 66 & 82 & 114 & 194 & 34 & 57 & $\hat{x}$ & $\hat{x}$ & 22 & 31 & 61 & 141 & 98 & 189 & 32 & 62 & 41 & 50 & 61 & 77 \\
\hline & & & FSM & $\mathrm{x}$ & 10 & 23 & 23 & 35 & 55 & - & $x$ & 12 & $\mathrm{x}$ & 37 & 48 & 17 & 27 & $\mathrm{x}$ & $x$ & 13 & $x$ & $x$ & $\mathrm{x}$ \\
\hline & & Statemented SEN & Not FSM & $x$ & $x$ & $x$ & $x$ & $x$ & $x$ & - & - & $x$ & $x$ & $x$ & $x$ & $x$ & 11 & $x$ & $x$ & $x$ & $\mathrm{x}$ & - & - \\
\hline & & & FSM & & & $\mathrm{x}$ & $\therefore$ & $\mathrm{x}$ & $x$ & - & - & . & - & . & $x$ & - & $x$ & $x$ & - & . & - & - & - \\
\hline
\end{tabular}

"x" represents 1-9 pupils, suppressed to protect confidentiality " "-" represents zero pupils 
Detailed Population Profile: Key Stage 2 Schools Below the Floor Standards ...continued

\begin{tabular}{|c|c|c|c|c|c|c|c|c|c|c|c|c|c|c|c|c|c|c|c|c|c|c|c|}
\hline \multirow[b]{2}{*}{ Ethnicity } & \multirow[b]{2}{*}{ First Language } & \multirow[b]{2}{*}{ SEN Status } & \multirow[b]{2}{*}{ FSM Status } & \multicolumn{2}{|c|}{$\begin{array}{c}\text { EAST } \\
\text { MIDLANDS }\end{array}$} & \multicolumn{2}{|c|}{$\begin{array}{l}\text { EAST OF } \\
\text { ENGLAND }\end{array}$} & \multicolumn{2}{|c|}{$\begin{array}{l}\text { INNER } \\
\text { LONDON }\end{array}$} & \multicolumn{2}{|c|}{ NORTH EAST } & \multicolumn{2}{|c|}{ NORTH WEST } & \multicolumn{2}{|c|}{$\begin{array}{l}\text { OUTER } \\
\text { LONDON }\end{array}$} & \multicolumn{2}{|c|}{ SOUTH EAST } & \multicolumn{2}{|c|}{ SOUTH WEST } & \multicolumn{2}{|c|}{$\begin{array}{c}\text { WEST } \\
\text { MIDLANDS }\end{array}$} & \multicolumn{2}{|c|}{$\begin{array}{c}\text { YORKSHIRE } \\
\text { AND THE } \\
\text { HUMEER }\end{array}$} \\
\hline & & & & Girls & Boys & Girls & Boys & Girls & Boys & Girls & Boys & Girls & Boys & Girls & Boys & Girls & Boys & Girls & Boys & Girls & Boys & Girls & \\
\hline \multirow{12}{*}{ Other Ethnicity } & English or Unclassified & No SEN & Not FSM & $x$ & 17 & 12 & $x$ & 25 & 25 & $x$ & $\mathrm{x}$ & 21 & 19 & 32 & 49 & 38 & 29 & $x$ & $x$ & $x$ & $\mathrm{x}$ & 20 & 14 \\
\hline & & & FSM & $x$ & $x$ & $x$ & $x$ & 15 & 21 & - & - & $x$ & $x$ & 11 & 11 & $x$ & $x$ & $x$ & - & $x$ & $x$ & 10 & $x$ \\
\hline & & SEN at Action $/$ Plus & NotFSM & - & $x$ & $x$ & $x$ & - & $x$ & - & - & $x$ & $x$ & $x$ & 22 & $x$ & $x$ & - & $x$ & $x$ & $x$ & $x$ & $x$ \\
\hline & & & FSM & $x$ & $x$ & $x$ & $x$ & $x$ & $x$ & $x$ & - & $x$ & $x$ & $x$ & 11 & $x$ & $x$ & $x$ & - & $x$ & - & $x$ & $\mathrm{x}$ \\
\hline & & Statemented SEN & Not FSM & - & $x$ & & $x$ & $x$ & $x$ & - & - & - & - & $x$ & $x$ & - & $x$ & - & - & $x$ & - & $x$ & - \\
\hline & & & FSM & & $x$ & & $x$ & & & & & & & & & & & & & & & & \\
\hline & Other than English & No SEN & Not FSM & 43 & 34 & 69 & 96 & 187 & 186 & $x$ & $x$ & 98 & 76 & 198 & 204 & 133 & 125 & 27 & 27 & 63 & 63 & 109 & 91 \\
\hline & & & FSM & 18 & 17 & 14 & 13 & 186 & 160 & - & $x$ & 48 & 47 & 88 & 85 & 14 & 15 & $x$ & $x$ & 35 & 40 & 38 & 35 \\
\hline & & SEN at Action / Plus & NotFSM & $x$ & 12 & 10 & 24 & 28 & 48 & $x$ & $x$ & $x$ & 20 & 34 & 76 & 12 & 31 & $x$ & $x$ & 10 & 17 & 13 & 25 \\
\hline & & & FSM & $\mathrm{x}$ & $\mathrm{x}$ & $\mathrm{x}$ & $\mathrm{x}$ & 48 & 70 & . & - & 12 & 22 & 30 & 61 & $\mathrm{x}$ & $\mathrm{x}$ & - & $\hat{-}$ & 10 & 10 & 10 & 17 \\
\hline & & Statemented SEN & Not FSM & - & - & - & - & $x$ & $x$ & - & - & - & $x$ & - & $x$ & - & $x$ & - & $x$ & - & $x$ & $\mathrm{x}$ & - \\
\hline & & & FSM & & & & & $\mathrm{x}$ & 10 & - & - & - & $x$ & $x$ & & & & $\mathrm{x}$ & $\hat{x}$ & - & & & $\mathrm{x}$ \\
\hline \multirow[t]{12}{*}{ Unknown Ethnicity } & English or Unclassified & No SEN & Not FSM & 846 & 807 & 294 & 317 & 48 & 61 & 99 & 99 & 60 & 58 & 247 & 253 & 178 & 172 & 121 & 98 & 585 & 546 & 129 & 112 \\
\hline & & & FSM & 125 & 128 & 113 & 107 & 32 & 25 & 28 & 31 & 24 & 20 & 90 & 66 & 28 & 37 & 15 & 13 & 244 & 220 & 18 & 20 \\
\hline & & SEN at Action / Plus & NotFSM & 47 & 110 & 23 & 43 & $x$ & $\mathrm{x}$ & $x$ & $x$ & $x$ & $x$ & 20 & 49 & 27 & 51 & 16 & 31 & 45 & 85 & $x$ & 12 \\
\hline & & & FSM & 35 & 54 & 16 & 28 & $\mathrm{x}$ & $x$ & $\mathrm{x}$ & $\mathrm{x}$ & $x$ & $x$ & 17 & 26 & 21 & 22 & $\mathrm{x}$ & 12 & 30 & 67 & $x$ & $\mathrm{x}$ \\
\hline & & Statemented SEN & NotFSM & $x$ & $\mathrm{x}$ & $x$ & $x$ & - & $x$ & - & $\hat{x}$ & - & $\hat{x}$ & $x$ & $x$ & - & $x$ & - & $x$ & - & - & - & . \\
\hline & & & FSM & & $\mathrm{x}$ & & $\mathrm{x}$ & & $\mathrm{x}$ & - & - & - & $x$ & & & & $\mathrm{x}$ & $x$ & $\mathrm{x}$ & $x$ & $x$ & - & $x$ \\
\hline & Other than English & No SEN & Not FSM & 78 & 103 & 16 & 21 & 50 & 48 & - & - & 11 & $\mathrm{x}$ & 10 & 16 & 23 & 22 & $x$ & $x$ & $x$ & 10 & $x$ & 13 \\
\hline & & & FSM & 11 & 18 & & $x$ & 35 & 24 & - & - & $x$ & - & $\mathrm{x}$ & $x$ & $x$ & & - & $\mathrm{x}$ & $\mathrm{x}$ & $\mathrm{x}$ & - & $\mathrm{x}$ \\
\hline & & SEN at Action / Plus & NotFSM & $x$ & 10 & - & $x$ & $x$ & $x$ & - & - & - & - & - & - & $x$ & $x$ & $x$ & - & $x$ & $x$ & $x$ & $x$ \\
\hline & & & FSM & - & $x$ & $x$ & - & $x$ & $x$ & - & - & $x$ & - & - & $x$ & $x$ & - & - & - & $x$ & $x$ & - & - \\
\hline & & Statemented SEN & NotFSM & - & $x$ & - & $x$ & - & $x$ & - & - & - & - & - & - & - & $x$ & - & - & $x$ & - & - & - \\
\hline & & & FSM & - & - & - & - & - & - & - & - & - & - & - & - & - & - & - & - & - & - & - & - \\
\hline
\end{tabular}

x" represents 1-9 pupils, suppressed to protect confidentiality

“-“ represents zero pupils 
Detailed Population Profile: Key Stage 2 Schools Below the Floor Standards ...continued

\begin{tabular}{|c|c|c|c|c|c|c|c|c|c|c|c|c|c|c|c|c|c|c|c|c|c|c|c|}
\hline \multirow[b]{3}{*}{ Ethnicity } & \multirow[b]{3}{*}{ First Language } & \multirow[b]{3}{*}{ SEN Status } & \multirow[b]{3}{*}{ FSM Status } & \multicolumn{20}{|c|}{ Below Floor 09 (BC) } \\
\hline & & & & \multicolumn{2}{|c|}{$\begin{array}{c}\text { EAST } \\
\text { MIDLANDS }\end{array}$} & \multicolumn{2}{|c|}{$\begin{array}{l}\text { EAST OF } \\
\text { ENGLAND }\end{array}$} & \multicolumn{2}{|c|}{$\begin{array}{l}\text { INNER } \\
\text { LONDON }\end{array}$} & \multirow{2}{*}{$\begin{array}{l}\text { NORTh } \\
\text { Girls }\end{array}$} & \multirow{2}{*}{$\begin{array}{l}\text { EAST } \\
\text { Bovs }\end{array}$} & \multicolumn{2}{|c|}{ NORTH WEST } & \multicolumn{2}{|c|}{$\begin{array}{l}\text { OUTER } \\
\text { LONDON }\end{array}$} & SOUT & EAST & SOUTh & WMEST & W & ST & $\begin{array}{l}\text { YORK } \\
\text { AND } \\
\text { HUN }\end{array}$ & $\begin{array}{l}\text { SHRE } \\
\text { THE } \\
\text { BER }\end{array}$ \\
\hline & & & & Girls & Boys & Girls & Boys & Girls & Boys & & & Girls & Boys & Girls & Boys & Girls & Boys & Girls & Boys & Girls & Boys & Girls & Boys \\
\hline Eangladeshi & English or Unclassified & No SEN & NotFSM & $x$ & $x$ & $x$ & $x$ & $x$ & $x$ & - & - & $x$ & $x$ & $x$ & $x$ & $\frac{\operatorname{mos}}{x}$ & $\frac{10}{x}$ & $x$ & $\frac{x}{x}$ & $x$ & $\frac{x}{x}$ & 14 & 17 \\
\hline & & & FSM & - & - & - & - & $x$ & $x$ & - & $x$ & $x$ & $x$ & - & $x$ & - & - & $x$ & - & $x$ & $x$ & $x$ & $x$ \\
\hline & & SEN at Action / Plus & Not FSM & $x$ & $x$ & - & - & $x$ & $x$ & $x$ & - & $x$ & - & - & - & - & - & - & $x$ & $x$ & $x$ & $x$ & $x$ \\
\hline & & & FSM & $x$ & - & - & - & - & $x$ & - & - & $x$ & - & - & - & - & - & - & - & - & $x$ & - & - \\
\hline & & Statemented SEN & Not FSM & - & - & - & - & - & - & - & - & - & - & - & - & - & - & - & - & - & - & - & - \\
\hline & & & FSM & - & & - & - & - & $x$ & - & - & - & - & - & - & - & - & - & - & - & - & - & - \\
\hline & Other than English & No SEN & Not FSM & 35 & 28 & 16 & 19 & 160 & 148 & 23 & 24 & 200 & 162 & 79 & 59 & 46 & 45 & 18 & 11 & 127 & 133 & 294 & 251 \\
\hline & & & FSM & 12 & $x$ & $x$ & $x$ & 90 & 75 & $x$ & $x$ & 72 & 54 & 31 & 22 & $x$ & $x$ & $x$ & $x$ & 74 & 55 & 82 & 69 \\
\hline & & SEN at Action / Plus & Not FSM & $x$ & $\mathrm{x}$ & $x$ & $x$ & 30 & 39 & $x$ & 16 & 32 & 61 & 12 & 22 & 14 & 19 & - & $x$ & 28 & 39 & 44 & 79 \\
\hline & & & FSM & $\mathrm{x}$ & $\mathrm{x}$ & $\mathrm{x}$ & $\mathrm{x}$ & 32 & 29 & 12 & $\mathrm{x}$ & 23 & 29 & $\mathrm{x}$ & $\mathrm{x}$ & $x$ & 10 & $x$ & $\mathrm{x}$ & 23 & 33 & 15 & 39 \\
\hline & & Statemented SEN & Not FSM & $x$ & $x$ & - & $\mathrm{x}$ & $x$ & $\mathrm{x}$ & - & $x$ & $x$ & $x$ & $\mathrm{x}$ & $x$ & $\mathrm{x}$ & $x$ & - & $\mathrm{x}$ & $x$ & $x$ & - & $x$ \\
\hline & & & FSM & $\mathrm{x}$ & & - & & $\mathrm{x}$ & $\mathrm{x}$ & - & $\therefore$ & $\hat{x}$ & $x$ & & $\hat{x}$ & . & - & - & $\therefore$ & $\mathrm{x}$ & & - & $x$ \\
\hline Indian & English or Unclassified & No SEN & Not FSM & 37 & 40 & $x$ & 11 & $x$ & $x$ & $x$ & $x$ & 14 & 15 & 11 & 10 & $\bar{x}$ & $x$ & $x$ & $x$ & 34 & 46 & 13 & $x$ \\
\hline & & & FSM & $x$ & $\mathrm{x}$ & $\mathrm{x}$ & $x$ & - & - & $x$ & - & $x$ & $x$ & $\mathrm{x}$ & $x$ & - & - & - & - & $x$ & $\mathrm{x}$ & $x$ & . \\
\hline & & SEN at Action / Plus & NotFSM & $x$ & $x$ & - & $\mathrm{x}$ & - & $\mathrm{x}$ & - & - & $x$ & $x$ & $x$ & $x$ & - & - & - & $\mathrm{x}$ & $x$ & $x$ & - & - \\
\hline & & & FSM & $x$ & - & - & - & - & - & - & $x$ & $x$ & $x$ & - & $x$ & - & - & - & $x$ & $x$ & $x$ & - & - \\
\hline & & Statemented SEN & Not FSM & - & $x$ & - & - & - & - & - & - & - & - & $x$ & $\mathrm{x}$ & - & $x$ & - & - & - & - & - & - \\
\hline & & & FSM & - & $x$ & - & - & - & - & - & $x$ & - & - & - & - & - & & - & - & - & - & - & - \\
\hline & Other than English & No SEN & Not FSM & 116 & 128 & 29 & 17 & 23 & 24 & $x$ & $x$ & 104 & 92 & 69 & 77 & 25 & 26 & 14 & 13 & 171 & 148 & 182 & 146 \\
\hline & & & FSM & 15 & 15 & - & - & $x$ & $x$ & - & - & 21 & 13 & $x$ & $x$ & $x$ & $x$ & $x$ & $x$ & 26 & 19 & 14 & 16 \\
\hline & & SEN at Action / Plus & Not FSM & $x$ & 27 & - & $x$ & $x$ & $\mathrm{x}$ & $x$ & $x$ & $x$ & $x$ & 17 & 15 & $x$ & $x$ & $x$ & - & 15 & 27 & 11 & 34 \\
\hline & & & FSM & $\mathrm{x}$ & $x$ & - & - & $x$ & $x$ & - & $x$ & $x$ & $x$ & $\mathrm{x}$ & $x$ & $x$ & - & - & - & $x$ & 10 & $x$ & $x$ \\
\hline & & Statemented SEN & Not FSM & - & $x$ & - & $x$ & - & $x$ & - & $\mathrm{x}$ & - & $x$ & $x$ & $x$ & - & - & $x$ & - & - & $\mathrm{x}$ & - & $x$ \\
\hline & & & FSM & - & $x$ & - & $\mathrm{x}$ & - & $\mathrm{x}$ & - & $\mathrm{x}$ & $x$ & - & $x$ & $\hat{x}$ & - & - & - & - & - & . & $x$ & \\
\hline Pakistani & English or Unclassified & No SEN & Not FSM & 11 & 12 & $x$ & - & $x$ & $x$ & $x$ & $x$ & 75 & 70 & 15 & $x$ & $x$ & $x$ & $x$ & $x$ & 56 & 46 & 85 & 78 \\
\hline & & & FSM & $x$ & $x$ & - & - & - & - & $x$ & $x$ & $x$ & 16 & - & $x$ & $x$ & $x$ & $x$ & $x$ & 33 & 28 & 15 & 19 \\
\hline & & SEN at Action / Plus & Not FSM & - & $\mathrm{x}$ & $x$ & $x$ & - & $x$ & . & - & $x$ & 12 & $x$ & $\hat{x}$ & $x$ & $x$ & $\mathrm{x}$ & $x$ & $x$ & 21 & $x$ & 25 \\
\hline & & & FSM & - & - & - & - & - & - & - & $x$ & $\mathrm{x}$ & $x$ & $x$ & $\mathrm{x}$ & - & - & - & - & $x$ & 19 & $\mathrm{x}$ & 10 \\
\hline & & Statemented SEN & Not FSM & - & - & - & - & - & - & - & - & - & - & $x$ & - & - & - & - & - & - & $x$ & $x$ & - \\
\hline & & & FSM & - & - & - & - & - & - & $x$ & - & - & $x$ & - & - & - & - & - & - & - & - & - & - \\
\hline & Other than English & No SEN & Not FSM & 41 & 42 & 12 & 21 & 29 & 30 & 23 & 15 & 486 & 461 & 107 & 113 & 43 & 36 & 15 & 17 & 904 & 780 & 1413 & 1193 \\
\hline & & & FSM & 12 & 21 & $x$ & $x$ & $x$ & $x$ & $x$ & $x$ & 141 & 125 & 25 & 25 & $x$ & $x$ & $x$ & $x$ & 321 & 293 & 393 & 320 \\
\hline & & SEN at Action / Plus & Not FSM & $x$ & 12 & $\mathrm{x}$ & $\hat{x}$ & 10 & 11 & $\mathrm{x}$ & $\mathrm{x}$ & 80 & 126 & 28 & 67 & 10 & 32 & - & $x$ & 165 & 376 & 293 & 463 \\
\hline & & & FSM & $\hat{x}$ & 12 & $\hat{x}$ & $\hat{x}$ & $x$ & $x$ & $\hat{x}$ & $\hat{x}$ & 42 & 56 & 16 & 19 & $x$ & 10 & - & $\mathrm{x}$ & 125 & 182 & 128 & 196 \\
\hline & & Statemented SEN & Not FSM & - & $x$ & $x$ & - & - & $x$ & $x$ & $x$ & $x$ & 11 & $x$ & $x$ & - & $x$ & - & - & 13 & 28 & 26 & 27 \\
\hline & & & FSM & - & - & $x$ & - & - & $x$ & - & - & $x$ & $x$ & - & $x$ & - & $x$ & - & - & $x$ & $\mathrm{x}$ & 15 & 15 \\
\hline Other Asian & English or Unclassified & No SEN & Not FSM & 10 & $x$ & $\mathrm{x}$ & $x$ & $x$ & $x$ & $x$ & $x$ & 18 & 12 & 12 & $x$ & 10 & $x$ & - & $x$ & 11 & $x$ & 11 & $x$ \\
\hline & & & FSM & $\mathrm{x}$ & $x$ & $x$ & $\mathrm{x}$ & $\mathrm{x}$ & $x$ & $x$ & - & $x$ & $x$ & $\mathrm{x}$ & - & $\mathrm{x}$ & - & - & $x$ & $x$ & $x$ & $x$ & $x$ \\
\hline & & SEN at Action / Plus & Not FSM & - & $x$ & $x$ & $x$ & - & $\mathrm{x}$ & - & $x$ & $x$ & $x$ & - & $x$ & $x$ & $x$ & - & $x$ & - & $x$ & - & $x$ \\
\hline & & & FSM & $x$ & $\hat{x}$ & - & - & $x$ & $x$ & - & $x$ & $x$ & $x$ & - & $\hat{x}$ & $\mathrm{x}$ & - & - & - & $x$ & $\mathrm{x}$ & $x$ & $\mathrm{x}$ \\
\hline & & Statemented SEN & Not FSM & . & 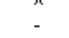 & - & - & $\hat{x}$ & 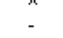 & . & . & $\hat{-}$ & 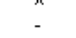 & - & $\hat{-}$ & . & - & - & - & 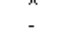 & . & $\hat{-}$ & 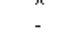 \\
\hline & & & FSM & - & - & - & $x$ & - & - & - & - & - & - & - & - & - & - & - & - & - & - & - & - \\
\hline & Other than English & No SEN & Not FSM & 28 & 30 & 14 & 16 & 46 & 40 & 27 & 17 & 46 & 38 & 62 & 67 & 50 & 62 & 12 & 16 & 50 & 53 & 74 & 74 \\
\hline & & & FSM & $x$ & $x$ & - & $x$ & 11 & 11 & $x$ & $x$ & 11 & $\mathrm{x}$ & 19 & 11 & $x$ & $x$ & $x$ & $\mathrm{x}$ & 24 & 19 & 17 & 16 \\
\hline & & SEN at Action / Plus & Not FSM & $x$ & $x$ & - & $x$ & $x$ & 14 & $\mathrm{x}$ & $x$ & $x$ & $x$ & 16 & 16 & 11 & $x$ & $x$ & $x$ & 11 & 11 & $\mathrm{x}$ & 11 \\
\hline & & & FSM & $x$ & $\mathrm{x}$ & - & - & - & $x$ & $\mathrm{x}$ & $\mathrm{x}$ & $\mathrm{x}$ & $\mathrm{x}$ & $x$ & $\mathrm{x}$ & $\mathrm{x}$ & $\mathrm{x}$ & - & $\mathrm{x}$ & $x$ & 10 & $\mathrm{x}$ & $x$ \\
\hline & & Statemented SEN & NotFSM & $x$ & . & - & - & $x$ & $\mathrm{x}$ & - & - & . & . & $x$ & $\hat{x}$ & $\hat{x}$ & . & - &. &. & - & . & - \\
\hline & & & FSM & - & - & - & - & $x$ & - & - & - & - & $x$ & - & - & - & - & - & - & - & $x$ & $x$ & - \\
\hline
\end{tabular}

"x" represents 1-9 pupils, suppressed to protect confidentiality " "-" represents zero pupils 
Detailed Population Profile: Key Stage 2 Schools Below the Floor Standards ...continued

\begin{tabular}{|c|c|c|c|c|c|c|c|c|c|c|c|c|c|c|c|c|c|c|c|c|c|c|c|}
\hline \multirow[b]{3}{*}{ Ethnicity } & \multirow[b]{3}{*}{ First L anouage } & \multirow[b]{3}{*}{ SEN Status } & \multirow[b]{3}{*}{ FSM Status } & \multicolumn{20}{|c|}{ Below floor 09 (BC) } \\
\hline & & & & \multicolumn{2}{|c|}{$\begin{array}{c}\text { EAST } \\
\text { MIDLANDS }\end{array}$} & \multicolumn{2}{|c|}{$\begin{array}{l}\text { EAST OF } \\
\text { ENGLAND }\end{array}$} & \multicolumn{2}{|c|}{$\begin{array}{l}\text { INNER } \\
\text { LONDON }\end{array}$} & \multirow{2}{*}{$\begin{array}{l}\text { NORTh } \\
\text { Girls }\end{array}$} & \multirow{2}{*}{ HEAST } & \multicolumn{2}{|c|}{ NORTH WEST } & \multicolumn{2}{|c|}{$\begin{array}{l}\text { OUTER } \\
\text { LONDON }\end{array}$} & SOUT & & SOUTh & WMEST & W & ST & $\begin{array}{l}\text { YORK } \\
\text { AND } \\
\text { HUI }\end{array}$ & $\begin{array}{l}\text { SHRE } \\
\text { THE } \\
\text { BER }\end{array}$ \\
\hline & & & & Girls & Boys & Girls & Boys & Girls & Boys & & & Girls & Boys & Girls & Boys & Girls & Boys & Girls & Boys & Girls & Boys & Girls & Boys \\
\hline Black African & English or Unclassified & No SEN & NotFSM & 43 & 31 & 33 & 25 & 54 & 56 & 12 & $x$ & 27 & 22 & 103 & 77 & 41 & 27 & 18 & 20 & 45 & 38 & 40 & 50 \\
\hline & & & FSM & $x$ & $x$ & $x$ & $x$ & 21 & 13 & $x$ & $x$ & 14 & 15 & 23 & 14 & 11 & $x$ & 11 & $x$ & 12 & 12 & $x$ & 11 \\
\hline & & SEN at Action / Plus & Not FSM & $x$ & 11 & $x$ & $x$ & 12 & 33 & $x$ & $x$ & $x$ & $x$ & 15 & 32 & $x$ & $x$ & $x$ & $x$ & $x$ & $x$ & $x$ & $x$ \\
\hline & & & FSM & $x$ & $x$ & - & $x$ & $x$ & 16 & - & - & $x$ & 11 & $\mathrm{x}$ & 15 & $x$ & $\mathrm{x}$ & - & $x$ & $x$ & $x$ & - & $x$ \\
\hline & & Statemented SEN & Not FSM & - & $\mathrm{x}$ & - & $\mathrm{x}$ & - & $x$ & - & - & $x$ & $x$ & $x$ & $x$ & - & $\mathrm{x}$ & - & - & - & - & - & - \\
\hline & & & FSM & - & & - & & - & $x$ & - & - & & & & & - & & - & - & - & - & - & - \\
\hline & Other than English & No SEN & Not FSM & 60 & 61 & 25 & 26 & 232 & 199 & 17 & $x$ & 50 & 45 & 263 & 244 & 68 & 63 & 53 & 64 & 78 & 73 & 85 & 80 \\
\hline & & & FSM & 26 & 29 & $x$ & $x$ & 203 & 193 & $x$ & 15 & 102 & 91 & 205 & 187 & 34 & 28 & 66 & 51 & 124 & 95 & 54 & 39 \\
\hline & & SEN at Action / Plus & Not FSM & 11 & 21 & - & 10 & 42 & 72 & - & $x$ & $x$ & 14 & 41 & 77 & 11 & 23 & 10 & $x$ & 17 & 15 & 14 & 24 \\
\hline & & & FSM & $\mathrm{x}$ & 16 & - & $\mathrm{x}$ & 72 & 105 & $x$ & $\mathrm{x}$ & 23 & 34 & 62 & 110 & 11 & 13 & 16 & 30 & 28 & 38 & 18 & 23 \\
\hline & & Statemented SEN & Not FSM & - & $x$ & $x$ & - & $x$ & 15 & - & - & - & $x$ & - & $x$ & - & $x$ & - & $x$ & $x$ & - & - & $x$ \\
\hline & & & FSM & - & $x$ & & $x$ & $x$ & 14 & - & - & $x$ & $x$ & $x$ & $\mathrm{x}$ & - & - & $x$ & $x$ & $x$ & $x$ & - & $x$ \\
\hline Elack Caribbean & English or Unclassified & No SEN & Not FSM & 35 & 38 & 13 & $x$ & 147 & 142 & - & - & 22 & 13 & 107 & 83 & $x$ & 10 & 14 & 30 & 66 & 49 & 24 & 18 \\
\hline & & & FSM & 11 & 12 & $\mathrm{x}$ & $\mathrm{x}$ & 130 & 77 & - & - & 11 & 11 & 37 & 28 & $\mathrm{x}$ & $x$ & 11 & 14 & 47 & 35 & 16 & 12 \\
\hline & & SEN at Action / Plus & Not FSM & $x$ & 10 & $\mathrm{x}$ & $x$ & 49 & 95 & - & - & $x$ & 17 & 32 & 48 & - & $\mathrm{x}$ & $x$ & 14 & 12 & 28 & $x$ & 12 \\
\hline & & & FSM & $x$ & 10 & $x$ & $\mathrm{x}$ & 63 & 67 & - & - & $\mathrm{x}$ & 12 & 16 & 27 & $x$ & $\mathrm{x}$ & $\mathrm{x}$ & $x$ & 15 & 17 & $\mathrm{x}$ & $x$ \\
\hline & & Statemented SEN & Not FSM & - & - & $\mathrm{x}$ & $\mathrm{x}$ & - & 13 & - & - & - & $x$ & $x$ & $x$ & - & - & - & . & - & $x$ & - & $\hat{x}$ \\
\hline & & & FSM & - & - & - & - & $\mathrm{x}$ & 11 & - & - & - & $x$ & $x$ & $\mathrm{x}$ & - & - & - & - & $x$ & $x$ & - & $x$ \\
\hline & Other than English & No SEN & Not FSM & - & - & - & - & $x$ & $x$ & - & - & - & $x$ & $x$ & $x$ & $x$ & $x$ & - & $x$ & $x$ & $\mathrm{x}$ & $x$ & $x$ \\
\hline & & & FSM & $\mathrm{x}$ & $x$ & - & - & $\mathrm{x}$ & $x$ & - & - & $\mathrm{x}$ & $\mathrm{x}$ & $\mathrm{x}$ & $\mathrm{x}$ & - & - & - & - & - & $x$ & - & - \\
\hline & & SEN at Action / Plus & Not FSM & - & - & - & - & $x$ & $x$ & - & - & - & - & $x$ & $x$ & $x$ & - & - & - & - & $x$ & - & $x$ \\
\hline & & & FSM & - & - & - & - & $\hat{x}$ & - & - & - & - & - & $\hat{x}$ & $\hat{x}$ & $\hat{x}$ & - & - & - & - & - & $x$ & - \\
\hline & & Statemented SEN & Not FSM & - & - & - & - & - & $x$ & - & - & - & - & - & - & - & - & - & - & - & - & - & - \\
\hline & & & FSM & - & - & - & - & - & - & - & - & - & - & - & - & - & - & - & - & - & - & - & - \\
\hline Other Black & English or Unclassified & No SEN & Not FSM & 19 & 23 & $x$ & $x$ & 41 & 20 & - & $x$ & 19 & 10 & 29 & 31 & $x$ & 13 & 11 & $x$ & 19 & 35 & 10 & $x$ \\
\hline & & & FSM & 12 & $x$ & $x$ & $x$ & 18 & 15 & $x$ & - & 13 & 12 & 12 & $x$ & $x$ & $x$ & $x$ & $x$ & 19 & 10 & $x$ & $\mathrm{x}$ \\
\hline & & SEN at Action / Plus & Not FSM & - & $\hat{x}$ & . & $\hat{x}$ & $\mathrm{x}$ & 12 & $\hat{.}$ & - & - & $x$ & $\mathrm{x}$ & 10 & $\hat{x}$ & $\hat{x}$ & . & . & $\mathrm{x}$ & $x$ & $\hat{x}$ & $\hat{x}$ \\
\hline & & & FSM & $x$ & $\mathrm{x}$ & - & - & 12 & $x$ & - & - & $x$ & $x$ & $x$ & $x$ & $\mathrm{x}$ & $x$ & $x$ & $x$ & $x$ & $x$ & $\mathrm{x}$ & $x$ \\
\hline & & Statemented SEN & Not FSM & . & $\mathrm{x}$ & - & - & - & $x$ & - & - & . & $x$ & . & $\mathrm{x}$ & - & $x$ & - & . & . & - & . & . \\
\hline & & & FSM & - & - & - & - & - & - & - & - & - & $x$ & - & $x$ & - & - & - & $x$ & - & - & - & - \\
\hline & Other than English & No SEN & Not FSM & $x$ & $x$ & $\mathrm{x}$ & $x$ & 28 & 17 & $\mathrm{x}$ & $\mathrm{x}$ & $\mathrm{x}$ & $x$ & 15 & 19 & 12 & 13 & $x$ & $x$ & 10 & $\mathrm{x}$ & $\mathrm{x}$ & 11 \\
\hline & & & FSM & $x$ & $x$ & $x$ & $x$ & 13 & $x$ & $x$ & - & $x$ & $x$ & 11 & 10 & $\mathrm{x}$ & $x$ & - & $x$ & $x$ & $\mathrm{x}$ & $x$ & $x$ \\
\hline & & SEN at Action / Plus & Not FSM &. & $\mathrm{x}$ & - & $\hat{x}$ & $x$ & $x$ & . & $x$ & $\mathrm{x}$ & $x$ & $x$ & $x$ & $\mathrm{x}$ & $x$ & - & - & $\mathrm{x}$ & $\mathrm{x}$ & $\mathrm{x}$ & $\mathrm{x}$ \\
\hline & & & FSM & - & . & - & 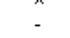 & $\hat{x}$ & $\mathrm{x}$ & $x$ & . & $\hat{x}$ & $\hat{x}$ & $\hat{x}$ & $\hat{x}$ & $\hat{x}$ & $\hat{x}$ & - & - & $\hat{x}$ & $\hat{x}$ & $\hat{x}$ & . \\
\hline & & Statemented SEN & Not FSM & - & - & - & - & - & - & - & - & - & - & - & - & - & - & - & - & - & - & $x$ & - \\
\hline & & & FSM & - & - & - & - & - & $x$ & - & - & - & - & $x$ & - & - & - & - & - & - & - & - & - \\
\hline Chinese & English or Unclassified & No SEN & Not FSM & $x$ & $x$ & $\mathrm{x}$ & $x$ & $x$ & $x$ & $x$ & $x$ & $x$ & $x$ & - & - & $x$ & $x$ & $x$ & $x$ & $x$ & - & $x$ & $x$ \\
\hline & & & FSM & - & - & - & - & $x$ & $x$ & - & - & - & $x$ & $x$ & - & - & - & - & - & $x$ & $x$ & - & - \\
\hline & & SEN at Action / Plus & Not FSM & - & - & - & - & - & $\mathrm{x}$ & - & - & - & - & - & - & - & - & - & $\mathrm{x}$ & - & - & - & - \\
\hline & & & FSM & - & - & - & - & - & - & - & - & - & $x$ & - & - & - & - & - & - & - & - & - & - \\
\hline & & Statemented SEN & Not FSM & - & - & - & - & - & - & - & - & - & 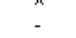 & - & - & - & - & - & - & - & - & - & - \\
\hline & & & FSM & - & - & - & - & - & - & - & - & - & - & - & - & - & - & - & - & - & - & - & $x$ \\
\hline & Other than English & No SEN & Not FSM & 14 & $x$ & $x$ & $x$ & 26 & 20 & 13 & 15 & 23 & 34 & 11 & 10 & 11 & $x$ & $x$ & 10 & $x$ & $x$ & 25 & 22 \\
\hline & & & FSM & & $\mathrm{x}$ & $\mathrm{x}$ & - & 12 & $x$ & - & - & - & $x$ & $\mathrm{x}$ & $x$ & - & $\mathrm{x}$ & - & - & $x$ & $\mathrm{x}$ & $x$ & $x$ \\
\hline & & SEN at Action / Plus & Not FSM & $x$ & $x$ & $x$ & $x$ & $x$ & $x$ & $x$ & $x$ & $x$ & $x$ & $x$ & $x$ & $x$ & $x$ & - & $x$ & - & $\mathrm{x}$ & $\mathrm{x}$ & $x$ \\
\hline & & & FSM & - & - & - & - & $\mathrm{x}$ & $x$ & - & - & $\mathrm{x}$ & $\mathrm{x}$ & - & - & - & - & - & - & - & $\mathrm{x}$ & $\mathrm{x}$ & $\mathrm{x}$ \\
\hline & & Statemented SEN & Not FSM & - & - & - & - & . & . & - & - & - & - & - & - & - & - & - & - & - & - & - & - \\
\hline & & & FSM & - & - & - & - & - & $x$ & - & - & - & - & - & - & - & - & - & - & - & - & - & - \\
\hline
\end{tabular}

" represents 1-9 pupils, suppressed to protect confidentiality "-" represents zero pupils 
Detailed Population Profile: Key Stage 2 Schools Below the Floor Standards ...continued

\begin{tabular}{|c|c|c|c|c|c|c|c|c|c|c|c|c|c|c|c|c|c|c|c|c|c|c|c|}
\hline \multirow[b]{3}{*}{ Ethnicity } & \multirow[b]{3}{*}{ First Language } & \multirow[b]{3}{*}{ SEN Status } & \multirow[b]{3}{*}{ FSM Status } & \multicolumn{20}{|c|}{ Below floor 09 (BC) } \\
\hline & & & & \multicolumn{2}{|c|}{$\begin{array}{l}\text { EAST } \\
\text { MIDLANDS }\end{array}$} & \multicolumn{2}{|c|}{$\begin{array}{l}\text { EAST OF } \\
\text { ENGLAND }\end{array}$} & \multicolumn{2}{|c|}{$\begin{array}{l}\text { INNER } \\
\text { LONDON }\end{array}$} & \multicolumn{2}{|c|}{ NORTH EAST } & \multicolumn{2}{|c|}{ NORTH WEST } & \multicolumn{2}{|c|}{$\begin{array}{l}\text { OUTER } \\
\text { LONDON }\end{array}$} & \multicolumn{2}{|c|}{ SOUTH EAST } & SOUTh $\mathrm{C}$ \& & WMEST & W & ST & & $\begin{array}{l}\text { THE } \\
\text { THER } \\
\text { BER }\end{array}$ \\
\hline & & & & Girls & Boys & Girls & Boys & Girls & Boys & Girls & Boys & Girls & Boys & Girls & Boys & Girls & Boys & Girls & Boys & Girls & Boys & Girls & Boys \\
\hline White \& Asian & English or Unclassified & No SEN & NotFSM & 22 & 34 & $x$ & $x$ & 13 & 11 & 13 & $x$ & 32 & 15 & 25 & 13 & 38 & $\frac{20}{20}$ & 14 & $\frac{12}{12}$ & 38 & 43 & 31 & 56 \\
\hline & & & FSM & 12 & $x$ & $x$ & $x$ & $\mathrm{x}$ & $x$ & $x$ & $x$ & 28 & 26 & $x$ & $x$ & $x$ & $x$ & $x$ & $x$ & 35 & 40 & 47 & 40 \\
\hline & & SEN at Action / Plus & NotFSM & $x$ & $x$ & $x$ & - & $x$ & $x$ & - & $x$ & $x$ & $x$ & $x$ & $x$ & $x$ & $x$ & - & $x$ & $x$ & 14 & $x$ & $x$ \\
\hline & & & FSM & $x$ & $x$ & $x$ & $x$ & $x$ & $x$ & $x$ & $x$ & $x$ & 16 & - & $x$ & $\mathrm{x}$ & $\mathrm{x}$ & $x$ & $x$ & $x$ & 23 & 12 & 22 \\
\hline & & Statemented SEN & Not FSM & - & - & - & $\mathrm{x}$ & - & - & - & $\mathrm{x}$ & - & - & $x$ & $x$ & - & $\mathrm{x}$ & - & $\mathrm{x}$ & - & - & - & $x$ \\
\hline & & & FSM & - & - & - & - & - & - & - & - & $x$ & $x$ & - & - & - & - & - & - & - & $\mathrm{x}$ & $x$ & $x$ \\
\hline & Other than English & No SEN & Not FSM & $x$ & $x$ & $\mathrm{x}$ & $\mathrm{x}$ & $x$ & $x$ & $x$ & $x$ & $x$ & $x$ & $x$ & 14 & $\mathrm{x}$ & $x$ & $x$ & $x$ & $x$ & $x$ & $x$ & $x$ \\
\hline & & & FSM & $x$ & $x$ & $\mathrm{x}$ & $x$ & - & - & - & $x$ & $\mathrm{x}$ & $x$ & - & $x$ & $x$ & $x$ & $x$ & $x$ & $x$ & $x$ & $\mathrm{x}$ & $x$ \\
\hline & & SEN at Action / Plus & Not FSM & - & $\mathrm{x}$ & - & $x$ & $x$ & $x$ & - & - & $\mathrm{x}$ & - & - & $\mathrm{x}$ & $x$ & $\mathrm{x}$ & . & - & $\mathrm{x}$ & $x$ & $\mathrm{x}$ & $x$ \\
\hline & & & FSM & - & - & - & $\mathrm{x}$ & $\mathrm{x}$ & . & - & - & . & - & - & $\mathrm{x}$ & $\mathrm{x}$ & - & $x$ & - & $\mathrm{x}$ & $\mathrm{x}$ & $\mathrm{x}$ & $\mathrm{x}$ \\
\hline & & Statemented SEN & Not FSM & $x$ & - & - & - & - & - & - & - & - & - & - & - & - & $x$ & - & - & - & - & - & - \\
\hline White \& Elack African & English or Unclassified & No SEN & Not FSM & 19 & 13 & 13 & 10 & 10 & $x$ & $x$ & $x$ & 19 & 12 & 21 & 17 & 23 & 23 & $x$ & 14 & 11 & 10 & 12 & 10 \\
\hline & & & FSM & $\mathrm{x}$ & $x$ & $\mathrm{x}$ & $x$ & $x$ & $x$ & $x$ & $x$ & $x$ & $x$ & $x$ & $x$ & $x$ & $x$ & $\hat{x}$ & $x$ & 13 & 12 & 17 & 11 \\
\hline & & SEN at Action / Plus & Not FSM & $x$ & $x$ & $\mathrm{x}$ & $\mathrm{x}$ & $\mathrm{x}$ & $x$ & - & $x$ & $\mathrm{x}$ & $x$ & $x$ & $x$ & $x$ & 10 & $x$ & $\mathrm{x}$ & - & $x$ & - & $x$ \\
\hline & & & FSM & $x$ & $x$ & $x$ & $\mathrm{x}$ & $\mathrm{x}$ & $\mathrm{x}$ & $x$ & $x$ & $\mathrm{x}$ & $\mathrm{x}$ & $x$ & $x$ & 10 & $\mathrm{x}$ & - & $\mathrm{x}$ & $x$ & $\mathrm{x}$ & $x$ & $\mathrm{x}$ \\
\hline & & Statemented SEN & Not FSM & - & - & - & - & - & - & . & - & - & - & - & $\mathrm{x}$ & - & $\mathrm{x}$ & $x$ & - & - & - & - & . \\
\hline & & & FSM & - & - & - & - & - & - & - & - & - & - & - & $\mathrm{x}$ & - & - & - & - & - & - & - & - \\
\hline & Other than English & No SEN & Not FSM & 12 & 10 & $x$ & $x$ & 15 & 15 & $x$ & $x$ & - & $x$ & 12 & 17 & $x$ & $x$ & - & $x$ & - & $\mathrm{x}$ & 13 & $x$ \\
\hline & & & FSM & - & $\mathrm{x}$ & $x$ & $\mathrm{x}$ & $\mathrm{x}$ & $x$ & - & $x$ & $\mathrm{x}$ & - & $x$ & $x$ & $x$ & $\mathrm{x}$ & $\mathrm{x}$ & - & - & $x$ & $x$ & $\mathrm{x}$ \\
\hline & & SEN at Action / Plus & Not FSM & $x$ & $x$ & $x$ & - & $x$ & $x$ & - & - & - & - & $x$ & $x$ & $x$ & $x$ & - & - & $x$ & - & $x$ & - \\
\hline & & & FSM & - & - & - & $x$ & $\hat{x}$ & $\hat{x}$ & - & - & - & $x$ & $\hat{x}$ & $\hat{x}$ & - & - & - & - & - & - & - & - \\
\hline & & Statemented SEN & Not FSM & - & - & - & - & - & - & - & - & - & - & - & - & - & - & - & - & - & - & - & - \\
\hline & & & FSM & - & - & $x$ & - & - & - & - & - & - & - & - & - & - & - & - & - & - & - & - & \\
\hline White \& Elack Caribbean & English or Unclassified & No SEN & Not FSM & 93 & 58 & 28 & 20 & 42 & 38 & $x$ & $x$ & 30 & 27 & 44 & 36 & 36 & 18 & 31 & 30 & 75 & 64 & 88 & 77 \\
\hline & & & FSM & 62 & 38 & 12 & $x$ & 35 & 28 & $x$ & $x$ & 24 & 21 & 24 & 17 & 13 & 13 & 18 & 11 & 74 & 48 & 53 & 39 \\
\hline & & SEN at Action / Plus & Not FSM & 16 & 26 & $\mathrm{x}$ & $\mathrm{x}$ & $\mathrm{x}$ & 13 & $\hat{x}$ & - & $x$ & $x$ & 11 & 21 & $x$ & 15 & $\mathrm{x}$ & 11 & 14 & 21 & 14 & 28 \\
\hline & & & FSM & 16 & 27 & $\mathrm{x}$ & $x$ & 11 & 33 & $x$ & - & $\mathrm{x}$ & $x$ & 12 & 23 & $\mathrm{x}$ & 10 & $\mathrm{x}$ & $x$ & 31 & 38 & 13 & 33 \\
\hline & & Statemented SEN & Not FSM & $x$ & $\mathrm{x}$ & - & - & - & $x$ & $\hat{-}$ & - & $\mathrm{x}$ & - & $\mathrm{x}$ & $\mathrm{x}$ & - & $x$ & $\mathrm{x}$ & . & $x$ & $x$ & - & $x$ \\
\hline & & & FSM & - & $x$ & - & $x$ & - & $\mathrm{x}$ & - & - & - & $x$ & $x$ & $\mathrm{x}$ & $x$ & - & $x$ & $\mathrm{x}$ & - & $x$ & - & $\mathrm{x}$ \\
\hline & Other than English & No SEN & Not FSM & - & - & - & - & $x$ & $x$ & - & - & $\mathrm{x}$ & $x$ & $\mathrm{x}$ & $x$ & - & $x$ & $\mathrm{x}$ & $\mathrm{x}$ & - & - & $\mathrm{x}$ & $\mathrm{x}$ \\
\hline & & & FSM & - & $x$ & - & - & - & - & - & $x$ & - & - & - & $x$ & - & - & - & - & - & - & $x$ & - \\
\hline & & SEN at Action / Plus & Not FSM & - & . & - & - & - & $x$ & - & - & - & - & $x$ & $\mathrm{x}$ & - & - & - & - & - & - & . & - \\
\hline & & & FSM & - & - & - & - & $x$ & . & - & - & - & - & . & $\hat{x}$ & - & - & - & - & - & - & - & - \\
\hline & & Statemented SEN & Not FSM & - & - & - & - & - & - & - & - & - & - & - & - & - & - & - & - & - & - & - & - \\
\hline & & & FSM & - & - & - & - & - & - & - & - & - & - & - & - & - & - & - & - & - & - & - & - \\
\hline Other Mixed & English or Unclassified & No SEN & Not FSM & 36 & 31 & 23 & 18 & 33 & 32 & $x$ & $x$ & 43 & 28 & 60 & 60 & 49 & 35 & 28 & 13 & 54 & 35 & 41 & 47 \\
\hline & & & FSM & 17 & 17 & 12 & $x$ & 13 & 16 & $x$ & $x$ & 23 & 23 & 15 & 11 & 16 & 13 & 12 & $x$ & 63 & 32 & 25 & 24 \\
\hline & & SEN at Action / Plus & NotFSM & $x$ & 12 & $\mathrm{x}$ & $\mathrm{x}$ & $x$ & 10 & - & $x$ & $x$ & $x$ & $x$ & 17 & 10 & 15 & $x$ & $x$ & $x$ & 10 & $\mathrm{x}$ & 13 \\
\hline & & & FSM & $\hat{x}$ & $x$ & $\hat{x}$ & $\mathrm{x}$ & $\mathrm{x}$ & 16 & $x$ & $x$ & $\mathrm{x}$ & 13 & $\mathrm{x}$ & 12 & $\mathrm{x}$ & 15 & $\mathrm{x}$ & $x$ & 15 & 24 & $\mathrm{x}$ & 14 \\
\hline & & Statemented SEN & Not FSM & . & 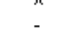 & . & $\hat{-}$ & $\hat{x}$ & $x$ & $\hat{-}$ & $\hat{x}$ & $\hat{-}$ & $x$ & 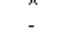 & $\mathrm{x}$ & $\hat{x}$ & $\mathrm{x}$ & 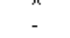 & 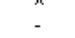 & - & $x$ & $\hat{-}$ & - \\
\hline & & & FSM & - & - & - & - & - & $x$ & - & - & - & $\hat{x}$ & $x$ & $x$ & $x$ & . & - & $x$ & $x$ & . & $x$ & $x$ \\
\hline & Other than English & No SEN & Not FSM & $x$ & $x$ & $x$ & $x$ & 31 & 25 & $x$ & $x$ & 12 & 10 & 38 & 42 & 14 & 11 & $x$ & $x$ & 10 & 17 & 16 & 16 \\
\hline & & & FSM & $\mathrm{x}$ & $\mathrm{x}$ & $\mathrm{x}$ & - & 14 & 12 & - & $\mathrm{x}$ & $x$ & $\mathrm{x}$ & 24 & 19 & $x$ & $x$ & - & - & 10 & $x$ & $x$ & $x$ \\
\hline & & SEN at Action / Plus & Not FSM & - & $x$ & $x$ & $x$ & $x$ & $x$ & $x$ & - & $\mathrm{x}$ & - & $x$ & 20 & $x$ & $x$ & $x$ & - & $x$ & $\mathrm{x}$ & $\mathrm{x}$ & $x$ \\
\hline & & & FSM & $x$ & - & - & - & $\mathrm{x}$ & $x$ & $\mathrm{x}$ & $x$ & - & $x$ & $\mathrm{x}$ & 12 & - & $x$ & - & - & $\mathrm{x}$ & $\mathrm{x}$ & $\mathrm{x}$ & $\mathrm{x}$ \\
\hline & & Statemented SEN & Not FSM &. & - & - & - &. & $\hat{x}$ & $\hat{x}$ &. & - &. & - & - & - & $x$ & - & - & . & . & . & $x$ \\
\hline & & & FSM & - & - & - & - & - & $x$ & - & - & - & - & $x$ & $x$ & - & - & - & - & $\mathrm{x}$ & - & - & - \\
\hline
\end{tabular}

"x" represents $1-9$ pupils, suppressed to protect confidentiality

"-" represents zero pupils 
Detailed Population Profile: Key Stage 2 Schools Below the Floor Standards ...continued

\begin{tabular}{|c|c|c|c|c|c|c|c|c|c|c|c|c|c|c|c|c|c|c|c|c|c|c|c|}
\hline \multirow[b]{3}{*}{ Ethnicity } & \multirow[b]{3}{*}{ First Lanquage } & \multirow[b]{3}{*}{ SEN Status } & \multirow[b]{3}{*}{ FSM Status } & \multicolumn{20}{|c|}{ Below Floor 09 (BC) } \\
\hline & & & & \multicolumn{2}{|c|}{$\begin{array}{c}\text { EAST } \\
\text { MIDLANDS }\end{array}$} & \multicolumn{2}{|c|}{$\begin{array}{l}\text { EAST OF } \\
\text { ENGLAND }\end{array}$} & \multicolumn{2}{|c|}{$\begin{array}{l}\text { INNER } \\
\text { LONDON }\end{array}$} & \multirow{2}{*}{$\begin{array}{l}\text { NORTh } \\
\text { Girls }\end{array}$} & EAST & \multicolumn{2}{|c|}{ NORTH WEST } & \multicolumn{2}{|c|}{$\begin{array}{l}\text { OUTER } \\
\text { LONDON }\end{array}$} & SOUTH & & SOUTH & WMEST & & ST & AND & $\begin{array}{l}\text { THE } \\
\text { THER } \\
\text { BER }\end{array}$ \\
\hline & & & & Girls & Boys & Girls & Boys & Girls & Boys & & Boys & Girls & Boys & Girls & Boys & Girls & Boys & Girls & Boys & Girls & Boys & Girls & Boys \\
\hline White British & English or Unclassified & No SEN & Not FSM & 1873 & 1691 & 1166 & 1099 & 186 & 150 & 2349 & 2153 & 3379 & 3100 & 728 & 695 & 2739 & 2291 & 1734 & 1609 & 2821 & 2543 & 3772 & 3536 \\
\hline & & & FSM & 602 & 477 & 406 & 276 & 82 & 80 & 1239 & 990 & 1745 & 1501 & 262 & 193 & 873 & 594 & 498 & 442 & 1389 & 1098 & 1588 & 1195 \\
\hline & & SEN at Action / Plus & NotFSM & 317 & 582 & 191 & 363 & 35 & 62 & 340 & 704 & 518 & 980 & 127 & 248 & 761 & 1306 & 257 & 446 & 449 & 965 & 663 & 1285 \\
\hline & & & FSM & 280 & 448 & 162 & 251 & 48 & 88 & 499 & 828 & 662 & 1069 & 120 & 178 & 571 & 736 & 170 & 335 & 536 & 926 & 826 & 1109 \\
\hline & & Statemented SEN & Not FSM & 15 & 35 & 23 & 78 & $x$ & $\mathrm{x}$ & 22 & 82 & 36 & 89 & 14 & 45 & 51 & 103 & 21 & 50 & 25 & 70 & 33 & 99 \\
\hline & & & FSM & 16 & 27 & 15 & 42 & $\mathrm{x}$ & 11 & 31 & 68 & 36 & 70 & $\mathrm{x}$ & 26 & 19 & 61 & 10 & 34 & 21 & 68 & 25 & 93 \\
\hline & Other than English & No SEN & Not FSM & $x$ & $x$ & $x$ & $x$ & $x$ & $x$ & $x$ & $x$ & $\mathrm{x}$ & $x$ & 13 & 19 & 20 & 18 & $x$ & $\mathrm{x}$ & 11 & $x$ & 14 & $\mathrm{x}$ \\
\hline & & & FSM & - & $x$ & $\mathrm{x}$ & $x$ & $x$ & $x$ & $x$ & $x$ & $x$ & $x$ & $x$ & $x$ & $x$ & $x$ & $x$ & - & $x$ & - & $x$ & - \\
\hline & & SEN at Action / Plus & Not FSM & $x$ & $\mathrm{x}$ & $\mathrm{x}$ & $\mathrm{x}$ & $x$ & $\mathrm{x}$ & - & $x$ & - & - & - & $\mathrm{x}$ & $x$ & $x$ & - & $x$ & $\mathrm{x}$ & $x$ & - & $x$ \\
\hline & & & FSM & - & $x$ & - & - & $x$ & $x$ & - & - & $x$ & $x$ & $x$ & $x$ & $x$ & $x$ & $x$ & $x$ & - & $x$ & $x$ & $x$ \\
\hline & & Statemented SEN & Not FSM & $x$ & $x$ & - & - & - & - & - & - & - & - & - & - & - & - & - & - & - & - & $\mathrm{x}$ & $\mathrm{x}$ \\
\hline & & & FSM & $\therefore$ & $\therefore$ & $\mathrm{x}$ & - & - & $x$ & - & - & - & - & - & - & - & - & - & - & - & - & $\mathrm{x}$ & . \\
\hline Irish & English or Unclassified & No SEN & Not FSM & $x$ & $x$ & $x$ & $x$ & $x$ & $x$ & $x$ & $x$ & $x$ & $x$ & $x$ & $x$ & $\bar{x}$ & $x$ & $x$ & $x$ & $\bar{x}$ & $x$ & $x$ & $x$ \\
\hline & & & FSM & $x$ & $\mathrm{x}$ & $\mathrm{x}$ & $\mathrm{x}$ & $\hat{x}$ & $x$ & - & - & $\mathrm{x}$ & $\hat{x}$ & $x$ & $x$ & $\mathrm{x}$ & $\mathrm{x}$ & - & - & $x$ & $\mathrm{x}$ & $\mathrm{x}$ & $\mathrm{x}$ \\
\hline & & SEN at Action / Plus & Not FSM & $x$ & $x$ & $\mathrm{x}$ & $x$ & $\mathrm{x}$ & $x$ & - & $x$ & - & - & $x$ & $x$ & - & - & $x$ & $\mathrm{x}$ & $\mathrm{x}$ & $\mathrm{x}$ & - & $x$ \\
\hline & & & FSM & - & $x$ & - & $x$ & $x$ & $x$ & - & - & $x$ & $x$ & $x$ & $x$ & - & $x$ & - & - & $x$ & $x$ & - & $x$ \\
\hline & & Statemented SEN & Not FSM & - & - & - & - & - & $x$ & - & - & - & - & - & -. & - & $x$ & - & - & - & - & - & -. \\
\hline & & & FSM & - & - & - & - & $\mathrm{x}$ & - & - & - & $x$ & - & - & - & - & - & - & - & $x$ & - & - & - \\
\hline & Other than English & No SEN & Not FSM & - & $x$ & - & - & - & - & - & - & - & - & - & - & - & - & - & - & - & - & - & - \\
\hline & & & FSM & - & - & - & - & - & - & - & - & - & - & $x$ & $x$ & - & - & - & - & - & $x$ & - & - \\
\hline & & SEN at Action / Plus & Not FSM & - & - & - & - & - & $x$ & - & - & - & - & - & - & - & - & - & - & - & - & - & $x$ \\
\hline & & & FSM & - & - & - & - & - & - & - & - & - & - & - & - & - & - & - & - & - & - & - & - \\
\hline & & Statemented SEN & Not FSM & - & - & - & - & - & - & - & - & - & - & - & - & - & - & - & - & - & - & - & - \\
\hline & & & FSM & - & - & - & - & - & - & - & - & - & - & - & - & - & - & - & - & - & - & - & - \\
\hline Gypsy/Roma Traveller & English or Unclassified & No SEN & Not FSM & $x$ & $x$ & - & - & - & - & - & $x$ & $x$ & $x$ & $x$ & - & 26 & 24 & - & $x$ & $x$ & $x$ & 10 & $x$ \\
\hline & & & FSM & $x$ & $x$ & 12 & $x$ & $x$ & $x$ & $x$ & - & $x$ & $x$ & $x$ & $x$ & $x$ & $x$ & $x$ & $x$ & $x$ & $x$ & $x$ & $\mathrm{x}$ \\
\hline & & SEN at Action / Plus & Not FSM & $x$ & $x$ & $x$ & $x$ & - & - & $x$ & - & $x$ & - & $x$ & $x$ & 10 & 14 & - & - & $x$ & - & $x$ & $x$ \\
\hline & & & FSM & $x$ & $\mathrm{x}$ & $\mathrm{x}$ & $x$ & $x$ & $x$ & $x$ & $x$ & $\mathrm{x}$ & $x$ & $x$ & $\mathrm{x}$ & $x$ & 12 & - & $x$ & $x$ & $x$ & $\mathrm{x}$ & $x$ \\
\hline & & Statemented SEN & Not FSM & . & . & - & - & - & . & $\hat{-}$ & - & . & - & . & . & - & - & - & . & . & - & . & . \\
\hline & & & FSM & - & - & - & - & - & - & - & - & - & - & - & $\mathrm{x}$ & $x$ & - & - & - & $x$ & - & - & $x$ \\
\hline & Other than English & No SEN & Not FSM & $x$ & $x$ & $x$ & $x$ & $x$ & $x$ & $\mathrm{x}$ & $\mathrm{x}$ & $\mathrm{x}$ & $x$ & $x$ & $x$ & $x$ & $x$ & - & - & $x$ & $\mathrm{x}$ & 57 & 48 \\
\hline & & & FSM & - & - & - & $x$ & $\mathrm{x}$ & $x$ & - & - & $x$ & $x$ & $x$ & $x$ & - & - & - & - & - & - & - & $\mathrm{x}$ \\
\hline & & SEN at Action / Plus & Not FSM & - & $x$ & - & - & $x$ & $x$ & - & $x$ & - & - & - & $\hat{x}$ & $x$ & $x$ & - & - & - & - & $x$ & 19 \\
\hline & & & FSM & - & . & $x$ & $x$ & $\hat{x}$ & $\mathrm{x}$ & - & . & - & - & $x$ & $\hat{x}$ & . & $\hat{x}$ & - & - & $x$ & $x$ & . & - \\
\hline & & Statemented SEN & Not FSM & - & - & - & - & - & - & - & - & - & - & - & - & - & - & - & - & - & - & - & $x$ \\
\hline & & & FSM & - & - & - & - & - & - & - & - & - & - & - & - & - & - & - & - & - & $x$ & - & $n$ \\
\hline Other White & English or Unclassified & No SEN & Not FSM & 32 & 43 & 22 & 15 & 19 & 19 & 12 & $x$ & 39 & 37 & 32 & 34 & 40 & 40 & 30 & 27 & 29 & 25 & 85 & 102 \\
\hline & & & FSM & 11 & 10 & $\mathrm{x}$ & $x$ & $x$ & 12 & $x$ & $x$ & 58 & 50 & 10 & $\mathrm{x}$ & $x$ & $x$ & 11 & $x$ & $x$ & 10 & 24 & 20 \\
\hline & & SEN at Action / Plus & Not FSM & $x$ & $x$ & $x$ & $\mathrm{x}$ & $x$ & $x$ & - & - & $x$ & $\mathrm{x}$ & $x$ & 13 & $x$ & 16 & $x$ & $x$ & $x$ & $x$ & $x$ & $x$ \\
\hline & & & FSM & . & $\hat{x}$ & $\hat{x}$ & $\mathrm{x}$ & $\mathrm{x}$ & $\hat{x}$ & - & - & $x$ & 22 & $x$ & $x$ & $\mathrm{x}$ & $\mathrm{x}$ & $\mathrm{x}$ & $x$ & $x$ & $\mathrm{x}$ & $\mathrm{x}$ & 10 \\
\hline & & Statemented SEN & Not FSM & - & $\hat{x}$ & . & $\hat{x}$ & 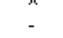 & $\hat{x}$ & . & - & $\hat{-}$ & $x$ & 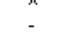 & $\hat{x}$ & $\hat{x}$ & $\hat{x}$ & $\hat{x}$ & 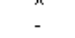 & 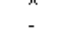 & . & $\hat{-}$ & $x$ \\
\hline & & & FSM & - & $x$ & - & - & - & 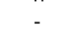 & - & - & $x$ & - & $x$ & $\mathrm{x}$ & 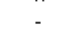 & - & - & - & - & - & - & - \\
\hline & Other than English & No SEN & Not FSM & 122 & 117 & 85 & 97 & 254 & 239 & 10 & 16 & 87 & 99 & 290 & 309 & 100 & 140 & 93 & 57 & 88 & 104 & 209 & 215 \\
\hline & & & FSM & 14 & $x$ & $x$ & 11 & 137 & 134 & $x$ & $\mathrm{x}$ & 14 & $\mathrm{x}$ & 160 & 163 & $\mathrm{x}$ & $x$ & $\mathrm{x}$ & - & 24 & 20 & 15 & 16 \\
\hline & & SEN at Action / Plus & Not FSM & 11 & 41 & 19 & 24 & 51 & 78 & $\mathrm{x}$ & $x$ & 14 & 22 & 66 & 122 & 26 & 30 & $x$ & 18 & 11 & 42 & 31 & 63 \\
\hline & & & FSM & $x$ & 10 & $\mathrm{x}$ & $x$ & 53 & 77 & $\mathrm{x}$ & $x$ & $x$ & $x$ & 57 & 88 & $x$ & $\mathrm{x}$ & - & $x$ & $x$ & $\mathrm{x}$ & $\mathrm{x}$ & $x$ \\
\hline & & Statemented SEN & Not FSM & $\mathrm{x}$ & $x$ & $\hat{x}$ & . & $x$ & $x$ &. & . & . & . & $x$ & $x$ & . & $\hat{x}$ & $x$ &. &. & $\hat{x}$ & . & $\hat{x}$ \\
\hline & & & FSM & - & $x$ & - & $x$ & $x$ & $x$ & - & - & - & - & $x$ & $x$ & - & - & - & - & - & - & - & - \\
\hline
\end{tabular}

"x" represents 1-9 pupils, suppressed to protect confidentiality

"-" represents zero pupils 
Detailed Population Profile: Key Stage 2 Schools Below the Floor Standards ...continued

\begin{tabular}{|c|c|c|c|c|c|c|c|c|c|c|c|c|c|c|c|c|c|c|c|c|c|c|c|}
\hline \multirow[b]{3}{*}{ Ethnicity } & \multirow[b]{3}{*}{ First Language } & \multirow[b]{3}{*}{ SEN Status } & \multirow[b]{3}{*}{ FSM Status } & \multicolumn{20}{|c|}{ Below Floor 09 (BC) } \\
\hline & & & & \multicolumn{2}{|c|}{$\begin{array}{c}\text { EAST } \\
\text { MIDLANDS }\end{array}$} & \multicolumn{2}{|c|}{$\begin{array}{l}\text { EAST OF } \\
\text { ENGLAND }\end{array}$} & \multicolumn{2}{|c|}{$\begin{array}{l}\text { INNER } \\
\text { LONDON }\end{array}$} & \multicolumn{2}{|c|}{ NORTH EAST } & \multicolumn{2}{|c|}{ NORTH WEST } & \multicolumn{2}{|c|}{$\begin{array}{c}\text { OUTER } \\
\text { LONDON }\end{array}$} & \multicolumn{2}{|c|}{ SOUTH EAST } & \multicolumn{2}{|c|}{ SOUTH WEST } & \multicolumn{2}{|c|}{$\begin{array}{c}\text { WEST } \\
\text { MIDLANDS }\end{array}$} & \multicolumn{2}{|c|}{$\begin{array}{l}\text { YORKSHIRE } \\
\text { AND THE } \\
\text { HUMEER }\end{array}$} \\
\hline & & & & Girls & Boys & Girls & Boys & Girls & Boys & Girls & Boys & Girls & Boys & Girls & Bovs & Girls & Boys & Girls & Boys & Girls & Bovs & & Boys \\
\hline \multirow[t]{12}{*}{ Other Ethnicity } & English or Unclassified & No SEN & Not FSM & \begin{tabular}{|l|l|l|}
$x$ \\
\end{tabular} & $\frac{100}{x}$ & $x$ & $\frac{x}{x}$ & $x$ & $\frac{x}{x}$ & $x$ & $\frac{x}{x}$ & 21 & 14 & $x$ & $\frac{x}{x}$ & $x$ & $\frac{x}{x}$ & $x$ & $\frac{x}{x}$ & $x$ & $\frac{x}{x}$ & $x$ & 13 \\
\hline & & & FSM & $\mathrm{x}$ & - & - & . & $\mathrm{x}$ & $\mathrm{x}$ & $x$ & $x$ & 10 & $x$ & $x$ & $x$ & $x$ & $x$ & $x$ & $x$ & $x$ & $x$ & $x$ & $x$ \\
\hline & & SEN at Action / Plus & Not FSM & - & $x$ & $x$ & - & $\hat{x}$ & $\mathrm{x}$ & - & - & $x$ & $\mathrm{x}$ & $x$ & $x$ & $\mathrm{x}$ & $\mathrm{x}$ & - & $\mathrm{x}$ & - & $\mathrm{x}$ & - & - \\
\hline & & & FSM & - & $x$ & $x$ & $x$ & $x$ & - & $x$ & - & $x$ & $x$ & $x$ & $x$ & $x$ & $x$ & - & $x$ & $x$ & $x$ & $x$ & $x$ \\
\hline & & Statemented SEN & Not FSM & - & - & - & - & - & $x$ & - & - & $x$ & - & - & $x$ & - & - & - & - & - & - & - & - \\
\hline & & & FSM & - & - & - & - & - & - & - & - & - & - & - & - & - & - & - & - & - & - & - & - \\
\hline & Other than English & No SEN & NotFSM & 18 & 15 & 24 & 20 & 109 & 120 & 11 & 10 & 51 & 53 & 89 & 56 & 35 & 36 & 22 & 21 & 97 & 105 & 71 & 70 \\
\hline & & & FSM & $\mathrm{x}$ & $x$ & - & - & 74 & 101 & $\mathrm{x}$ & $x$ & 29 & 39 & 52 & 37 & $\mathrm{x}$ & $\mathrm{x}$ & $\mathrm{x}$ & $\mathrm{x}$ & 115 & 113 & 35 & 24 \\
\hline & & SEN at Action / Plus & Not FSM & $x$ & $x$ & $x$ & $x$ & 24 & 42 & $x$ & $x$ & $x$ & $x$ & 15 & 31 & $x$ & $x$ & $x$ & $x$ & 21 & 38 & 15 & 16 \\
\hline & & & FSM & $\mathrm{x}$ & $\mathrm{x}$ & - & - & 30 & 28 & $\mathrm{x}$ & $\mathrm{x}$ & $\mathrm{x}$ & $x$ & 14 & 38 & $\mathrm{x}$ & $\mathrm{x}$ & $\mathrm{x}$ & - & 46 & 71 & $\mathrm{x}$ & $\mathrm{x}$ \\
\hline & & Statemented SEN & Not FSM & - & $x$ & - & - & $\mathrm{x}$ & $\mathrm{x}$ & - & $x$ & - & - & $x$ & $\mathrm{x}$ & $x$ & - & - & - & $x$ & - & - & - \\
\hline & & & FSM & & & & - & & $\mathrm{x}$ & - & & - & $x$ & & $\mathrm{x}$ & & - & - & - & $\mathrm{x}$ & $\mathrm{x}$ & - & $x$ \\
\hline \multirow{12}{*}{ Unknown Ethnicity } & English or Unclassified & No SEN & NotFSM & 145 & 160 & 60 & 51 & 193 & 241 & 69 & 63 & 132 & 132 & 106 & 78 & 23 & 30 & 35 & 66 & 649 & 593 & 72 & 84 \\
\hline & & & FSM & 50 & 35 & 14 & $\mathrm{x}$ & 40 & 53 & 17 & 18 & 84 & 68 & 33 & 24 & $x$ & $\mathrm{x}$ & $\mathrm{x}$ & 12 & 291 & 260 & 15 & 19 \\
\hline & & SEN at Action / Plus & NotFsM & 13 & 16 & $x$ & $x$ & 24 & 37 & 27 & 24 & $x$ & 12 & 16 & 23 & $\hat{x}$ & $x$ & $\hat{x}$ & $x$ & 34 & 95 & $x$ & $x$ \\
\hline & & 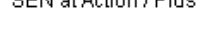 & FSM & $x$ & $\times$ & $x_{x}^{x}$ & $x^{x}$ & $\begin{array}{c}24 \\
x\end{array}$ & 23 & $\begin{array}{l}27 \\
19\end{array}$ & $\begin{array}{l}24 \\
25\end{array}$ & $x^{x}$ & 12 & 12 & 20 & $x_{x}^{x}$ & $x^{x}$ & - & 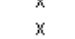 & $\begin{array}{l}34 \\
31\end{array}$ & 81 & $x^{x}$ & $x$ \\
\hline & & Statemented SEN & NotFSM & $x$ & $x$ & & $x$ & $x$ & $x$ & $x$ & & $x$ & $x$ & - & - & & $x$ & - & $x$ & $x$ & $x$ & - & - \\
\hline & & & FSM & 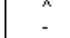 & - & . & $x$ & $x$ & $x_{x}^{x}-x$ & . & $x$ & . & $x_{x}^{x}+x$ & . & $x$ & $x$ & - & . & . & $x$ & 10 & . & $x$ \\
\hline & Other than English & No SEN & NotFSM & 33 & 42 & $x$ & $\mathrm{x}$ & $x$ & $\mathrm{x}$ & $x$ & $\mathrm{x}$ & $x$ & $x$ & $x$ & $x$ & $x$ & $x$ & $x$ & $x$ & $\mathrm{x}$ & $\mathrm{x}$ & $x$ & $x$ \\
\hline & & & FSM & $x$ & $\mathrm{x}$ & $x$ & - & $x$ & $x$ & - & . & $x$ & $x$ & $x$ & . & $x$ & $x$ & $x$ & . & . & . & $x$ & - \\
\hline & & SEN at Action / Plus & NotFSM & $\mathrm{x}$ & $\mathrm{x}$ & $x$ & $x$ & - & $\mathrm{x}$ & - & - & $x$ & - & $x$ & $x$ & $x$ & $x$ & - & - & - & - & - & - \\
\hline & & & FSM & - & - & - & - & $x$ & $\hat{x}$ & $x$ & - & - & $x$ & $\hat{x}$ & $\hat{x}$ & - & - & - & - & $x$ & - & - & - \\
\hline & & Statemented SEN & NotFsM & - & - & - & - & - & - & - & - & - & - & - & - & - & $x$ & - & - & - & - & - & - \\
\hline & & & FSM & - & - & - & - & - & - & - & - & - & - & - & - & - & - & - & - & - & - & - & - \\
\hline
\end{tabular}

"x" represents 1-9 pupils, suppressed to protect confidentiality

represents zero pupils 
Detailed Population Profile: Key Stage 4 Schools Below the Floor Standards

\begin{tabular}{|c|c|c|c|c|c|c|c|c|c|c|c|c|c|c|c|c|c|c|c|c|c|c|c|}
\hline \multirow[b]{3}{*}{ Ethnicity } & \multirow[b]{3}{*}{ First Language } & \multirow[b]{3}{*}{ SEN Status } & \multirow[b]{3}{*}{ FSM Status } & \multicolumn{20}{|c|}{ Schools Below the Floor } \\
\hline & & & & \multicolumn{2}{|c|}{$\begin{array}{c}\text { EAST } \\
\text { MIDLANDS }\end{array}$} & \multicolumn{2}{|c|}{$\begin{array}{l}\text { EAST OF } \\
\text { ENGLAND }\end{array}$} & \multicolumn{2}{|c|}{$\begin{array}{l}\text { INNER } \\
\text { LONDON }\end{array}$} & \multicolumn{2}{|c|}{ NORTH EAST } & \multicolumn{2}{|c|}{ NORTH WEST } & \multicolumn{2}{|c|}{$\begin{array}{c}\text { OUTER } \\
\text { LONDON }\end{array}$} & \multicolumn{2}{|c|}{ SOUTHEAST } & sou & HWEST & & $\begin{array}{l}\text { EST } \\
\text { ANDS }\end{array}$ & $\begin{array}{l}\text { YORL } \\
\text { ANL } \\
\text { HU }\end{array}$ & $\begin{array}{l}\text { SSHRE } \\
\text { THE } \\
\text { MEERR }\end{array}$ \\
\hline & & & & Girls & Boys & Girls & Boys & Girls & Boys & Girls & Boys & Girls & Boys & Girls & Boys & Girls & Boys & Girls & Boys & Girls & Boys & Girls & Boys \\
\hline Bangladeshi & English or Unclassified & No SEN & Not FSM & $x$ & $x$ & $x$ & $x$ & $x$ & $x$ & $x$ & $x$ & $x$ & $x$ & - & $x$ & 12 & 15 & $x$ & $x$ & $x$ & $x$ & 10 & 14 \\
\hline & & & FSM & - & - & $x$ & $x$ & $\mathrm{x}$ & $x$ & - & - & - & $\mathrm{x}$ & - & - & $\mathrm{x}$ & $x$ & $\mathrm{x}$ & - & $x$ & $x$ & 13 & $x$ \\
\hline & & SEN at Action / Plus & Not FSM & $x$ & $x$ & $x$ & - & - & - & $x$ & - & $x$ & - & - & $x$ & $x$ & $x$ & - & - & - & $x$ & $x$ & $x$ \\
\hline & & & FSM & - & - & - & - & - & $\mathrm{x}$ & - & $x$ & - & $\mathrm{x}$ & - & $x$ & - & $x$ & - & - & $x$ & $x$ & $x$ & $\mathrm{x}$ \\
\hline & & Statemented SEN & Not FSM & - & - & - & $x$ & - & - & - & - & - & - & - & - & $x$ & - & - & - & - & $x$ & - & - \\
\hline & & & FSM & - & - & - & . & $x$ & - & - & - & - & - & - & - & . & - & - & - & $x$ & . & - & - \\
\hline & Other than English & No SEN & Not FSM & 11 & 19 & 61 & 79 & $x$ & $x$ & 25 & 21 & 10 & 10 & 12 & $x$ & 75 & 60 & $x$ & $x$ & 52 & 72 & 109 & 102 \\
\hline & & & FSM & $\mathrm{x}$ & $\mathrm{x}$ & 31 & 25 & 28 & 32 & 20 & 12 & $\mathrm{x}$ & 13 & $\mathrm{x}$ & $\hat{x}$ & 30 & 32 & . & $\hat{x}$ & 43 & 41 & 60 & 67 \\
\hline & & SEN at Action / Plus & Not FSM & $x$ & 12 & 13 & 21 & $x$ & $x$ & 12 & 14 & - & $x$ & $x$ & $\mathrm{x}$ & 21 & 28 & - & $x$ & 12 & 11 & 17 & 26 \\
\hline & & & FSM & $\hat{x}$ & $\mathrm{x}$ & $\mathrm{x}$ & $x$ & 11 & 18 & $\mathrm{x}$ & $\mathrm{x}$ & $x$ & $x$ & $x$ & $x$ & 12 & 23 & - & $x$ & 13 & 19 & 11 & 20 \\
\hline & & Statemented SEN & Not FSM & - & - & - & - & - & $x$ & - & - & - & - & - & - & - & - & - & - & $x$ & - & - & - \\
\hline & & & FSM & - & $x$ & - & - & - & $\mathrm{x}$ & - & - & - & - & - & - & $x$ & - & - & - & - & $\mathrm{x}$ & - & $x$ \\
\hline Indian & English or Unclassified & No SEN & Not FSM & 17 & 11 & 20 & 38 & $x$ & $x$ & $x$ & $x$ & 26 & 35 & $x$ & 10 & 26 & 31 & $x$ & - & 44 & 55 & 22 & 28 \\
\hline & & & FSM & $x$ & $x$ & $x$ & $x$ & $x$ & $x$ & $x$ & $x$ & $x$ & $x$ & $x$ & $x$ & $x$ & $x$ & - & $x$ & 12 & $x$ & $x$ & $x$ \\
\hline & & SEN at Action / Plus & Not FSM & $x$ & $x$ & $x$ & $x$ & - & $x$ & - & - & $x$ & $x$ & - & $x$ & 14 & $x$ & - & $x$ & $x$ & $x$ & - & $\mathrm{x}$ \\
\hline & & & FSM & - & $\mathrm{x}$ & - & - & - & $\mathrm{x}$ & - & $x$ & $x$ & $\mathrm{x}$ & - & - & $x$ & - & - & - & $x$ & $\mathrm{x}$ & - & $\mathrm{x}$ \\
\hline & & Statemented SEN & Not FSM & - & . & $x$ & $x$ & - & - & - & $\mathrm{x}$ & - & $\mathrm{x}$ & - & - & . & $x$ & - & - & . & $\mathrm{x}$ & - & $x$ \\
\hline & & & FSM & - & - & & & - & - & - & - & - & & - & - & - & 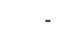 & - & - & - & & - & \\
\hline & Other than English & No SEN & Not FSM & 131 & 120 & 75 & 92 & $x$ & $x$ & $x$ & $x$ & 96 & 119 & 38 & 50 & 49 & 70 & $x$ & $x$ & 219 & 193 & 52 & 50 \\
\hline & & & FSM & 15 & 16 & 12 & 11 & 10 & $x$ & $x$ & - & 19 & 34 & $x$ & $x$ & $x$ & $x$ & $x$ & - & 25 & 26 & $x$ & 12 \\
\hline & & SEN at Action / Plus & Not FSM & $x$ & 17 & 15 & 22 & $x$ & $x$ & $x$ & $x$ & $x$ & 29 & $x$ & 11 & 24 & 21 & - & $x$ & 18 & 40 & $x$ & $x$ \\
\hline & & & FSM & $\mathrm{x}$ & $\mathrm{x}$ & $\mathrm{x}$ & $\mathrm{x}$ & - & $\mathrm{x}$ & $\mathrm{x}$ & - & $\mathrm{x}$ & $x$ & $\mathrm{x}$ & $x$ & $\mathrm{x}$ & $x$ & - & - & $\mathrm{x}$ & $x$ & $\mathrm{x}$ & $\mathrm{x}$ \\
\hline & & Statemented SEN & Not FSM & - & $x$ & - & $x$ & - & - & - & - & $x$ & $x$ & - & - & $x$ & $x$ & $x$ & - & $x$ & $x$ & - & $x$ \\
\hline & & & FSM & - & $x$ & - & & - & $x$ & - & - & $x$ & & - & $x$ & & & - & - & $x$ & $x$ & - & $x$ \\
\hline Pakistani & English or Unclassified & No SEN & Not FSM & $x$ & $\frac{n}{x}$ & 25 & 32 & $x$ & $\frac{n}{x}$ & $x$ & - & 31 & 30 & $x$ & $\frac{n}{x}$ & 34 & 32 & - & - & 20 & 37 & 137 & 365 \\
\hline & & & FSM & $x$ & $x$ & 13 & 10 & $x$ & $x$ & - & $x$ & 13 & 25 & $x$ & $x$ & $x$ & $x$ & - & - & 15 & 22 & 84 & 196 \\
\hline & & SEN at Action / Plus & Not FSM & . & - & $\mathrm{x}$ & $\mathrm{x}$ & . & - & - & - & $\mathrm{x}$ & 16 & - & $\hat{x}$ & $\hat{x}$ & $\hat{x}$ & - & - & $\mathrm{x}$ & 14 & 39 & 145 \\
\hline & & & FSM & $x$ & $x$ & $x$ & $x$ & - & - & - & - & $x$ & $x$ & - & - & $x$ & $x$ & - & - & 14 & 10 & 30 & 98 \\
\hline & & Statemented SEN & Not FSM & - & - & - & $x$ & $x$ & - & - & - & - & $x$ & - & - & - & $x$ & - & - & $\mathrm{x}$ & $x$ & - & $\mathrm{x}$ \\
\hline & & & FSM & - & - & - & - & - & - & - & - & - & $\mathrm{x}$ & - & - & - & & - & - & & & $x$ & $\mathrm{x}$ \\
\hline & Other than English & No SEN & Not FSM & 38 & 49 & 118 & 113 & $x$ & $x$ & 14 & 27 & 127 & 173 & 30 & 47 & 190 & 133 & $x$ & $x$ & 152 & 178 & 601 & 633 \\
\hline & 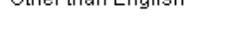 & 190 JeT & FSM & 23 & 16 & 59 & 35 & 19 & $\hat{11}$ & $\mathrm{x}$ & $x$ & 68 & 92 & 13 & 13 & 35 & 35 & - & 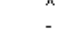 & 97 & 102 & 302 & 324 \\
\hline & & SEN at Action / Plus & Not FSM & $x$ & $x$ & 21 & 47 & $x$ & $x$ & 10 & 18 & 32 & 59 & $\mathrm{x}$ & 10 & 43 & 82 & - & - & 43 & 60 & 178 & 318 \\
\hline & & & FSM & $\hat{x}$ & $\hat{x}$ & 28 & 42 & $\hat{x}$ & $\hat{x}$ & $\mathrm{x}$ & 10 & 31 & 39 & $\hat{x}$ & $x$ & 13 & 21 & - & - & 33 & 49 & 164 & 200 \\
\hline & & Statemented SEN & Not FSM & - & - & - & $x$ & - & - & - & - & $x$ & $x$ & - & - & $x$ & $x$ & - & - & $x$ & 11 & 13 & 25 \\
\hline & & & FSM & - & - & - & $x$ & - & - & - & - & $\mathrm{x}$ & $x$ & - & - & $x$ & $\mathrm{x}$ & - & - & $\mathrm{x}$ & $x$ & $\mathrm{x}$ & 16 \\
\hline \begin{tabular}{|l|} 
Other Asian \\
\end{tabular} & English or Unclassified & No SEN & Not FSM & 11 & 10 & 12 & 18 & $x$ & $x$ & $x$ & $x$ & 11 & $x$ & 11 & $x$ & 27 & 26 & $x$ & $x$ & $x$ & 16 & 16 & 17 \\
\hline & & & FSM & $x$ & $\mathrm{x}$ & - & $\mathrm{x}$ & $x$ & - & - & - & $x$ & $x$ & $x$ & $x$ & $x$ & $x$ & $x$ & $x$ & $x$ & 10 & $\mathrm{x}$ & $x$ \\
\hline & & SEN at Action / Plus & Not FSM & $x$ & - & - & $x$ & - & - & - & - & $x$ & $x$ & $x$ & $x$ & $x$ & 12 & - & $x$ & $x$ & $\mathrm{x}$ & $\mathrm{x}$ & $\mathrm{x}$ \\
\hline & & & FSM & $\hat{x}$ & $x$ & - & $\hat{x}$ & - & - & $x$ & - & - & $x$ & $\hat{x}$ & - & $\hat{x}$ & $\mathrm{x}$ & - & - & . & $\hat{x}$ & $\hat{x}$ & 11 \\
\hline & & Statemented SEN & Not FSM & - & - & $x$ & - & - & - & - & - & - & - & - & - & - & - & - & - & - & - & - & - \\
\hline & & & FSM & - & - & - & $x$ & - & - & - & - & - & - & - & - & - & - & - & - & - & - & - & - \\
\hline & Other than English & No SEN & Not FSM & 20 & 33 & 74 & 83 & $x$ & 16 & 10 & 12 & 31 & 29 & 57 & 74 & 144 & 160 & $x$ & 16 & 26 & 44 & 75 & 97 \\
\hline & & & FSM & $x$ & $x$ & 12 & 16 & $x$ & $x$ & $\mathrm{x}$ & $x$ & 14 & 24 & $x$ & $x$ & $x$ & 14 & - & - & 20 & 27 & 70 & 69 \\
\hline & & SEN at Action / Plus & Not FSM & $x$ & 15 & 14 & 21 & - & $x$ & $x$ & $x$ & $x$ & 11 & $x$ & 13 & 33 & 40 & $x$ & $x$ & 13 & 22 & 13 & 44 \\
\hline & & & FSM & $x$ & $x$ & $\mathrm{x}$ & $x$ & - & $x$ & $\mathrm{x}$ & - & $x$ & $\mathrm{x}$ & - & $x$ & $\mathrm{x}$ & 10 & - & - & $x$ & 12 & 22 & 42 \\
\hline & & Statemented SEN & Not FSM & - & - & - & - & - & - & - & - & - & $x$ & - & - & - & $x$ & - & - & - & $x$ & $x$ & $x$ \\
\hline & & & FSM & - & - & $\mathrm{x}$ & - & - & - & $x$ & $x$ & . & . & - & - & . & . & - & - & - & . & .- & $\mathrm{x}$ \\
\hline
\end{tabular}

"x" represents 1-9 pupils, suppressed to protect confidentiality "-“ represents zero pupils 
Detailed Population Profile: Key Stage 4 Schools Below the Floor Standards ...continued

\begin{tabular}{|c|c|c|c|c|c|c|c|c|c|c|c|c|c|c|c|c|c|c|c|c|c|c|c|}
\hline \multirow[b]{3}{*}{ Ethnicity } & \multirow[b]{3}{*}{ First Language } & \multirow[b]{3}{*}{ SEN Status } & \multirow[b]{3}{*}{ FSM Status } & \multicolumn{20}{|c|}{ Schools Below the Floor } \\
\hline & & & & \multicolumn{2}{|c|}{$\begin{array}{l}\text { EAST } \\
\text { MIDLANDS }\end{array}$} & \multicolumn{2}{|c|}{$\begin{array}{l}\text { EAST OF } \\
\text { ENGLAND }\end{array}$} & \multicolumn{2}{|c|}{$\begin{array}{l}\text { INNER } \\
\text { LONDON }\end{array}$} & \multicolumn{2}{|c|}{ NORTH EAST } & \multicolumn{2}{|c|}{ NORTH WEST } & \multicolumn{2}{|c|}{$\begin{array}{l}\text { OUTER } \\
\text { LONDON }\end{array}$} & \multicolumn{2}{|c|}{ SOUTHEAST } & SOUT & HWEST & & $\begin{array}{l}\text { EST } \\
\text { ANDS }\end{array}$ & $\begin{array}{l}\text { YORK } \\
\text { ANL } \\
\text { HUI }\end{array}$ & $\begin{array}{l}\text { SHIRE } \\
\text { THE } \\
\text { MEER }\end{array}$ \\
\hline & & & & Girls & Boys & Girls & Boys & Girls & Boys & Girls & Boys & Girls & Boys & Girls & Boys & Girls & Boys & Girls & Boys & Girls & Boys & Girls & Boys \\
\hline Black African & English or Unclassified & No SEN & Not FSM & 25 & 38 & 68 & 68 & 75 & 81 & - & $x$ & 26 & 30 & 35 & 30 & 97 & 118 & $x$ & $\frac{x}{x}$ & 34 & 33 & 68 & 65 \\
\hline & & & FSM & 10 & $x$ & 10 & $\mathrm{x}$ & 43 & 39 & $x$ & $\mathrm{x}$ & 10 & 17 & $\mathrm{x}$ & $x$ & 10 & 15 & - & - & 20 & 10 & 20 & 25 \\
\hline & & SEN at Action / Plus & NotFSM & $x$ & 10 & $x$ & 15 & 20 & 34 & - & $x$ & $x$ & $x$ & $x$ & $x$ & 21 & 39 & $x$ & $x$ & $x$ & 15 & 10 & 22 \\
\hline & & & FSM & $x$ & $x$ & - & $x$ & $x$ & 23 & - & - & $x$ & $x$ & $x$ & $x$ & $x$ & $x$ & - & - & $x$ & $x$ & $x$ & $x$ \\
\hline & & Statemented SEN & Not FSM & - & . & - & $\mathrm{x}$ & - & $x$ & - & - & - & - & - & $x$ & - & $\mathrm{x}$ & - & - & - & $x$ & - & $x$ \\
\hline & & & FSM & - & - & - & - & $x$ & $\mathrm{x}$ & - & - & - & $x$ & - & - & - & $x$ & - & - & - & $x$ & - & - \\
\hline & Other than English & No SEN & Not FSM & 45 & 52 & 65 & 68 & 99 & 117 & $x$ & 11 & 43 & 44 & 38 & 66 & 139 & 113 & $x$ & $x$ & 70 & 67 & 149 & 144 \\
\hline & & & FSM & 23 & 27 & 20 & 17 & 98 & 97 & $x$ & $x$ & 41 & 71 & 16 & 37 & 34 & 28 & - & $x$ & 84 & 88 & 99 & 112 \\
\hline & & SEN at Action / Plus & NotFSM & $x$ & 12 & 11 & 18 & 43 & 78 & $x$ & $x$ & $x$ & 10 & 10 & 22 & 26 & 46 & $x$ & $x$ & 14 & 21 & 39 & 53 \\
\hline & & & FSM & $\hat{x}$ & 14 & $x$ & 14 & 43 & 84 & $\hat{x}$ & $\hat{x}$ & 32 & 22 & 19 & 29 & 15 & 20 & $\hat{x}$ & $\mathrm{x}$ & 42 & 47 & 65 & 65 \\
\hline & & Statemented SEN & Not FSM & - & $x$ & $x$ & $x$ & $x$ & $x$ & - & - & - & $x$ & $x$ & $x$ & - & $x$ & - & - & - & $x$ & - & - \\
\hline & & & FSM & & & $\mathrm{x}$ & & $\mathrm{x}$ & $\mathrm{x}$ & - & - & - & & $\mathrm{x}$ & - & - & - & - & - & - & $\mathrm{x}$ & $\mathrm{x}$ & $\mathrm{x}$ \\
\hline Black Caribbean & English or Unclassified & No SEN & Not FSM & 37 & 44 & 53 & 38 & 159 & 172 & - & - & 14 & 18 & 41 & 42 & 68 & 53 & $x$ & $x$ & 129 & 107 & 43 & 43 \\
\hline & & & FSM & 20 & 14 & 15 & $\mathrm{x}$ & 66 & 75 & $x$ & $x$ & $\mathrm{x}$ & $\mathrm{x}$ & 10 & $x$ & $\mathrm{x}$ & 12 & $x$ & $x$ & 59 & 54 & 28 & 24 \\
\hline & & SEN at Action / Plus & NotFSM & 11 & 29 & $x$ & 19 & 43 & 108 & . & . & $\hat{x}$ & $x$ & 11 & 38 & 13 & 28 & $x$ & $\hat{x}$ & 41 & 61 & 25 & 32 \\
\hline & & & FSM & 13 & 12 & $\hat{x}$ & $x$ & 29 & 75 & - & $x$ & $x$ & $\mathrm{x}$ & 11 & 10 & $x$ & 11 & - & $x$ & 29 & 35 & 15 & 30 \\
\hline & & Statemented SEN & Not FSM & - & $x$ & $x$ & $x$ & - & $x$ & - & - & - & - & $x$ & $x$ & $x$ & $x$ & - & - & $x$ & $x$ & $x$ & $x$ \\
\hline & & & FSM & - & - & - & $\mathrm{x}$ & $\mathrm{x}$ & 10 & - & - & - & - & - & $\mathrm{x}$ & $\mathrm{x}$ & $\mathrm{x}$ & - & - & $\mathrm{x}$ & $\mathrm{x}$ & - & $\mathrm{x}$ \\
\hline & Other than English & No SEN & Not FSM & - & $x$ & $x$ & $x$ & 10 & 10 & - & - & $x$ & $x$ & $x$ & $x$ & $x$ & $x$ & - & - & 22 & 13 & $x$ & $x$ \\
\hline & & & FSM & - & - & $x$ & - & $x$ & $x$ & - & - & - & - & - & - & - & - & - & - & $x$ & $x$ & $x$ & - \\
\hline & & SEN at Action / Plus & Not FSM & - & - & - & - & $x$ & $x$ & - & $x$ & - & - & $x$ & $x$ & $x$ & - & - & - & $x$ & $x$ & $x$ & $x$ \\
\hline & & & FSM & - & - & - & $x$ & $x$ & $x$ & - & - & - & - & - & $x$ & - & $x$ & - & - & - & $x$ & - & - \\
\hline & & Statemented SEN & Not FSM & - & - & - & - & - & - & - & - & - & - & - & - & - & - & - & - & $x$ & - & - & - \\
\hline & & 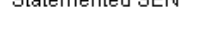 & FSM & - & . & . & . & - & $x$ & . & . & - & . & . & . & . & . & - & . & . & $x$ & . & . \\
\hline \begin{tabular}{|l} 
Other Black \\
\end{tabular} & English or Unclassified & No SEN & Not FSM & 16 & 16 & 24 & 19 & 15 & 24 & $x$ & - & 11 & 17 & 12 & 14 & 25 & 18 & $x$ & $x$ & 23 & 13 & 28 & 24 \\
\hline & & & FSM & $x$ & $x$ & $x$ & $x$ & 14 & 14 & - & - & 16 & 11 & $x$ & - & $x$ & $x$ & $x$ & - & 14 & 11 & 16 & 17 \\
\hline & & SEN at Action / Plus & NotFSM & $x$ & $x$ & $\mathrm{x}$ & $\mathrm{x}$ & $x$ & 16 & - & - & $\mathrm{x}$ & $x$ & $x$ & $x$ & $x$ & $x$ & - & - & $x$ & 10 & $\mathrm{x}$ & 18 \\
\hline & & & FSM & $\hat{x}$ & $\hat{x}$ & $\hat{x}$ & $\hat{x}$ & $\hat{x}$ & 19 & - & - & $\hat{x}$ & 15 & $\hat{x}$ & $\hat{x}$ & $\hat{x}$ & $\hat{x}$ & - & $x$ & $\hat{x}$ & $\mathrm{x}$ & $\hat{x}$ & 13 \\
\hline & & Statemented SEN & Not FSM & - & - & & - & - & - & - & - & - & $\mathrm{x}$ & - & $\hat{x}$ & $\hat{x}$ & $\hat{x}$ & - & - & - & $x$ & - & - \\
\hline & & & FSM & - & - & - & $x$ & $x$ & $x$ & - & - & $x$ & - & - & $x$ & - & - & - & - & - & $\mathrm{x}$ & - & $\mathrm{x}$ \\
\hline & Other than English & No SEN & Not FSM & $x$ & $x$ & 14 & 18 & 17 & 14 & $x$ & - & $x$ & 25 & $x$ & $x$ & 11 & 14 & - & $x$ & $x$ & 10 & 20 & $\mathrm{x}$ \\
\hline & & & FSM & $\mathrm{x}$ & $x$ & $x$ & $x$ & 13 & $\mathrm{x}$ & $x$ & - & $x$ & 10 & $x$ & $x$ & $\mathrm{x}$ & $\mathrm{x}$ & - & - & $\mathrm{x}$ & $\mathrm{x}$ & $x$ & $x$ \\
\hline & & SEN at Action / Plus & Not FSM & $x$ & $x$ & $x$ & $x$ & $x$ & $x$ & - & $x$ & $x$ & $\mathrm{x}$ & - & $x$ & $x$ & $x$ & - & - & $x$ & $x$ & $x$ & $x$ \\
\hline & & & FSM & $\hat{x}$ & $\hat{x}$ & $\hat{x}$ & $\hat{x}$ & 10 & 12 & $x$ & - & $\hat{x}$ & $\hat{x}$ & - & $\hat{x}$ & $\hat{x}$ & $\hat{x}$ & - & - & $\hat{x}$ & $\hat{x}$ & $\hat{x}$ & $x$ \\
\hline & & Statemented SEN & Not FSM & - & - & - & - & - & - & - & - & - & - & - & $x$ & - & - & - & - & - & - & - & - \\
\hline & & & FSM & - & - & - & $x$ & - & - & - & - & - & - & - & - & - & - & - & - & - & - & - & - \\
\hline Chinese & English or Unclassified & No SEN & Not FSM & $x$ & $x$ & $x$ & $x$ & - & $x$ & - & $x$ & $x$ & $x$ & - & $x$ & $x$ & $x$ & - & - & $x$ & $x$ & - & 11 \\
\hline & & & FSM & $x$ & $x$ & - & - & - & - & - & - & - & - & - & - & - & - & - & - & - & $x$ & - & - \\
\hline & & SEN at Action / Plus & NotFSM & $x$ & . & $x$ & - & - & - & - & $x$ & - & - & - & - & - & $x$ & - & $x$ & $x$ & $\mathrm{x}$ & - & - \\
\hline & & & & - & - & - & - & - & - & - & - & $x$ & - & - & - & - & - & - & - & - & - & - & - \\
\hline & & Statemented SEN & Not FSM & - & - & - & $x$ & - & - & - & - & - & - & - & - & - & - & - & - & - & - & - & - \\
\hline & & & FSM & . & . & . & . & - & - & . & - & . & . & - & . & . & . & - & - & . & - & . & . \\
\hline & Other than English & No SEN & Not FSM & $x$ & 11 & 17 & 16 & $x$ & $x$ & $x$ & $x$ & 30 & 36 & $x$ & $x$ & 15 & 20 & $x$ & 11 & $x$ & $x$ & 13 & 15 \\
\hline & & & FSM & $\hat{x}$ & $x$ & $x$ & - & $\hat{x}$ & $\hat{x}$ & $\hat{x}$ & $\hat{x}$ & $x$ & $x$ & . & . & - & - & $\hat{-}$ & $x$ & $\hat{x}$ & $\hat{x}$ & $x$ & $x$ \\
\hline & & SEN at Action / Plus & NotFSM & - & $x$ & $x$ & $x$ & $x$ & $x$ & $x$ & $x$ & $x$ & $x$ & - & $x$ & $x$ & 11 & $x$ & $x$ & $x$ & $x$ & $x$ & $x$ \\
\hline & & & FSM & - & . & . & - & $\mathrm{x}$ & $\hat{x}$ & - & . & . & $\mathrm{x}$ & - & $\hat{x}$ & $\hat{x}$ & - & - & . & $\hat{x}$ & . & . & $\mathrm{x}$ \\
\hline & & Statemented SEN & Not FSM & $x$ & - & - & - & - & - & - & - & - & - & - & - & - & $x$ & - & $x$ & - & - & - & . \\
\hline
\end{tabular}

"x" represents 1-9 pupils, suppressed to protect confidentiality "-“ represents zero pupils 
Detailed Population Profile: Key Stage 4 Schools Below the Floor Standards ...continued

\begin{tabular}{|c|c|c|c|c|c|c|c|c|c|c|c|c|c|c|c|c|c|c|c|c|c|c|c|}
\hline \multirow[b]{3}{*}{ Ethnicity } & \multirow[b]{3}{*}{ First Language } & \multirow[b]{3}{*}{ SEN Status } & \multirow[b]{3}{*}{ FSM Status } & \multicolumn{20}{|c|}{ Schools Below the Floor } \\
\hline & & & & \multicolumn{2}{|c|}{$\begin{array}{l}\text { EAST } \\
\text { MIDLANDS }\end{array}$} & \multicolumn{2}{|c|}{$\begin{array}{l}\text { EAST OF } \\
\text { ENGLAND }\end{array}$} & \multicolumn{2}{|c|}{$\begin{array}{l}\text { INNER } \\
\text { LONDON }\end{array}$} & \multicolumn{2}{|c|}{ NORTH EAST } & \multicolumn{2}{|c|}{ NORTH WEST } & \multicolumn{2}{|c|}{$\begin{array}{l}\text { OUTER } \\
\text { LONDON }\end{array}$} & \multicolumn{2}{|c|}{ SOUTHEAST } & sou & HWEST & & $\begin{array}{l}\text { EST } \\
\text { ANDS }\end{array}$ & $\begin{array}{l}\text { YORK } \\
\text { ANL } \\
\text { HUI }\end{array}$ & $\begin{array}{l}\text { SHIRE } \\
\text { THE } \\
\text { MEER }\end{array}$ \\
\hline & & & & Girls & Boys & Girls & Boys & Girls & Boys & Girls & Boys & Girls & Boys & Girls & Boys & Girls & Boys & Girls & Boys & Girls & Boys & Girls & Boys \\
\hline White \& Asian & English or Unclassified & No SEN & Not FSM & 19 & 30 & 33 & 33 & $x$ & - & $x$ & $\frac{x}{x}$ & 12 & 21 & $x$ & $\frac{x}{x}$ & 45 & 44 & $x$ & 19 & 42 & 32 & 47 & 31 \\
\hline & & & FSM & $\mathrm{x}$ & $x$ & 13 & $x$ & - & $x$ & $x$ & $\mathrm{x}$ & 16 & 14 & - & $\mathrm{x}$ & $x$ & $x$ & $\mathrm{x}$ & $x$ & 28 & 21 & 29 & 26 \\
\hline & & SEN at Action / Plus & Not FSM & $x$ & $x$ & $x$ & 13 & - & $x$ & $x$ & $x$ & 12 & $x$ & $x$ & $x$ & 21 & 14 & $x$ & $x$ & $x$ & 19 & 11 & 18 \\
\hline & & & FSM & $x$ & $x$ & $x$ & $x$ & - & - & $x$ & - & $x$ & 10 & - & - & $x$ & $x$ & $x$ & $x$ & 11 & $x$ & 23 & 29 \\
\hline & & Statemented SEN & Not FSM & - & - & - & $\mathrm{x}$ & - & - & $x$ & - & $x$ & - & - & - & $x$ & $\mathrm{x}$ & - & $x$ & $x$ & . & - & - \\
\hline & & & FSM & - & - & - & $\mathrm{x}$ & - & - & - & - & $\mathrm{x}$ & $x$ & $x$ & - & - & $x$ & - & - & . & $x$ & - & $x$ \\
\hline & Other than English & No SEN & Not FSM & $x$ & $x$ & $x$ & $x$ & $x$ & - & $x$ & - & $x$ & $x$ & $x$ & $x$ & 10 & 12 & $x$ & $x$ & - & $x$ & 12 & $x$ \\
\hline & & & FSM & $\mathrm{x}$ & $x$ & $x$ & - & $x$ & $x$ & - & - & $x$ & $x$ & - & - & $\mathrm{x}$ & $\mathrm{x}$ & - & - & $x$ & $x$ & 15 & $x$ \\
\hline & & SEN at Action / Plus & Not FSM & - & $x$ & $x$ & $x$ & - & - & - & - & - & - & - & - & $x$ & $x$ & - & - & $x$ & $x$ & $x$ & $x$ \\
\hline & & & FSM & $x$ & - & - & $\mathrm{x}$ & $x$ & - & - & - & $x$ & $x$ & - & $x$ & - & $\mathrm{x}$ & - & - & - & $\hat{x}$ & $x$ & $x$ \\
\hline & & Statemented SEN & Not FSM & - & - & - & - & - & - & - & - & - & - & - & - & - & - & - & - & - & - & - & - \\
\hline & & & FSM & - & - & - & - & - & - & - & - & - & - & - & - & - & - & - & - & - & - & $x$ & - \\
\hline White \& Black African & English or Unclassified & No SEN & Not FSM & $x$ & $x$ & 16 & 13 & $x$ & $x$ & $x$ & $x$ & $x$ & 14 & $x$ & $x$ & 31 & 28 & $x$ & $x$ & 14 & 10 & 17 & 15 \\
\hline & & & FSM & 12 & $x$ & $\mathrm{x}$ & $x$ & $\mathrm{x}$ & $x$ & $\mathrm{x}$ & $x$ & 20 & $x$ & $\mathrm{x}$ & - & 10 & $x$ & - & $x$ & $x$ & $x$ & $x$ & $x$ \\
\hline & & SEN at Action / Plus & Not FSM & $x$ & $x$ & $x$ & $x$ & - & $x$ & $x$ & $x$ & $x$ & $x$ & $x$ & $x$ & 10 & 15 & - & $x$ & $x$ & $x$ & $x$ & $x$ \\
\hline & & & FSM & $x$ & $x$ & $x$ & - & $\mathrm{x}$ & $x$ & - & $x$ & $x$ & $x$ & - & $x$ & $x$ & 10 & $\mathrm{x}$ & $x$ & $x$ & $x$ & $x$ & $x$ \\
\hline & & Statemented SEN & Not FSM & - & - & - & $x$ & - & - & - & - & - & $x$ & - & - & - & $x$ & - & - & - & - & - & - \\
\hline & & & FSM & - & - & $x$ & - & - & - & - & - & - & $\hat{x}$ & - & - & - & - & - & - & $x$ & - & - & - \\
\hline & Other than English & No SEN & Not FSM & $x$ & $x$ & $x$ & $x$ & $x$ & $x$ & $x$ & - & $x$ & $x$ & $x$ & - & $x$ & $x$ & - & $x$ & $x$ & $x$ & $x$ & $x$ \\
\hline & & & FSM & $x$ & $\hat{x}$ & $\hat{x}$ & $\hat{x}$ & $\hat{x}$ & $\hat{x}$ & $x$ & - & $\mathrm{x}$ & $\hat{x}$ & $\mathrm{x}$ & - & $\hat{x}$ & $\hat{x}$ & - & - & $\hat{x}$ & $\hat{x}$ & $\hat{x}$ & $\mathrm{x}$ \\
\hline & & SEN at Action / Plus & Not FSM & - & $x$ & - & $x$ & - & $x$ & $x$ & - & - & - & - & $x$ & $x$ & $x$ & - & $x$ & $x$ & $x$ & $x$ & $x$ \\
\hline & & & FSM & - & $x$ & - & - & $x$ & - & - & $x$ & $\mathrm{x}$ & - & - & - & - & - & - & - & - & $x$ & $x$ & - \\
\hline & & Statemented SEN & Not FSM & - & - & - & - & - & $x$ & - & - & - & - & - & $x$ & - & - & - & - & - & - & - & - \\
\hline & & 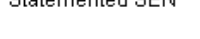 & FSM & . & . & . & . & - & $x^{x}$ & . & . & - & . & . & - & - & - & - & - & - & $\therefore$ & - & . \\
\hline White \& Black Caribbean & English or Unclassified & No SEN & Not FSM & 73 & 78 & 87 & 60 & 15 & 12 & $x$ & $x$ & 28 & 34 & 15 & 11 & 101 & 114 & 15 & 16 & 113 & 110 & 114 & 75 \\
\hline & & & FSM & 56 & 32 & 27 & 17 & 20 & 15 & $x$ & $x$ & 32 & 20 & $x$ & $x$ & 47 & 30 & $x$ & $x$ & 74 & 65 & 56 & 49 \\
\hline & & SEN at Action / Plus & Not FSM & 29 & 45 & 25 & 28 & $\mathrm{x}$ & $x$ & $\mathrm{x}$ & $x$ & $\mathrm{x}$ & 17 & $x$ & 11 & 35 & 68 & $x$ & $x$ & 46 & 47 & 36 & 59 \\
\hline & & & FSM & 21 & 40 & $\mathrm{x}$ & 17 & $\hat{x}$ & 16 & $\hat{x}$ & $\hat{x}$ & 20 & 22 & $\hat{x}$ & $x$ & 28 & 35 & $\hat{x}$ & $\hat{x}$ & 46 & 65 & 41 & 58 \\
\hline & & Statemented SEN & Not FSM & - & $x$ & & $\mathrm{x}$ & $\mathrm{x}$ & $x$ & - & - & $\mathrm{x}$ & $x$ & - & $\hat{x}$ & $x$ & $\mathrm{x}$ & - & $\hat{x}$ & $\mathrm{x}$ & - & - & $x$ \\
\hline & & & FSM & - & $x$ & - & $x$ & - & $x$ & - & - & - & $x$ & $x$ & - & $x$ & $x$ & - & - &. & $x$ & $x$ & $\mathrm{x}$ \\
\hline & Other than English & No SEN & Not FSM & $x$ & - & $x$ & - & $x$ & $x$ & - & - & $x$ & $x$ & $x$ & - & $x$ & - & - & $x$ & $x$ & $x$ & - & $x$ \\
\hline & & & FSM & - & - & - & - & - & - & - & - & $\mathrm{x}$ & - & - & - & - & - & - & - & - & $\mathrm{x}$ & $x$ & - \\
\hline & & SEN at Action / Plus & Not FSM & - & - & - & - & - & - & - & - & - & - & - & $x$ & - & - & - & - & $x$ & - & - & - \\
\hline & & & FSM & $x$ & - & - & - & - & $x$ & - & - & - & - & - & . & - & - & - & $x$ & $\hat{x}$ & - & $x$ & - \\
\hline & & Statemented SEN & Not FSM & - & - & - & - & - & - & - & - & - & - & - & - & - & - & - & - & - & - & - & - \\
\hline & & & & & - & - & - & - & - & - & - & - & - & - & - & - & - & - & - & - & - & - & \\
\hline Other Mixed & English or Unclassified & No SEN & Not FSM & 38 & 30 & 66 & 45 & $\mathrm{x}$ & 16 & 11 & $x$ & 30 & 37 & 14 & 11 & 90 & 86 & 10 & 29 & 42 & 32 & 40 & 35 \\
\hline & & & FSM & 16 & 11 & 20 & 11 & 11 & 26 & $x$ & $\mathrm{x}$ & 24 & 28 & $x$ & $x$ & 17 & 18 & $\mathrm{x}$ & 11 & 28 & 19 & 37 & 26 \\
\hline & & SEN at Action / Plus & Not FSM & 16 & 21 & 18 & 14 & $\mathrm{x}$ & 13 & $\mathrm{x}$ & $\mathrm{x}$ & $\mathrm{x}$ & $x$ & $\mathrm{x}$ & $\mathrm{x}$ & 26 & 39 & $x$ & $\mathrm{x}$ & 11 & 28 & 14 & 17 \\
\hline & & & FSM & 13 & 19 & $x$ & 15 & $x$ & 12 & - & - & 15 & 24 & - & $x$ & 12 & 19 & $x$ & $x$ & 14 & 12 & 14 & 22 \\
\hline & & Statemented SEN & Not FSM & - & $x$ & - & $x$ & - & $\mathrm{x}$ & - & - & - & $\mathrm{x}$ & - & $x$ & $x$ & $\mathrm{x}$ & - & - & - & $x$ & - & $x$ \\
\hline & & & FSM & . & . & . & $\mathrm{x}$ & . & $\mathrm{x}$ & . & - & $x$ & $\mathrm{x}$ & . &. & . & $\mathrm{x}$ & - & - & . & $\hat{x}$ & $x$ &. \\
\hline & Other than English & No SEN & Not FSM & $x$ & $x$ & 24 & 27 & $x$ & 10 & $x$ & $x$ & $x$ & 10 & 14 & 13 & 34 & 39 & - & $x$ & $x$ & $x$ & $\hat{x}$ & 21 \\
\hline & & & FSM & $\hat{x}$ & . & $x$ & $x$ & $\hat{x}$ & $x$ & . & - & $\hat{x}$ & $x$ & - & $x$ & $\mathrm{x}$ & $x$ & - & . & $\hat{x}$ & $\hat{x}$ & $\hat{x}$ & $x$ \\
\hline & & SEN at Action / Plus & Not FSM & - & $x$ & $x$ & $x$ & $x$ & $x$ & $x$ & $x$ & $x$ & $x$ & $x$ & $x$ & 14 & 16 & $x$ & - & $x$ & $x$ & $x$ & $x$ \\
\hline & & & & - & $\mathrm{x}$ & $\mathrm{x}$ & $\mathrm{x}$ & $x$ & $\hat{x}$ & - & $\mathrm{x}$ & $\mathrm{x}$ & . & - & $\mathrm{x}$ & $x$ & $\mathrm{x}$ & . & $x$ & $\mathrm{x}$ & $\hat{x}$ & $\hat{x}$ & $\mathrm{x}$ \\
\hline & & Statemented SEN & Not FSM & - & - & - & - & - & - & - & - & - & - & - & - & - & - & - & - & $x$ & - & - & - \\
\hline & & & & - & . & - & - & - & - & - & - & - & - & - & - & - & $x$ & - & - & . & . & . & $x$ \\
\hline
\end{tabular}

"x" represents 1-9 pupils, suppressed to protect confidentiality "-“ represents zero pupils 
Detailed Population Profile: Key Stage 4 Schools Below the Floor Standards ...continued

\begin{tabular}{|c|c|c|c|c|c|c|c|c|c|c|c|c|c|c|c|c|c|c|c|c|c|c|c|}
\hline \multirow[b]{3}{*}{ Ethnicity } & \multirow[b]{3}{*}{ First Language } & \multirow[b]{3}{*}{ SEN Status } & \multirow[b]{3}{*}{ FSM Status } & \multicolumn{20}{|c|}{ Schools Below the Floor } \\
\hline & & & & \multicolumn{2}{|c|}{$\begin{array}{c}\text { EAST } \\
\text { MIDLANDS }\end{array}$} & \multicolumn{2}{|c|}{$\begin{array}{c}\text { EAST OF } \\
\text { ENGLAND }\end{array}$} & \multicolumn{2}{|c|}{$\begin{array}{l}\text { INNER } \\
\text { LONDON }\end{array}$} & \multicolumn{2}{|c|}{ NORTH EAST } & \multicolumn{2}{|c|}{ NORTH WEST } & \multicolumn{2}{|c|}{$\begin{array}{c}\text { OUTER } \\
\text { LONDON }\end{array}$} & \multicolumn{2}{|c|}{ SOUTH EAST } & SOUTh & HWEST & & $\begin{array}{l}\text { EST } \\
\text { ANDS }\end{array}$ & $\begin{array}{l}\text { YORK } \\
\text { AND } \\
\text { HUM }\end{array}$ & $\begin{array}{l}\text { SSHIRE } \\
\text { THEE } \\
\text { MEER }\end{array}$ \\
\hline & & & & Girls & & Girls & & Girls & Boys & Girls & Boys & Girls & Boys & Girls & Boys & Girls & Boys & Girls & Boys & Girls & Boys & Girls & Boys \\
\hline White British & English or Unclassified & No SEN & NotFSM & 4,377 & 4,032 & 5,531 & 4,942 & 60 & 82 & 2,201 & 2,082 & 4,608 & 4,447 & 333 & 331 & 8,250 & 7,867 & 1,910 & 2,446 & 3,365 & 2,977 & 6,215 & 5,348 \\
\hline & & & FSM & 944 & 749 & 959 & 731 & 67 & 66 & 1,004 & 800 & 1,810 & 1,660 & 117 & 109 & 1,334 & 1,016 & 548 & 514 & 1,238 & 857 & 2,200 & 1,714 \\
\hline & & SEN at Action / Plus & NotFSM & 1,439 & 2,349 & 1,197 & 1,991 & 29 & 57 & 762 & 1,131 & 1,062 & 1,898 & 186 & 326 & 2,918 & 4,851 & 643 & 1,090 & 955 & 1,473 & 1,720 & 2,737 \\
\hline & & & FSM & 796 & 1,011 & 560 & 709 & 41 & 74 & 687 & 910 & 981 & 1,566 & 105 & 181 & 1,229 & 1,530 & 329 & 461 & 704 & 950 & 1,294 & 1,746 \\
\hline & & Statemented SEN & Not FSM & 51 & 166 & 89 & 259 & $x$ & $x$ & 56 & 109 & 82 & 257 & $x$ & 27 & 124 & 475 & 36 & 132 & 51 & 123 & 67 & 202 \\
\hline & & & FSM & 38 & 85 & 45 & 143 & $x$ & 11 & 51 & 92 & 71 & 207 & $x$ & 18 & 44 & 137 & 10 & 56 & 30 & 94 & 57 & 175 \\
\hline & Other than English & No SEN & Not FSM & $x$ & $x$ & 10 & 11 & $\hat{x}$ & $x$ & - & $x$ & $x$ & $x$ & $\mathrm{x}$ & $x$ & 25 & 19 & $\mathrm{x}$ & $\mathrm{x}$ & $x$ & $x$ & $x$ & $x$ \\
\hline & & & FSM & $x$ & $x$ & $x$ & $\mathrm{x}$ & $x$ & - & - & $x$ & $x$ & $x$ & - & - & $x$ & $x$ & - & $x$ & $x$ & $x$ & $x$ & $x$ \\
\hline & & SEN at Action / Plus & Not FSM & $x$ & $x$ & $x$ & $x$ & - & - & $x$ & $x$ & $x$ & - & - & $x$ & $x$ & 15 & $x$ & $x$ & - & $x$ & $x$ & $x$ \\
\hline & & & FSM & - & - & $x$ & $x$ & - & - & - & - & - & - & $x$ & $x$ & $x$ & $\mathrm{x}$ & - & - & $x$ & - & $x$ & $x$ \\
\hline & & Statemented SEN & Not FSM & - & - & - & $x$ & - & - & $x$ & - & - & $x$ & - & - & - & $x$ & - & - & $x$ & - & - & - \\
\hline & & & FSM & - & - & - & - & - & - & - & - & - & - & - & - & - & & - & - & . & $x$ & - & $x$ \\
\hline Irish & English or Unclassified & No SEN & Not FSM & $x$ & $x$ & 15 & $x$ & $x$ & $x$ & $x$ & $\mathrm{x}$ & 10 & $x$ & $x$ & $x$ & 30 & 34 & - & $x$ & 10 & $\mathrm{x}$ & $x$ & $x$ \\
\hline & & & FSM & - & - & $x$ & $x$ & - & $x$ & - & - & $x$ & 11 & $x$ & - & $x$ & - & $x$ & $x$ & $x$ & $x$ & $x$ & $x$ \\
\hline & & SEN at Action / Plus & NotFSM & $x$ & $x$ & $x$ & $x$ & - & $x$ & - & - & $x$ & $x$ & $x$ & $x$ & $x$ & 12 & - & $x$ & $x$ & $x$ & $x$ & $x$ \\
\hline & & & FSM & $\mathrm{x}$ & $\mathrm{x}$ & $x$ & 11 & $x$ & $\mathrm{x}$ & $x$ & - & $x$ & $\mathrm{x}$ & - & $\mathrm{x}$ & $x$ & $x$ & $x$ & $\mathrm{x}$ & $x$ & $\mathrm{x}$ & $x$ & $\mathrm{x}$ \\
\hline & & Statemented SEN & Not FSM & - & $x$ & $x$ & $x$ & - & $x$ & - & - & $x$ & - & - & - & $x$ & $x$ & - & - & - & $x$ & $x$ & - \\
\hline & & & FSM & - & - & - & - & - & - & - & - & - & $x$ & - & - & - & - & - & - & - & $x$ & - & $\mathrm{x}$ \\
\hline & Other than English & No SEN & Not FSM & $x$ & - & - & - & - & - & - & - & - & - & - & - & - & $x$ & - & - & - & - & - & - \\
\hline & & & FSM & - & - & $x$ & - & - & - & - & - & - & $x$ & - & - & - & - & - & - & - & - & - & - \\
\hline & & SEN at Action / Plus & NotFSM & - & $x$ & - & - & - & - & - & - & - & $x$ & - & - & $x$ & - & - & - & - & - & - & - \\
\hline & & 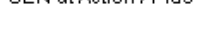 & FSM & - & - & - & - & - & - & - & - & - & - & - & - & - & - & - & - & - & - & - & - \\
\hline & & Statemented SEN & Not FSM & - & - & - & - & - & - & - & - & - & - & - & - & - & - & - & - & - & - & - & - \\
\hline & & & FSM & - & - & - & - & - & - & - & - & - & - & - & - & - & - & - & - & - & - & - & - \\
\hline Gypsy/Roma Traveller & English or Unclassified & No SEN & Not FSM & $x$ & $x$ & $x$ & $x$ & - & - & $x$ & $x$ & $x$ & $x$ & $x$ & $x$ & 20 & $x$ & - & - & $x$ & $x$ & $x$ & $x$ \\
\hline & & & FSM & $x$ & $x$ & 11 & $x$ & - & - & $x$ & $x$ & $x$ & $x$ & $x$ & - & $x$ & $x$ & - & - & $x$ & $x$ & 13 & $x$ \\
\hline & & SEN at Action / Plus & Not FSM & $x$ & $x$ & $x$ & $x$ & - & $x$ & $x$ & $x$ & $\mathrm{x}$ & $x$ & $x$ & $\mathrm{x}$ & 11 & 19 & - & - & $x$ & $\mathrm{x}$ & $x$ & $\mathrm{x}$ \\
\hline & & & FSM & $x$ & $x$ & 14 & $x$ & $x$ & $x$ & $x$ & $x$ & $x$ & $x$ & $x$ & $x$ & 15 & 16 & $x$ & - & $x$ & $x$ & $x$ & $x$ \\
\hline & & Statemented SEN & Not FSM & - & $x$ & - & $x$ & - & - & - & - & - & $x$ & - & - & - & $\mathrm{x}$ & - & - & $x$ & - & - & - \\
\hline & & & FSM & - & $x$ & - & $\mathrm{x}$ & - & - & - & - & - & $\mathrm{x}$ & - & - & $x$ & $\mathrm{x}$ & - & - & - & - & $x$ & $\mathrm{x}$ \\
\hline & Other than English & No SEN & Not FSM & 31 & 21 & $x$ & $x$ & $x$ & $x$ & $x$ & $x$ & 21 & 39 & - & $x$ & $\hat{x}$ & $x$ & - & - & $x$ & $x$ & 40 & 26 \\
\hline & & & FSM & $x$ & $x$ & $x$ & $x$ & - & $x$ & $x$ & $x$ & 11 & $\mathrm{x}$ & - & - & - & $x$ & - & - & - & - & $x$ & $x$ \\
\hline & & SEN at Action / Plus & NotFSM & 12 & 10 & $x$ & $x$ & - & $x$ & $x$ & - & $x$ & $x$ & $x$ & - & - & $x$ & - & - & $x$ & $x$ & 19 & 17 \\
\hline & & & FSM & $x$ & $x$ & $x$ & $x$ & $x$ & $x$ & - & - & $x$ & 12 & - & - & $x$ & $x$ & - & - & $x$ & $x$ & $\mathrm{x}$ & $x$ \\
\hline & & Statemented SEN & Not FSM & - & - & - & - & - & - & - & - & - & - & - & - & - & - & - & - & - & - & - & . \\
\hline & & & FSM & - & - & - & - & - & - & - & - & - & - & - & - & - & - & - & - & - & - & - & - \\
\hline \begin{tabular}{|l} 
Other White \\
\end{tabular} & English or Unclassified & No SEN & Not FSM & 89 & 71 & 115 & 114 & $x$ & $x$ & 66 & 71 & 52 & 47 & 11 & $x$ & 139 & 117 & 14 & 26 & 23 & 20 & 33 & 29 \\
\hline & & & FSM & 19 & 14 & 17 & 20 & $x$ & $x$ & $x$ & $\mathrm{x}$ & 15 & 20 & - & $x$ & 22 & 23 & $x$ & $x$ & 12 & 11 & $x$ & 11 \\
\hline & & SEN at Action / Plus & NotFSM & 43 & 43 & 21 & 28 & $\mathrm{x}$ & $\hat{x}$ & 23 & 21 & $x$ & 12 & $x$ & $\hat{x}$ & 44 & 66 & $\hat{x}$ & $\hat{x}$ & $x$ & $x$ & $\mathrm{x}$ & 15 \\
\hline & & & FSM & 17 & 24 & 13 & 12 & $\hat{x}$ & $\hat{x}$ & $x$ & 12 & $\hat{x}$ & 13 & - & $\hat{x}$ & 22 & 25 & $x$ & $\hat{x}$ & $x$ & $x$ & $\hat{x}$ & 15 \\
\hline & & Statemented SEN & Not FSM & $x$ & $x$ & - & $x$ & - & - & $x$ & $x$ & - & - & $x$ & - & $x$ & 10 & - & $\mathrm{x}$ & - & $x$ & - & $x$ \\
\hline & & & FSM & - & $x$ & $x$ & $x$ & - & - & $x$ & $x$ & $x$ & $x$ & - & - & $x$ & $x$ & - & $x$ & $x$ & $x$ & $x$ & $x$ \\
\hline & Other than English & No SEN & Not FSM & 216 & 266 & 320 & 335 & 94 & 59 & 22 & 27 & 93 & 93 & 78 & 83 & 278 & 255 & 24 & 40 & 58 & 41 & 236 & 221 \\
\hline & & & FSM & 13 & $x$ & 36 & 48 & 47 & 38 & $x$ & $x$ & $x$ & 15 & 12 & 21 & 18 & 15 & $x$ & $x$ & 26 & 13 & 24 & 22 \\
\hline & & SEN at Action / Plus & NotFSM & 63 & 97 & 97 & 120 & 49 & 87 & $x$ & $x$ & 20 & 20 & 10 & 34 & 105 & 147 & 15 & 20 & 24 & 25 & 61 & 71 \\
\hline & & & FSM & $x$ & $x$ & 31 & 28 & 14 & 27 & $x$ & - & $x$ & $x$ & $x$ & 14 & 18 & 15 & - & - & $x$ & $x$ & $x$ & 16 \\
\hline & & Statemented SEN & Not FSM & - & $x$ & $x$ & $x$ & - & $x$ & - & - & - & $x$ & - & - & $x$ & $x$ & - & - & $x$ & - & - & $x$ \\
\hline & & & FSM & - & & & & - & $x$ & - & - & - & - & - & - & & ${ }^{2}$ & - & - & - & - & - & - \\
\hline
\end{tabular}

"x" represents 1-9 pupils, suppressed to protect confidentiality "-“ represents zero pupils 
Detailed Population Profile: Key Stage 4 Schools Below the Floor Standards ...continued

\begin{tabular}{|c|c|c|c|c|c|c|c|c|c|c|c|c|c|c|c|c|c|c|c|c|c|c|c|}
\hline \multirow[b]{3}{*}{ Ethnicity } & \multirow[b]{3}{*}{ First Language } & \multirow[b]{3}{*}{ SEN Status } & \multirow[b]{3}{*}{ FSM Status } & \multicolumn{20}{|c|}{ Schools Below the Floor } \\
\hline & & & & \multicolumn{2}{|c|}{$\begin{array}{c}\text { EAST } \\
\text { MIDLANDS }\end{array}$} & \multicolumn{2}{|c|}{$\begin{array}{l}\text { EAST OF } \\
\text { ENGLAND }\end{array}$} & \multicolumn{2}{|c|}{$\begin{array}{l}\text { INNER } \\
\text { LONDON }\end{array}$} & \multicolumn{2}{|c|}{ NORTH EAST } & \multicolumn{2}{|c|}{ NORTH WEST } & \multicolumn{2}{|c|}{$\begin{array}{l}\text { OUTER } \\
\text { LONDON }\end{array}$} & \multicolumn{2}{|c|}{ SOUTHEAST } & \multicolumn{2}{|c|}{ SOUTH WEST } & \multicolumn{2}{|c|}{$\begin{array}{c}\text { WEST } \\
\text { MIDLANDS }\end{array}$} & \multicolumn{2}{|c|}{$\begin{array}{l}\text { YORKSHIRE } \\
\text { AND THE } \\
\text { HUMEER }\end{array}$} \\
\hline & & & & Girls & Boys & Girls & Boys & Girls & Boys & Girls & Boys & Girls & Boys & Girls & Boys & Girls & Boys & Girls & Boys & Girls & Boys & Girls & Boys \\
\hline \multirow[t]{11}{*}{ Other Ethnicity } & English or Unclassified & No SEN & Not FSM & $x$ & $\frac{x}{x}$ & 22 & 22 & 11 & 11 & $x$ & $\frac{x}{x}$ & $x$ & 10 & $x$ & $\frac{x}{x}$ & 27 & 21 & $x$ & $\frac{x}{x}$ & $x$ & $\frac{x}{x}$ & 11 & 14 \\
\hline & & & FSM & $x$ & $\mathrm{x}$ & $\mathrm{x}$ & $x$ & $\mathrm{x}$ & $\mathrm{x}$ & & & $\mathrm{x}$ & $\mathrm{x}$ & $\mathrm{x}$ & $\mathrm{x}$ & $\mathrm{x}$ & $\mathrm{x}$ & & $\mathrm{x}$ & $\mathrm{x}$ & $\mathrm{x}$ & 11 & $x$ \\
\hline & & SEN at Action/Plus & NotFSM & $x$ & $x$ & $x$ & $x$ & $x$ & $x$ & $x$ & $x$ & & $x$ & $x$ & $x$ & $x$ & $x$ & - & $x$ & - & $x$ & $x$ & $x$ \\
\hline & & & FSM & $x$ & $x$ & $x$ & $x$ & $x$ & $x$ & - & - & $\mathrm{x}$ & $x$ & - & $x$ & $x$ & $x$ & $x$ & - & $x$ & $x$ & $\mathrm{x}$ & $x$ \\
\hline & & Statemented SEN & NotFSM & - & - & - & - & - & $x$ & - & - & - & $x$ & - & - & $\mathrm{x}$ & - & - & - & - & $\mathrm{x}$ & - & - \\
\hline & & & FSM & - & - & - & - & - & $x$ & - & - & - & - & - & - & - & - & - & - & - & $x$ & $\dot{-}$ & - \\
\hline & Other than English & No SEN & Not FSM & 26 & 33 & 76 & 83 & 41 & 56 & 13 & 27 & 21 & 19 & 49 & 64 & 58 & 90 & $x$ & 11 & 24 & 43 & 86 & 83 \\
\hline & & & FSM & $x$ & $x$ & $x$ & $x$ & 31 & 42 & $x$ & $x$ & 26 & 42 & 12 & 23 & $x$ & $\mathrm{x}$ & - & $\mathrm{x}$ & 16 & 27 & 78 & 74 \\
\hline & & SEN at Action / Plus & Not FSM & $x$ & 16 & 15 & 21 & 22 & 34 & $\mathrm{x}$ & 13 & $x$ & $x$ & $\mathrm{x}$ & 21 & 14 & 33 & $x$ & $x$ & $\mathrm{x}$ & 16 & 30 & 29 \\
\hline & & & FSM & $\mathrm{x}$ & $\mathrm{x}$ & $\mathrm{x}$ & $x$ & 13 & 26 & $\hat{x}$ & $\mathrm{x}$ & $\mathrm{x}$ & 17 & $\mathrm{x}$ & 12 & $x$ & $x$ & $\mathrm{x}$ & $\hat{x}$ & $\mathrm{x}$ & 12 & 28 & 55 \\
\hline & & Statemented SEN & NotFSM & 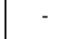 & $x$ & & - & - & - & - & - & - & - & $\mathrm{x}$ & $x$ & - & - & - & - & - & $x$ & - & - \\
\hline \multirow{12}{*}{ Unknown Ethnicity } & English or Unclassified & No SEN & NotF FSM & 58 & $\frac{x}{55}$ & $\overline{71}$ & 47 & $\frac{x}{x}$ & $\frac{-}{x}$ & $x$ & $x$ & 89 & 82 & $x$ & $x$ & 162 & 177 & $x$ & $\bar{x}$ & 24 & 28 & 52 & 37 \\
\hline & & & FSM & $x$ & 15 & 15 & 17 & $x$ & - & $x$ & $x$ & 62 & 64 & $x$ & $x$ & 32 & 28 & $\mathrm{x}$ & $x$ & 15 & 15 & 28 & 17 \\
\hline & & SEN at Action / Plus & NotFSM & $\mathrm{x}$ & 34 & 14 & 22 & $\hat{x}$ & $x$ & $\hat{x}$ & $\mathrm{x}$ & 19 & 51 & $x$ & $x$ & 67 & 92 & $\mathrm{x}$ & 13 & $\mathrm{x}$ & 15 & 19 & 29 \\
\hline & & & FSM & $x$ & 17 & $x$ & $x$ & $\mathrm{x}$ & $x$ & - & $\mathrm{x}$ & 25 & 47 & - & $x$ & 25 & 49 & $x$ & $x$ & $x$ & 11 & 17 & 13 \\
\hline & & Statemented SEN & NotFSM & - & $x$ & & $x$ & & - & - & $x$ & $\mathrm{x}$ & $x$ & - & - & $x$ & $\mathrm{x}$ & & $x$ & $x$ & & - & $\mathrm{x}$ \\
\hline & & & FSM & - & $x$ & $x$ & & - & - & - & & $x$ & $x$ & - & - & $x$ & $x$ & $x$ & $x$ & & $x$ & & \\
\hline & Other than English & No SEN & Not FSM & $x$ & - & 20 & 12 & $x$ & $x$ & - & - & $x$ & 22 & $x$ & $x$ & 21 & 19 & - & $x$ & 13 & 25 & 16 & $x$ \\
\hline & & & FSM & - & - & $x$ & $x$ & $\mathrm{x}$ & - & - & - & $x$ & $\mathrm{x}$ & - & $x$ & $x$ & $x$ & - & - & $x$ & $x$ & $\mathrm{x}$ & $x$ \\
\hline & & SEN at Action / Plus & Not FSM & $x$ & $x$ & $x$ & $x$ & - & $x$ & - & - & - & 14 & $x$ & - & $x$ & 10 & - & $x$ & $x$ & $x$ & $x$ & $x$ \\
\hline & & & FSM & - & - & $\mathrm{x}$ & $x$ & - & - & - & - & $\mathrm{x}$ & $x$ & $x$ & - & $x$ & $x$ & $\mathrm{x}$ & - & $x$ & $x$ & $x$ & $x$ \\
\hline & & Statemented SEN & Not FSM & - & - & - & - & - & - & - & - & - & - & - & - & $\mathrm{x}$ & - & - & - & - & - & - & $x$ \\
\hline & & & FSM & - & - & - & $x$ & $x$ & - & - & - & - & $x$ & - & - & - & - & - & - & - & $x$ & - & . \\
\hline
\end{tabular}

"x" represents 1-9 pupils, suppressed to protect confidentiality "-“ represents zero pupils 


\section{Annex B: Additional Attainment and Progress Analyses}

\section{English and Maths Test Score Distributions at KS2}

KS2 English Test Score Distribution for Above Floor Schools

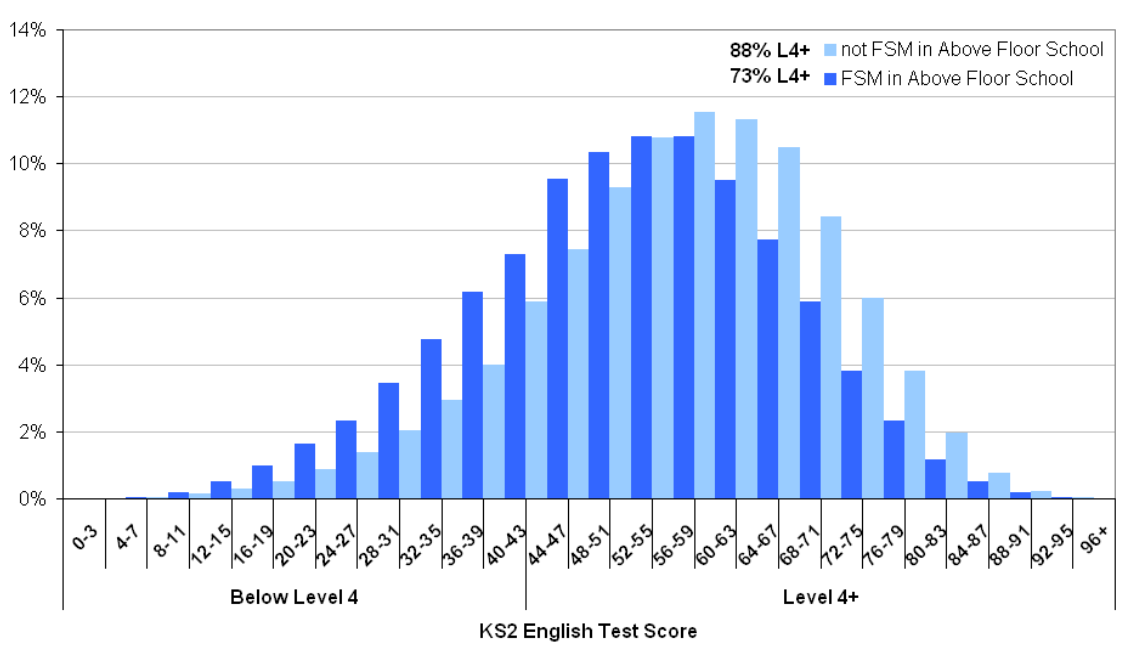

KS2 English Test Score Distribution for Below Floor Schools

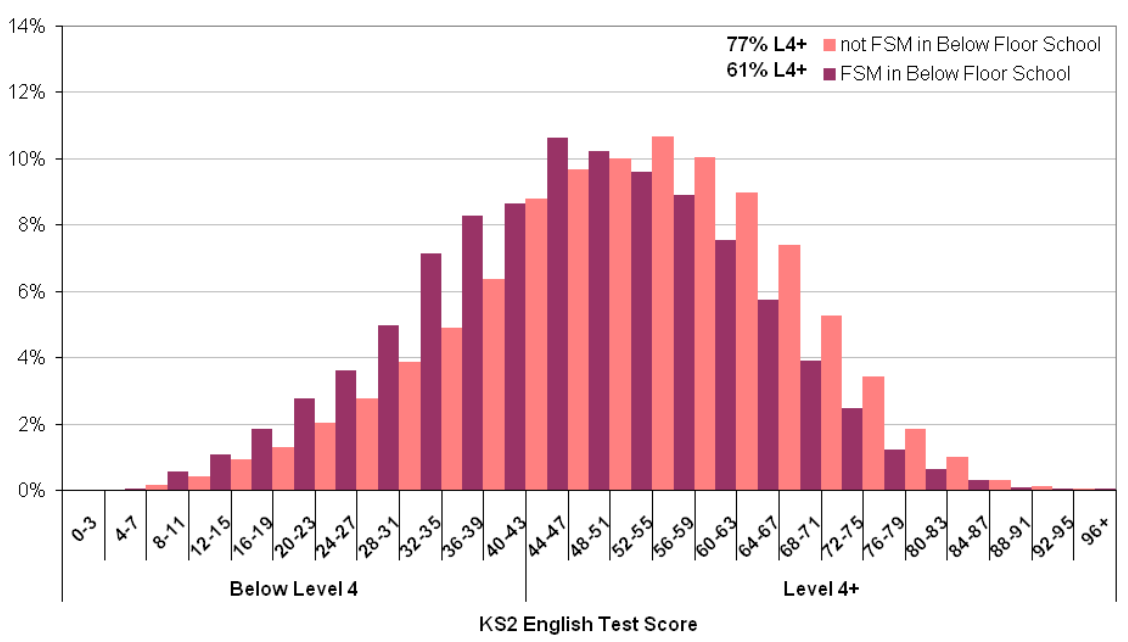

KS2 English Test Score Distribution for Below Floor 09 (BC) Schools

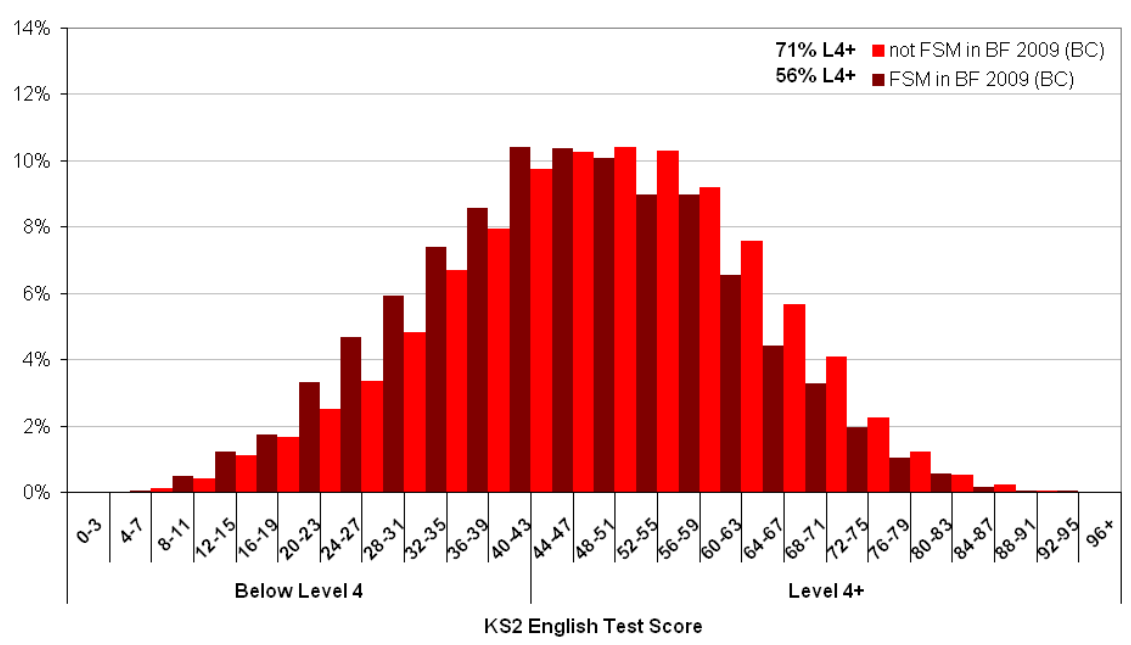


KS2 Maths Test Score Distribution for Above Floor Schools

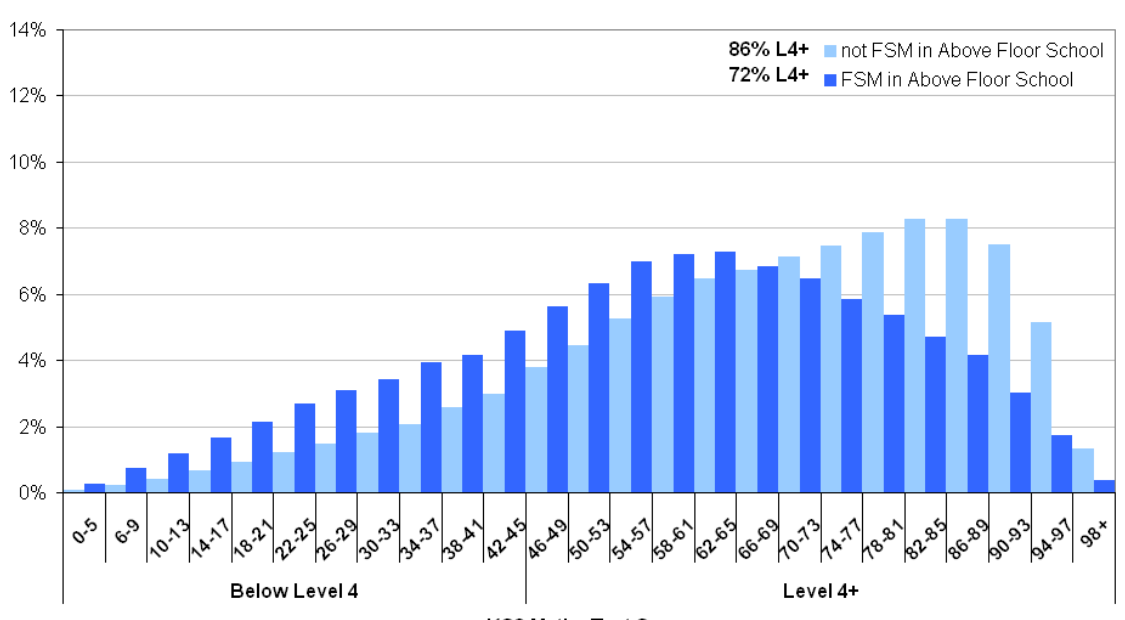

KS2 Maths Test Score

KS2 Maths Test Score Distribution for Below Floor Schools

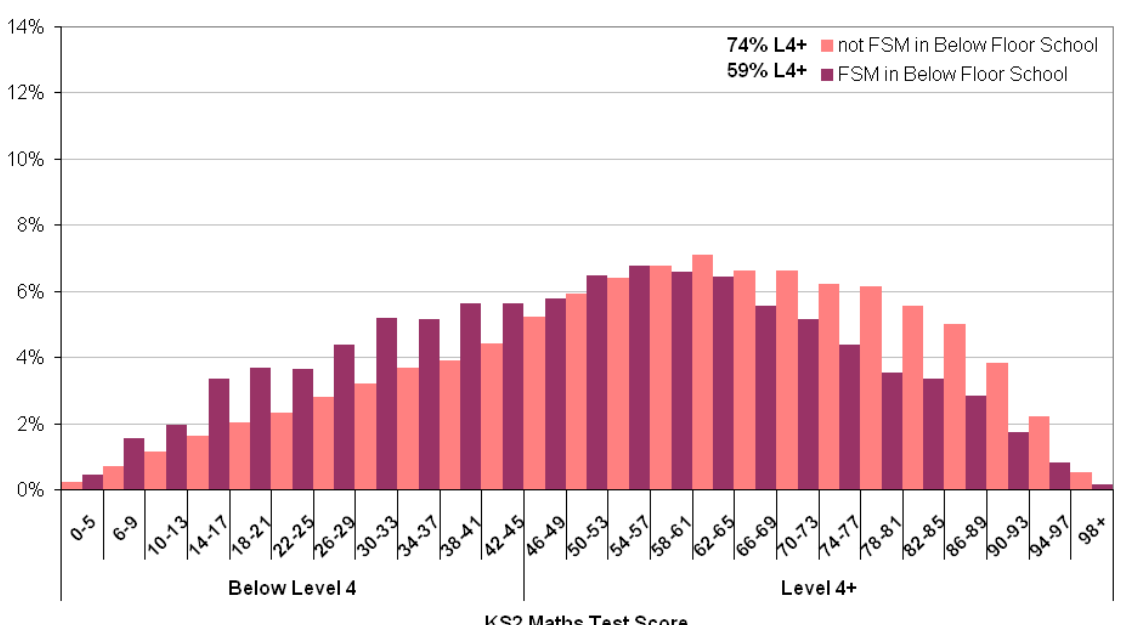

KS2 Maths Test Score Distribution for Below Floor 09 (BC) Schools

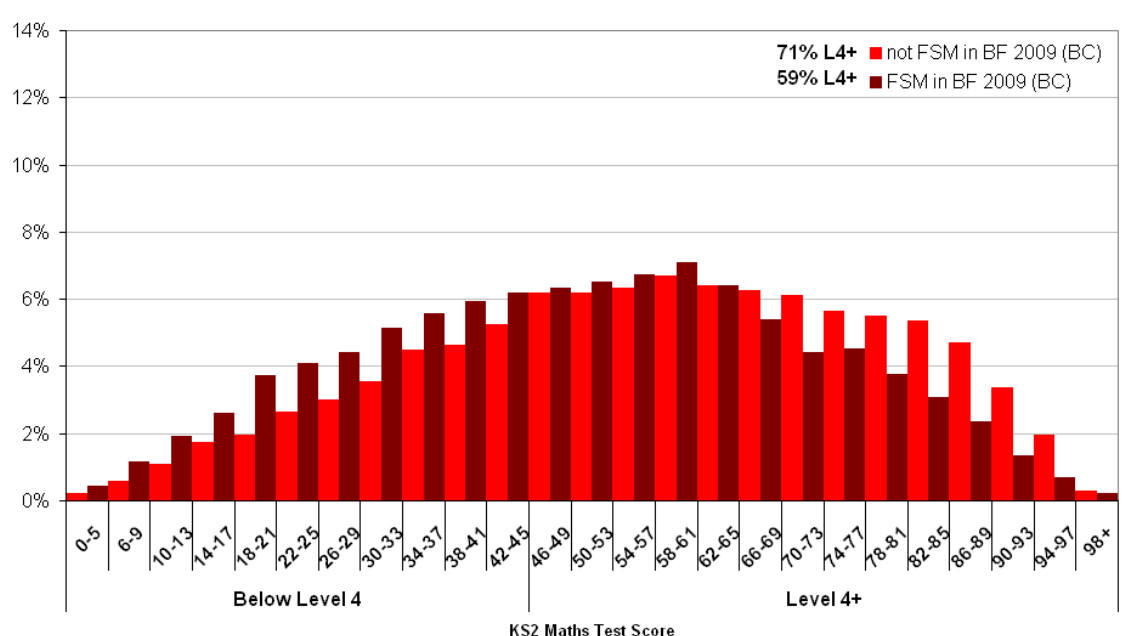




\section{English and Maths GCSE Grade Distributions}

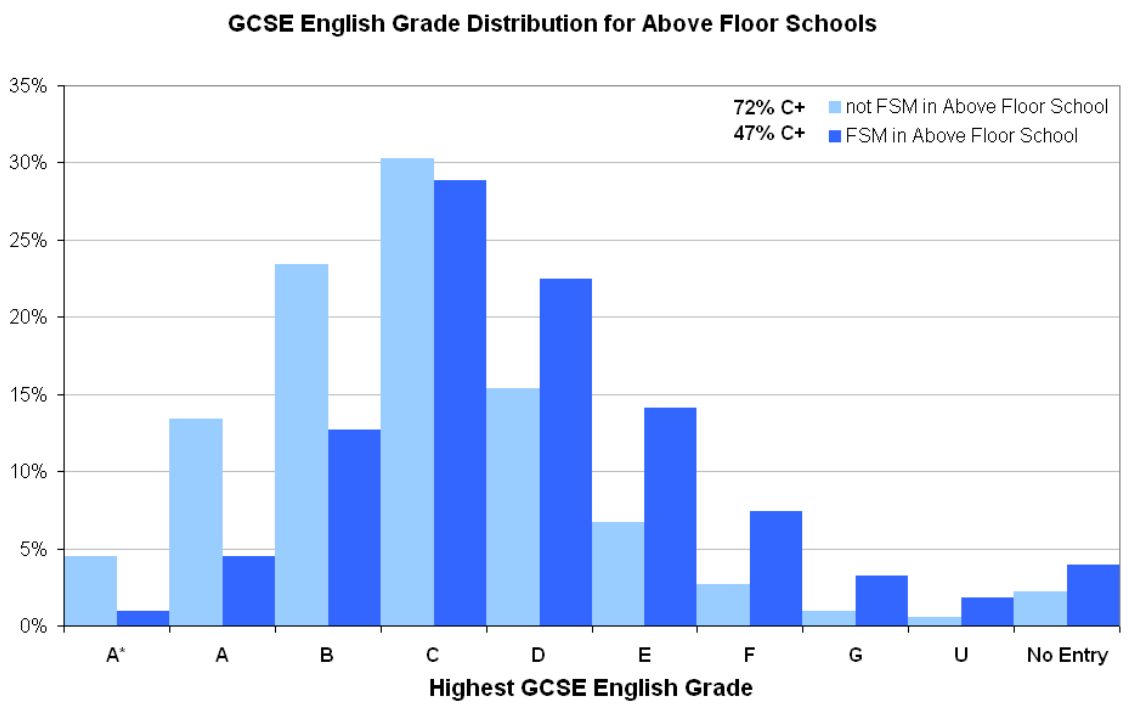

GCSE English Grade Distribution for Below Floor Schools

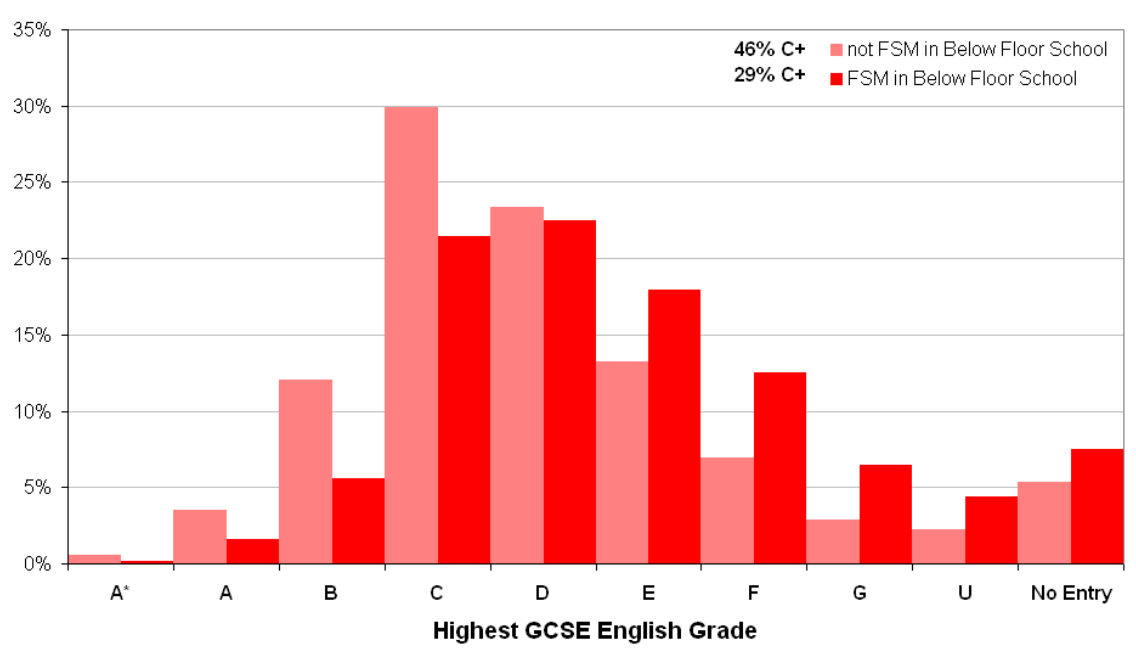


GCSE Maths Grade Distribution for Above Floor Schools

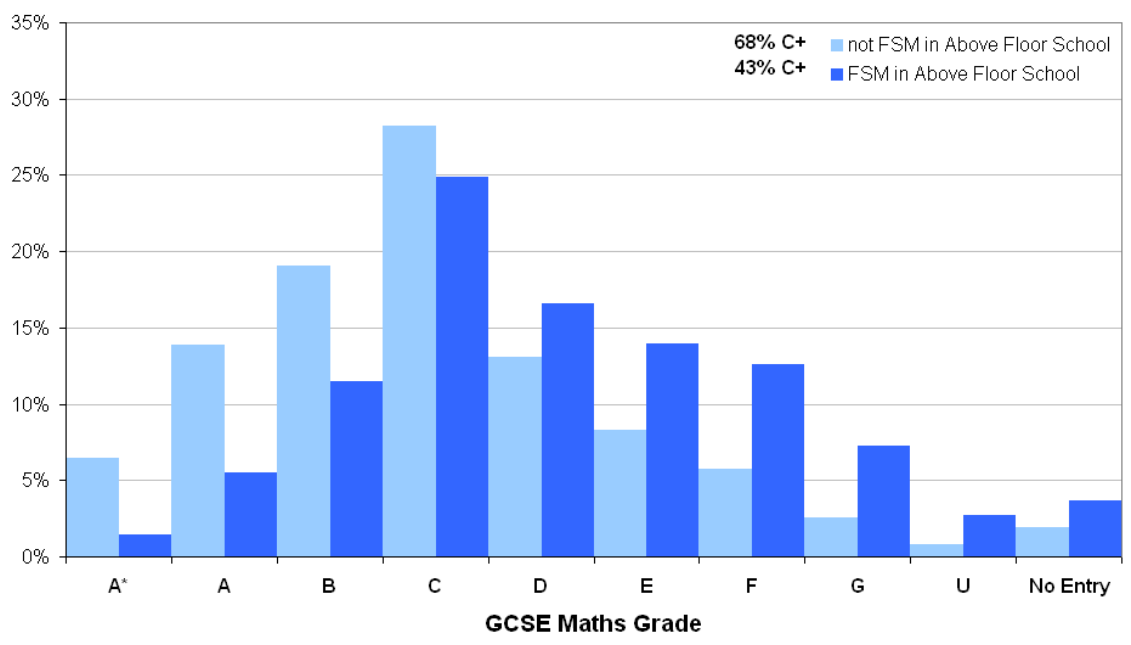

GCSE Maths Grade Distribution for Below Floor Schools

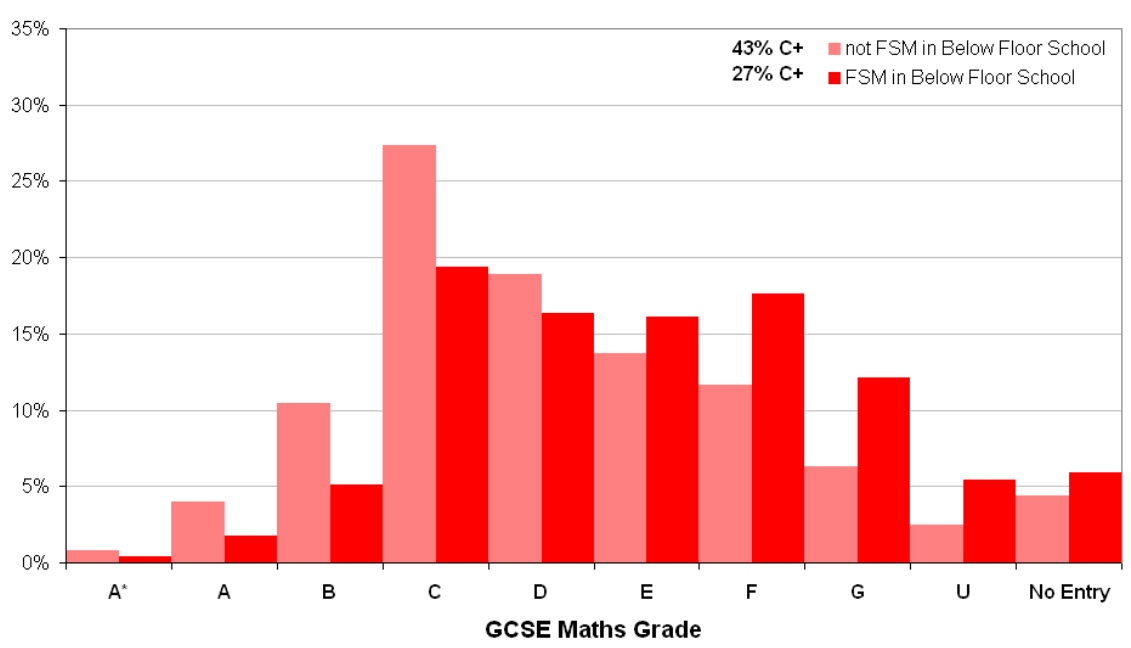




\section{Attainment by Pupil Characteristics in KS2 Below Floor Schools}

KS2 Attainment by Area Deprivation, School Group and FSM

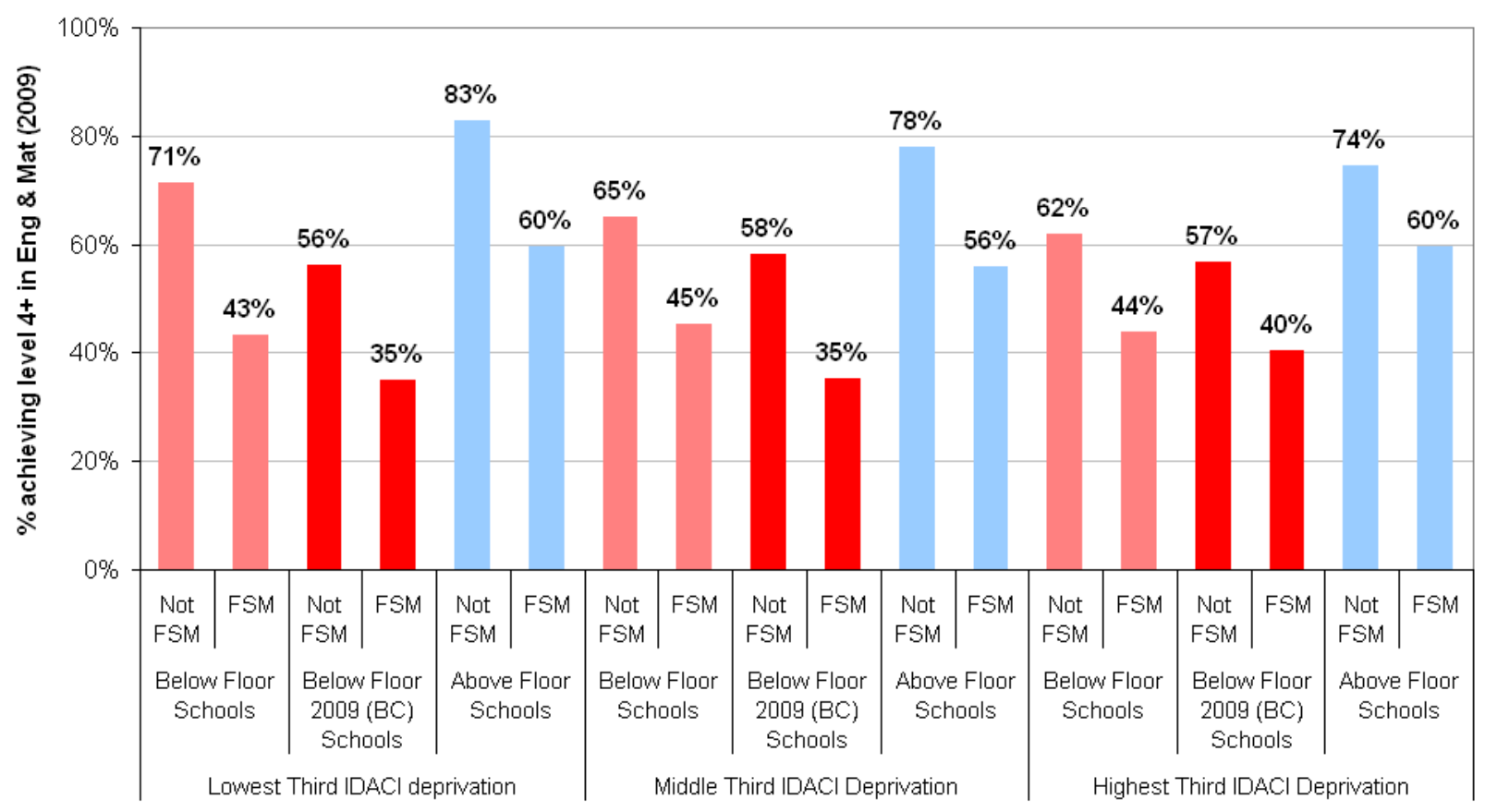

KS2 Attainment by Gender, School Group and FSM

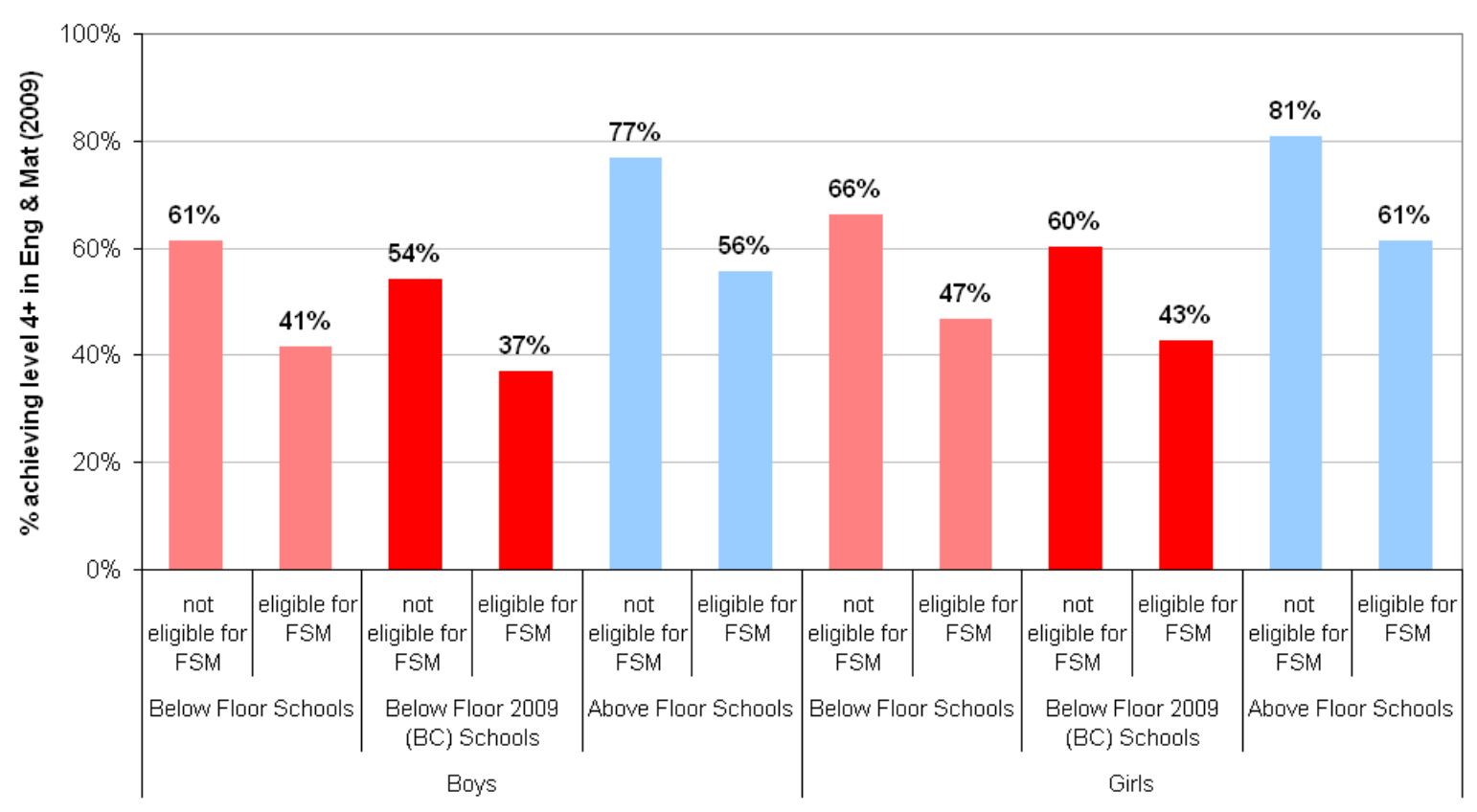


KS2 Attainment by Ethnicity, School Group and FSM - Asian Pupils

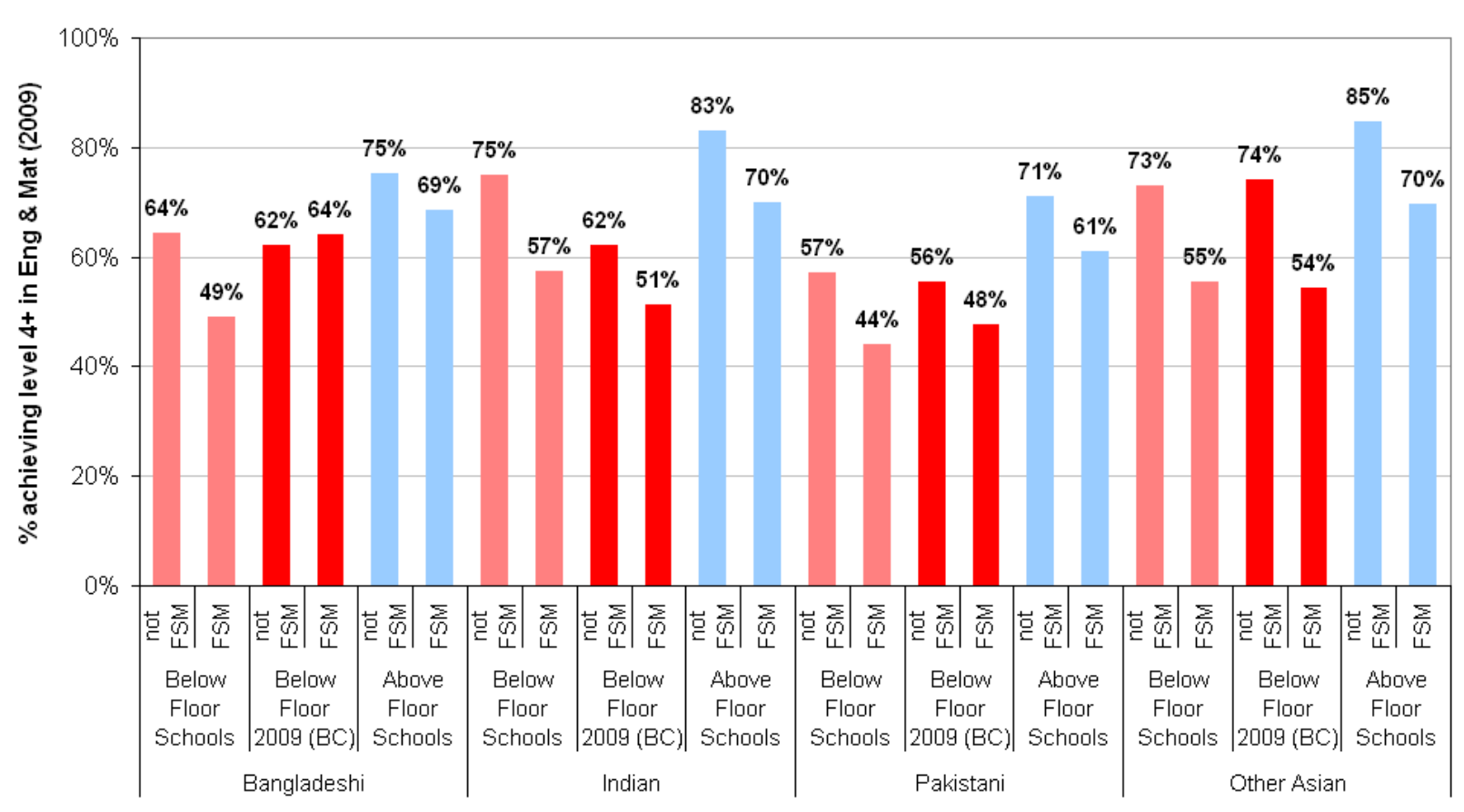

KS2 Attainment by Ethnicity, School Group and FSM - Black Pupils

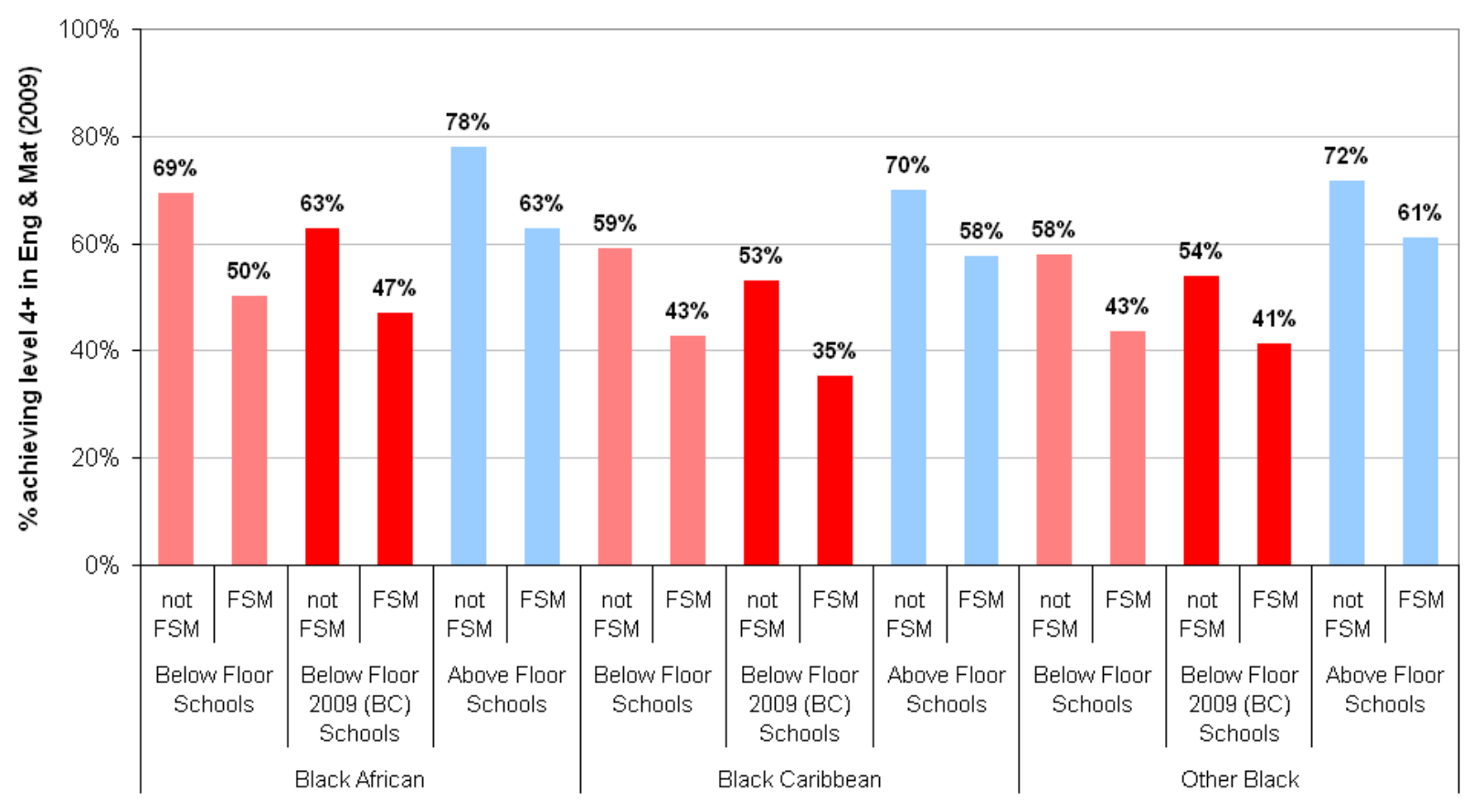


KS2 Attainment by Ethnicity, School Group and FSM - Chinese \& Mixed Ethnicity Pupils

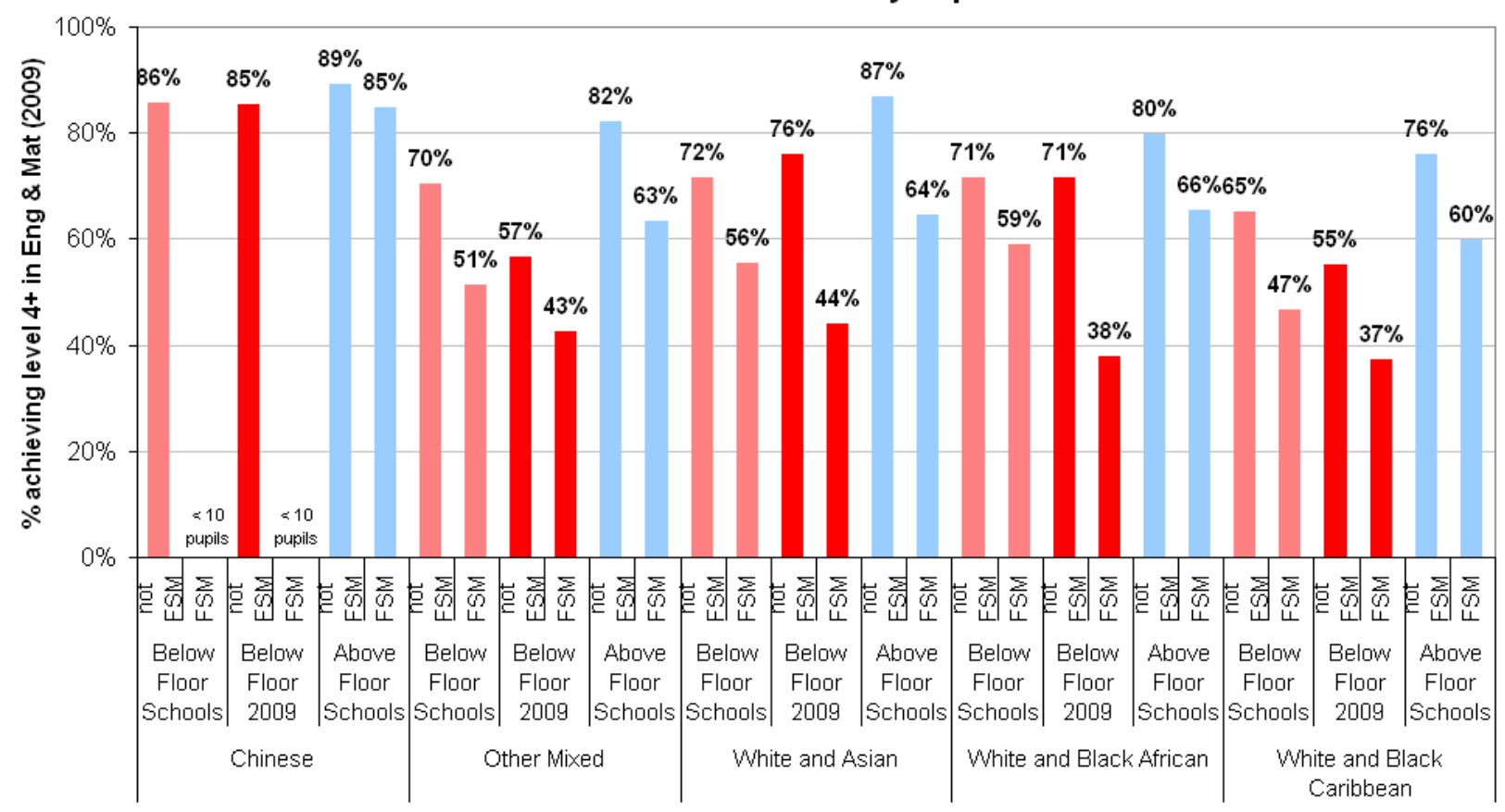

KS2 Attainment by Ethnicity, School Group and FSM - White \& Other Ethnicity Pupils

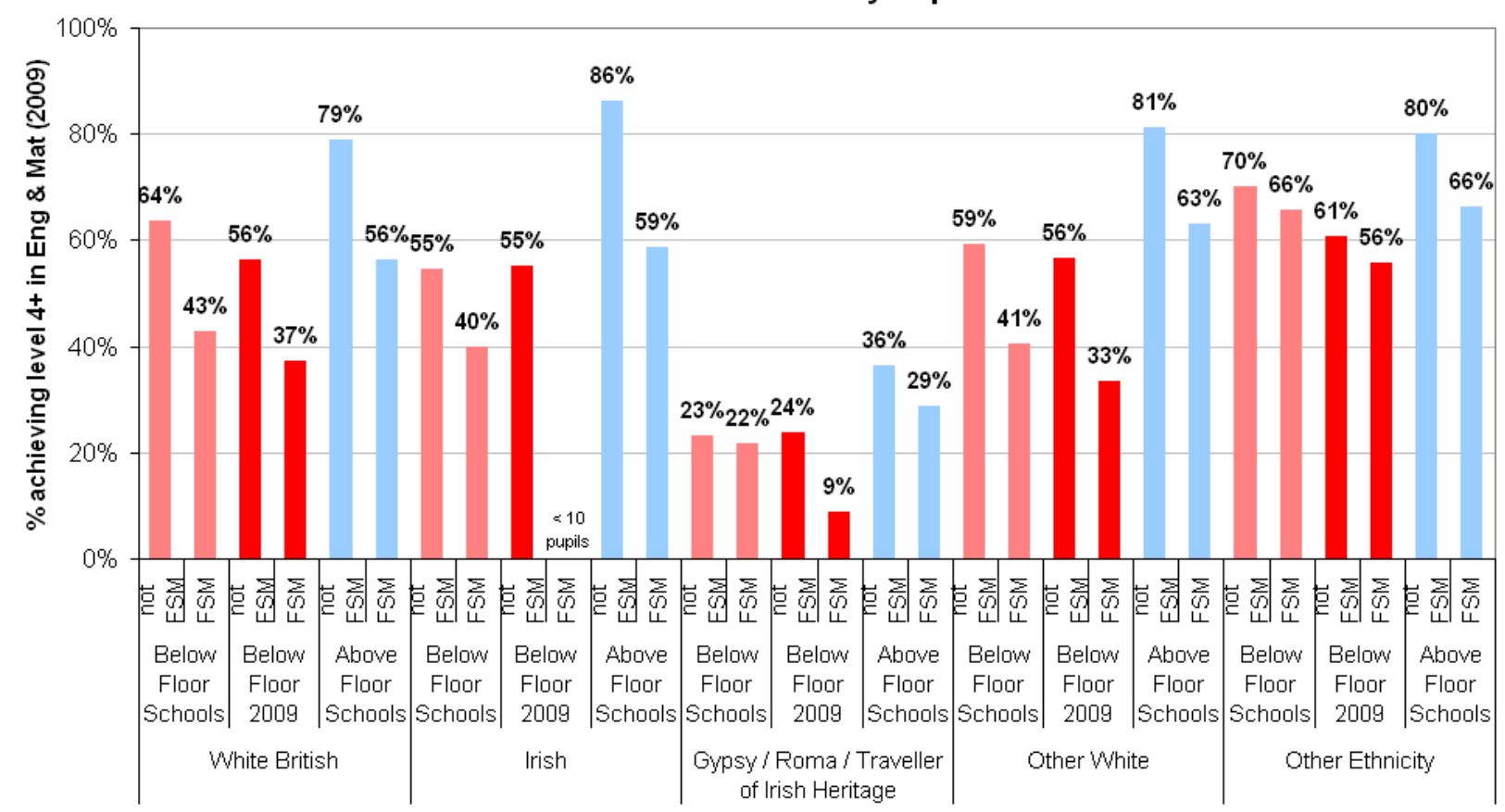


KS2 Attainment by First Language, School Group and FSM

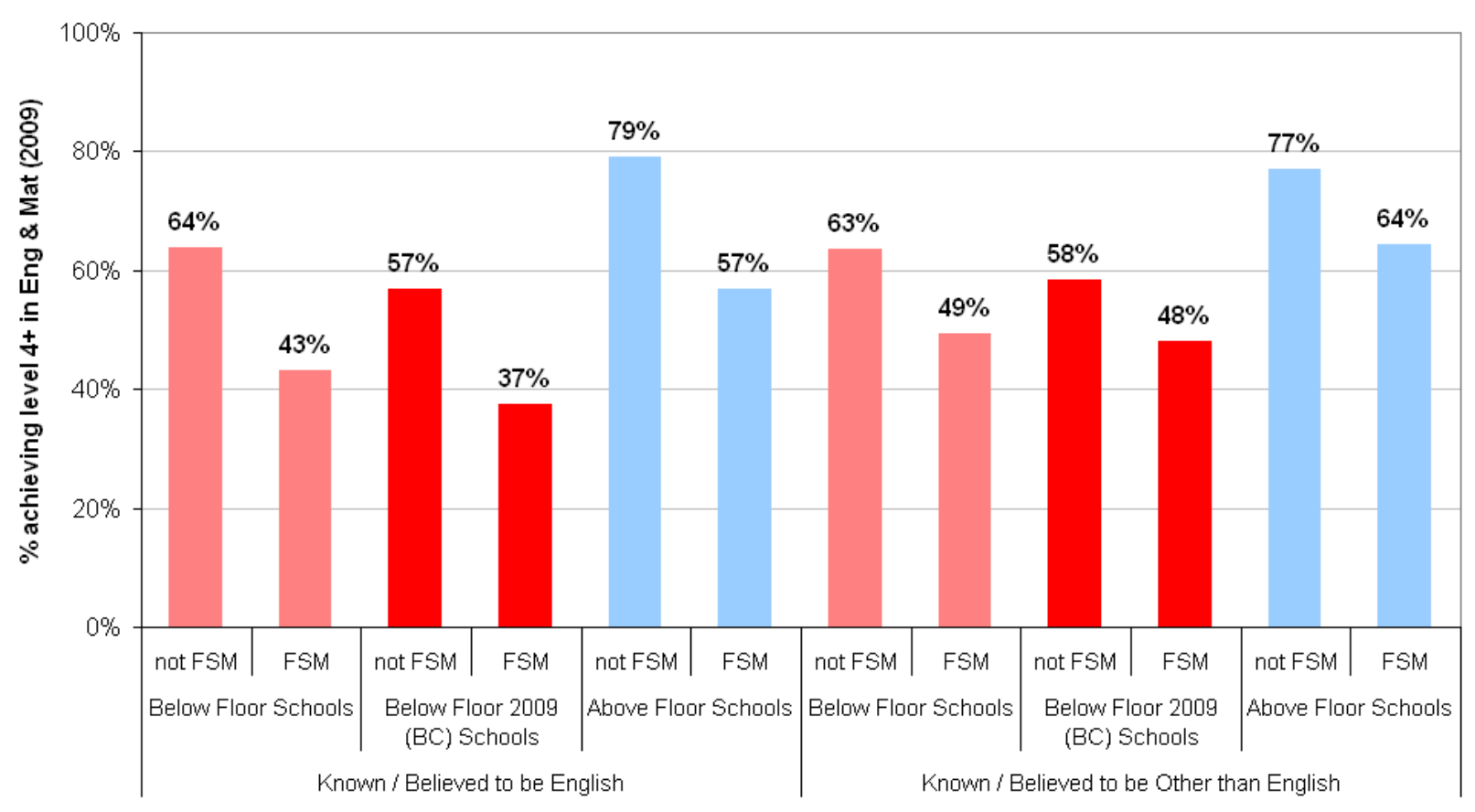


KS2 Attainment by Special Educational Needs, School Group and FSM

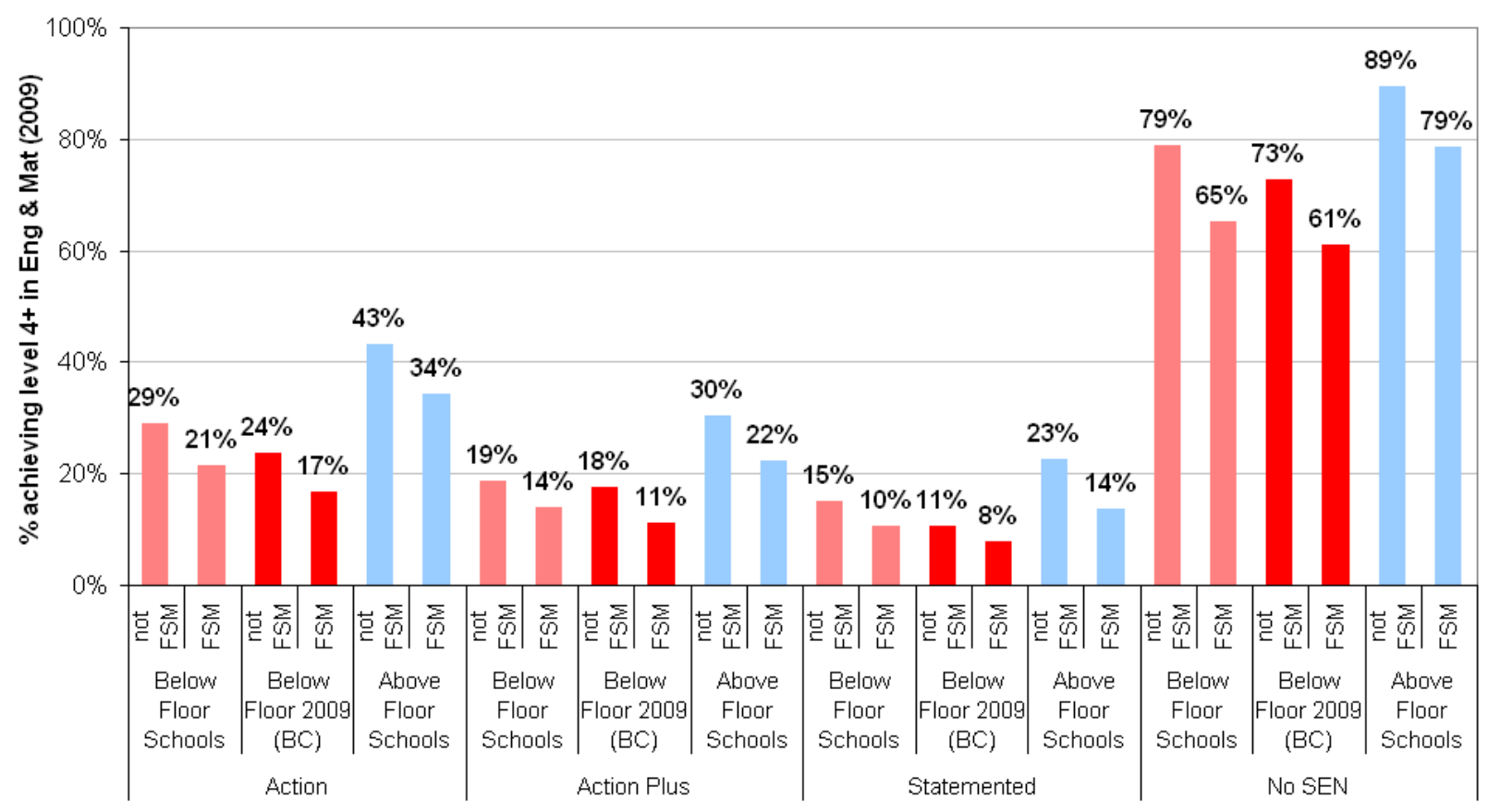


KS2 Attainment by Region, School Group and FSM

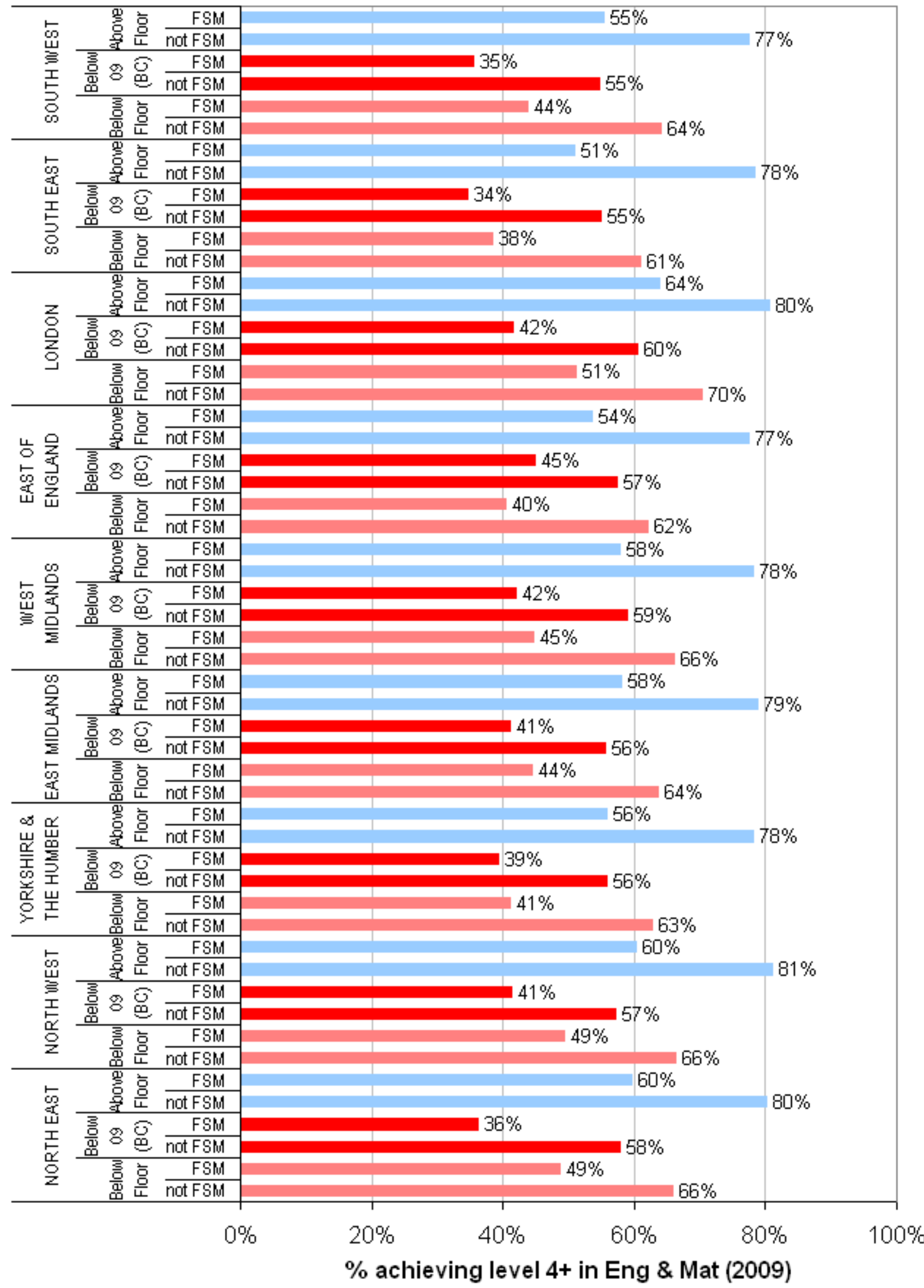




\section{Attainment by Pupil Characteristics in KS4 Below Floor Schools}

KS4 Attainment by Area Deprivation, School Group and FSM

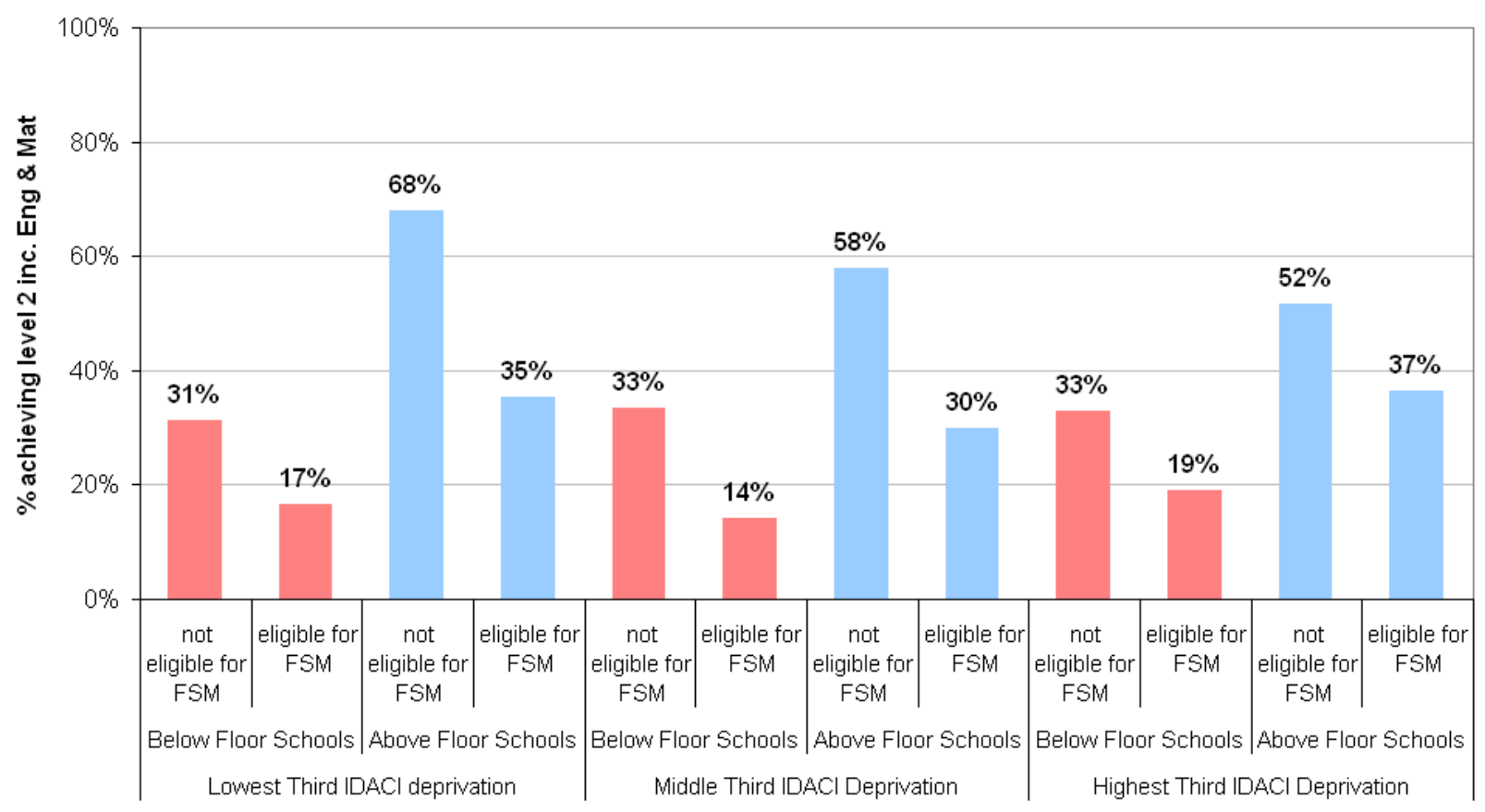

KS4 Attainment by Gender, School Group and FSM

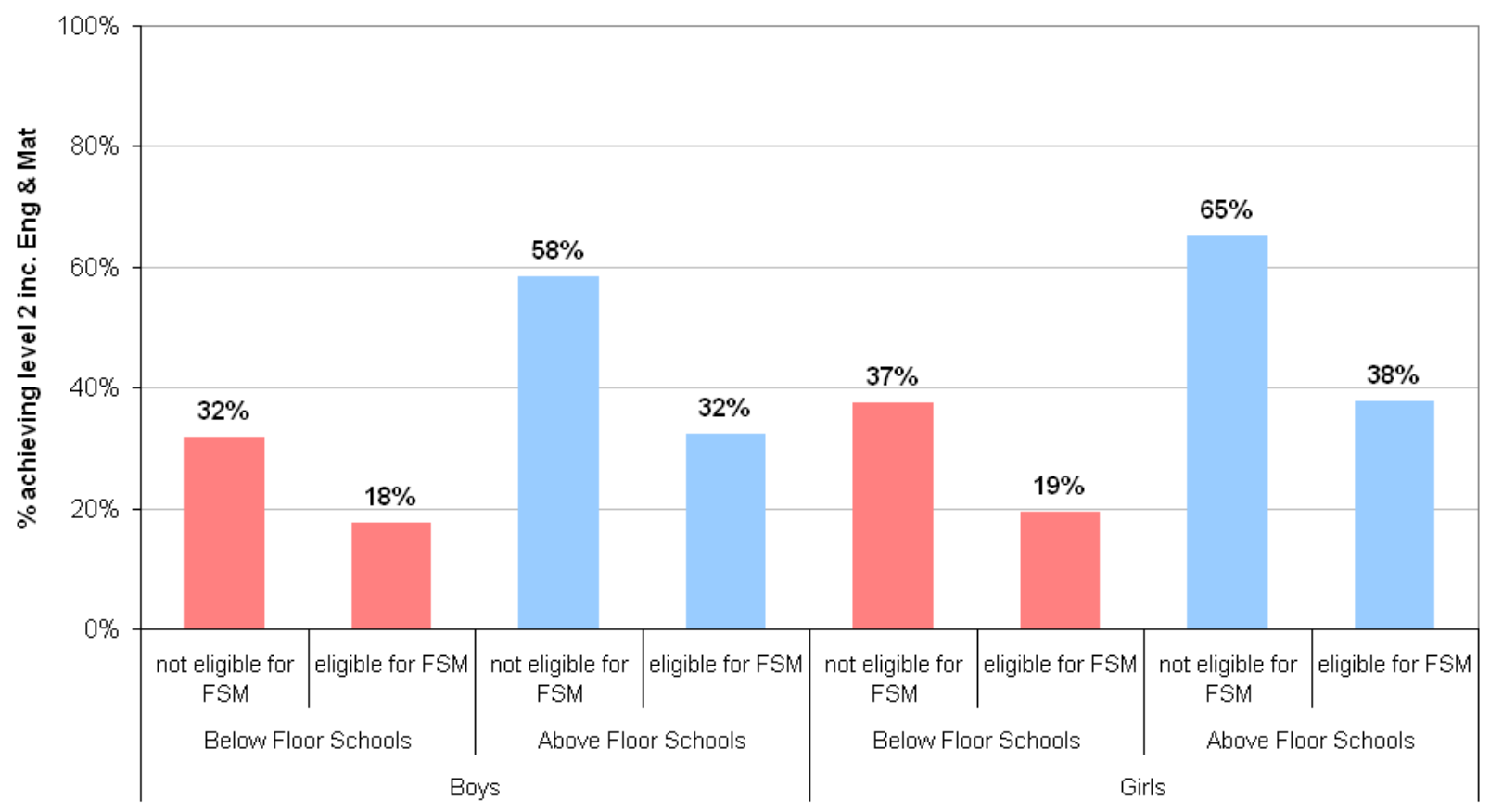


KS4 Attainment by Ethnicity, School Group and FSM - Asian Pupils

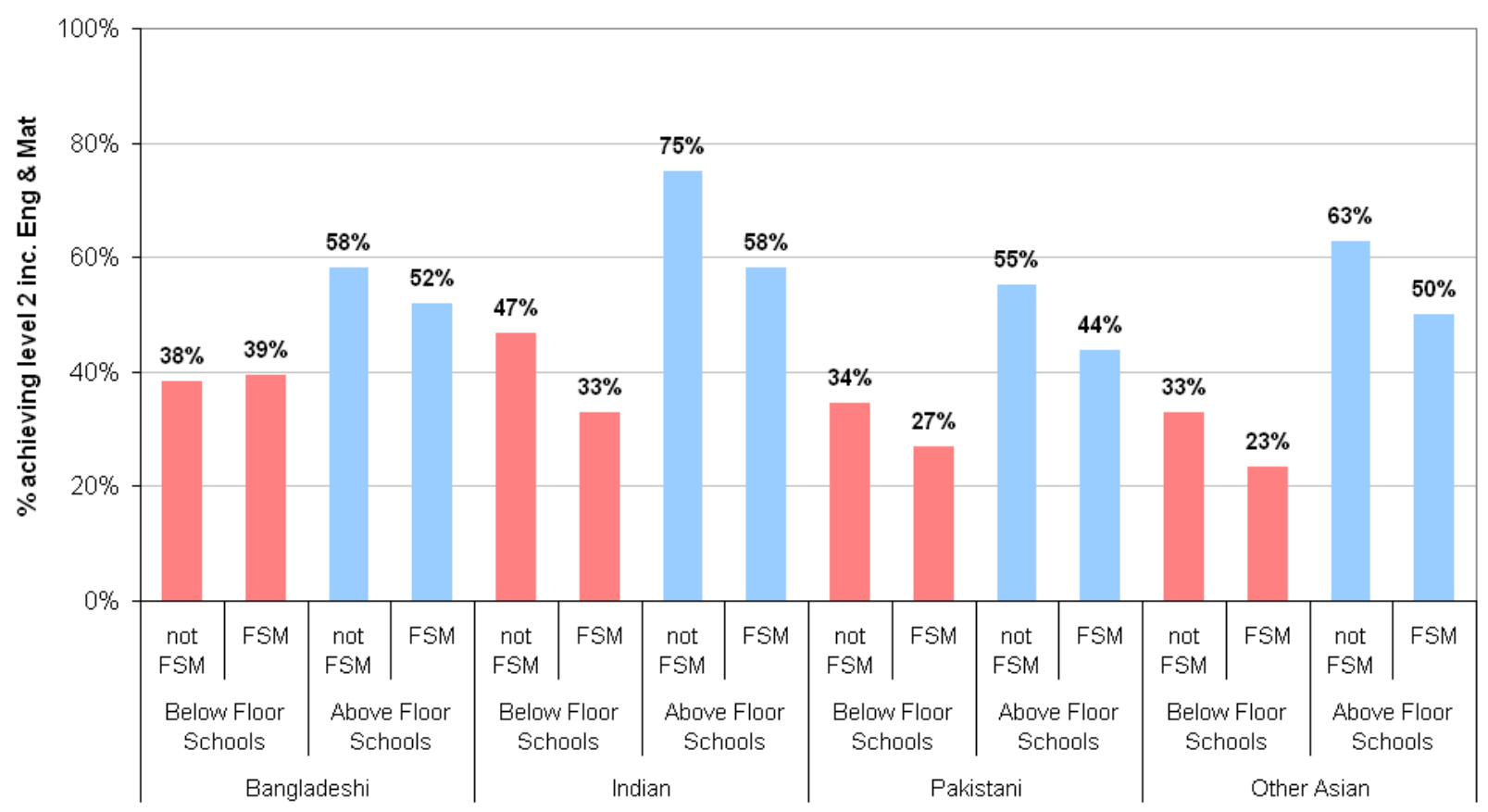

KS4 Attainment by Ethnicity, School Group and FSM - Black Pupils

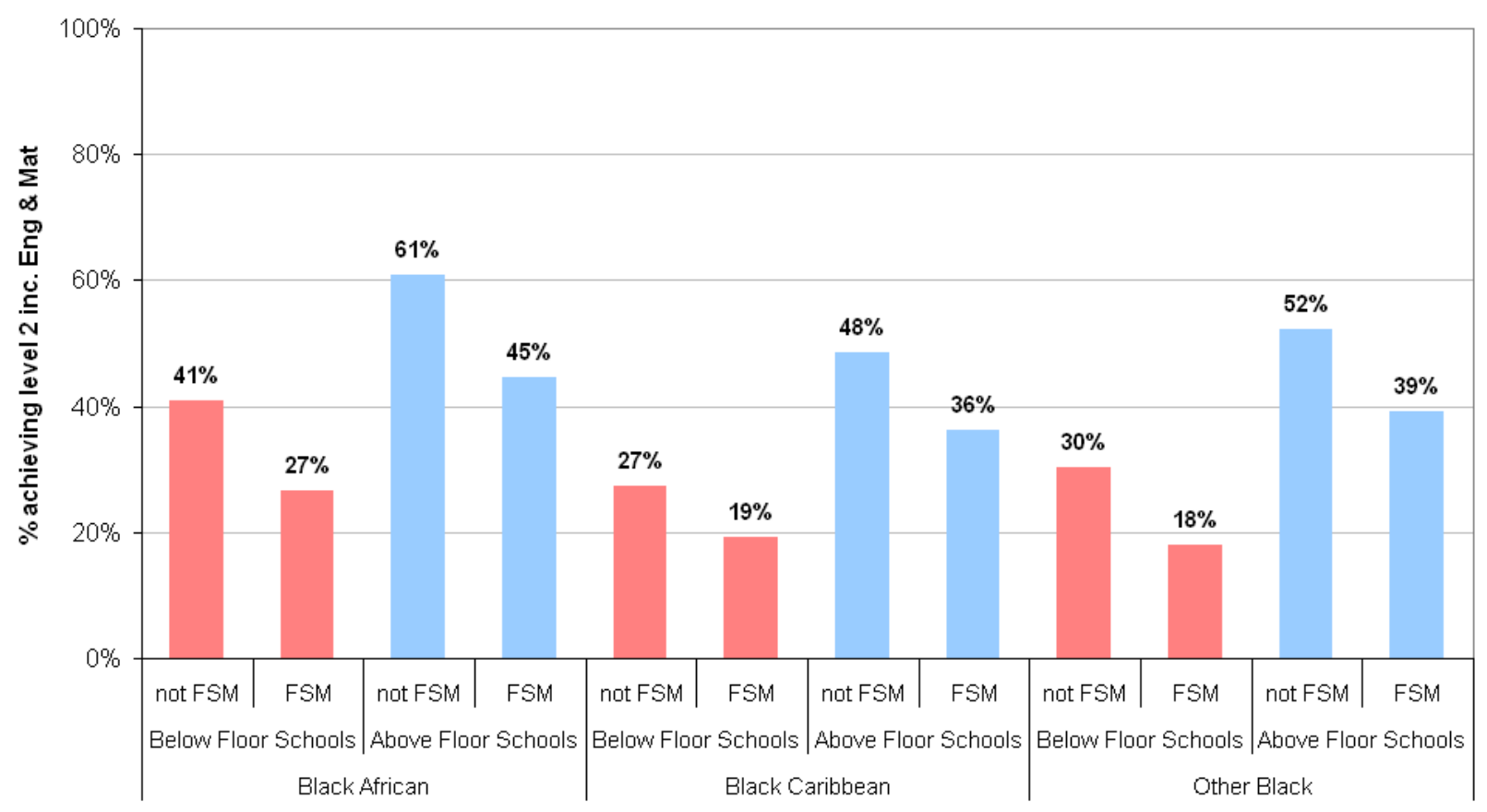


KS4 Attainment by Ethnicity, School Group and FSM - Chinese \& Mixed Ethnicity Pupils

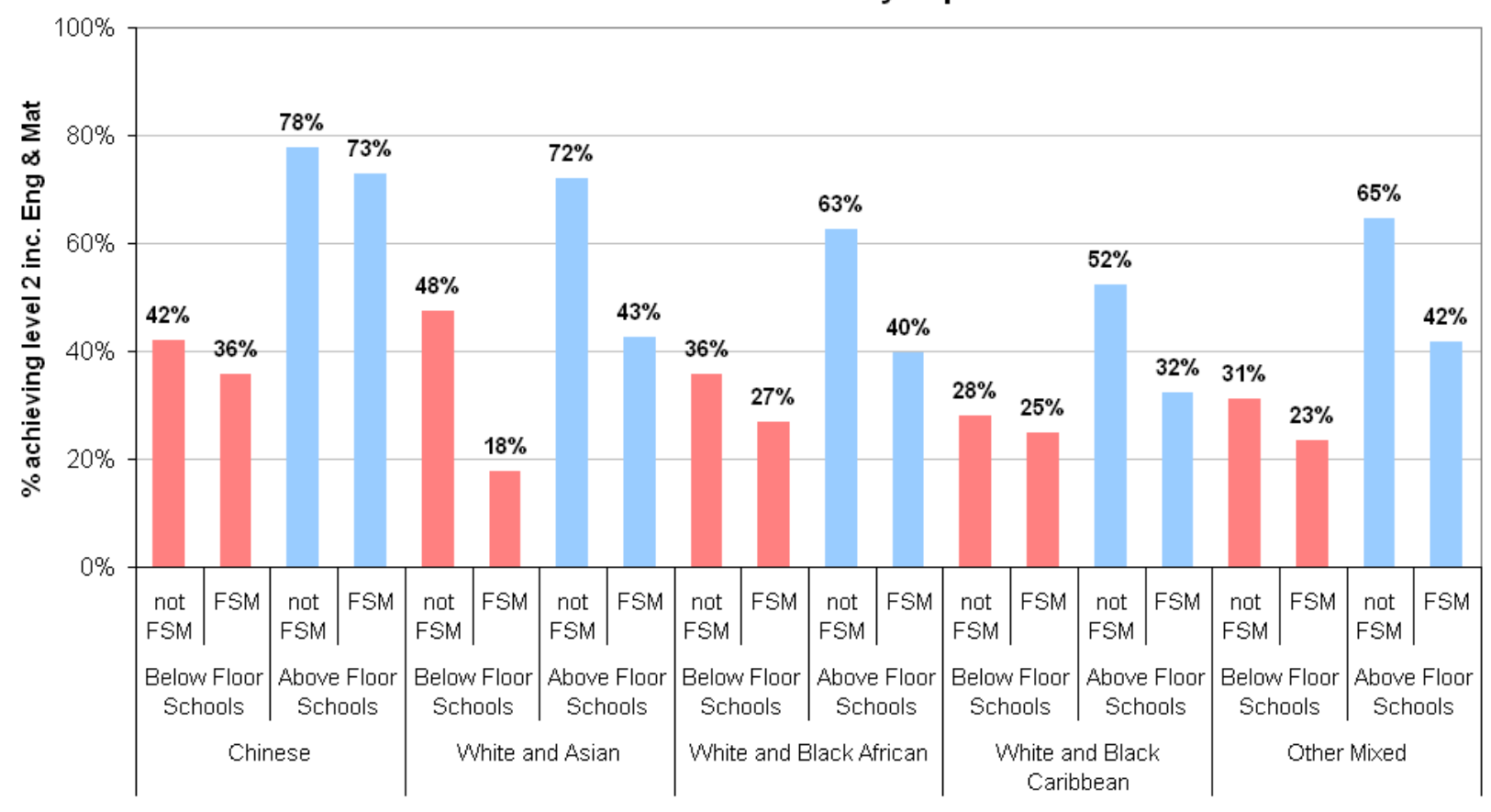

KS4 Attainment by Ethnicity, School Group and FSM - White \& Other Ethnicity Pupils

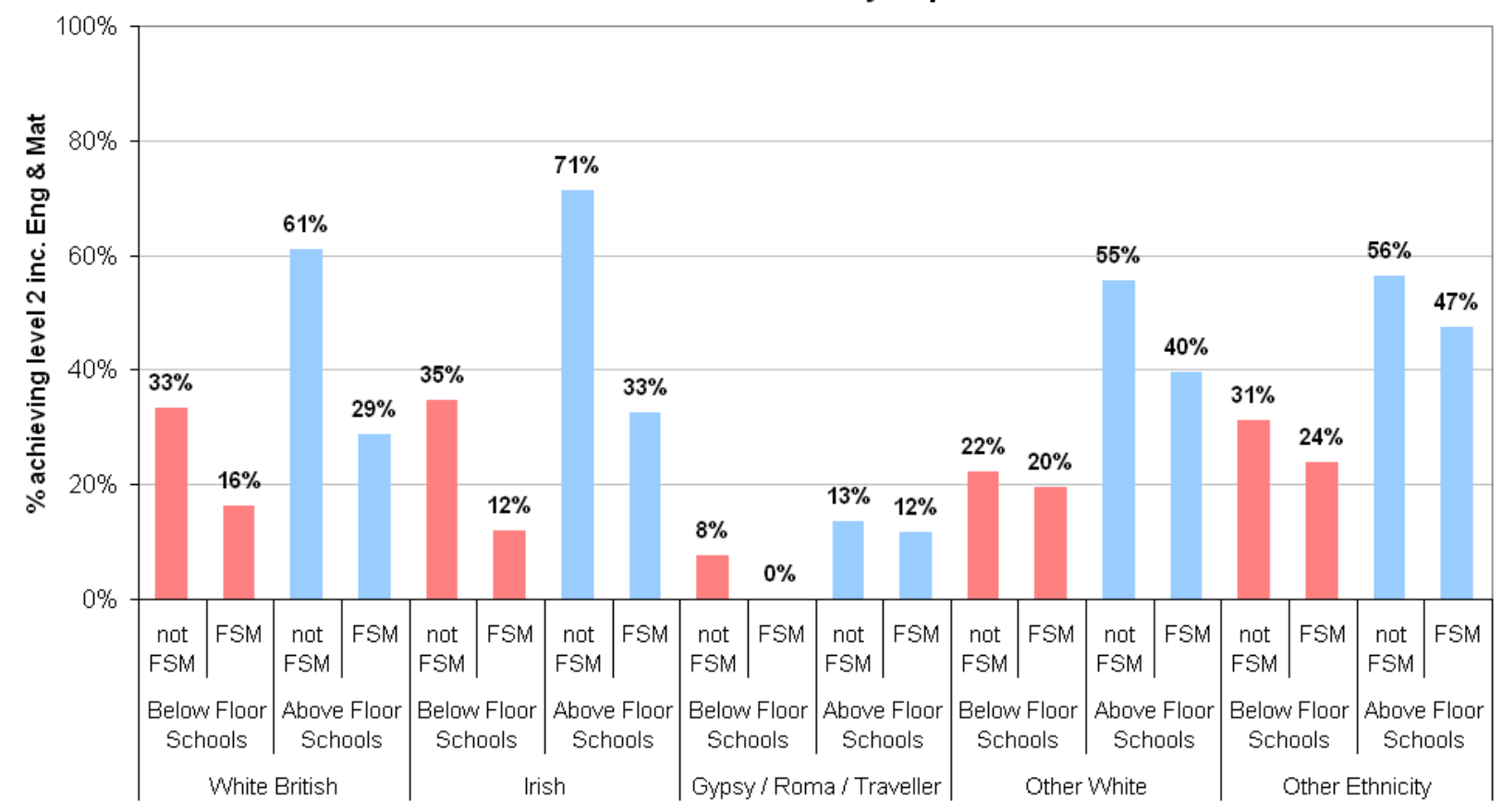


KS4 Attainment by First Language, School Group and FSM

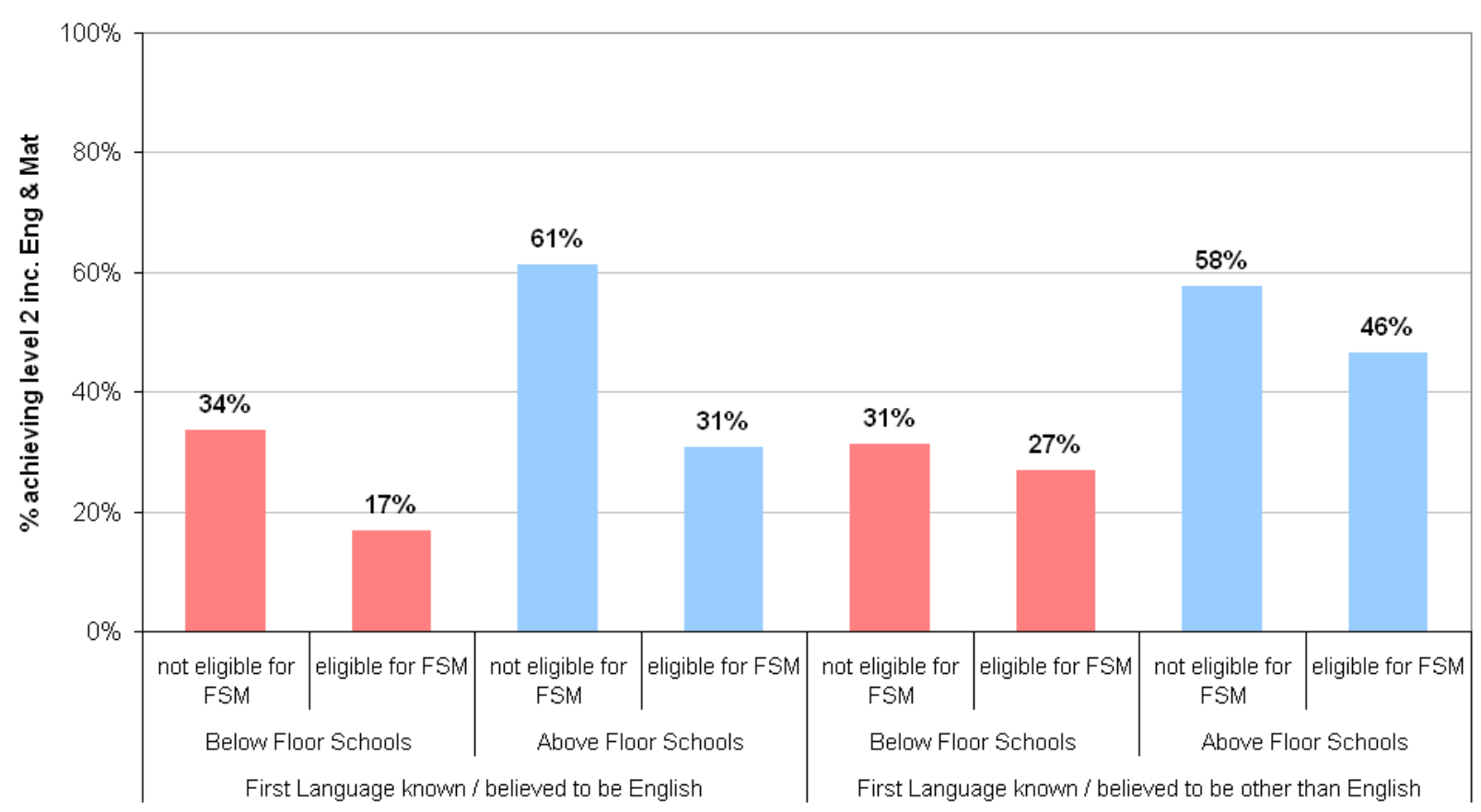

KS4 Attainment by Special Educational Needs, School Group and FSM

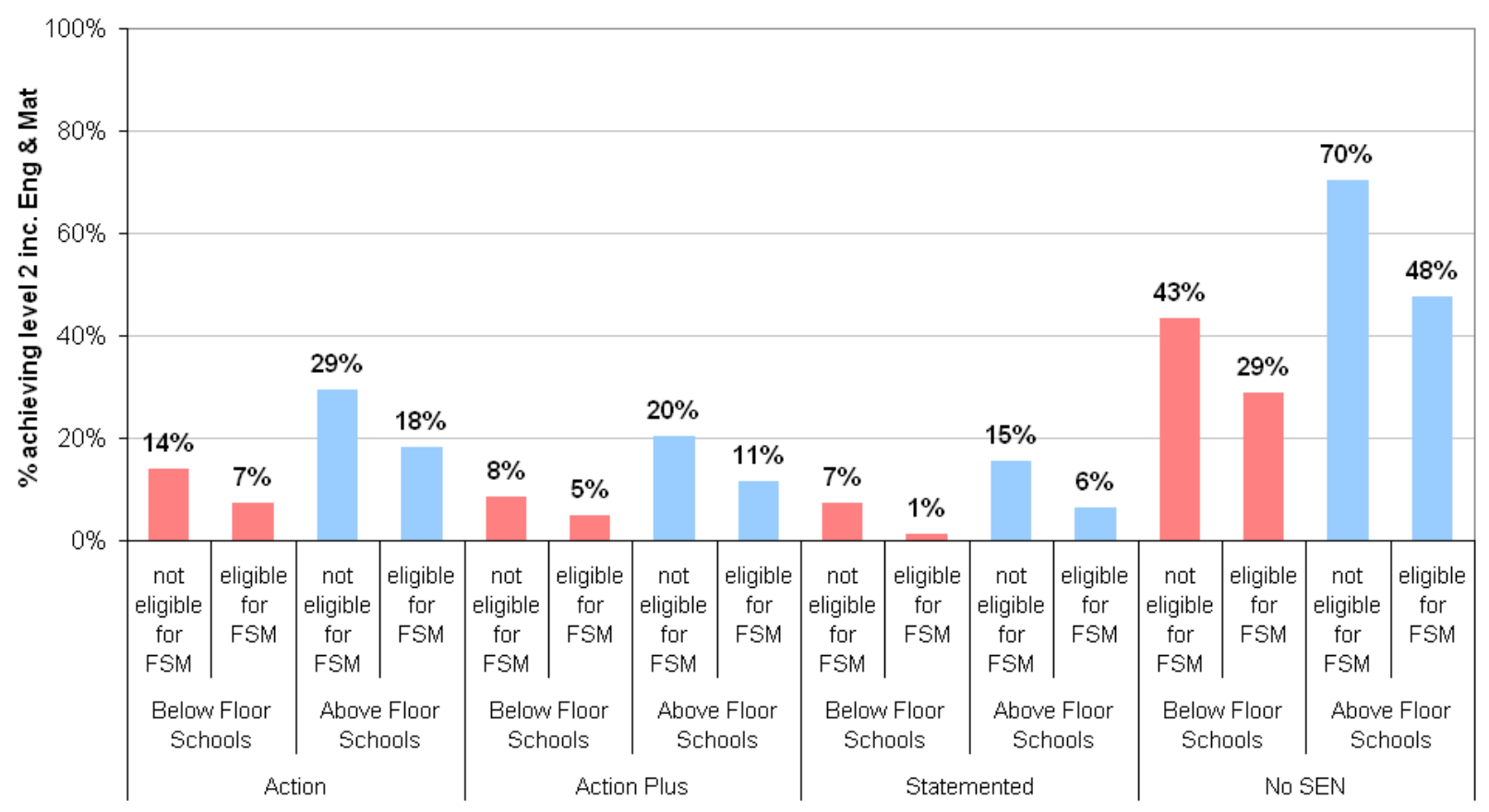


KS4 Attainment by Region, School Group and FSM

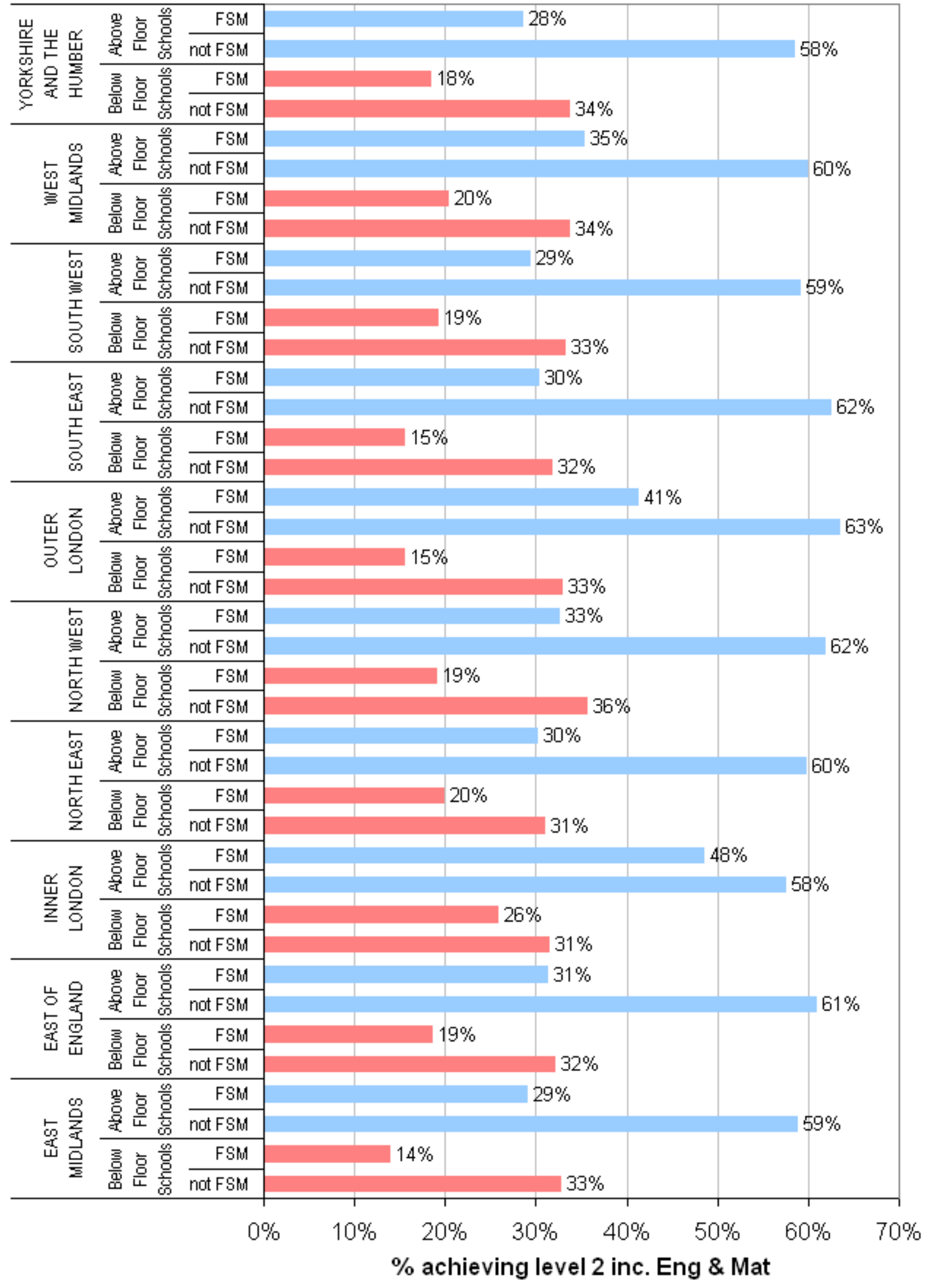




\section{Attainment of Looked After Children at key Stages 2 and 4}

Note: The below floor schools figures in this analysis are based on small numbers of pupils (200-300 per KS) due to the size of the LAC population in the maintained mainstream Key Stage cohorts.

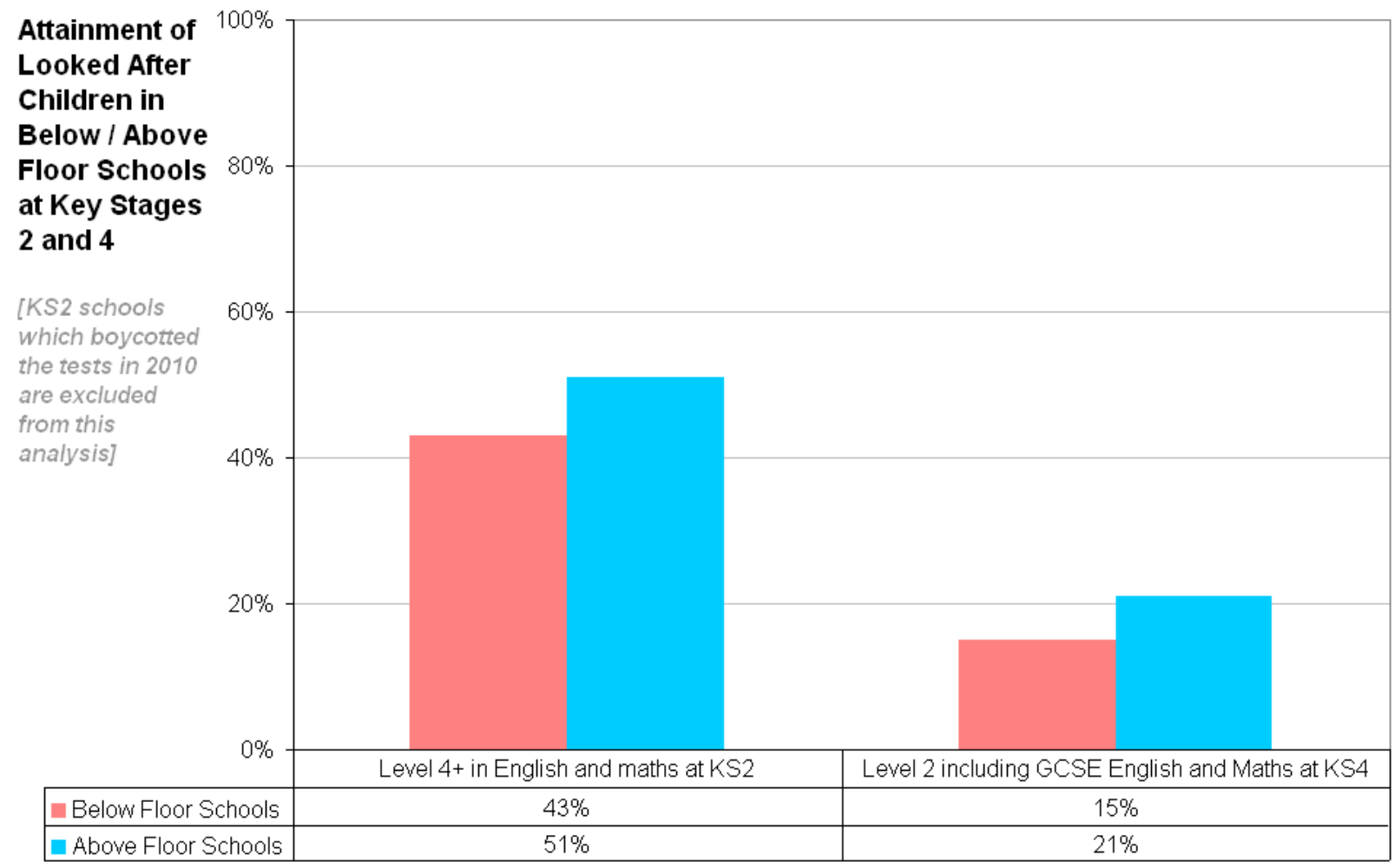




\section{English Progress by Pupil Characteristics from KS1-2}

KS2 English Progress by Area Deprivation, School Group and FSM
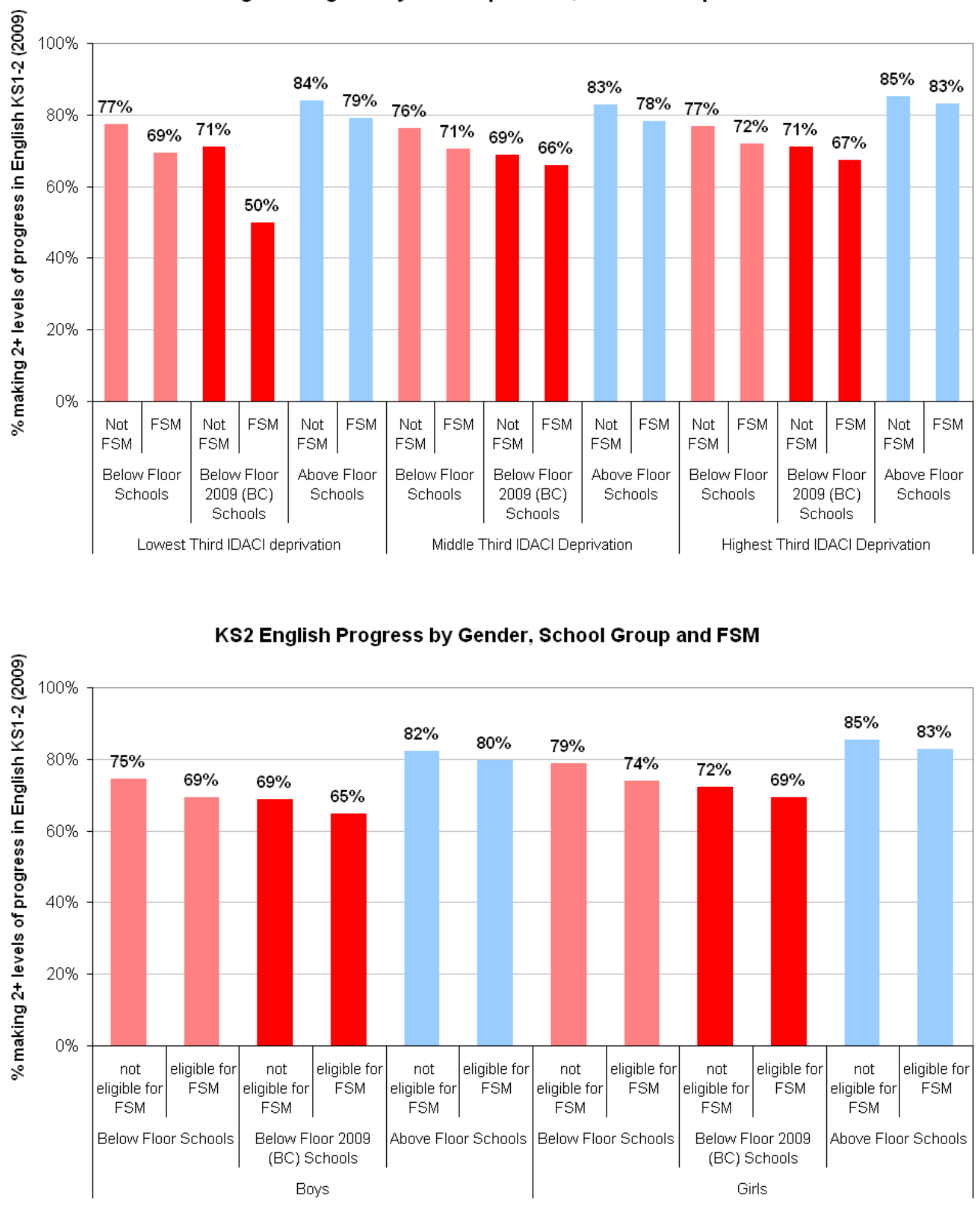
KS2 English Progress by Ethnicity, School Group and FSM - Asian Pupils

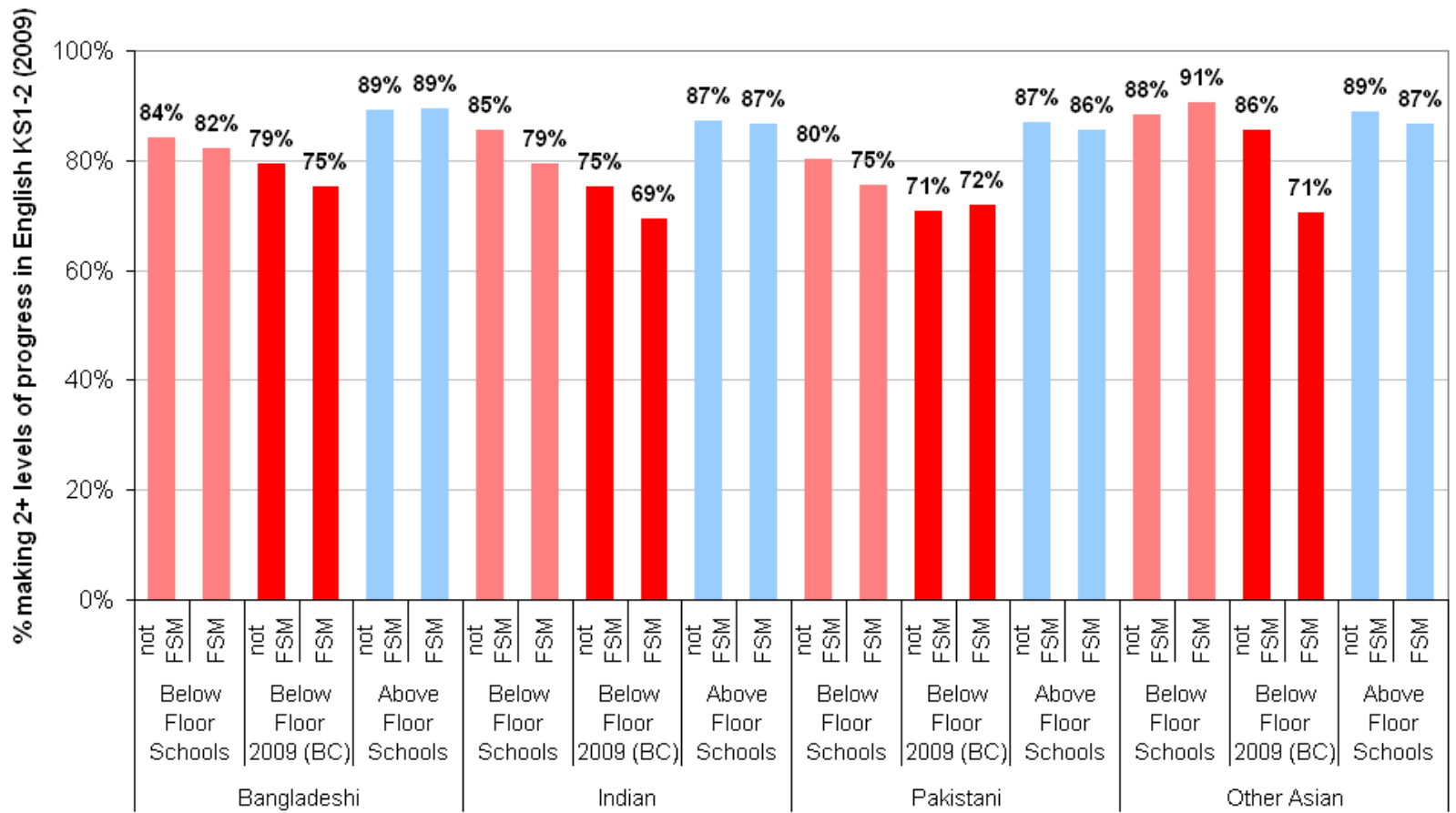

KS2 English Progress by Ethnicity, School Group and FSM - Black Pupils

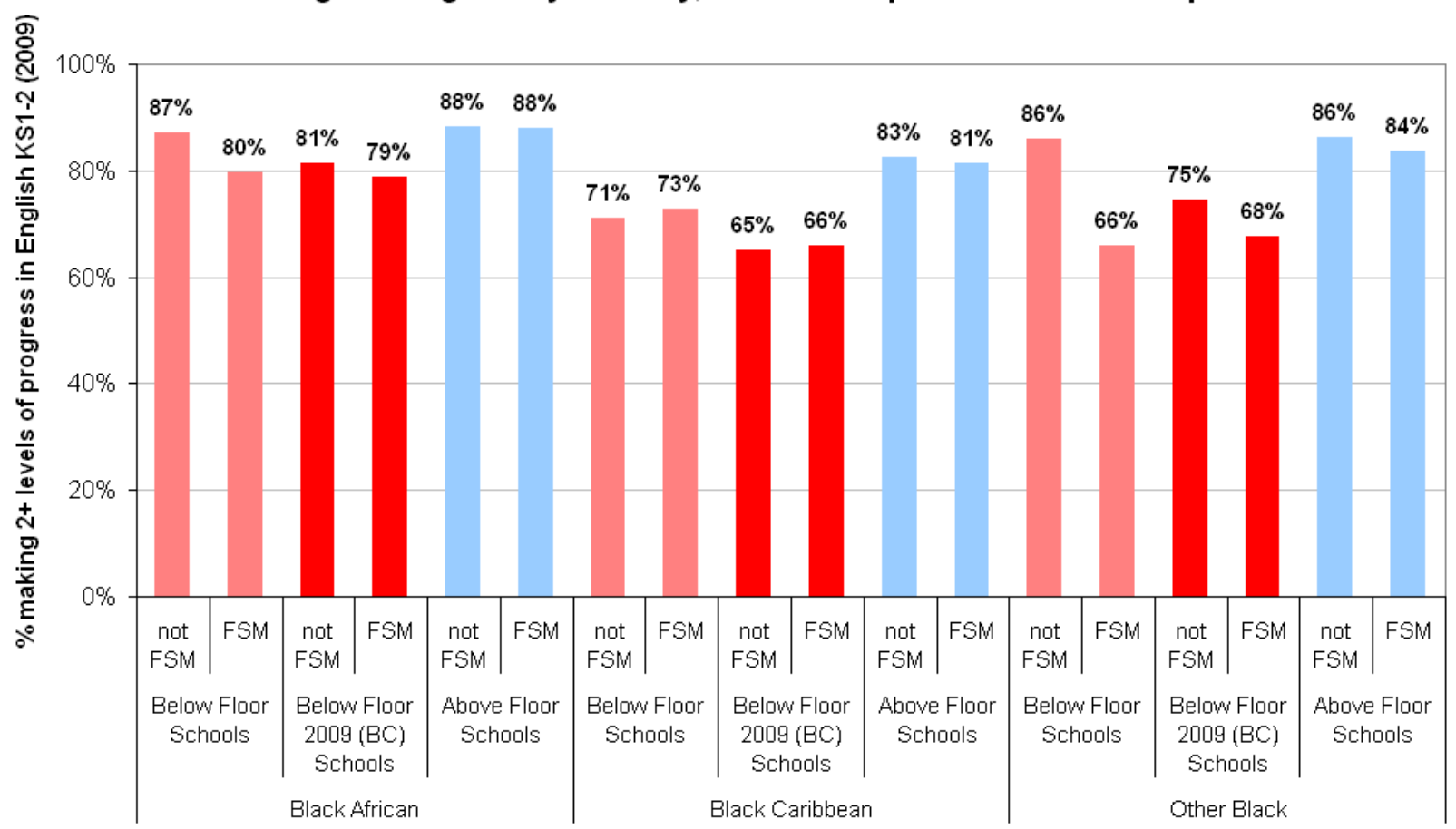



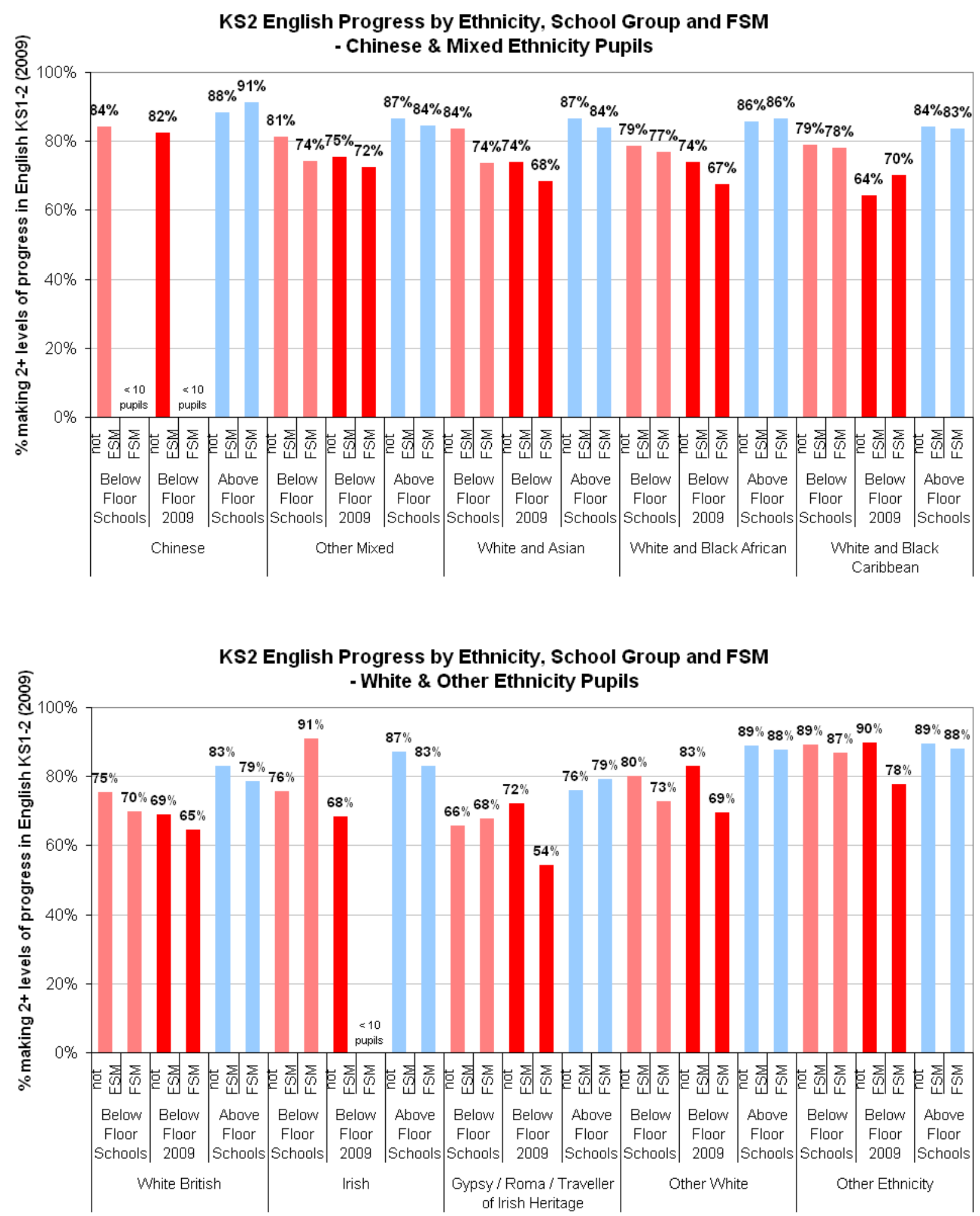
KS2 English Progress by First Language, School Group and FSM

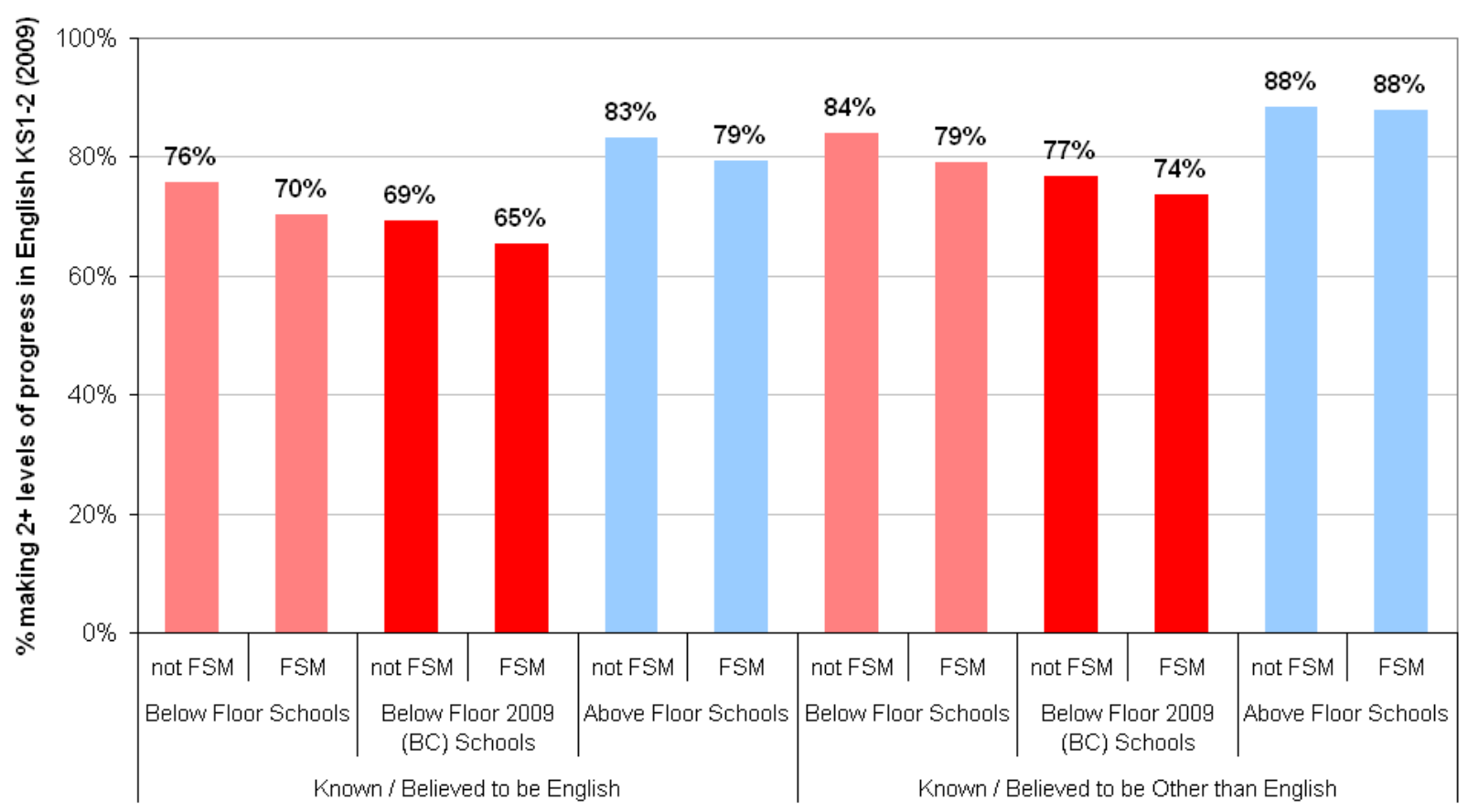

KS2 English Progress by Special Educational Needs, School Group and FSM

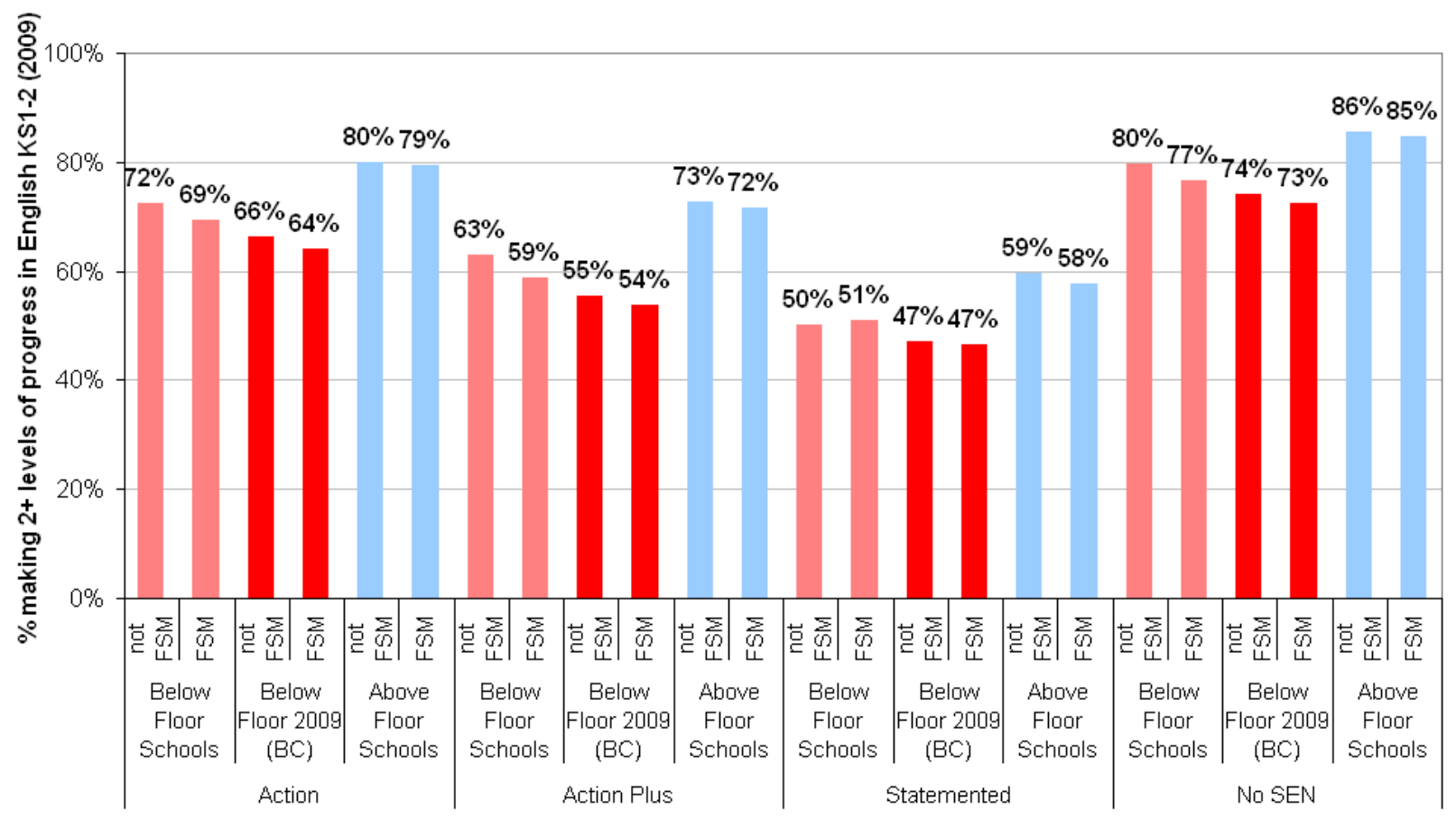




\section{KS2 English Progress by Region, School Group \& FSH}

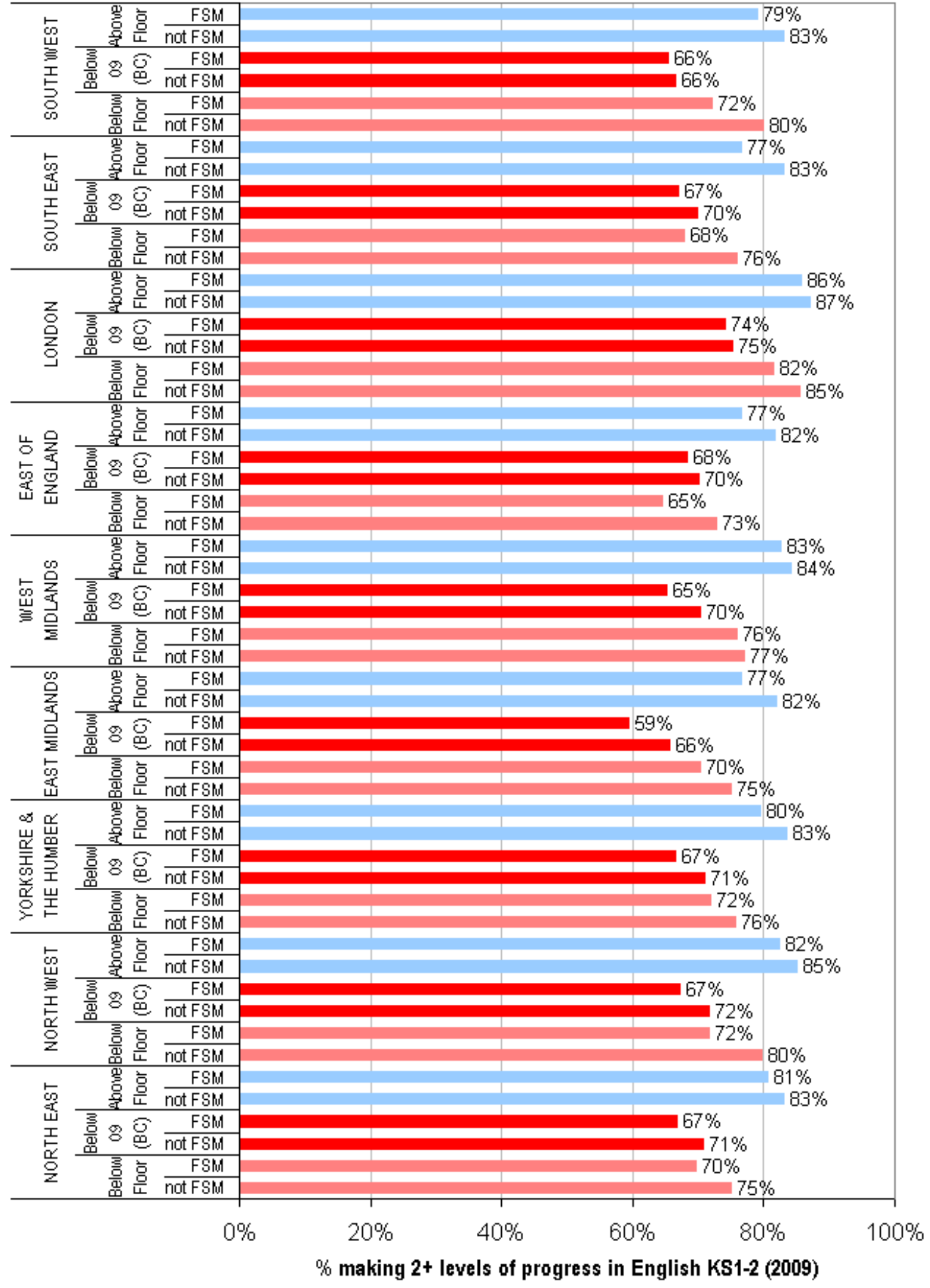




\section{English Progress by Pupil Characteristics from KS2-4}

\section{KS4 English Progress by Area Deprivation, School Group and FSM}

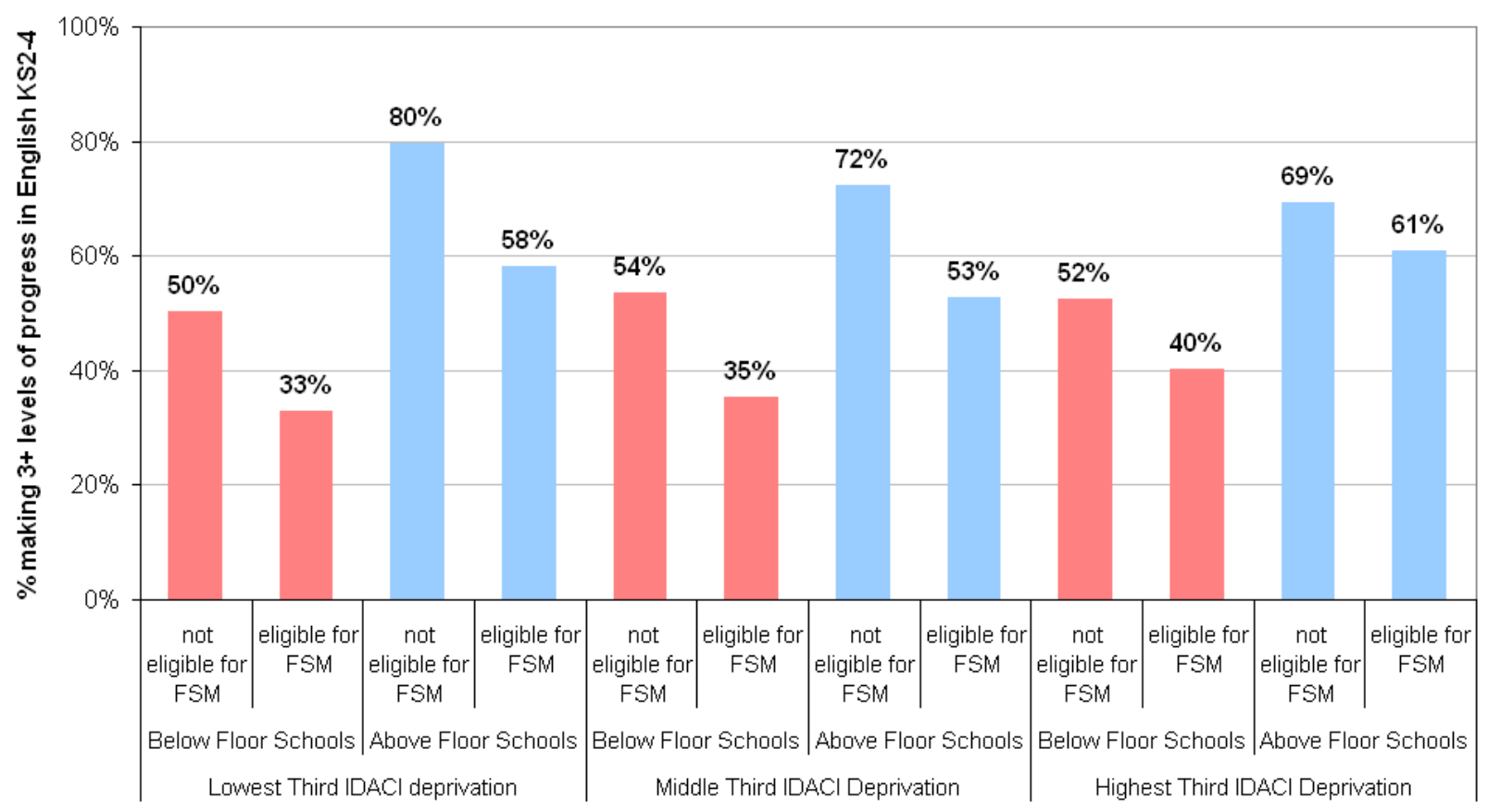

KS4 English Progress by Gender, School Group and FSM

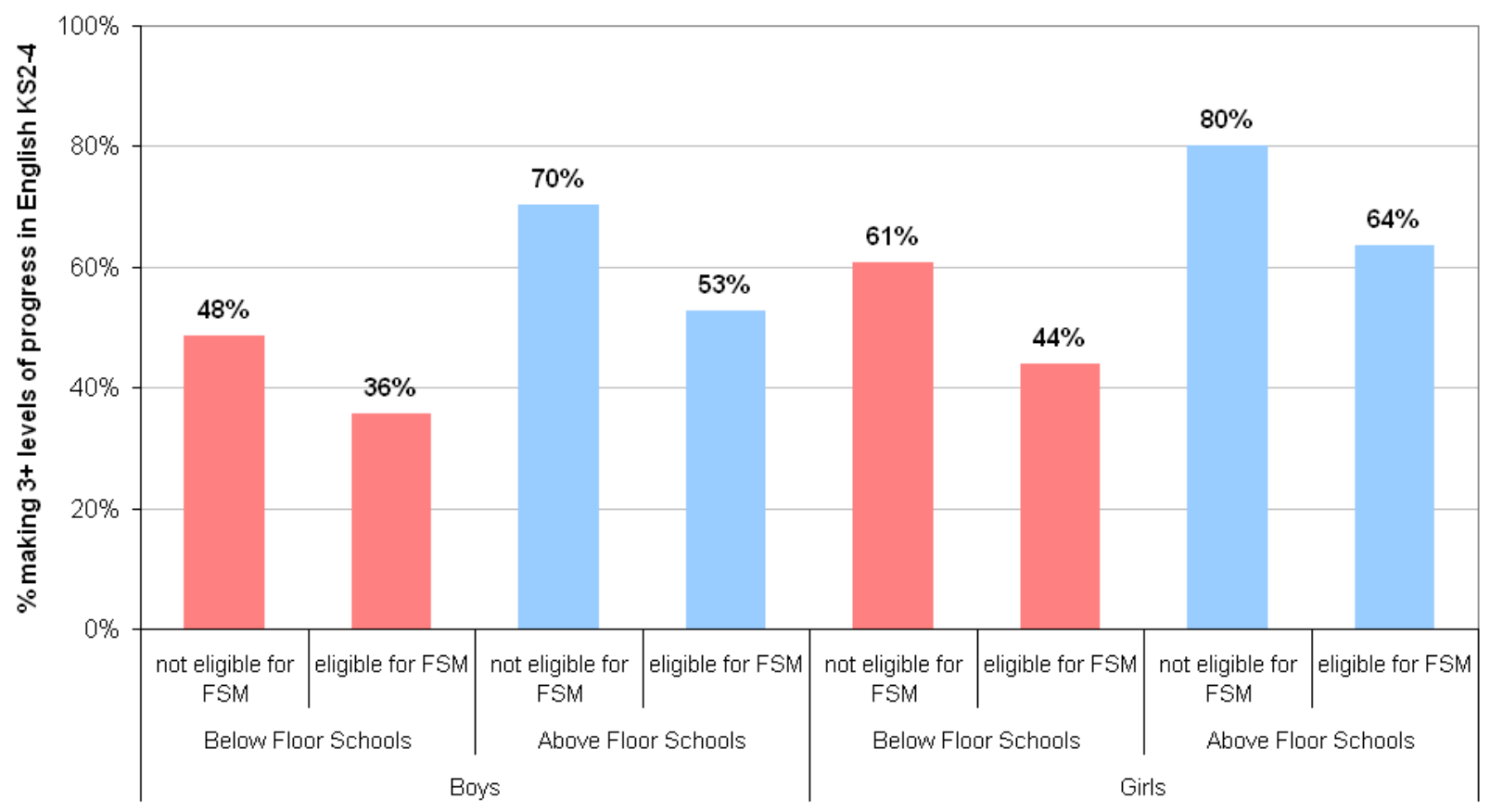


KS4 English Progress by Ethnicity, School Group and FSM - Asian Pupils

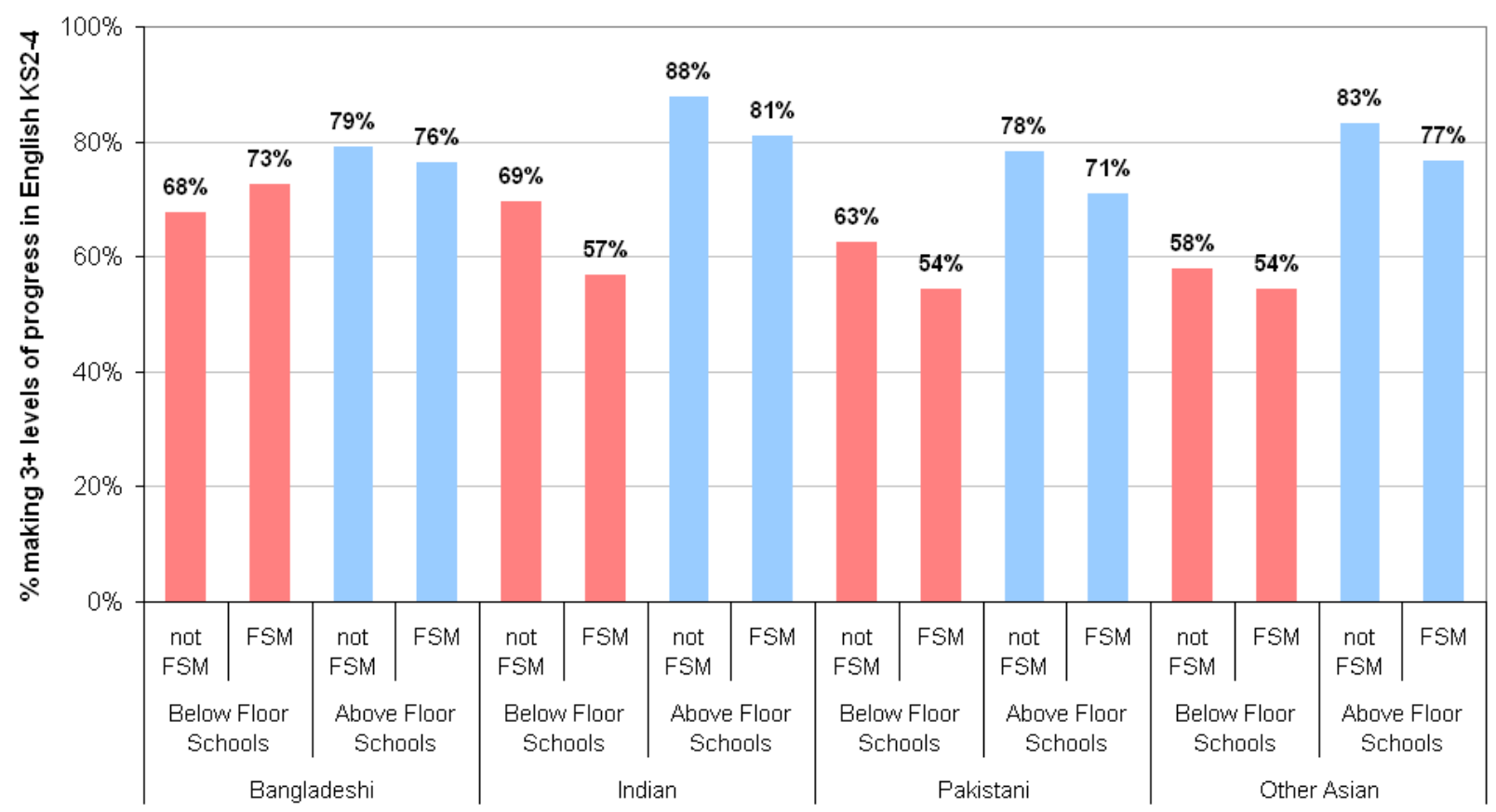

KS4 English Progress by Ethnicity, School Group and FSM - Black Pupils

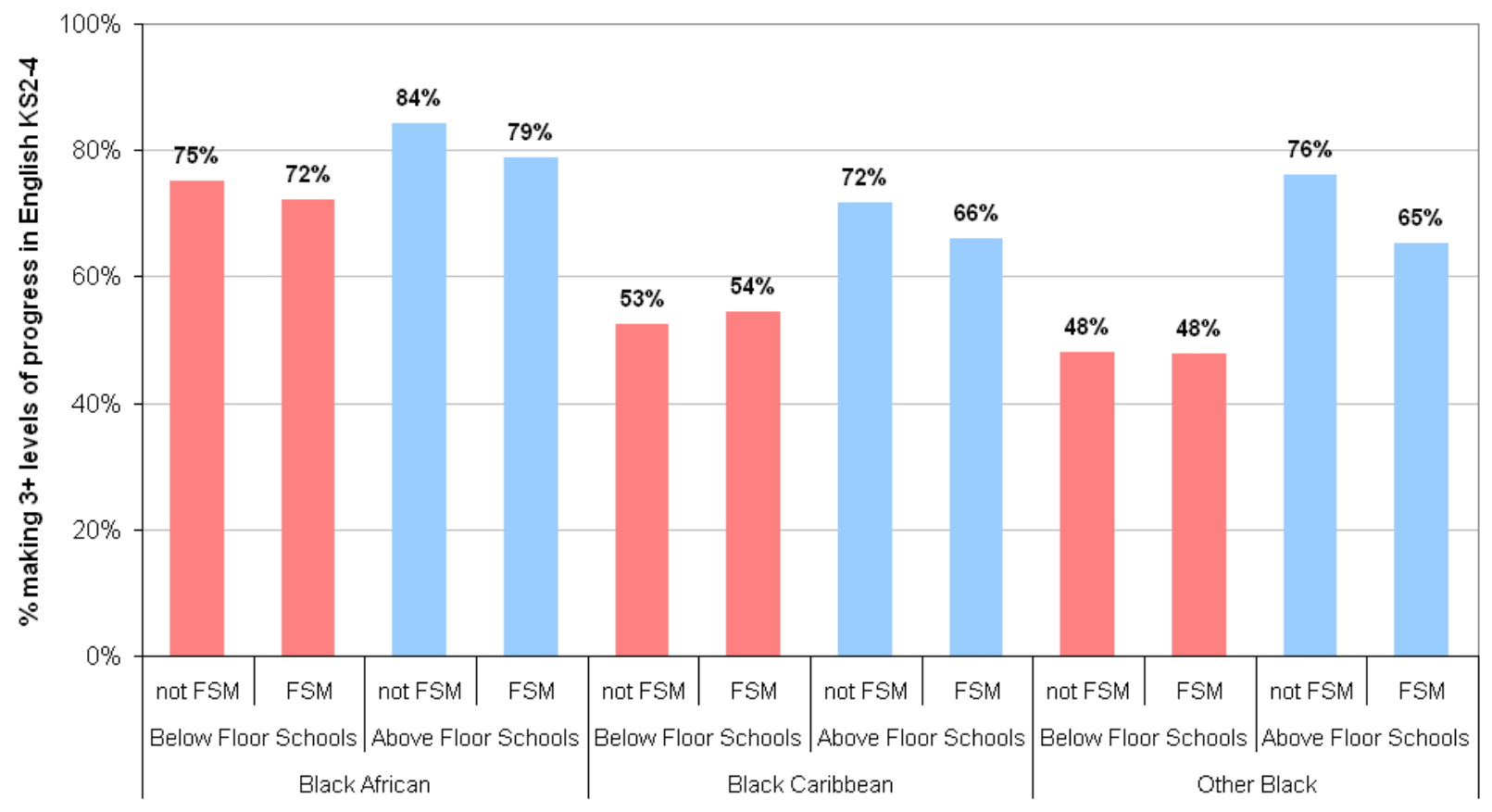


KS4 English Progress by Ethnicity, School Group and FSM

- Chinese \& Mixed Ethnicity Pupils

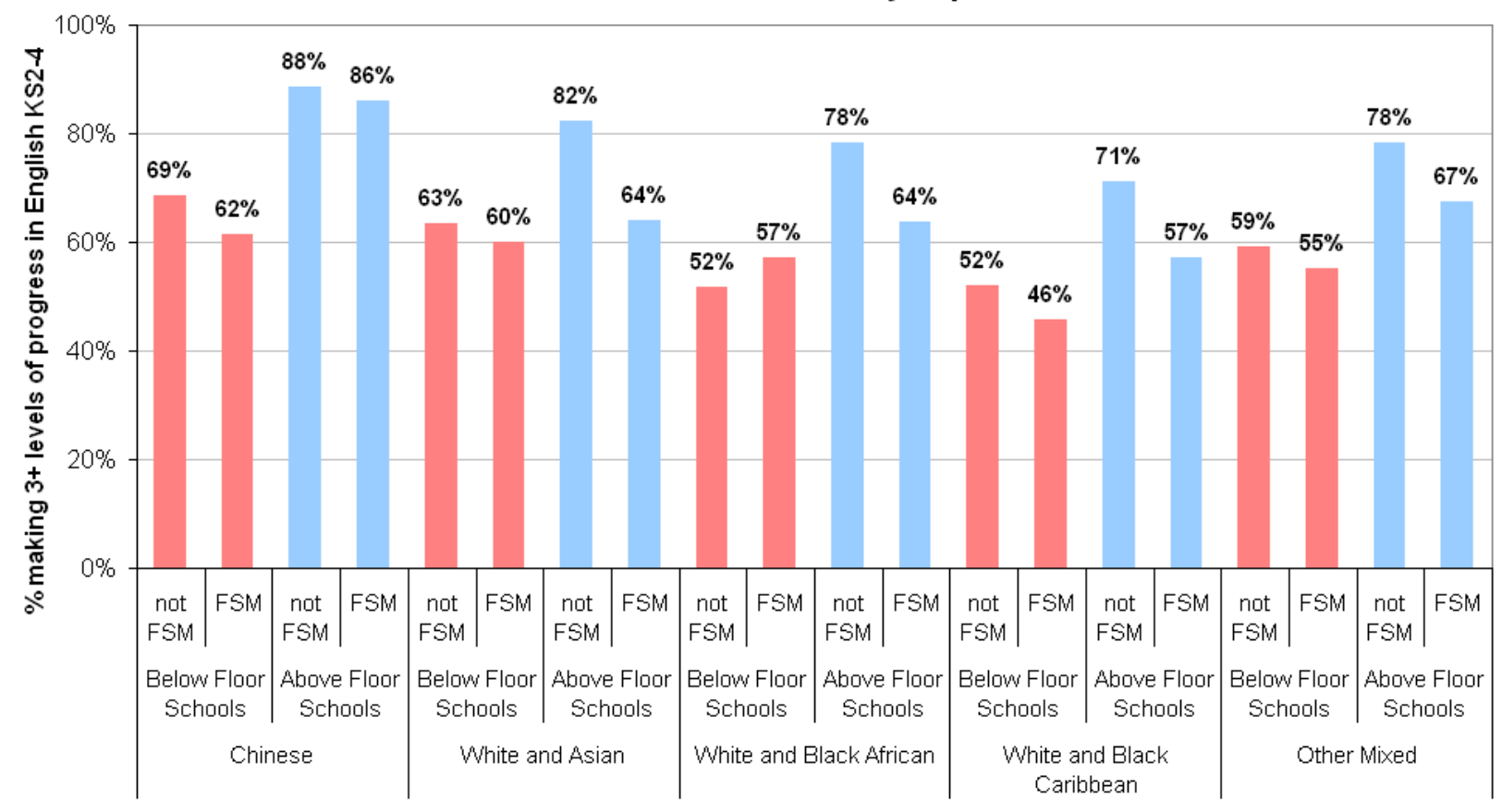

KS4 English Progress by Ethnicity, School Group and FSM

- White \& Other Ethnicity Pupils

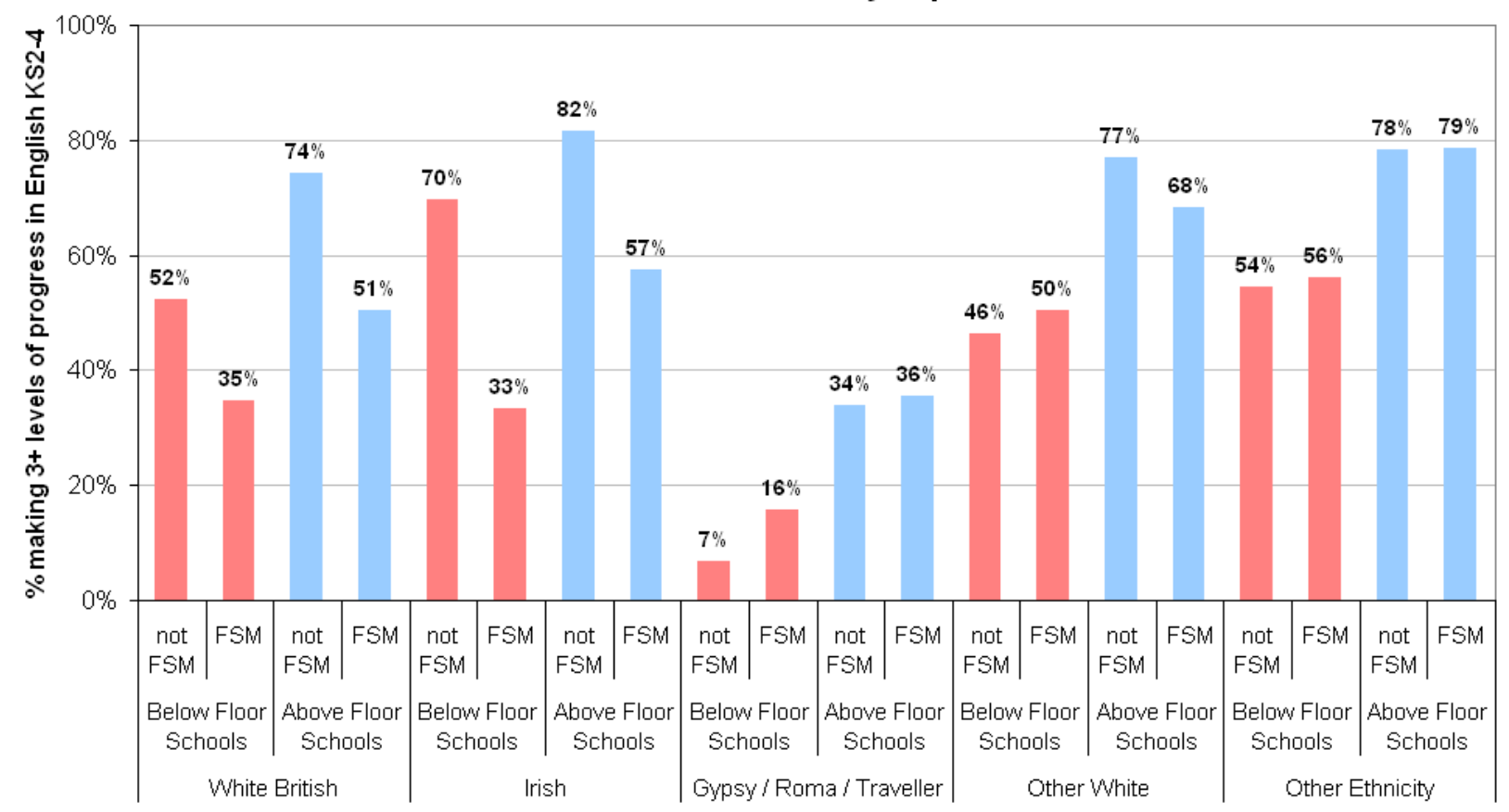


KS4 English Progress by First Language, School Group and FSM

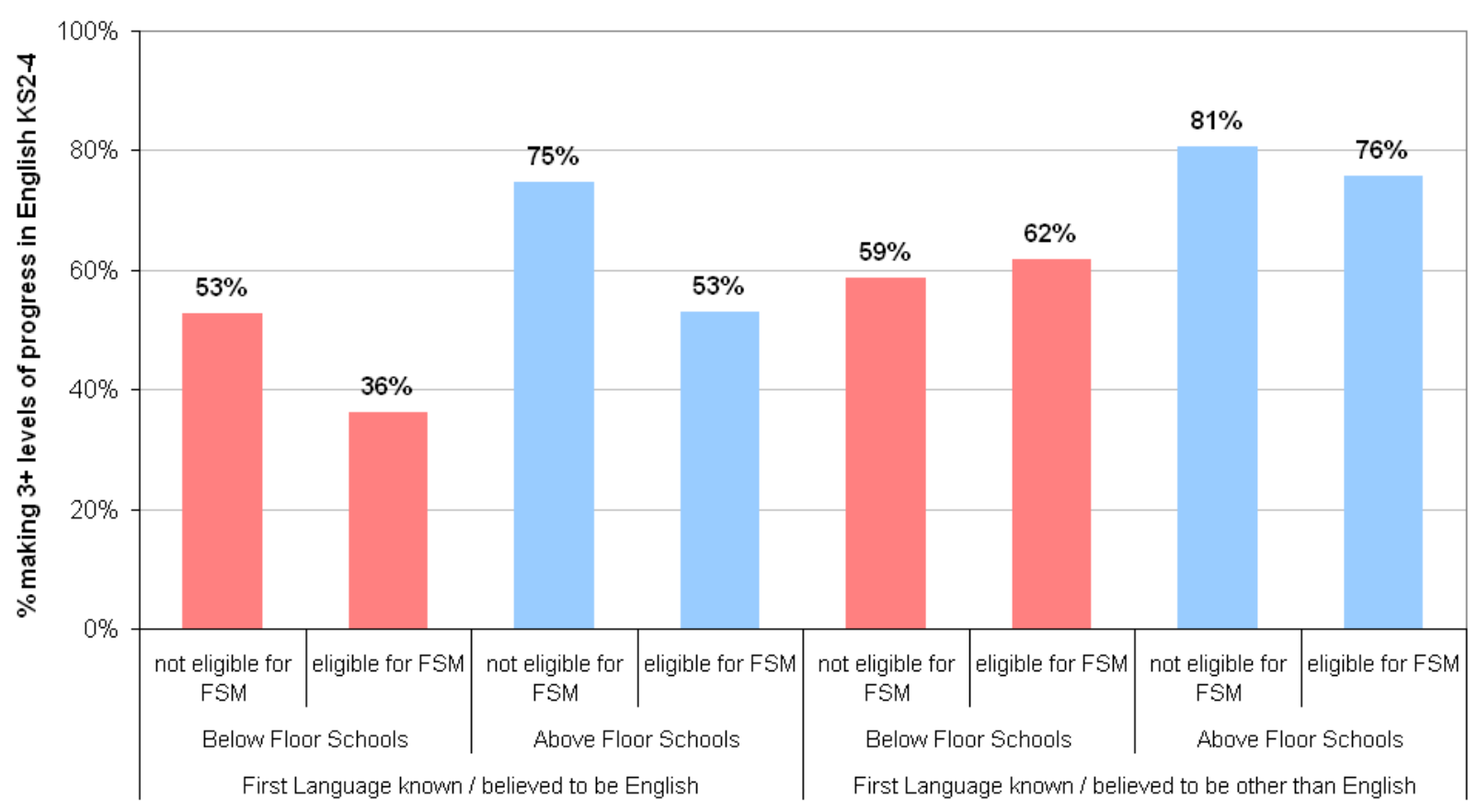

KS4 English Progress by Special Educational Needs, School Group and FSM

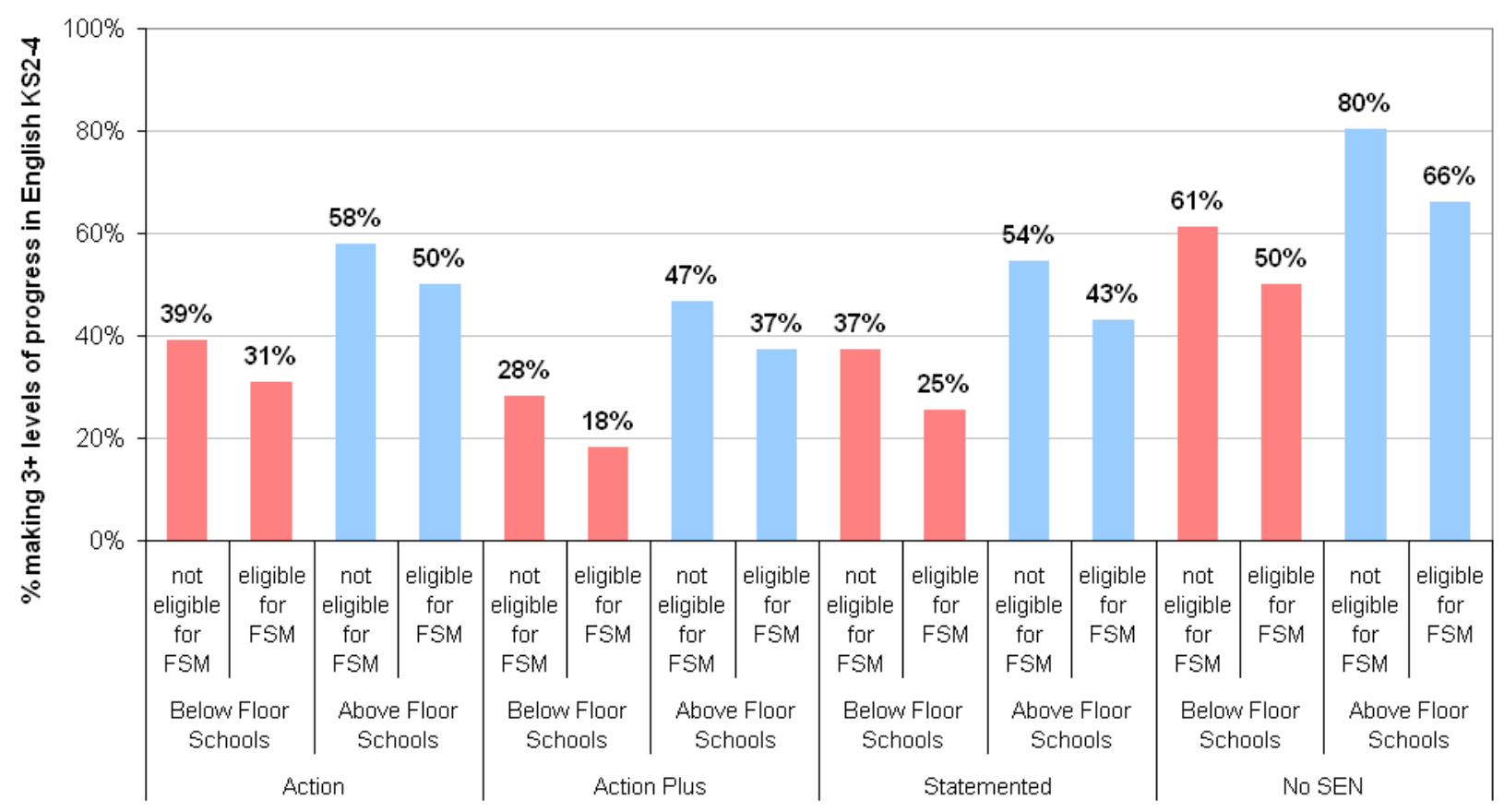


KS4 English Progress by Region, School Group \& FSH

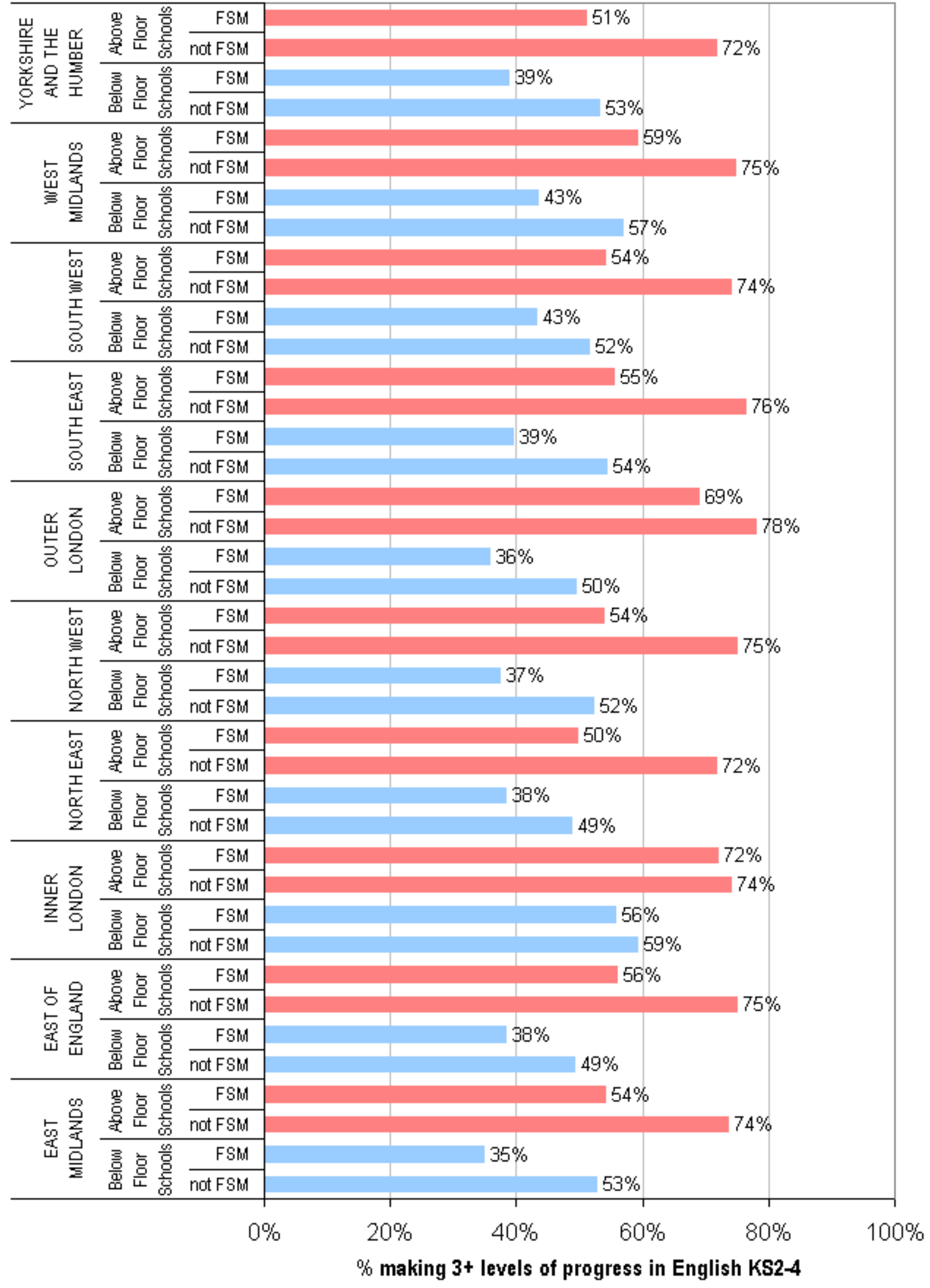




\section{Maths Progress by Pupil Characteristics from KS1-2}
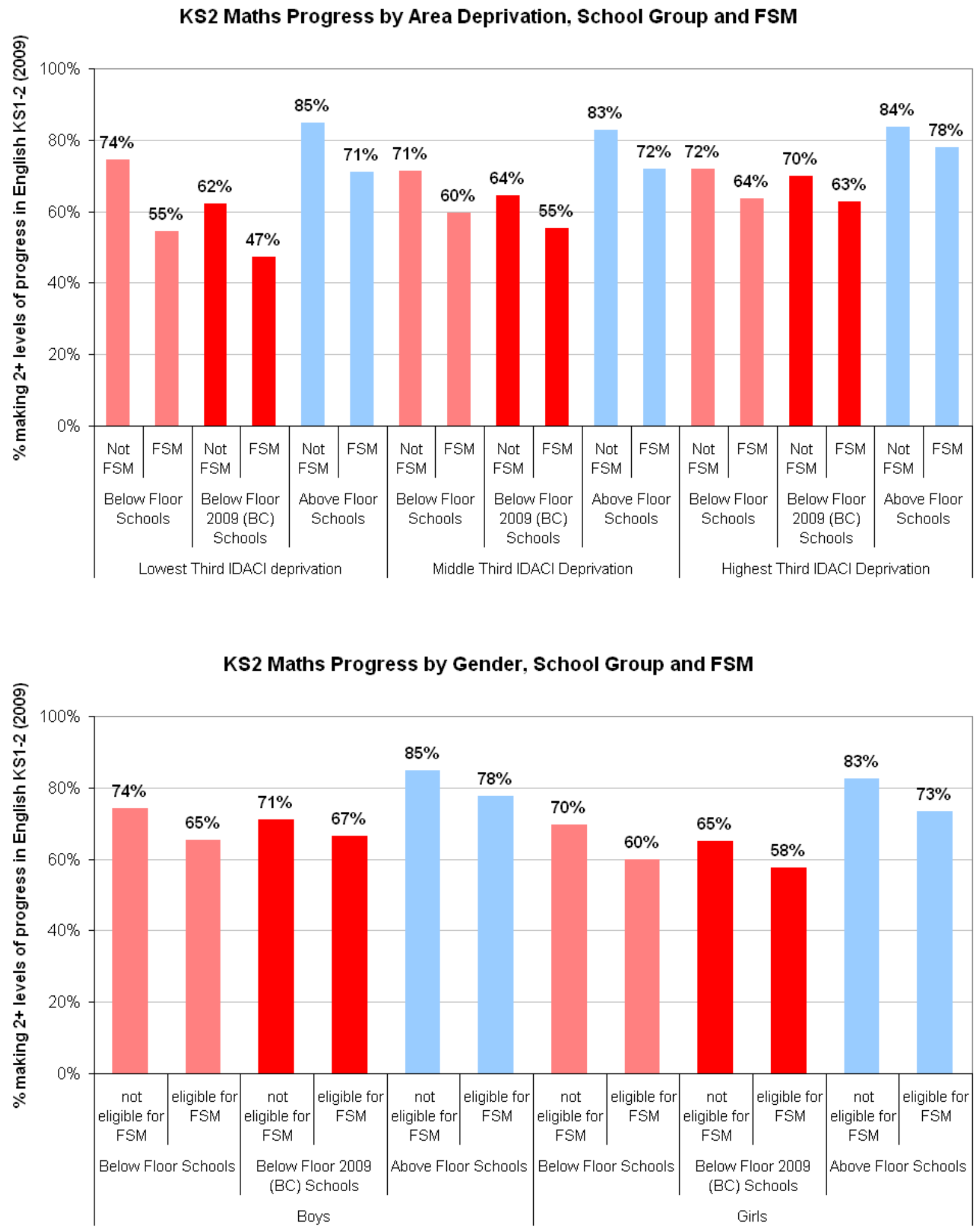
KS2 Maths Progress by Ethnicity, School Group and FSM - Asian Pupils

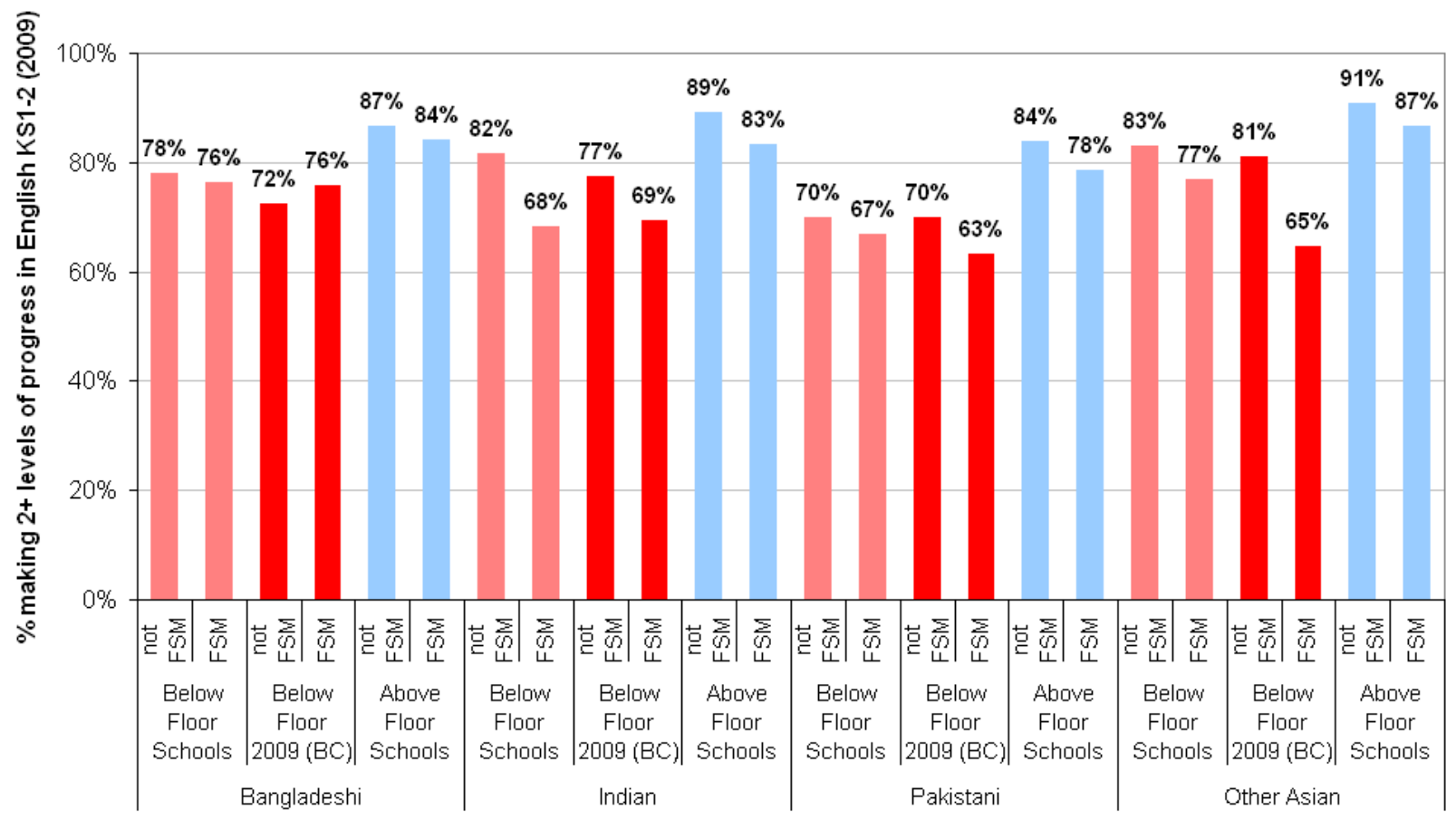

KS2 Maths Progress by Ethnicity, School Group and FSM - Black Pupils

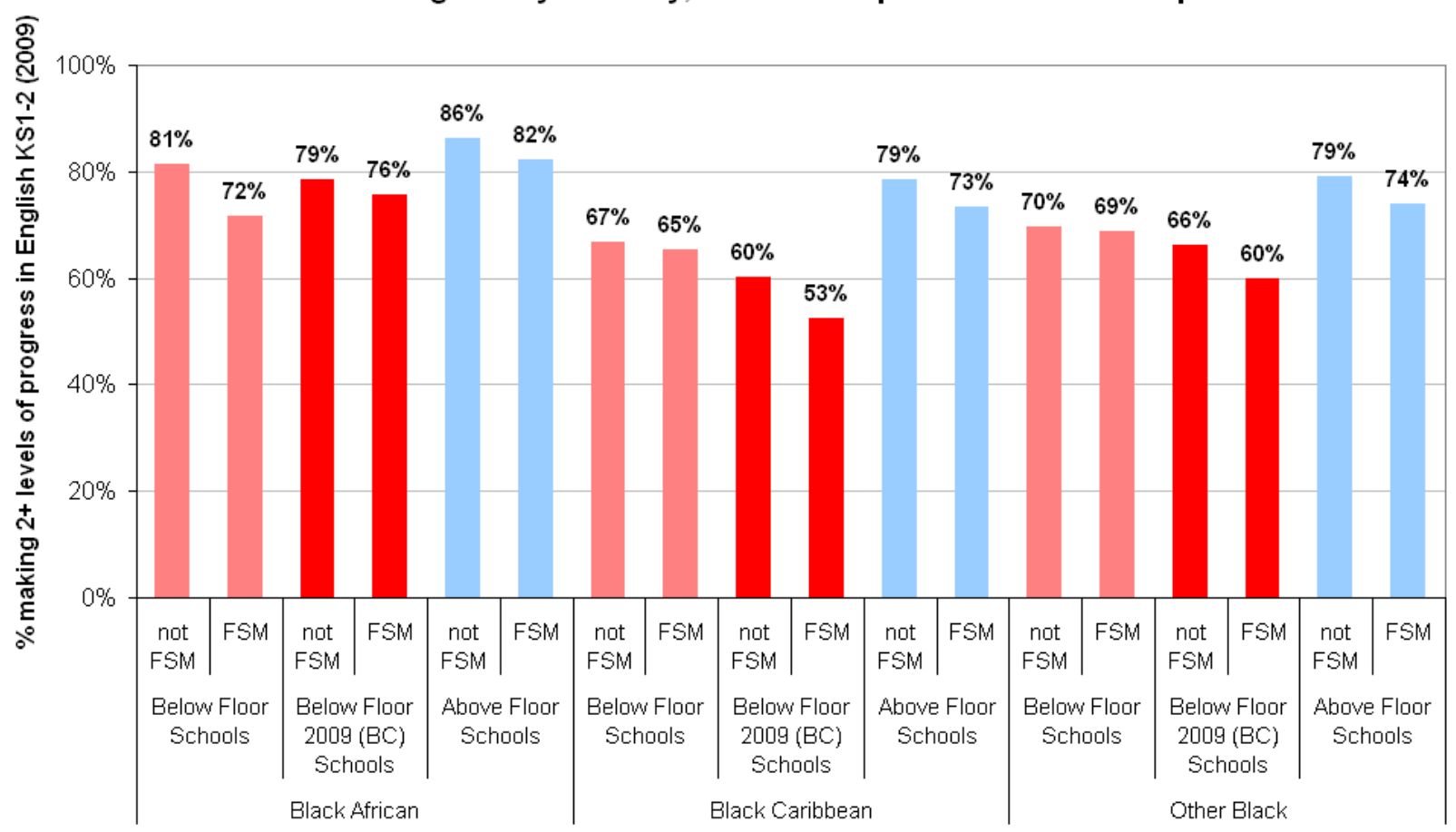



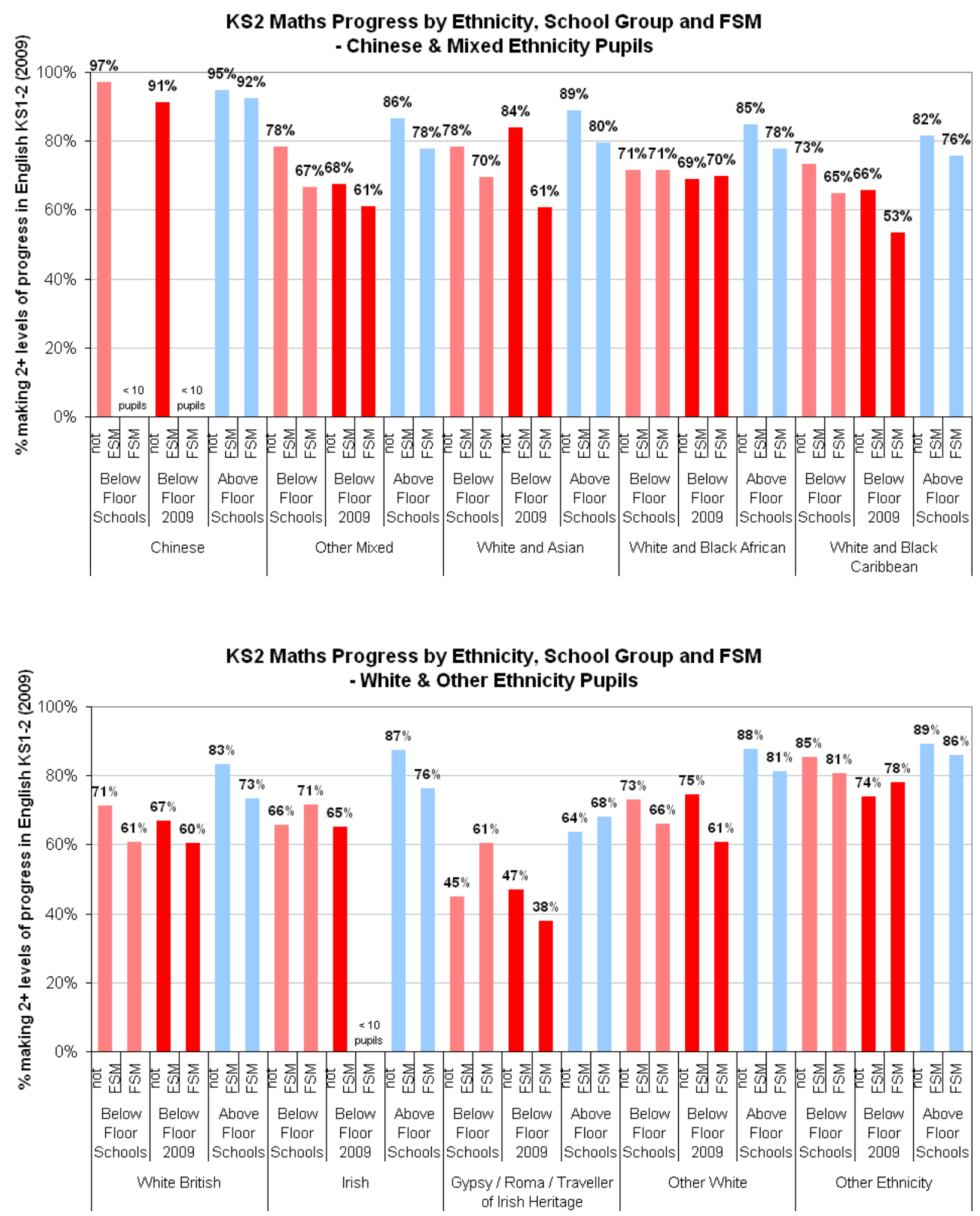
KS2 Maths Progress by First Language, School Group and FSM

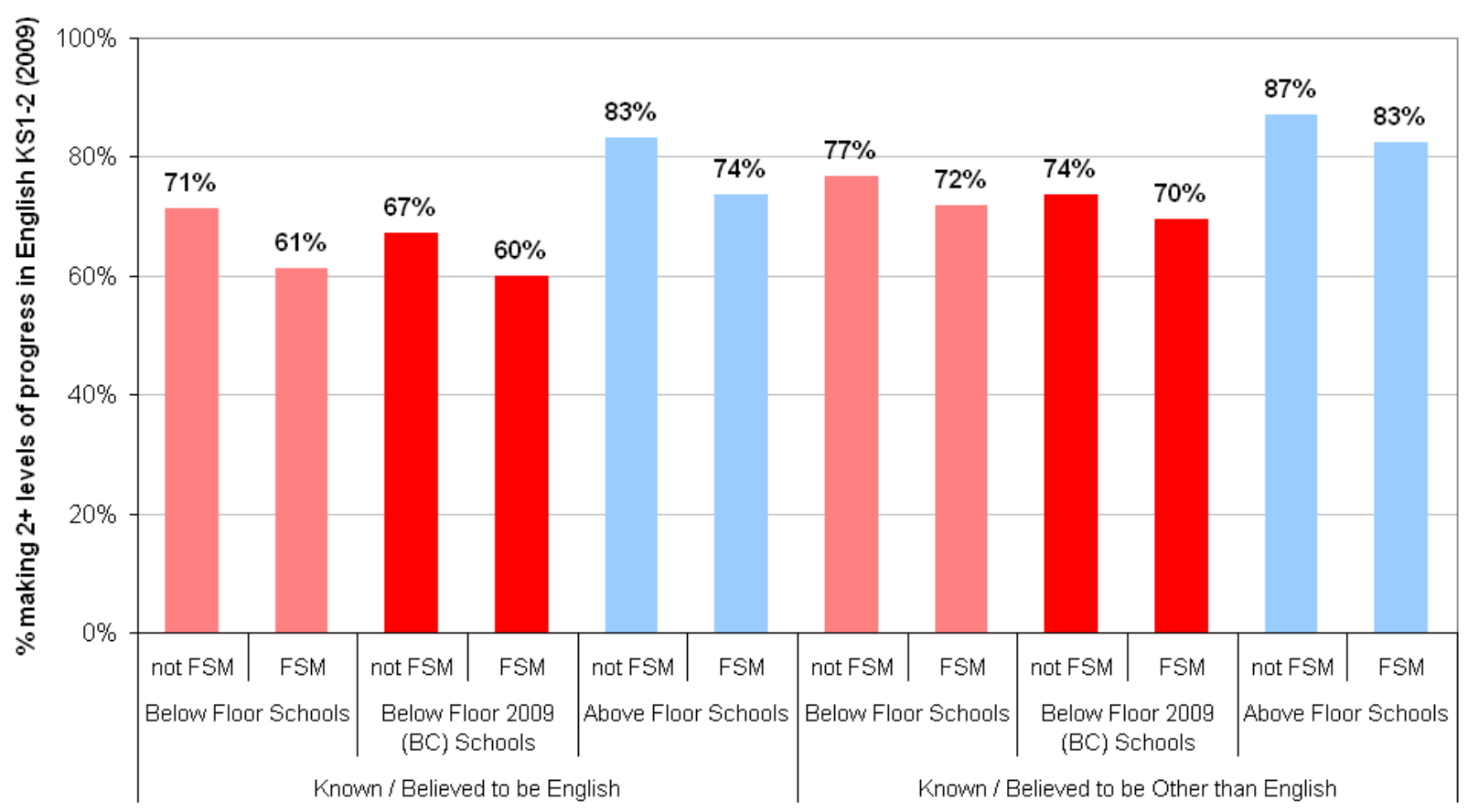

KS2 Maths Progress by Special Educational Needs, School Group and FSM

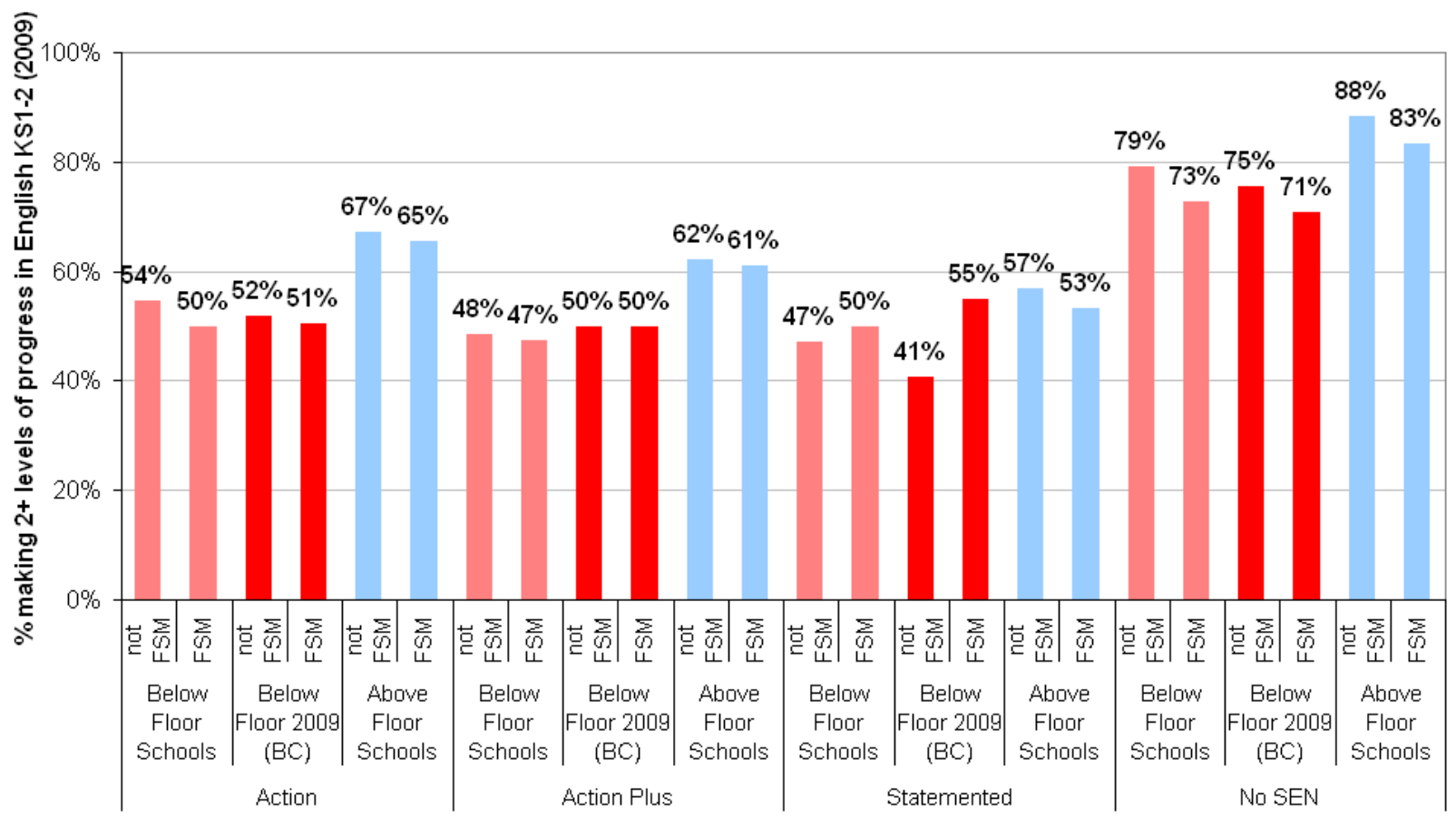


KS2 Maths Progress by Region, School Group \& FSM

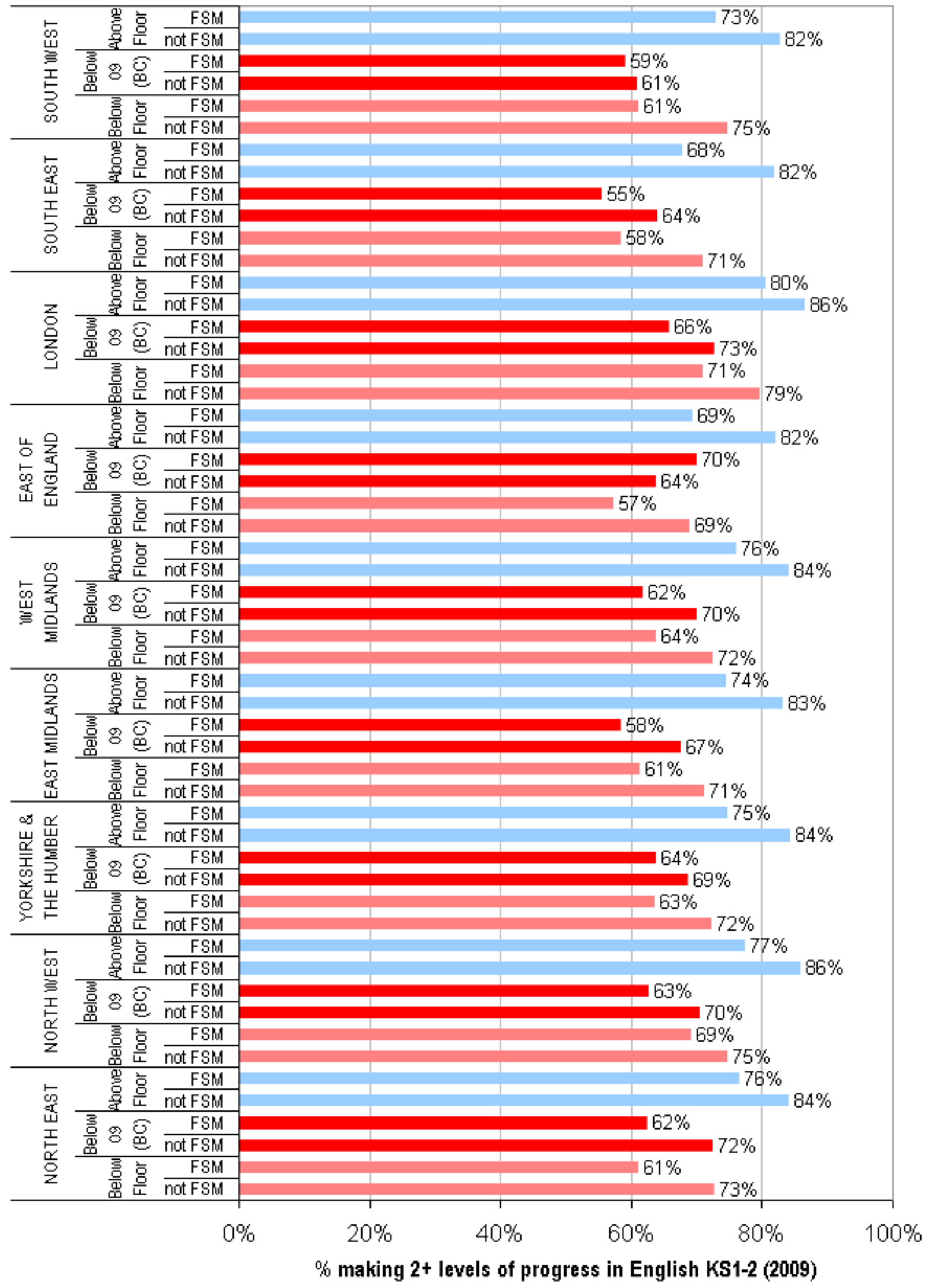




\section{Maths Progress by Pupil Characteristics from KS2-4}

KS4 Maths Progress by Area Deprivation, School Group and FSM

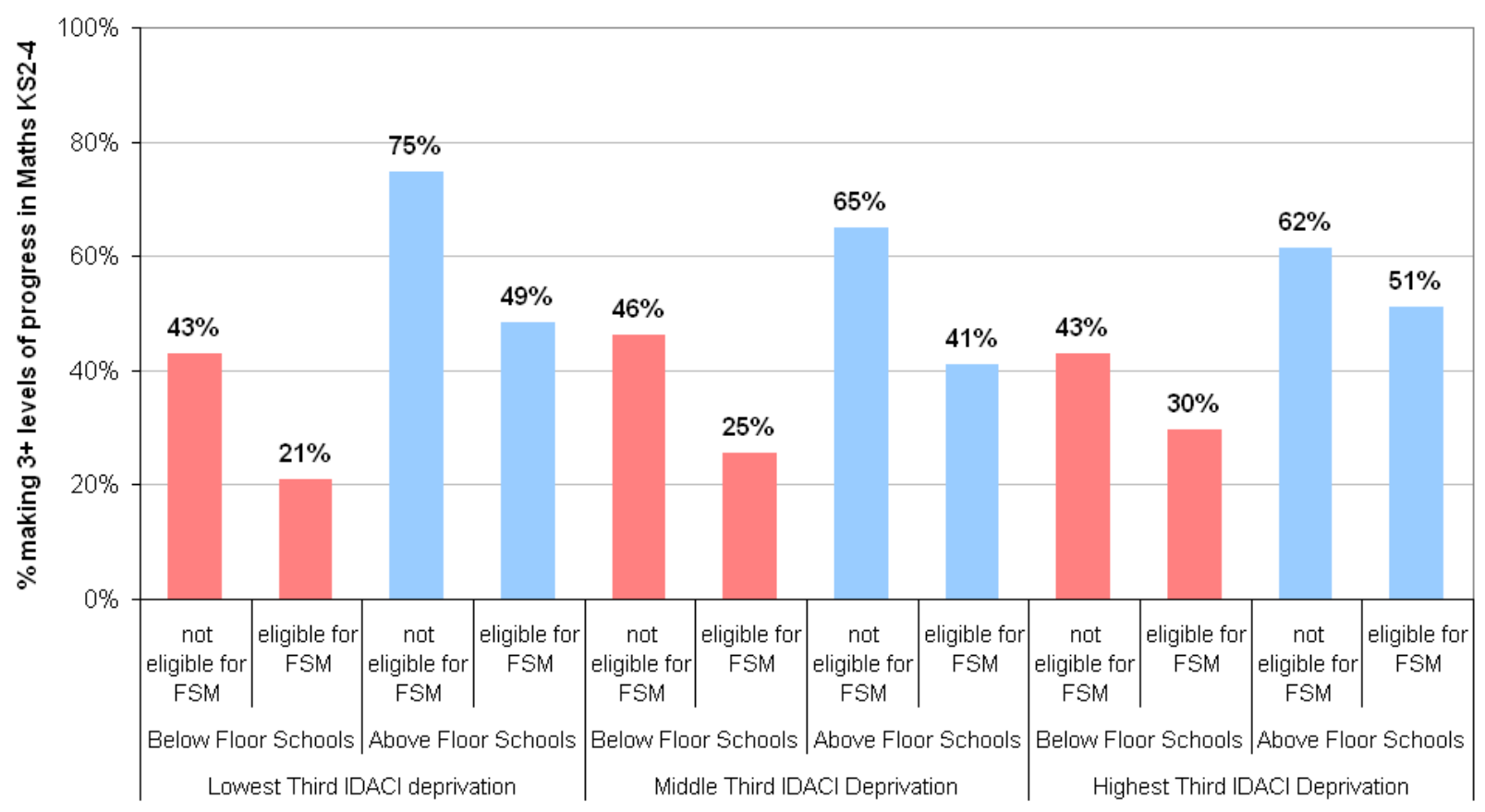

KS4 Maths Progress by Gender, School Group and FSM

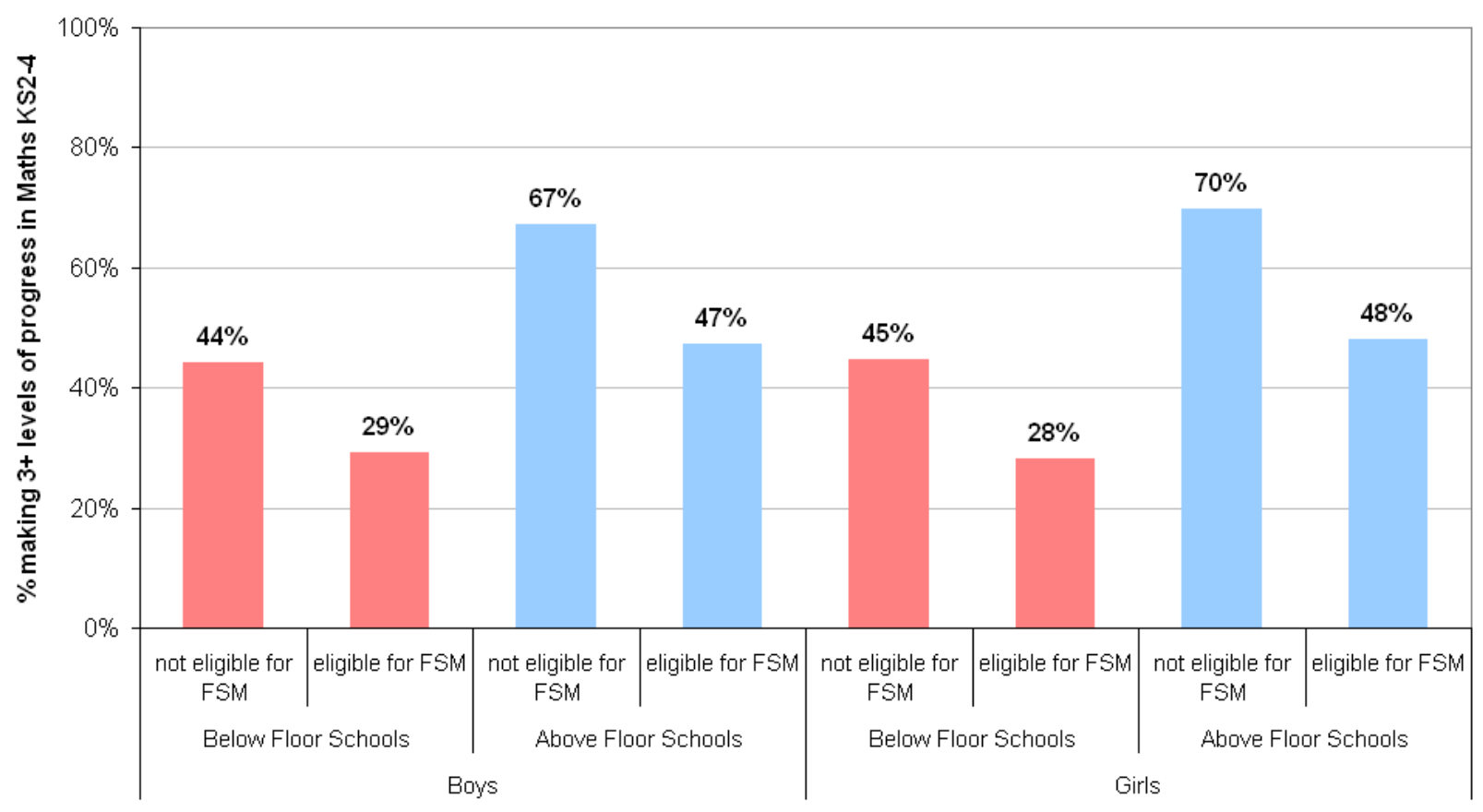


KS4 Maths Progress by Ethnicity, School Group and FSM - Asian Pupils

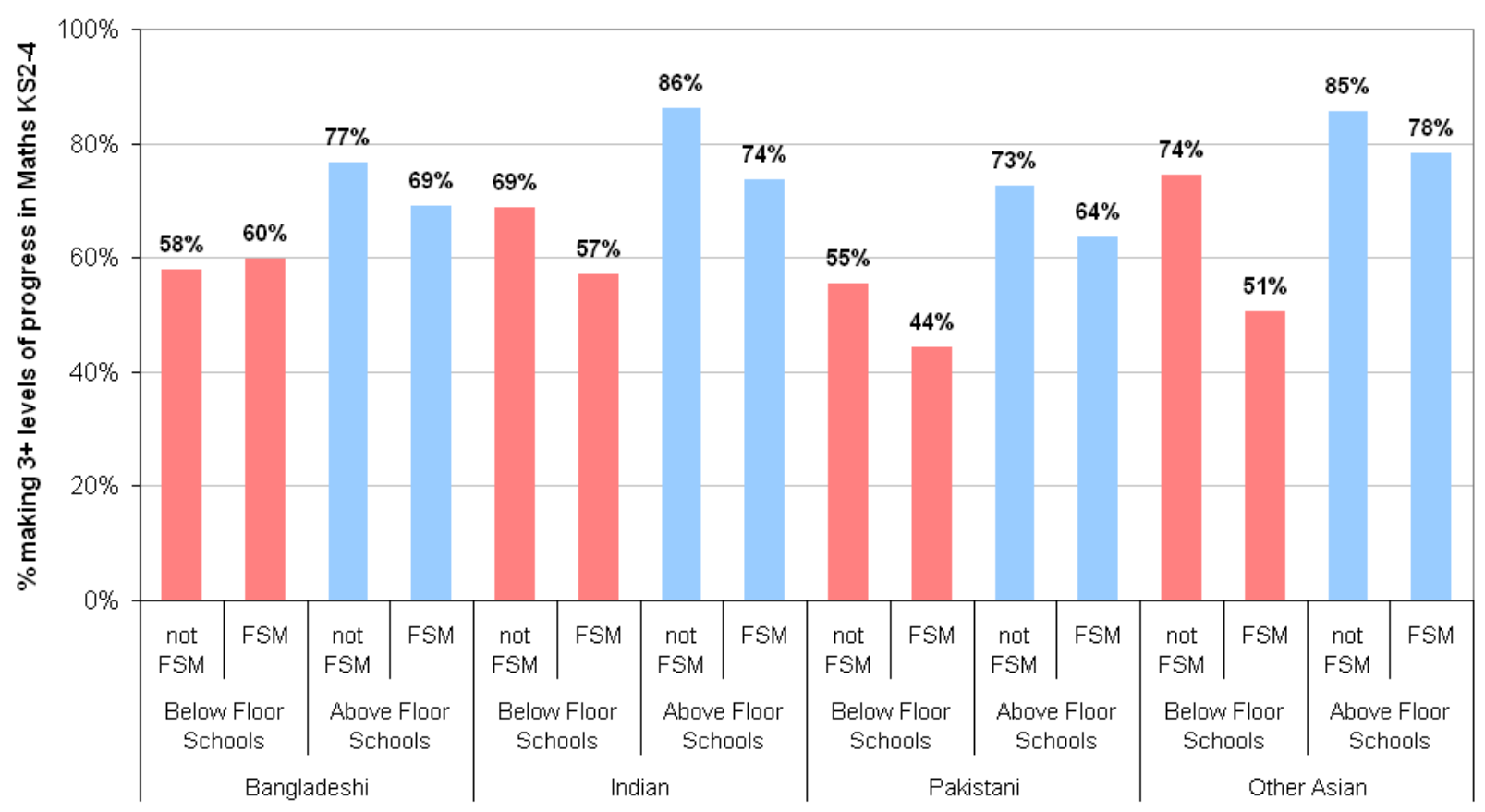

KS4 Maths Progress by Ethnicity, School Group and FSM - Black Pupils

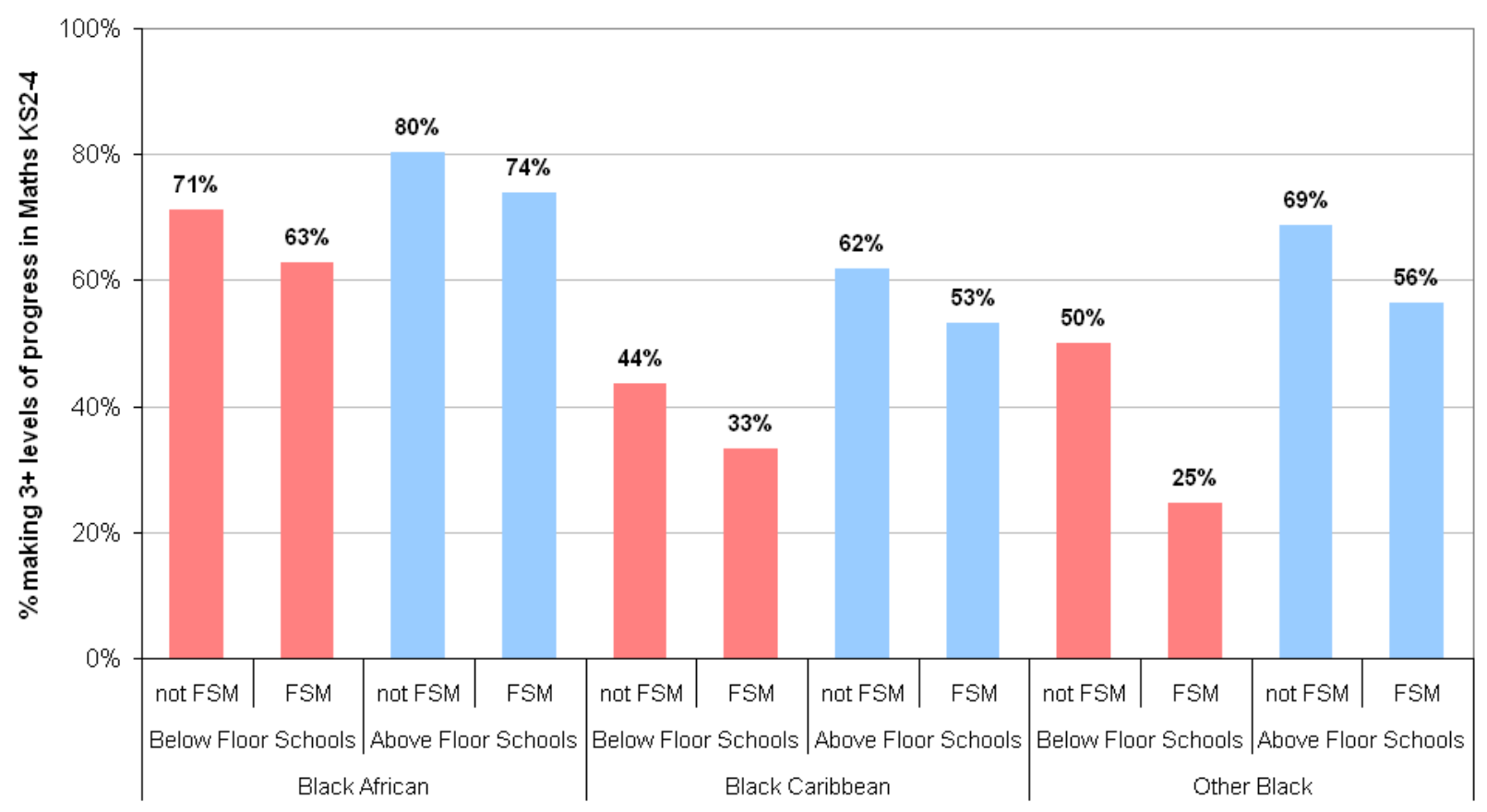


KS4 Maths Progress by Ethnicity, School Group and FSM - Chinese \& Mixed Ethnicity Pupils

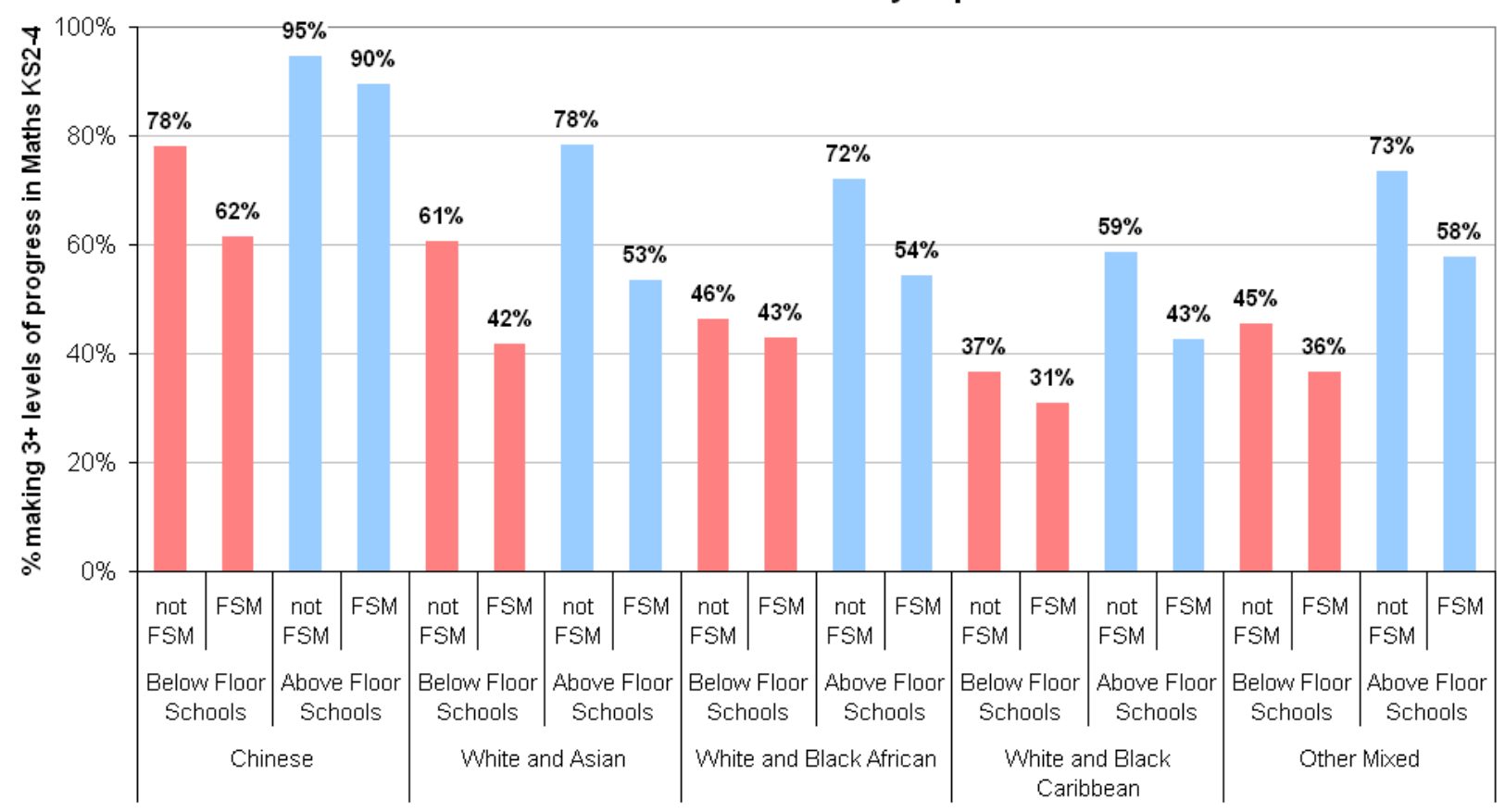

KS4 Maths Progress by Ethnicity, School Group and FSM - White \& Other Ethnicity Pupils

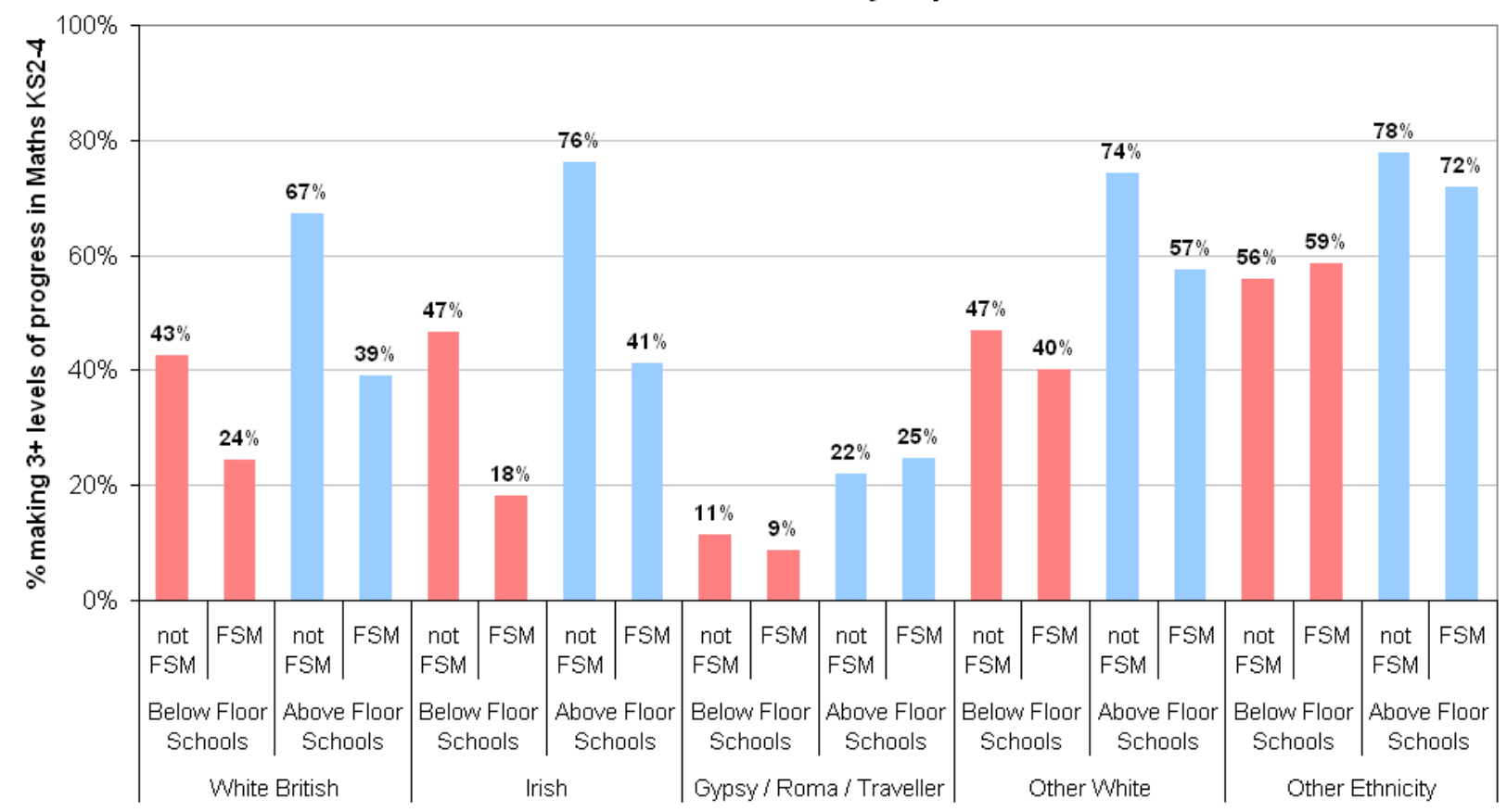


KS4 Maths Progress by First Language, School Group and FSM

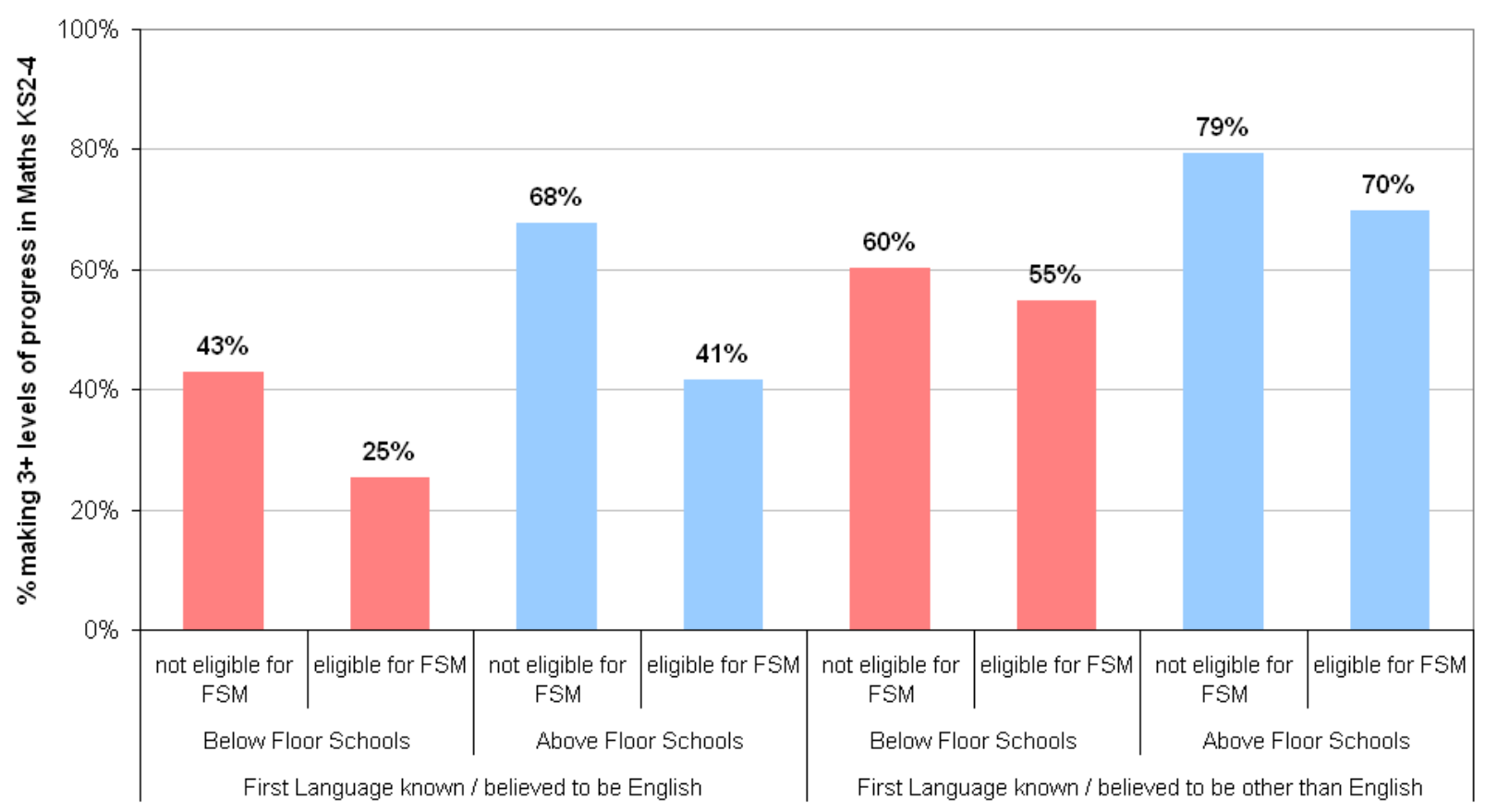

KS4 Maths Progress by Special Educational Needs, School Group and FSM

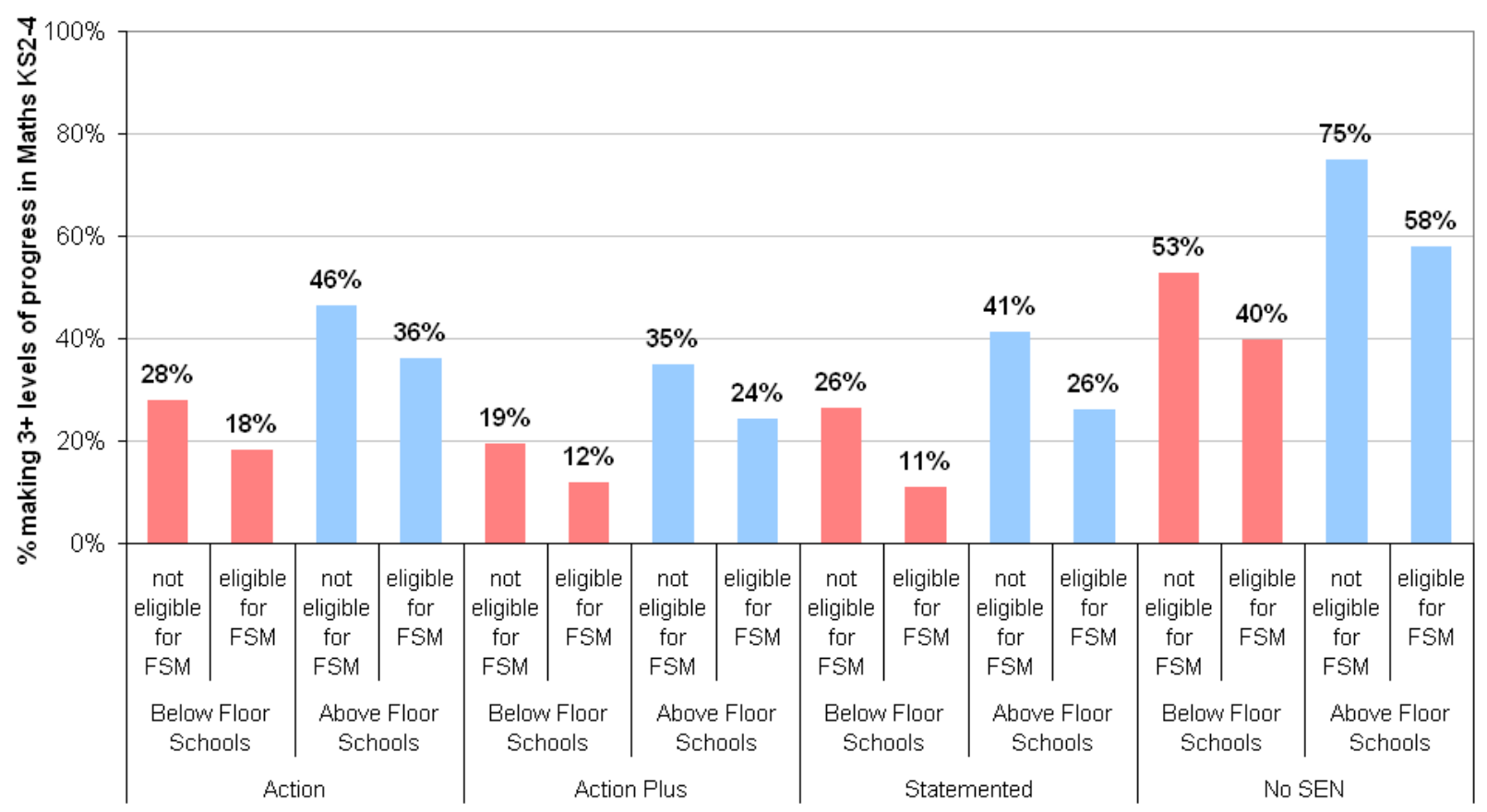


KS4 Maths Progress by Region, School Group \& FSH

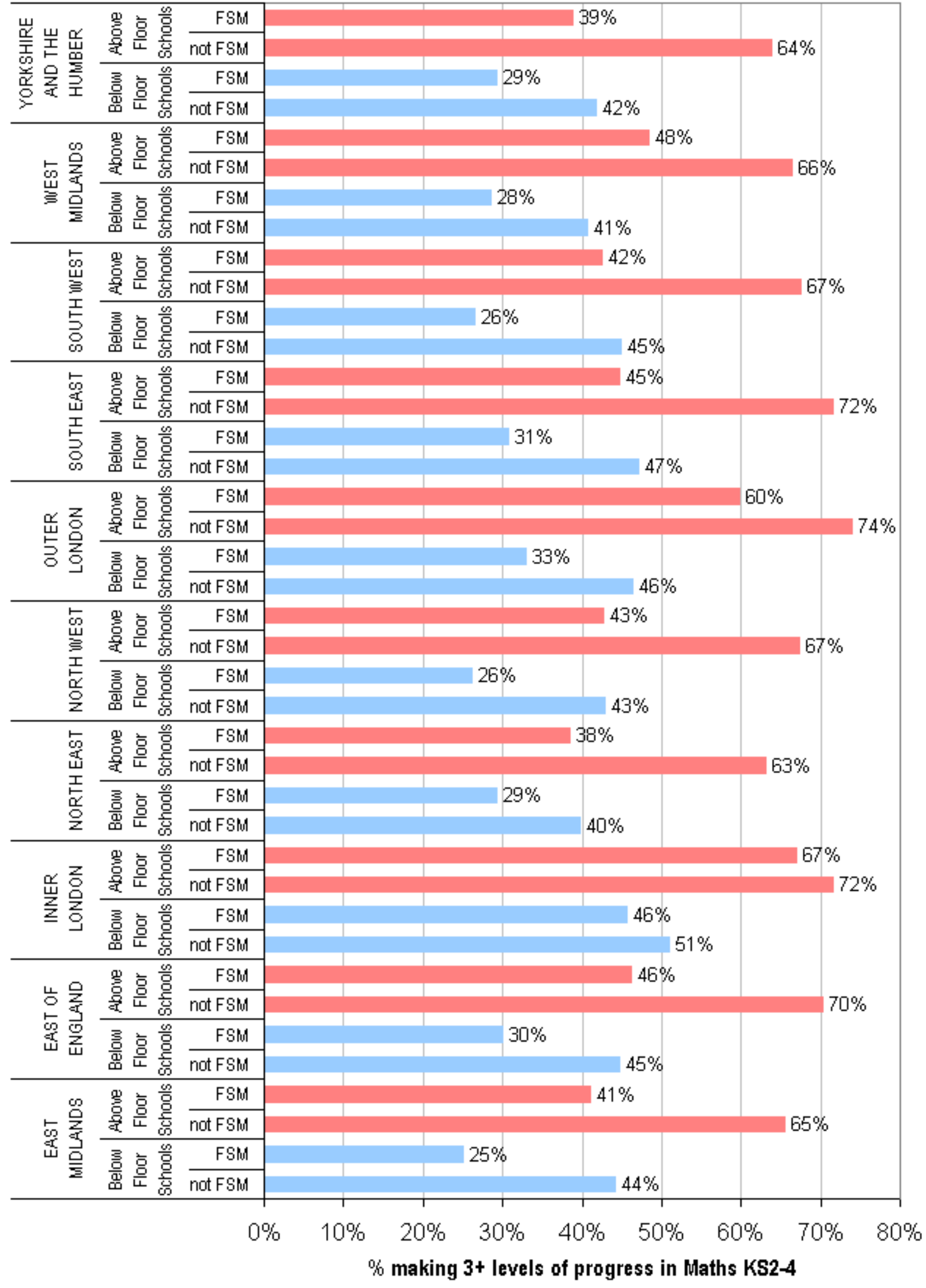


Ref: DFE-RR141

ISBN: 978-1-84775-955-9

(C) Department for Education

June 2011 